\title{
Leticia Segeren
}

\section{Atendimento Fonoaudiológico a crianças com Distúrbios do Espectro do Autismo: um estudo longitudinal}

Tese apresentada à Faculdade de Medicina da Universidade de São Paulo para obtenção do título de Doutor em Ciências.

Programa: Ciências da Reabilitação Orientadora: Prof a Dra. Fernanda Dreux Miranda Fernandes

\section{São Paulo}


Dados Internacionais de Catalogação na Publicação (CIP)

Preparada pela Biblioteca da

Faculdade de Medicina da Universidade de São Paulo

Creprodução autorizada pelo autor

Segeren, Letícia

Atendimento fonoaudiológico a crianças com

Distúrbios do Espectro do Autismo : um estudo

longitudinal / Letícia Segeren. -- são Paulo, 2019.

Tese (doutorado)--Faculdade de Medicina da

Universidade de são Paulo.

Programa de Ciências da Reabilitação.

Orientadora: Fernanda Dreux Miranda Fernandes.

Descritores: 1.Transtorno autístico 2.Estudo longitudinal 3. Fonoaudiologia 4.Avaliação

5.Linguagem 6.Comunicação

USP/FM/DBD-151/19

Responsável: Erinalva da Conceição Batista, CRB-8 6755 


\section{Dedicatóría}

Dedico esse trabalho aos meus pais, que são a minha base e meus methores exemplos. 


\section{Agradecimentos}

À minha querida orientadora Profa. Dra. Fernanda Dreux

Miranda Fernandes, um agradecimento especial por todos os ensinamentos e principalmente pelo apoio em tudo. Esses anos de

convivêncía me proporcionaram não só um crescimento profissional como também pessoal, sou muito grata por todas as coisas que passamos juntas!

Ao meu marido Bruno, por tudo, príncipalmente pelo companheirismo! Que sorte a minha ter ao meu lado meu melhor amigo.

À minha família, pelo apoío incondicional de sempre. Im especial à minha cunhada Mariah, pelo carinho sincero. Aquela que em todos os momentos se faz presente, apesar da distância e acima de qualquer dificuldade.

À minha segunda família, José Luiz, Bete e Júlio, por me acolherem, me ajudarem, sempre com coração aberto.

À equipe do $\mathcal{L} I \mathcal{F}$-DEA por toda colaboração durante esses anos $e$ principalmente no período de coleta de dados. Im especial à Clarice, Carol, Isabela C., Lucas e Cído que dividiram diversos momentos de angustias e ajudaram a criar um ambiente mais leve e animado.

Às minhas grandes amigas e fonoaudiólogas Camila e Daní, pela amizade sincera e por compartitharem esse amor à profissão e a pesquisa. Camila, obrigada pelos conselhos, ajudas e o carinho de sempre! Dani, obrigada principalmente por ser você e por fazer parte da minha vida, sempre com a palavra certa!

Às minhas companheiras Ignês e Mirela, pelo estímulo de sempre e por essa troca diáría que acrescenta muito!

$\mathcal{A}$ todos os meus amigos e familiares, por compreenderem os meus momentos de ausência. 
Aos sujeitos dessa pesquisa e seus familiares, pela confiança em nosso trabatho e por nos permitirem aprender cada dia mais.

$\mathcal{E}$ não podería deixar de agradecer também à Kent State University, Marcus Autism Center (Emory University), University of Central Florida e Seton Hall University por abrirem as portas, me acolherem, compartitharem experiências e um pouco da rotina de cada universidade.

And I would also like to thank Kent State University, Marcus Autism Center (Emory University), University of Central Florida and Seton Hall University for opening doors, welcoming, sharing experiences and a little bit of the routine of each University.

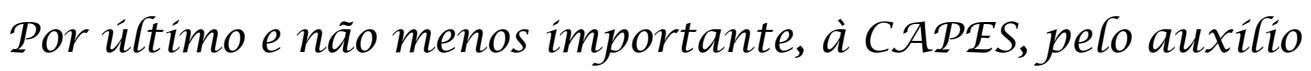
financeiro ao desenvolvimento desta pesquisa. 
"Não é sobre chegar no topo do mundo e saber que venceu. É sobre escalar e sentir que o caminho te fortaleceu"

(Música: Trem-6ala, Ana Vilela). 
Esta tese está de acordo com as seguintes normas, em vigor no momento desta publicação:

Referências: adaptado de International Committee of Medical Journals Editors (Vancouver).

Universidade de São Paulo. Faculdade de Medicina. Divisão de Biblioteca e Documentação. Guia de apresentação de dissertações, teses e monografias. Elaborado por Anneliese Carneiro da Cunha, Maria Julia de A. L. Freddi, Maria F. Crestana, Marinalva de Souza Aragão, Suely Campos Cardoso, Valéria Vilhena. 3a ed. São Paulo: Divisão de Biblioteca e Documentação; 2011.

Abreviaturas dos títulos dos periódicos de acordo com List of Journals Indexed in Index Medicus. 


\section{Sumário}

LISTA DE GRÁFICOS

LISTA DE QUADROS

LISTA DE FIGURAS

LISTA DE TABELAS

LISTA DE SIGLAS E ABREVIATURAS

RESUMO

ABSTRACT

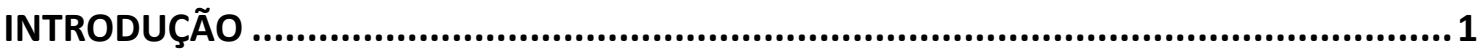

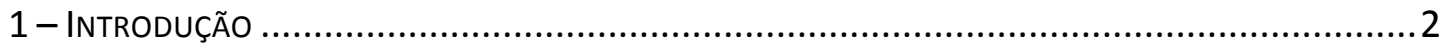

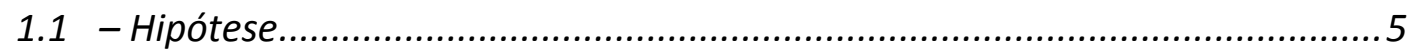

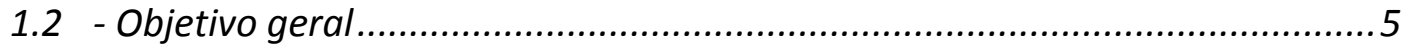

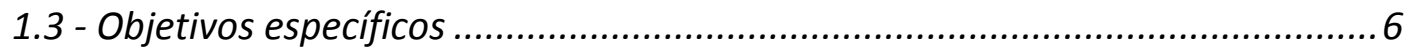

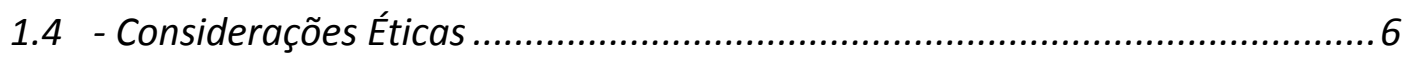

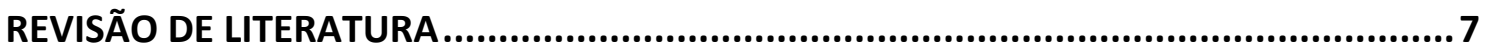

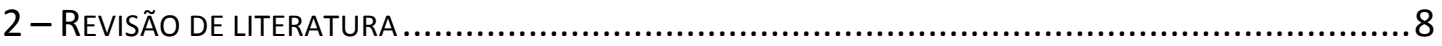

2.1 - Autismo: Conceitos e diagnóstico .................................................................. 8

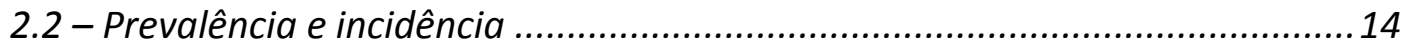

2.2.1 Importância da metodologia...................................................................................18

2.3 - Intervenções a pessoas com DEA e seus direitos ........................................19

2.4 - O papel do fonoaudiólogo e os diferentes modelos de intervenção..............24

2.5 - Estudos longitudinais envolvendo autismo ................................................32

ESTUDO 1 - ATENDIMENTO FONOAUDIOLÓGICO DE CRIANÇAS COM DEA: ANÁLISE DE

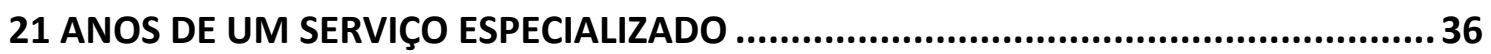

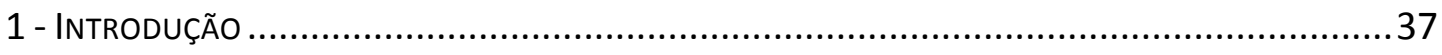

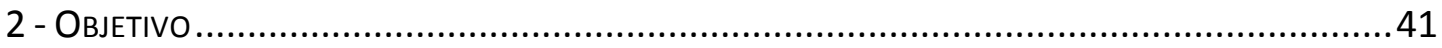

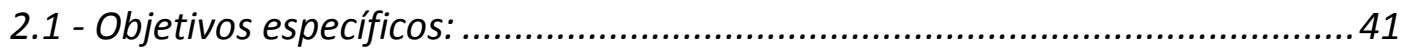


3 - MÉTODO

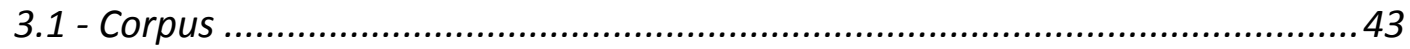

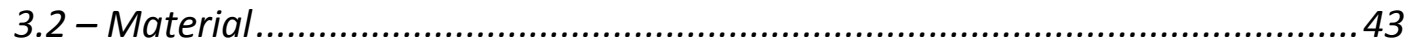

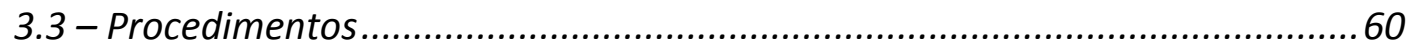

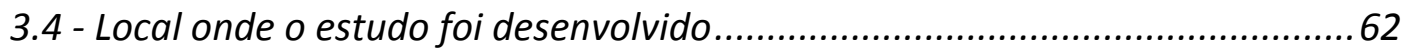

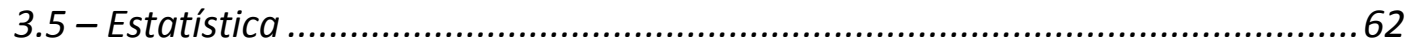

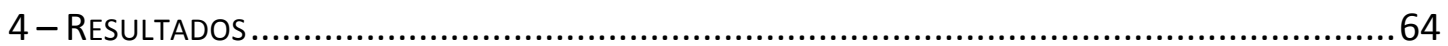

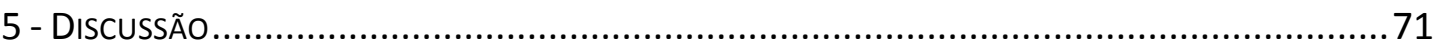

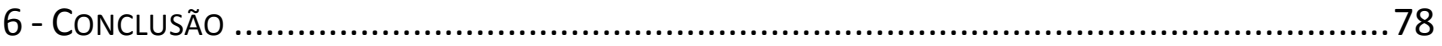

\section{ESTUDO 2 - AVALIAÇÃO DE CRIANÇAS COM DEA: ESTUDO LONGITUDINAL DE UM

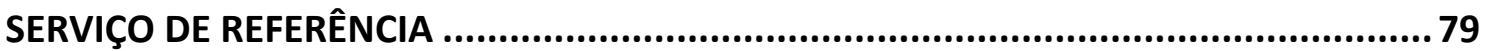

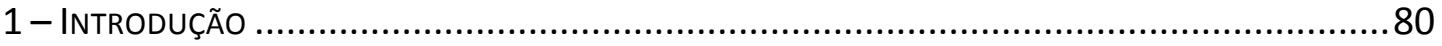

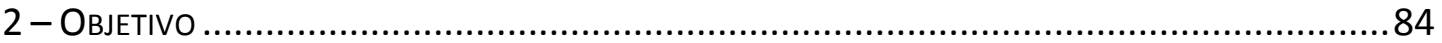

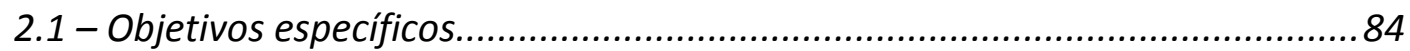

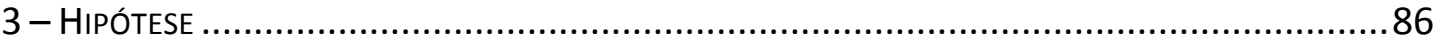

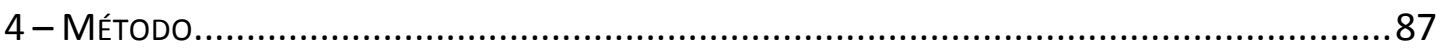

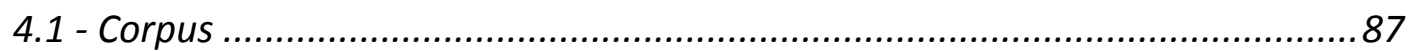

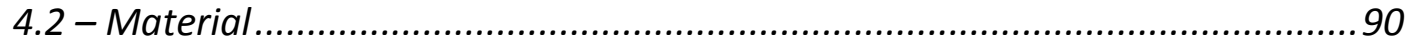

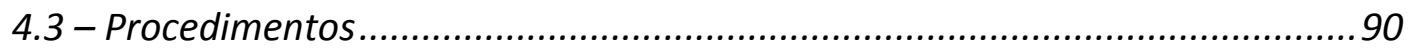

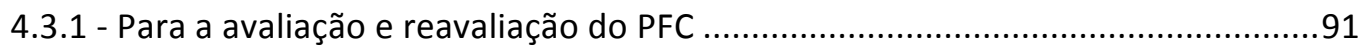

4.3.2 - Para a avaliação e reavaliação do DSC ...............................................................92

4.4 - Local onde o estudo foi desenvolvido..................................................... 93

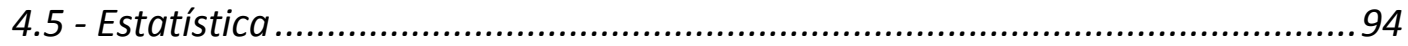

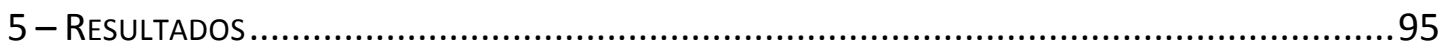

5.1 - Caracterização da amostra do estudo quanto à idade, ao desempenho na prova do Perfil Funcional da Comunicação e ao escore do Desempenho Sócio

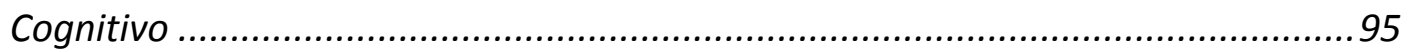

5.2 - Comparação entre as seis primeiras avaliações do PFC e o DSC .................... 97

5.3 - Investigação da capacidade preditiva das ações do PFC em relação ao escore

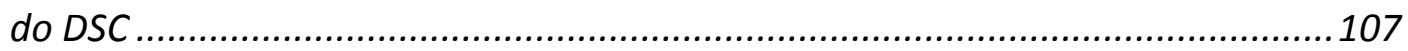

5.4 - Comparação das faixas etárias em relação ao PFC e o escore do DSC..........113 
5.5 - Investigação da presença de correlação entre a evolução nos parâmetros do PFC e a idade de início da intervenção.

5.6 - Investigação da presença de correlação entre o número de respostas no PFC e escore do DSC e porcentagem de atos interativos ............................................129

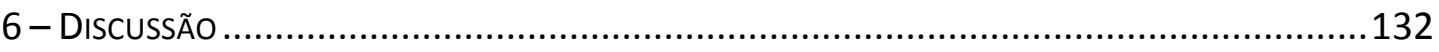

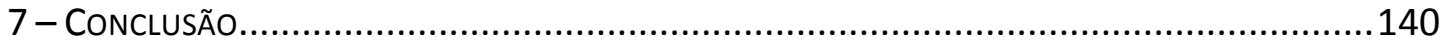

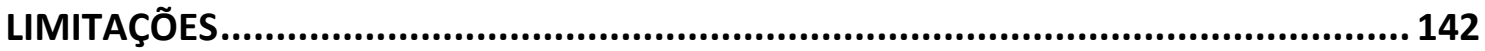

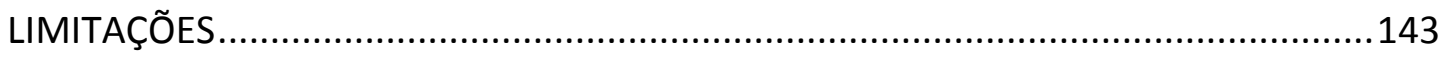

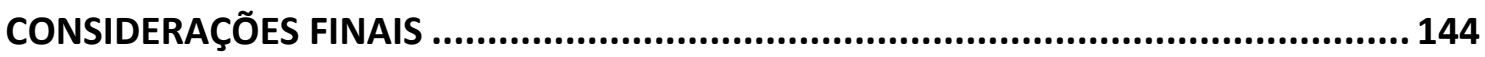

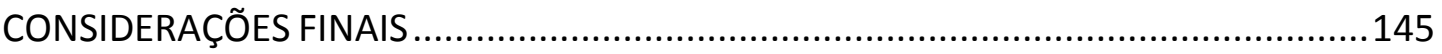

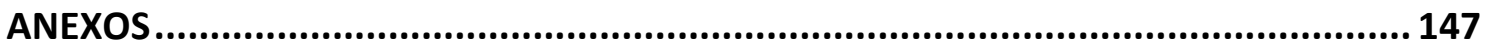

ANEXO A - APRovaÇÃo do COMITÊ DE ÉTICA EM PESQUISA..............................................148

ANEXO B - PROTOCOLO PARA TRANSCRIÇÃO DE 5 MINUTOS DA FILMAGEM PARA AVALIAÇÃO DO PFC

ANEXO C - FICHA SÍNTESE PARA ANÁLISE APÓS A TRANSCRIÇÃO DO PFC.................................150

ANEXO D - PROTOCOLO DE REGISTRO INDIVIDUAL DA PONTUAÇÃO OBTIDA NO DSC ..................151

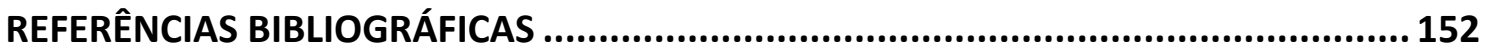

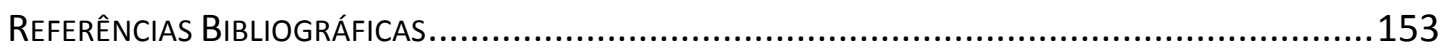




\section{Lista de Gráficos}

Gráfico 1 - Caracterização da amostra com base no sexo .64

Gráfico 2 - Proporção de indivíduos que buscaram atendimento por ano com relação ao sexo. .65

Gráfico 3 - Caracterização da amostra com base na faixa etária de início do atendimento. 66

Gráfico 4 - Média da idade de início da avaliação e atendimento fonoaudiológico. 67

Gráfico 5 - Diferença da idade e sexo com relação a idade na qual buscou pela avaliação/terapia. 67

Gráfico 6 - Quantidade de indivíduos que iniciaram o tratamento em cada ano. .68

Gráfico 7 - Motivos relatados pelos responsáveis para a interrupção do tratamento .70

Gráfico 8 - Número de sujeitos e o tempo de atendimento. 145 


\section{Lista de Quadros}

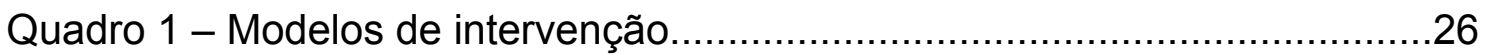

Quadro 2 - Análise de intervenções segundo The National Autism Center (2015)

Quadro 3 - Avaliações realizadas por fonoaudiólogos....................................29 


\section{Lista de Figuras}

Figura 1 - Tela inicial do programa IDEA ................................................ 44

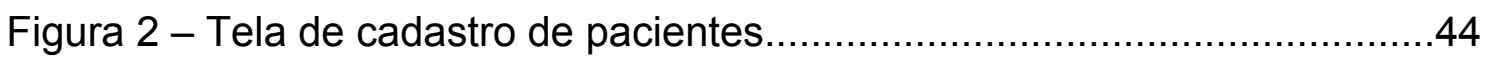

Figura 3 - Aba de preenchimento dos dados da avaliação...........................45

Figura 4 - Aba de preenchimento dos dados da anamnese ........................46

Figura 5 - Aba de preenchimento dos dados da avaliação da pragmática.......46

Figura 6 - Aba de preenchimento dos dados do desempenho sócio cognitivo

Figura 7 - Aba de preenchimento dos dados Inventário de Comportamento da Criança Autista. 48

Figura 8 - Aba de preenchimento dos dados do questionário de Qualidade de Vida: QOL 48

Figura 9 - Aba de preenchimento dos dados do Perfil Funcional da Comunicação - Checklist. 49

Figura 10 - Aba de preenchimento dos dados da avaliação de Fonologia.......49

Figura 11 - Aba de preenchimento dos dados da avaliação de vocabulário....50

Figura 12 - Aba de preenchimento dos dados de escolarização .50

Figura 13 - Aba de preenchimento dos dados de conduta............................51

Figura 14 - Aba de preenchimento dos dados de devolutiva........................51

Figura 15 - Aba de preenchimento de Verificação.........................................52

Figura 16 - Aba extra de participação em pesquisas: Comportamentos e interesses 
Figura 17 - Aba extra de participação em pesquisas: Sociabilidade e interação. .53

Figura 18 - Aba extra de participação em pesquisas: Linguagem. 54

Figura 19 - Aba extra de participação em pesquisas: Aspectos Pragmáticos..54

Figura 20 - Aba extra de participação em pesquisas: Cognição .55

Figura 21 - Aba extra de participação em pesquisas: ADI-R 56

Figura 22 - Aba extra de participação em pesquisas: Raven .56

Figura 23 - Aba extra de participação em pesquisas: Questionário de pais.

Figura 24 - Aba extra de participação em pesquisas: Cars .57

Figura 25 - Aba extra de participação em pesquisas: DAADD .58

Figura 26 - Menu de pesquisas. .59

Figura 27 - relatório de avaliações cadastradas. .59

Figura 28 - Totalização dos Pacientes analisados conforme os critérios de inclusão e exclusão no Estudo 1 61

Figura 29 - Gráfico de dispersão do tempo de atendimento em função da idade de chegada. 69

Figura 30 - Totalização dos Pacientes analisados conforme os critérios de inclusão e exclusão no Estudo 2 89

Figura 31 - Gráfico de dispersão do escore do DSC em função do número de respostas no PFC 130

Figura 32 - Gráfico de dispersão da porcentagem de atos interativos em função do número de respostas no PFC 131

Figura 33 - Quantidade de pacientes que realizaram atendimento ao longo de 4 anos. 


\section{Lista de Tabelas}

Tabela 1 - Valores descritivos do tempo de atendimento com a idade de chegada. 66

Tabela 2 - Análise de correlação entre o tempo de atendimento e a idade de chegada para a amostra total do estudo

Tabela 3 - Caracterização do grupo do estudo em relação à idade, ao desempenho no PFC e DSC .95

Tabela 4 - Valores descritivos e análise comparativa dos momentos de avaliação em relação aos parâmetros do PFC e DSC

Tabela 5 - Análise post hoc para os parâmetros que apresentaram diferença estatisticamente significativa entre os momentos 106

Tabela 6 - Análise de multicolinearidade entre as variáveis independentes do modelo de regressão linear múltipla envolvendo cada função comunicativa no PFC 108

Tabela 7 - Análise fatorial para investigação de multicolinearidade entre as variáveis independentes do modelo 109

Tabela 8 - Modelo linear de regressão múltipla das porcentagens de ocorrência das funções comunicativas consideradas como mais interativas do PFC como preditoras do escore do DSC controlando os efeitos de idade

Tabela 9 - Valores descritivos e análise comparativa das idades em relação aos parâmetros do PFC e o escore do DSC 
Tabela 10 - Análise post hoc para os parâmetros que apresentaram diferenças estatisticamente significativas entre as faixas etárias. 125

Tabela 11 - Análise de correlação entre a evolução nos parâmetros da prova de pragmática e a idade de início da intervenção 129

Tabela 12 - Análise de correlação entre o número de respostas no PFC e o escore do DSC e porcentagem de atos interativos 130 


\section{Lista de Siglas e abreviaturas}

ABA - Applied Behavioral Analysis ou Análise Aplicada do Comportamento ABC - Autism Behavior Checklist

ABFW - Teste de Linguagem Infantil (Andrade, Befi-Lopes, Fernandes, Wertzner)

ADDMN - The Autism and Developmental Disabilities Monitoring Network

ADI-R - Autism Diagnostic Interview - Revised

ADOS - Autism Diagonsti Observation Schedule

Al - Atos Comunicativos com Funções Interativas

APA - Associação Americana de Psiquiatria

APAE - Associação de Pais e Amigos dos Excepcionais

AR - Auto regulatório

ASHA - American Speech-Language-Hearing Association

ATEC - Autism Treatment Evaluation Checklist

C - Comentário

CAPS - Centros de Atenção Psicossocial

CARS - Childrood Autism Rating Scale

CDC - Centers for Disease Control and Prevention

CELF - Clinical Evaluation of Language Fundamentals

CER - Centros Especializados de Reabilitação

CFC - Comunicação Funcional Criativa

CID - Classificação Internacional de Doenças

CIPTEA - Carteira de Identificação da Pessoa com Transtorno do Espectro Autista

CSA - Comunicação Suplementar e Alternativa 
DAADD - Differential Assessment of Autism and Other Developmental Disorders

DEA - Distúrbios no Espectro do Autismo

DIR - Desenvolvimento Individualizado e baseado no Relacionamento

DP - Desvio padrão

DSC - Desempenho Sócio Cognitivo

DSM - Manual Diagnóstico e Estatístico de Transtornos Mentais

E - Exibição

EP - Expressão de protesto

ESDM - Early Start Denver Model

EUA - Estados Unidos da América

EX - Exclamativo

FCT - Treinamento da Comunicação Funcional

$\mathrm{FI}$ - Funções consideradas como mais interativas

FIV - Fator de inflação de variância

FMUSP - Faculdade de Medicina da Universidade de São Paulo

HCV - Habilidade Comunicativa Verbal

IACC - Interagency Autism Coordinating Commitee

IDEA - Informatização do LIF-DEA.

J - Jogo

JC - Jogo compartilhado

LIF-DEA - Laboratório de Investigação Fonoaudiológica dos Distúrbios do Espectro do Autismo

LIFs - Laboratórios de Investigação Fonoaudiológica

Máx. - Máximo 
M-CHAT-R - Modified Checklist for Autism in Toddlers - Revised

MG - Meio comunicativo gestual

Mín. - Mínimo

MVE - Meio comunicativo verbal

MVO - Meio comunicativo vocal

$n^{0}$ - Número

$\mathrm{N}$ - Nomeação

NA - Narrativa

NA/M - Número de atos por minuto

NF - Não-focalizada

NFI - Número de funções consideradas como mais interativas

NFU - Número de Funções

NIHR - National Institute for Health Research

NSP - National Standards Project

OMS - Organização Mundial da Saúde

ONG - Organização Não Governamental

PA - Pedido de ação

PC - Pedido de rotina social

PCIT - Terapia de interação entre pais-crianças

PDD - Pervasive Developmental Disorders

PE - Performativo

PECS - Picture Exchange Communication System

PFC - Perfil Funcional da Comunicação

PFC-C - Perfil Funcional da Comunicação - Checklist

PI - Pedido de informação 
PLS-V - Preschool Language Scales

PO - Pedido de objeto

PR - Protesto

PS - Pedido de rotina social

QOL - Questionário de Qualidade de Vida

Raven - Teste das Matrizes Progressivas Coloridas de Raven

RDI - Intervenção no Desenvolvimento de Relacionamento

RE - Reativo

Resp - Número de respostas

RPMT - Responsive Education and Prelinguistic Milieu Teaching

RO - Reconhecimento do outro

SEPIA - Serviço de Psiquiatria da Infância e Adolescência

SUS - Sistema Único de Saúde

TDAH - Transtorno do Déficit de Atenção com Hiperatividade

TEA - Transtorno do Espectro Autista

TEACCH - Tratamento e Educação para Crianças com Transtornos do Espectro do Autismo

TID - Transtornos Invasivos do Desenvolvimento

TID-SOE - Transtornos Invasivos do Desenvolvimento Não Especificados

TOPL-2 - Test of Pragmatic Language-2

EU - União Europeia

USP - Universidade de São Paulo

WHO - World Health Organization

WHOQOL - BREF - Questionário de Qualidade de Vida abreviado

XP - Exploratória 


\section{Resumo}

Segeren, L. Atendimento Fonoaudiológico a crianças com Distúrbios do Espectro do Autismo: um estudo longitudinal. [Tese]. São Paulo: Faculdade de Medicina, Universidade de São Paulo; 2019.

A presente tese é formada por dois estudos envolvendo análises longitudinais de dados sobre um serviço especializado no atendimento fonoaudiológico a crianças com DEA. O serviço de atendimento realizado atualmente pelo LIFDEA tem mais de 30 anos de existência e, com intuito de reforçar a importância da prática baseada em evidência, buscou-se analisar os dados relacionados às crianças e adolescentes que realizaram avaliação e atendimento nos últimos 21 anos. O primeiro estudo contém uma descrição da história do LIFDEA, além de um levantamento do número de pacientes atendidos, seus dados sociodemográficos, tempo médio de atendimento, idade de início do tratamento e sua evolução, com base nos dados encontrados nos prontuários do arquivo morto. Para o Estudo 1 foram selecionados todos os prontuários de pacientes que realizaram terapia fonoaudiológica no LIFDEA entre janeiro de 1997 e dezembro de 2017. Nesse primeiro estudo não foi possível verificar que a idade de início do atendimento fonoaudiológico diminuiu com o passar os anos, sendo a média de 6 anos de idade no início da avaliação; com manutenção média de 3 anos e meio de terapia. Na tabulação de dados foi observado que o índice de abandono do tratamento é muito alto. Dentre os 340 pacientes analisados, $24 \%$ realizaram um ano ou menos de terapia. Concluiu-se no Estudo 1 que o número de indivíduos que desistem ou abandonam o atendimento é considerável e a idade de início da terapia não está relacionada à maior manutenção do tratamento. No segundo Estudo foi realizado um recorte nos dados levantados no Estudo 1, juntamente com os dados referentes aos pacientes que frequentaram o serviço entre os anos de 2011 e 2017. Este segundo estudo teve um enfoque na análise aprofundada e retrospectiva das avaliações mais aplicadas ao longo destes anos, ou seja, do PFC e do DSC. No Estudo 2 foram selecionados os pacientes que realizaram atendimento neste mesmo serviço entre os anos de 2011 e 2017 e que para os quais foram obtidos dados completos referentes ao protocolo do PFC aplicados semestralmente. Nos resultados do Estudo 2 foi possível observar que as funções comunicativas mais frequentes foram o JC, PE e XP, com uma média de nove funções em cada PFC analisado. Foram identificados os dados do DSC de 138 pacientes e o escore médio nessa verificação foi de 22 pontos. Alguns coeficientes do PFC indicam que há associação com o DSC. Há correlação negativa entre a idade de início e o número de atos comunicativos e correlação positiva entre o número de respostas apresentados no PFC, o escore do DSC e os atos comunicativos com funções mais interativas. Concluise que é possível observar evolução clínica a partir da análise destes dois protocolos em períodos de três anos de intervenção e que a idade no início da terapia fonoaudiológica está relacionada à maior evolução clínica.

Descritores: Transtorno autístico; Estudo Iongitudinal; Fonoaudiologia; Avaliação; Linguagem; Comunicação. 


\begin{abstract}
Segeren, L. Speech-Language Intervention with Children with Autism Spectrum Disorders: longitudinal study. [Thesis]. São Paulo: Faculdade de Medicina, Universidade de São Paulo; 2019.
\end{abstract}

The present dissertation is comprised by two studies regarding the longitudinal analysis of the data referring to a specialized speech-language service to children with Autism Spectrum Disorders. The Speech-Language Research Laboratory on ASD has been providing services to this population for over 30 years and, aiming to point-out to the importance of evidence-based practice the study aimed to analyze the data referring to children and adolescents that received services in this service in the last 21 years. The first study describes the history of this Laboratory and the number of patients enrolled, their socialdemographic data, mean period of intervention, age in the intervention onset and clinical evolution, based on the data obtained in the data-bank. Data to the Study 1 were selected from all the records of patients enrolled in this Laboratory in the period from January 1997 to December 2017. In this first study we didn't verify a decrease in the age of the beginning of the treatment. The mean age of intervention onset was 6 years and the average duration of the therapy was 3.5 years. In the data analyses it was observed that the dropt-out index is very high: of the 340 patients considered, $24 \%$ received less than one year of therapy. Study 1 concluded that the number of individuals that give-up or abandon the service is high and that the age at the onset of the treatment is not related to the adherence to the intervention process. The second study considered the data of patients that received services between 2011 and 2017. This study focused on the analyses of the Functional Communicative Profile and of the Social Cognitive Performance on a retrospective in-depth analysis. In Study 2 data refer to the patients that received therapy ion this service in the period determined and for whom there were complete data referring to the Functional Communicative Profile obtained every semester. In the results of Study 2 it was possible to observe that the most frequent communicative functions were joint play, performative and exploratory, with an average of nine different functions in each protocol analyzed. Data about the Social Cognitive Performance of 138 patients were available and resulted on the average score of 22 points. Some results of the Functional Communicative Profile suggest that there is some association with the Social Cognitive Performance. There is a negative correlation between the age of the onset of the intervention and number of communicative acts expressed and positive correlation between the number of responses presented in the Functional Communication Profile, the Social Cognitive Performance score and the communicative acts with more interactive functions. It can be concluded that it is possible to observe clinical evolution over a three-year period based on the analyses of the two protocols used and that the age at the beginning of the intervention is associated to a larger clinical evolution.

Descriptors: Autistic disorder; Longitudinal study; Speech, Language and hearing sciences; evaluation; Language; Communication. 


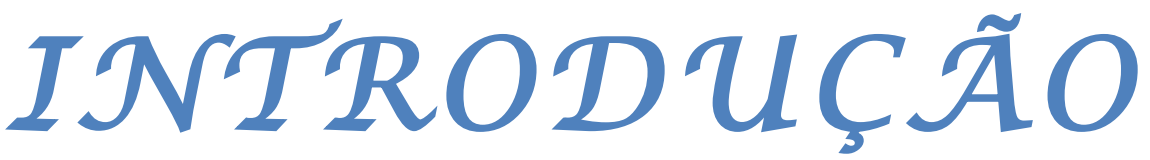




\section{1 - Introdução}

Em 2012 iniciei meus estudos no Laboratório de Investigação Fonoaudiológica dos Distúrbios do Espectro do Autismo (LIF-DEA) como aluna de aprimoramento. Foi uma realização muito grande, pois, além de poder me especializar nos Distúrbios ${ }^{1}$ no Espectro do Autismo (DEA), que é uma área que me intriga e me realiza, pude também fazer parte da história de um serviço de referência, juntamente com a idealizadora deste serviço, minha professora e orientadora, Fernanda Dreux Miranda Fernandes.

Durante a minha trajetória no LIF-DEA, realizando o aprimoramento profissional e o mestrado, foi possível observar a dinâmica dos atendimentos, quantidade de dados colhidos, número de pessoas em formação, diferentes pesquisas realizadas e o grande potencial deste serviço que, em 2016, completou 30 anos de existência.

Analisando a quantidade de pacientes atendidos neste período e o grande número de pessoas envolvidas nestes atendimentos, observou-se que a informatização dos dados auxilia no armazenamento e controle dos mesmos, facilitando a sistematização das informações relativas aos atendimentos. Sendo assim, surgiu a ideia de utilizar um programa que reúna informações relevantes sobre o paciente, assim como os resultados dos protocolos aplicados com este paciente. O uso desta tecnologia pode evitar a perda de dados e possibilitar maior praticidade do acesso e análise dos mesmos.

\footnotetext{
1 No DSM-5 o termo "disorders" foi traduzido por "transtorno", porém, no decorrer do trabalho, optou-se
} 
Durante toda a minha formação, observei uma dificuldade de organização de dados em vários setores, inclusive na área da saúde, tanto no âmbito hospitalar como em clínicas particulares. As informações de um prontuário, que legalmente são propriedade do paciente, auxiliam na condução do caso e se tornam o histórico do atendimento realizado, sendo de suma importância em todos os setores.

O Conselho Federal de Medicina (2002), na resolução $n^{\circ} 1.638$, assim como o Conselho Federal de Fonoaudiologia (2009), considerando o disposto na Lei $n^{\circ}$ 6965/81, definem o prontuário como sendo um documento único, formado por um conjunto de informações, sinais e imagens registradas, padronizadas, determinadas com base nos acontecimentos e situações referentes aos cuidados prestados ao usuário, que tem caráter legal, sigiloso e científico.

Os dados, assim como a aplicação de protocolos e avaliações, quando realizados de modo estruturado e registrados rotineiramente, facilitam a integração de informações e melhoraram a condução do caso, principalmente em ambientes que envolvem diversos profissionais.

Sabendo da importância da prática baseada em evidencia, surgiu a ideia de realizar uma pesquisa cuja proposta inicial era analisar 10 anos de um serviço especifico de Fonoaudiologia especializada nos DEA.

No início da coleta para a pesquisa, foi observado um grande volume de dados nos prontuários, de forma diversificada (pouco relacionadas) e incompleta, o que dificultou a sistematização e categorização dos mesmos, diminuindo o número de sujeitos da pesquisa. 
Pensando em aumentar e melhorar esta análise, optou-se por ampliar o estudo para os últimos 21 anos de atendimento, buscando assim dados mais significativos. Isso resultou em um volume maior de informações, porém o problema com a diversidade e dados incompletos se manteve, exigindo uma mudança no foco da pesquisa.

Sendo assim, foi realizada uma pesquisa empírica exploratória, retrospectiva (ex-post-facto) e longitudinal que pudesse englobar parte da história do LIF-DEA, contendo o levantamento de dados e informações relevantes, realizando uma caracterização do atendimento para a otimização do serviço e uma análise aprofundada dos dados digitalizados buscando identificar fatores relacionados a evolução clínica.

Levando em conta todos esses aspectos foram propostos dois estudos diferentes. O primeiro deles, contendo uma descrição da história do LIF-DEA, um levantamento do número de pacientes atendidos, seus dados sóciodemográficos (idade e sexo), tempo médio de atendimento, idade de início do tratamento e sua evolução, com base nos dados encontrados nos prontuários. O segundo estudo, realizado após o levantamento dos dados do estudo 1, teve um enfoque na análise aprofundada e retrospectiva das avaliações mais aplicadas ao longo destes anos, ou seja, do Perfil Funcional da Comunicação (PFC) e do Desempenho Sócio Cognitivo (DSC) dos sujeitos atendidos.

Esta pesquisa propõe a utilização da casuística única proporcionada por um serviço de referência, com história consistente e registro sistemático de dados para a análise longitudinal da evolução de um número significativo de crianças, analisando especificamente os dados referentes ao DSC e ao PFC 
dos pacientes nos últimos 21 anos, ou seja, de 1997 a 2017 no estudo 1 e de 2011 a 2017 no estudo 2, delineando assim sua evolução, condução e maior adesão à terapia. Esses dados também podem revelar o papel fundamental do fonoaudiólogo no atendimento de crianças com DEA.

Ainda neste capítulo serão apresentados a hipótese, o objetivo geral, os objetivos específicos e as considerações éticas que norteiam toda a pesquisa.

O próximo capítulo será composto por uma revisão de literatura, com um breve levantamento de pesquisas que fornecem uma fundamentação para os estudos relatados posteriormente.

No último capítulo estão enumeradas as referências bibliográficas utilizadas.

\section{1 - Hipótese}

A pesquisa proposta envolveu duas hipóteses fundamentais. A primeira é que, a partir do levantamento longitudinal dos registros dos atendimentos no LIF-DEA será possível identificar a consistência dos dados bem como as lacunas nesses registros. A segunda hipótese investigada é que serão obtidos dados longitudinais a respeito de um número relevante de crianças com DEA que permitirão a identificação de correlações significativas.

\section{2 - Objetivo geral}

Realizar um estudo empírico exploratório para levantamento de dados dos últimos 21 anos de atendimento a crianças do espectro do autismo do Laboratório de Investigação Fonoaudiológica nos Distúrbios do Espectro do Autismo da Faculdade de Medicina da Universidade de São Paulo (USP) 


\section{3 - Objetivos específicos}

- Caracterizar o número de pacientes atendidos e seus dados sócios demográficos (idade e sexo);

- Verificar a idade de início do tratamento e o tempo médio de atendimento;

- Verificar a existência de associações relevantes entre as informações a respeito de idade e desempenho no início do atendimento com a evolução clínica;

- Analisar os protocolos mais utilizados e suas correlações com o desenvolvimento clínico de cada paciente, comparando os dados do início do atendimento e após 3 anos.

\section{4 - Considerações Éticas}

A pesquisa de protocolo $n^{\circ} 224 / 16$, recebeu a aprovação da Comissão de Ética para Análise de Projetos de Pesquisa da Faculdade de Medicina da Universidade de São Paulo (Anexo A).

A coordenadora do LIF-DEA, orientadora desta pesquisa, autorizou a utilização do banco de dados do laboratório para este estudo. 


$$
\begin{array}{r}
\mathcal{R E} \mathcal{V I S} \tilde{\mathcal{A}} O \mathcal{D E} \\
\mathcal{L} \mathcal{T} \mathcal{E} \mathcal{A} \mathcal{A} \mathcal{T} \mathcal{R} \mathcal{A}
\end{array}
$$




\section{2 - Revisão de literatura}

Este capítulo visa fornecer a base teórica para o melhor acompanhamento e compreensão da pesquisa realizada. Desta forma, o conteúdo foi selecionado de acordo com os pontos principais de interesse. 0 encadeamento das ideias foi priorizado, ao invés da cronologia das referências.

\section{1 - Autismo: Conceitos e diagnóstico}

Os DEA apresentam uma grande variabilidade de características e a manifestação dos sintomas pode aparecer logo nos primeiros anos de vida. Contudo, o diagnóstico é clinico e esta variabilidade de características, que podem ser encontradas de forma complexa e com variação ao longo do desenvolvimento, dificulta o fechamento do diagnóstico nos primeiros anos de vida da criança (Wozniak et al., 2017)

Para auxiliar no processo diagnóstico e na análise dos elementos de classificação, o Manual Diagnóstico e Estatístico de Transtornos Mentais (DSM), cuja primeira versão foi publicada em 1952 é um dos instrumentos mais reconhecidos.

Ao longo dos anos o DSM foi objeto de diversas atualizações; mesmo assim, até o ano de 1980 a Associação Americana de Psiquiatria (APA) não havia publicado critérios que separassem o autismo da esquizofrenia (Achkova e Manolova, 2014).

O conceito de autismo evoluiu muito desde sua primeira citação em 
1943 por Kanner, que recorreu à noção introduzida por Eugen Bleuler em 1911. Em meados de 1960, a literatura citava o autismo como sendo resultado da falta de interações entre pais e bebê (Lima, 2014).

A partir de 1970 esse conceito não era mais defendido pelos pesquisadores (Rutter et al., 1971; Rutter e Bartak, 1971; Achkova e Manolova, 2014; Lima, 2014), que passaram a estudar sobre os sintomas, critérios diagnósticos, evolução e delimitações entre autismo e outros quadros.

As pesquisas de Rutter (1978) foram fundamentais para que a diferenciação em termos clínicos e de prognóstico ocorresse. Neste mesmo período as pesquisas foram mostrando uma ampliação das tendências, separando o autismo da esquizofrenia e relacionando-o às bases cognitivas e determinantes do quadro, aproximando-se mais dos critérios diagnósticos atuais (Rutter, 1978; Lima, 2014).

O mesmo é relatado no documento publicado por Lima (2014), que refere que a partir de 1943 os conceitos de autismo, psicose e esquizofrenia, se confundiam e foram usados de maneira intercambiável durante muitos anos. Este documento, no entanto, mostra que atualmente este conceito mudou.

Pesquisas relacionadas ao autismo ao longo do tempo foram mostrando diferentes variações dentro do quadro e com isso, em 1979, Wing introduziu o termo "contínuo do autismo", trazendo a consideração da noção do autismo como um espectro, sendo este, um termo amplamente utilizado até os dias atuais (Wing e Gould, 1979; Achkova e Manolova, 2014). 
A Classificação Internacional de Doenças - CID 10 (WHO, 1993), publicada pela Organização Mundial da Saúde (OMS) $)^{2}$ é uma das referências em saúde mental no Brasil (Guareschi et al., 2016) e outro importante instrumento de classificação e diagnóstico dos DEA.

A primeira vez em que a classificação de distúrbios mentais apareceu na CID foi em 1948, quando foi lançada a CID-6 (WHO, 1948).

Logo após a publicação CID-6 (WHO, 1948), foi lançada a primeira versão do DSM (DSM-I), com uma forte influência dos sistemas de classificação e da CID-6 (WHO, 1948). Com isso, as histórias do DSM e da CID se entrelaçaram e continuaram assim desde então (Clark et al., 2017).

Na CID-10 (WHO, 1993), o autismo é incluído nos Transtornos Invasivos do Desenvolvimento (TID) (uma tradução diferente para o mesmo termo, PDD Pervasive Developmental Disorders, usado tanto na CID quanto no DSM), inseridos na Classificação de Transtornos Mentais e de Comportamento, subdividido em oito categorias: Autismo infantil; Autismo atípico; Síndrome de Rett; Outros transtornos desintegrativos da infância; Transtorno de hipercinesia associado a retardo mental e a movimentos estereotipados; Síndrome de Asperger; Outros transtornos globais do desenvolvimento; e Transtornos globais do desenvolvimento não especificados (WHO, 1993; Guareschi et al., 2016).

A WHO (1993) define o TID como um grupo de transtornos caracterizados por alterações qualitativas das interações sociais recíprocas, padrões de comunicação e por um repertório de interesses e atividades restrito,

\footnotetext{
${ }^{2} \mathrm{Ou}$ World Health Organization (WHO), em inglês.
} 
estereotipado e repetitivo. Estas anomalias qualitativas constituem uma característica global do funcionamento do sujeito, em todas as situações.

O DSM, como já dito anteriormente, é um instrumento muito utilizado, que apresenta os critérios diagnósticos mais reconhecidos e, desde sua primeira publicação em 1952, passou por algumas atualizações. Em 1980, apresentou sua terceira atualização (DSM III - APA, 1980) no qual, o termo autismo infantil apareceu pela primeira vez.

Em sua última versão publicada, o DSM-5 (APA, 2013) propõe a classificação de Transtorno do Espectro do Autismo (TEA) em substituição à de Transtornos Globais do Desenvolvimento, adotada no DSM-IV-TR (APA, 2002), mostrando assim, uma variedade desse conjunto de condições que fazem parte do espectro e as controvérsias em relação ao diagnóstico diferencial entre elas.

Essa nova proposta, quando comparada ao DSM-IV-TR (APA, 2002), afirma também que os sintomas apresentados podem ser de grau leve a grave, ao invés de um diagnóstico de uma doença específica, ou seja, o DSM-5 (APA, 2013), recomenda o uso da caracterização de gravidade dos sintomas, que propiciam uma descrição mais abrangente do DEA, quanto à capacidade cognitiva, a capacidade de linguagem, a existência de uma condição médica ou genética e comorbidades associadas, realizando assim um diagnóstico com mais especificidade, porém menos sensível para os diferentes subtipos (APA, 2013; Kulage et al., 2014; Machado et al., 2015).

Outra mudança que ocorreu após a última atualização diz respeito à redução de três para dois domínios principais da síndrome: déficits de 
comunicação social e interação social; e comportamento, interesses e atividades restritos e repetitivos (APA, 2013).

Nesta nova versão, os prejuízos de interação social e de comunicação foram fundidos em um único domínio, no qual é avaliada a ausência de reciprocidade social e emocional, habilidades para manter e desenvolver a formação de vínculos, comunicação e linguagem pragmática. O segundo domínio de sintomas incluem interesses restritos e repetitivos exibidos por pelo menos dois dos seguintes itens: comportamentos motores ou verbais estereotipados, hipersensibilidade ou hiposensibilidade a estímulos sensoriais, aderência excessiva a rotinas e padrões de comportamento ritualizados e restritos (APA, 2013; Machado, 2015).

A CID também passou por uma atualização e no ano de 2018 foi lançada sua $11^{\circ}$ versão, sendo esta sua pré-edição.

Seguindo a mesma linha do DSM-5 (APA, 2013), a CID 11 reuniu todos os transtornos em um só diagnóstico, o TEA. Ele está classificado nos Transtornos mentais, comportamentais ou de neurodesenvolvimento, situado nos transtornos neurodesenvolvimentais (WHO, 2018).

Conforme os critérios diagnósticos do DSM-5 (APA, 2013), é possível observar as primeiras manifestações do autismo antes dos 36 meses de idade. O diagnóstico é clinico e realizado com base em instrumentos diagnósticos padronizados como, por exemplo, o Autism Diagonsti Observation Schedule ADOS (Lord et al., 2000) ou Autism Diagnostic Interview - Revised - ADI-R (Lord et al., 1994) que são considerados padrão ouro na parte de diagnóstico e seguem os critérios propostos pela CID 10 (WHO, 1993) e pelo DSM-5 (APA, 2013). 
Alguns instrumentos de rastreamento diagnósticos estão disponíveis para facilitar a identificação dos DEA, como, por exemplo, o Modified Checklist for Autism in Toddlers - Revised (Inventário Modificado de Autismo para Crianças - M-CHAT-R) (Losapio e Pondé, 2008), um instrumento de triagem de baixo custo capaz de indicar os sinais do autismo. Outro instrumento bastante utilizado, de fácil aplicação e de livre acesso é o Autism Behavior Checklist (ABC), traduzido e adaptado para o Brasil por Marteleto e Pedromônico (2005).

No entanto, ao aplicar estes instrumentos de rastreamento, é importante levar em consideração tanto as características que ainda podem ser observadas, como aquelas que apareceram e depois de um tempo deixaram de ocorrer, pois como relatado por Wozniak et al. (2017) algumas características ficam mais evidentes em certas etapas do desenvolvimento e outras deixam de aparecer ou só aparecem em certas idades.

Para auxiliar no diagnóstico precoce, em 26 de abril de 2017, foi aprovada a Lei $n^{\circ} 13.438$ (Diário Oficial da União, 2017), alterando a Lei $n^{\circ}$ 8.069, de 13 de julho de 1990 (Estatuto da Criança e do Adolescente). Esta lei tornou obrigatória a adoção pelo Sistema Único de Saúde (SUS) de um protocolo ou outro instrumento construído com a finalidade de facilitar a detecção de risco para o desenvolvimento psíquico. Deverá ser aplicado a todas as crianças, nos seus primeiros dezoito meses de vida.

Fica difícil definir um período no qual será possível obter uma real noção da influência do DSM-5 (APA, 2013) nas alterações da incidência do DEA. Maenner et al. (2014) sugerem que as estimativas de prevalência podem ser menores com os novos critérios do DSM-5 (APA, 2013), do que com os critérios baseados no DSM-IV-TR (APA, 2002). 
No Brasil, pode-se supor que, em estudos publicados até 2015, a maioria dos sujeitos analisados foi diagnosticada de acordo com os critérios do DSM-IV-TR (Fernandes et al., 2016).

Como dito anteriormente é possível que o diagnóstico seja realizado até os 36 meses de idade e há um consenso na literatura mostrando que quanto antes forem iniciados os tratamentos necessários, melhor será o prognóstico. Porém, estudos mostram que o diagnóstico continua ocorrendo de forma tardia, em média aos cinco anos de idade, podendo chegar até os 10 anos (Oro et al., 2012; Daniels e Mandell, 2013; Segeren e Françoso, 2014).

Como pode ser visto, mesmo havendo diversas opções para rastreamento e atualizações nos principais manuais de diagnóstico, o diagnóstico ainda ocorre de modo tardio e muitas vezes o fonoaudiólogo é o primeiro profissional a ser procurado pelos responsáveis que estão suspeitando que a criança possa pertencer ao DEA. Sendo assim, há também instrumentos para a realização de avaliação e métodos de intervenção da criança que serão mais bem descritos no item 2.4 - O papel do fonoaudiólogo e os diferentes tratamentos.

\section{2 - Prevalência e incidência ${ }^{3}$}

Estimar a prevalência de deficiências do desenvolvimento traz muitos desafios, que incluem, por exemplo, mudança de definições e práticas de rotulagem ao longo do tempo, bem como a alta probabilidade de coocorrência

\footnotetext{
${ }^{3}$ Pereira et al. (2000) afirmam que incidência e prevalência são medidas de frequência de ocorrência de doença. No entanto, a prevalência mede quantas pessoas estão doentes em um determinado momento e a incidência mede quantas pessoas tornaram-se doentes.
} 
de condições que se enquadram no termo "guarda-chuva" de deficiências do desenvolvimento (Zablotsky et al., 2015).

Artigos, documentários e mídias em geral têm mencionado frequentemente o aumento da prevalência dos DEA. Como relatam Will et al. (2018), este aumento pode estar ligado à melhoria das ferramentas de diagnóstico, ao aumento da conscientização sobre o distúrbio e/ou a um aumento na incidência ao longo do tempo.

Na edição do DSM III (1980), em que o termo autismo infantil apareceu pela primeira vez, considerava-se que sua prevalência atingia uma criança dentre 10.000 ou até 50.000. De acordo com Centers for Disease Control and Prevention (CDC), atualmente uma em cada 59 crianças nos Estados Unidos da América (EUA) está incluída no Espectro do Autismo (Baio et al., 2018) e segundo a Agencia de Saúde Pública do Canada (Public Health Agency of Canada, 2018) o número é de um em cada 66.

Mesmo sendo um dado de suma importância, principalmente para as políticas públicas, há poucos estudos brasileiros relatando esses dados. Com isso, em 2018 foi instituído o projeto de Lei 10.119/2018 que estabelece como direito da pessoa com DEA a sua correta identificação por meio de documento oficial denominado Carteira de Identificação da Pessoa com Transtorno do Espectro Autista (CIPTEA). Segundo este projeto de Lei, há a estimativa de que 2 milhões de brasileiros integram o público com essa deficiência e com essa carteira de identificação, além de ter seus direitos básicos assegurados, será possível obter números mais fidedignos sobre a realidade brasileira (Brasil, 2018). 
Segundo o Projeto Autismo do Instituto de Psiquiatria do Hospital das Clínicas da Universidade de São Paulo, em 2007 havia aproximadamente uma pessoa com DEA para cada 190 habitantes (Júnior e Ribeiro, 2010). Um estudo piloto de 2011, apontou uma prevalência de 1 para 360 casos (Paula et al., 2011). Embora esse número esteja subestimado devido à metodologia utilizada no estudo, é um dos poucos que ilustram esses dados.

Elsabbagh et al. (2012) analisaram dados disponíveis de outros países e notaram que DEA não aparentava ser mais prevalente em qualquer localização geográfica em especifico, nível socioeconômico ou etnia e a incidência mediana estimada foi de 62 por 10.000 .

Entretanto, temos pesquisas que mostram números de incidências diferentes para determinadas regiões e etnias (Travers et al., 2014; Jo et al., 2015; Zablotsky et al., 2017) que nos fazem pensar a respeito de como é a disponibilidade de serviços para todas as populações.

O aumento da prevalência é notório ao longo do tempo e mesmo não aparentando estar relacionado a uma determinada localização geográfica, observa-se uma variação da incidência em diferentes regiões, podendo estar relacionado à ampliação/mudança dos critérios diagnósticos, disponibilidade de serviços e conscientização a respeito do DEA (Elsabbagh et al., 2012).

Daniels \& Mandell (2013) relataram que a diferença da idade no momento do diagnóstico variou conforme a localização geográfica, sugerindo assim, que os recursos comunitários e as políticas públicas desempenham um papel importante para a identificação precoce.

A conclusão de um estudo (Atladottir et al., 2015) realizado entre 4 diferentes países mostrou um aumento crescente e rápido no número de 
pessoas diagnosticadas com DEA até os 20 anos de idade, durante os anos de 1990 até 2007, em todas as regiões e sistemas de saúde da Dinamarca, Finlândia, Suécia e Austrália Ocidental. Neste mesmo estudo os autores compararam também outros distúrbios psiquiátricos da infância (síndrome de Tourette, Transtorno Obsessivo Compulsivo e Transtorno do Déficit de Atenção com Hiperatividade (TDAH)) e mostraram que esse aumento não se restringe apenas ao DEA.

Como citado no início deste capítulo, em 2018 o CDC (Baio et al., 2018) trouxe dados coletados pelo The Autism and Developmental Disabilities Monitoring Network (ADDMN) que é um sistema de vigilância que utiliza dados de 11 locais dos EUA estimando a prevalência de crianças com 8 anos de idade com diagnóstico de autismo durante o ano de 2014. Esses dados foram coletados com base nos arquivos de provedores de serviços profissionais nestes locais. A maioria das análises (85\%) além de realizar o estudo inicial também passou pela comparação entre os critérios diagnósticos estabelecidos pelo DSM-IV-TR e pelo DSM-5, mostrando uma diferença de $4 \%$ a mais de crianças diagnosticadas pelo antigo critério quando comparado ao DSM-5 (Baio et al., 2018).

Em outro estudo (Hansen et al., 2015) realizado na Dinamarca chegouse a conclusão que o aumento da prevalência é em grande parte atribuída às mudanças nas práticas de notificação. Porém este fato não é totalmente responsável pelo o aumento ao longo dos anos, podendo explicar somente $60 \%$ desde aumento, segundo os autores, sendo necessária a busca de outras explicações etiológicas. 
Em uma revisão sistemática da literatura realizada por Baxter et al., (2015), envolvendo dados de estudos epidemiológicos relacionados ao DEA e a incidência, prevalência, remissão e riscos de mortalidade do mundo todo, não foram encontraram evidências claras de uma mudança na prevalência de autismo entre 1990 e 2010. Relatam também que em todo o mundo, houve pouca variação regional na prevalência de DEA.

Este mesmo artigo (Baxter et al., 2015) finaliza chamando a atenção às perdas substanciais de saúde ao longo da vida devido ao DEA. Mostrando que, dados como a incidência e prevalência são realmente necessários, além de uma descrição epidemiológica precisa, para que assim facilite as políticas de saúde pública, o planejamento serviços e apoios.

\subsubsection{Importância da metodologia}

Na busca por diferentes dados, assim como mostra no estudo de Sheldrick et al. (2017), atentar-se à metodologia pela qual foram coletados os dados é de suma importância, assim como especificar o nível de gravidade do DEA; o tipo de coleta realizada e considerada pode trazer diferenças e variações significativas na idade do diagnóstico e também em sua prevalência.

Como relatam Zablotsky et al. (2015), quando realizamos uma pesquisa e a comparamos a outra é preciso levar em consideração a especificidade de cada estudo e realizar as comparações com cuidado, pois pequenas mudanças na forma de coleta de dados e/ou na metodologia podem mudar significantemente os resultados. Sendo assim, uma comparação realizada sem 
levar isso em conta pode ilustrar uma diferença ou igualdade que na verdade não ilustra a realidade.

Com esse mesmo raciocínio, Baxter et al. (2015) também concordam que a metodologia de cada estudo é altamente variável, o que dificulta a realização de comparações e agrupamentos das descobertas para chegar a um quadro abrangente da distribuição dos DEA. Reforçando essa importância, na revisão sistemática da literatura que realizaram, contabilizaram e controlaram estatisticamente as variações metodológicas dos dados coletados, para então conseguir chegar a um resultado.

Por estes motivos, ainda não há um consenso na literatura sobre os dados de prevalência e incidência do DEA.

\section{3 - Intervenções a pessoas com DEA e seus direitos}

Quando buscamos na literatura por assuntos envolvendo o DEA, é possível ver que a todo o momento estão ocorrendo pesquisas com diferentes enfoques, sempre em busca de atualizações. Porém, é necessário que as políticas públicas acompanhem no mesmo ritmo. Mesmo sabendo que esta não é a realidade de grande parte do mundo, a busca pelos direitos das pessoas com DEA deve ser realizada constantemente, e em grande parte das vezes, a luta começa com os responsáveis por essas pessoas.

Ao pesquisar sobre as políticas públicas relacionadas ao DEA em outros países foi possível encontrar sites bem estruturados com boas orientações e movimentos em prol desta população (p. ex: Autism Society, National Autistic Society e Autism Europe). 
Em 2006 se tornou lei nos EUA o Autism CARES act, (EUA - Public Law 113-157, 2014), que é a Lei de Colaboração, Responsabilidade, Pesquisa, Educação e Apoio ao Autismo, sendo esta a principal fonte de financiamento federal para pesquisa, serviços, treinamento e monitoramento de autismo.

Segundo o site do Autism Speaks com a lei Autism CARES buscam:

- Monitoramento da prevalência do Autismo

- Treinamento de profissionais da área para detectar e diagnosticar

- Desenvolvimento de novos tratamentos das condições médicas associadas ao DEA

- Apoio para o Comitê Interagencial de Coordenação do Autismo (IACC) assim como seu plano estratégico anual

- Centros de excelência em vigilância e epidemiologia do autismo

- Inúmeros programas e bolsas de pesquisa para beneficiar indivíduos com autismo

O capítulo relacionado às políticas públicas e aos direitos jurídicos, do livro publicado pela National Research Council (2001), traz em questão diversos pontos e questionamentos a respeito dos direitos das pessoas com DEA. Segundo a legislação as pessoas com deficiência tem direito a educação especial e aos serviços relacionados, tais como tratamento fonoaudiológico, psicológico, terapia ocupacional, entre outros. Alguns advogados buscaram separar a legislação envolvendo leis diretamente relacionadas a pessoas com DEA, porém isso demoraria anos e dúvidas surgiram a respeito de como seria o tratamento a um segmento menor da população.

Em relação aos serviços de fonoaudiologia, foi possível constatar durante visitas realizadas a universidades dos EUA, que o governo 
disponibiliza fundos de financiamentos aos centros de pesquisa, grande parte das escolas possui uma equipe multiprofissional atuando diretamente dentro da escola (incluindo um fonoaudiólogo), além de possuir um contrato direto com o terapeuta quando o paciente necessita de atendimento individual particular e consegue o serviço por meio das leis.

Contudo, da mesma forma que foi relatado na conclusão do National Research Council (2001), a grande necessidade de busca por direitos por meio de processos judiciais é um "sintoma" de que as coisas não funcionem tão bem.

A União Europeia (EU) também possui um plano estratégico traçado até 2020, com diretrizes envolvendo acessibilidade, inclusão, igualdade, trabalho/ocupação, educação e treinamento, proteção social, saúde e ação externa. Esta estratégia destina-se a aproveitar o potencial combinado da Carta dos Direitos Fundamentais da UE, do Tratado sobre o Funcionamento da União Europeia e da Convenção das Nações Unidas e utilizada plenamente na Europa (European Commission, 2010).

No Brasil, desde 1988 foi estabelecido um sistema de saúde dinâmico e complexo (o Sistema Único de Saúde - SUS), no qual todo cidadão tem o direito e o Estado é responsável pelo acesso universal e igualitário à saúde. Entretanto, mesmo apresentando uma evolução significativa desde sua instauração, é comum a escassez na oferta de serviços (Kleinert e Horton, 2011; Paim et al., 2011; Santos et al., 2017).

Como relatam Santos et al. (2017), o acesso ao serviço de saúde está relacionado ao desenho organizacional e a disponibilidade geográfica, e também deveriam estar diretamente relacionados ao atendimento das 
necessidades de saúde da população. Apesar disso, é de conhecimento geral que a ideia do sistema é boa, porém sua execução não ocorre de forma satisfatória.

Estudos relatam que a oferta de serviços fonoaudiológicos é insuficiente e desigual entre as capitais do país e a Atenção Básica é onde há o menor número de fonoaudiólogos atuando (Santos et al., 2017).

Outro exemplo pode ser encontrado no estudo realizado por DefenseNetrval e Fernandes (2016), relacionado a locais de atendimento a pessoas com DEA, no qual foram selecionados inicialmente 62 locais de atendimentos na cidade de São Paulo e apenas 25 destes concordaram em participar da pesquisa (onze escolas especiais/inclusivas, cinco associações, quatro clinicas, quatro instituições e uma Organização Não Governamental (ONG)).

Com isso, nota-se que, se para a participação em uma pesquisa o acesso já é restrito, encontrar um local de atendimento especializado para o tratamento dos indivíduos com DEA também não é uma tarefa nada fácil, sendo muitas vezes necessário buscar o serviço particular.

O Ministério da Saúde do Brasil (Brasil, 2015(a)), em sua publicação sobre a Linha de Cuidado às Pessoas com Transtornos do Espectro do Autismo e Suas Famílias na Rede de Atenção Psicossocial do Sistema Único de Saúde, relata que as crianças com autismo eram inicialmente atendidas pela rede filantrópica (como, por exemplo, a APAE e a Sociedade Pestalozzi) e educacional, em dispositivos da assistência social ou em serviços oferecidos pelas próprias associações de familiares.

Poucos tinham acesso a serviços especializados no DEA e estes serviços geralmente eram oferecidos por hospitais psiquiátricos ou 
universitários, que ofereciam tratamento multiprofissional. Outros realizavam tratamento ambulatorial exclusivamente medicamentoso, realizado por psiquiatra ou neurologista (Brasil, 2015(a)).

O anúncio do Protocolo do Estado de São Paulo de Diagnóstico, Tratamento e Encaminhamento de Pacientes com Transtorno do Espectro Autista - TEA (São Paulo, 2013) representou um avanço com relação aos direitos das pessoas com DEA, principalmente após a Lei 12.764/12 que instituiu a Política Nacional de Proteção dos Direitos da Pessoa com Transtorno do Espectro Autista (Brasil, 2012) e foi a primeira a considerar o portador de DEA como uma pessoa com deficiência. Logo após isso, foi editada a Lei 13.146/15, mais conhecida como Estatuto da Pessoa com Deficiência (Brasil, 2015 (b)).

Segundo o Protocolo do Estado de São Paulo de Diagnóstico Tratamento e Encaminhamento de Pacientes com Transtorno do Espectro Autista (São Paulo, 2013), o tratamento dos pacientes será definido a partir do grau de severidade do transtorno: aqueles com menor severidade deverão ser tratados nos Centros Especializados de Reabilitação (CER) do SUS e os pacientes com maior severidade no transtorno deverão ser encaminhados para os Centros de Atenção Psicossocial (CAPS).

A Lei 12.764/2012 também trata das questões referentes aos tratamentos custeados pelos planos e seguros de saúde (Brasil, 2012), garantindo aos usuários o fornecimento de tratamento suficiente para abranger todas as necessidades da criança/adolescente/adulto com DEA. 
2.4 - O papel do fonoaudiólogo e os diferentes modelos de intervenção

Os DEA apresentam uma grande variedade de manifestações, sendo bem difícil encontrar duas pessoas que estejam dentro do espectro e que apresentem as mesmas características. No geral, como mostra Will et al. (2018), os tratamentos são focados principalmente nos déficits de interação ou comunicação social, comportamentos restritos e estereotipados, questões sensoriais ou comportamentos coocorrêntes desafiadores que impactam o desenvolvimento de habilidades funcionais e independência.

Assim como não há uma causa única e não há comprovação científica sobre a cura para o DEA, ou seja, é irremediável; deste mesmo modo também não há uma definição sobre qual é a melhor opção de tratamento (Will et al., 2018). No entanto, um tratamento efetivo envolve uma intervenção multidisciplinar, que pode/deve incluir fonoaudiólogos, psicólogos, terapeutas ocupacionais, educadores/psicopedagogos e médicos.

Assim como ocorre no Brasil, estudos internacionais (Bethell et al., 2011; Radecki et al., 2011) mostram que não faz parte da rotina clínica de médicos pediatras a aplicação de questionários padronizados de rastreamentos do desenvolvimento infantil que poderiam alertar sobre as possíveis red flags (sinais de alerta) do desenvolvimento infantil.

Em uma iniciativa de saúde pública, o CDC (2018) lançou o “Learn the Signs. Act Early." em uma página em seu site, o qual contem materiais informativos gratuitos disponibilizados para pais e profissionais. Além disso, 
também desenvolveram um aplicativo de acesso gratuito e de fácil compreensão (somente em inglês e espanhol), para o acompanhamento do desenvolvimento da criança desde os 2 meses até os 5 anos, auxiliando na identificação precoce de sinais de alerta para o desenvolvimento infantil.

Com a dificuldade de identificação precoce, a ausência ou atraso das primeiras palavras e frases é um dos principais motivos de apreensão dos pais de crianças com DEA (McConkey et al., 2009; Zanon et al., 2014), trazendo inquietações familiares em relação ao desenvolvimento da linguagem. Em decorrência disto, um dos primeiros profissionais a serem procurados é o fonoaudiólogo, ressaltando assim a importância da avaliação fonoaudiológica e identificação precoce de um possível risco para esses transtornos (Fernandes, 1996; Veldhuizen et al., 2015).

É fundamental que o fonoaudiólogo conheça instrumentos específicos para o diagnóstico das alterações de comunicação que são sensíveis para identificar as características da linguagem de crianças com DEA (Santos, 2017).

Como relatam Gillon et al. (2017), a alta incidência de distúrbios/alterações da/na linguagem coexistentes com DEA mostram como o papel do fonoaudiólogo é fundamental no processo diagnóstico e no tratamento.

Fernandes e Pastorello (1995), também já haviam evidenciado a importância do papel do fonoaudiólogo como profissional que atua especificadamente com as questões de linguagem e comunicação, tanto no diagnóstico como nos tratamentos terapêuticos. Green et al. (2006), Hess et al. (2008), AL Jabery et al. (2014), assim como Salomone et al. (2015), concordam 
que o tratamento fonoaudiológico está entre as intervenções mais comuns e dentre as intervenções que pessoas com autismo mais realizam.

O tratamento, independentemente da linha teórico-clínica escolhida, deve começar o mais cedo possível e ser adaptado às necessidades específicas de cada criança e família. A intervenção nos primeiros anos de vida tem impacto significativo sobre o funcionamento de muitas crianças autistas, e a participação dos pais como coterapeutas em alguns programas de intervenção é fundamental (Lampreia, 2007; Zablotsky et al., 2013).

Observa-se que na literatura há diversos modelos de intervenção propostos e utilizados por fonoaudiólogos (Prizant et al., 2003; Hess et al., 2008; Paul, 2008; Warren et al., 2011; Gillon et al., 2017; ASHA, 2019), como pode ser observado no Quadro 1, abaixo.

\begin{tabular}{|c|c|}
\hline \multicolumn{2}{|c|}{ Quadro 1 - Modelos de intervenção: } \\
\hline Tratamento clínico de base psicanalística & $\begin{array}{c}\text { O programa Desenvolvimento Individualizado } \\
\text { e baseado no Relacionamento (DIR) }\end{array}$ \\
\hline $\begin{array}{c}\text { Análise do Comportamento Aplicada (Applied } \\
\text { Behavioral Analysis - ABA) }\end{array}$ & $\begin{array}{c}\text { O modelo de intervenção Habilidade } \\
\text { Comunicativa Verbal (HCV) }\end{array}$ \\
\hline $\begin{array}{c}\text { Comunicação Suplementar e Alternativa (CSA) } \\
\text { O modelo Picture Exchange Communication } \\
\text { System (PECS) }\end{array}$ & $\begin{array}{c}\text { Treinamento da Comunicação Funcional } \\
\text { (FCT) }\end{array}$ \\
\hline Integração Sensorial & Milieu Teaching (RPMT) \\
\hline Abordagem Funcional da Linguagem & A abordagem pragmática \\
\hline Son-Rise & Early Start Denver Model (ESDM) \\
\hline The SCERTS model; & More Than Words (Hanen) \\
\hline $\begin{array}{c}\text { Tratamento e Educação para Crianças com } \\
\text { Transtornos do Espectro do Autismo (TEACCH) }\end{array}$ & Terapia de interação entre pais-crianças \\
(PCIT)
\end{tabular}


Em uma revisão sistemática da literatura, o The National Autism Center (2015) lançou o National Standards Project (NSP), no qual analisaram, em duas etapas, estudos de 1957 até 2012, caracterizando assim a prática baseada em evidência relacionada ao DEA.

Nesta revisão, como pode ser observado no Quadro 2, as seguintes intervenções foram caracterizadas com base nas evidências científicas encontradas com relação a cada modelo de tratamento. Os tratamentos foram divididos em três categorias: tratamentos com evidências estabelecidas, tratamentos com evidencias emergentes e tratamentos com evidência não estabelecida.

\begin{tabular}{|c|c|c|}
\hline $\begin{array}{c}\text { Evidencia estabelecida } \\
\text { (para até } 22 \text { anos de } \\
\text { idade): }\end{array}$ & $\begin{array}{c}\text { Evidencia emergente } \\
\text { (para até } 22 \text { anos de } \\
\text { idade): }\end{array}$ & $\begin{array}{c}\text { Evidencia não } \\
\text { estabelecida (para até } 22 \\
\text { anos de idade): }\end{array}$ \\
\hline Intervenções comportamentais & $\begin{array}{l}\text { Dispositivos de comunicação } \\
\text { suplementar e alternativa }\end{array}$ & Terapia Assistida por Animais \\
\hline $\begin{array}{c}\text { Intervenção Comportamental } \\
\text { Cognitiva }\end{array}$ & $\begin{array}{c}\text { Tratamento baseado em } \\
\text { desenvolvimento de relações } \\
\text { (RDI) }\end{array}$ & $\begin{array}{c}\text { Treinamento de integração } \\
\text { auditiva }\end{array}$ \\
\hline $\begin{array}{c}\text { Tratamento comportamental para } \\
\text { crianças pequenas }\end{array}$ & $\begin{array}{l}\text { Treinamento em comunicação } \\
\text { funcional }\end{array}$ & Mapeamento de conceito \\
\hline $\begin{array}{l}\text { Treinamento de Linguagem } \\
\text { (Produção) }\end{array}$ & $\begin{array}{l}\text { Treinamento de Linguagem } \\
\text { (Produção e Compreensão) }\end{array}$ & $\begin{array}{l}\text { Estratégia Comportamental de } \\
\text { Aprendizagem Social }\end{array}$ \\
\hline $\begin{array}{l}\text { Treinamento de pais e } \\
\text { responsáveis }\end{array}$ & $\begin{array}{c}\text { Treinamento de Teoria da } \\
\text { Mente }\end{array}$ & $\begin{array}{c}\text { Intervenção baseada em } \\
\text { movimento }\end{array}$ \\
\hline Estratégias Naturais de Ensino & $\begin{array}{c}\text { Intervenção baseada em } \\
\text { imitação }\end{array}$ & Dieta sem glúten/livre de caseína \\
\hline Modelagem & Treinamento de iniciação & SENSE Intervenção Teatral \\
\hline Treinamento com pares & Pacote de Exposição & Comunicação facilitada \\
\hline $\begin{array}{l}\text { Treinamento de resposta crucial } \\
\text { (PRT) }\end{array}$ & Massagem Terapêutica & Intervenção de Cognição Social \\
\hline Intervenção baseada em história & Pacote multi-componente & $\begin{array}{c}\text { Intervenção do Pensamento } \\
\text { Social }\end{array}$ \\
\hline Scripting & Musicoterapia & DIR/Floor Time \\
\hline
\end{tabular}




\begin{tabular}{|c|c|c|}
\hline Autogestão & Ensino Estruturado & Intervenção Sensorial \\
\hline Competências Sociais & Pacote Redutivo & Terapia de Choque \\
\hline Cronograma & Instrução de Sinais & \\
\hline & $\begin{array}{c}\text { Intervenção na Comunicação } \\
\text { Social }\end{array}$ & \\
\hline & $\begin{array}{c}\text { PECS (Picture Exchange } \\
\text { Communication System) }\end{array}$ & \\
\hline & $\begin{array}{c}\text { Intervenção baseada na } \\
\text { tecnologia }\end{array}$ & \\
\hline
\end{tabular}

Estudos mostram que não há definição exata de qual método seja o melhor a ser aplicado, sendo necessário levar em consideração a adaptação e as características de cada indivíduo (Fernandes et al., 2008; Mullas et al., 2010; National Autism Center, 2015; Will et al., 2018).

No entanto, Pasco (2018) relata que as três principais intervenções para crianças pequenas com DEA são as abordagens Pragmáticas de Desenvolvimento, Análise de Comportamento Aplicada (ABA) e Sistemas Ambientais Abrangentes.

Um guia publicado na França em 2018, organizado por Houte Autorité de Santé (Alto Comissariado da Saúde), possui recomendações para otimizar o processo de detecção e diagnóstico de DEA em crianças ou adolescentes com menos de 18 anos de idade. Neste manual, recomendam a avaliação diagnóstica multidisciplinar, envolvendo também os fonoaudiólogos. Assim como no Brasil, indicam a aplicação do M-CHAT (Losapio e Pondé, 2008), para avaliação de indicadores de risco. Para contribuir no processo diagnóstico, indicam a utilização do ADI-R (Lord et al., 1994) e ADOS (Lord et al., 2000) e outros protocolos para avaliação do grau de severidade e funcionalidade. Para avaliação da linguagem, entre os citados estão: Test of Pragmatic Language-2 
(TOPL-2/ Phelps-Terasaki and Phelps-Gunn, 2007) e Clinical Evaluation of Language Fundamentals (CELF/ Wigg et al., 2013).

O ADI-R (Lord et al., 1994) e ADOS (Lord et al., 2000) são protocolos considerados padrão ouro para classificação do autismo na literatura internacional, sendo muito utilizado em pesquisas devido a fácil reaplicabilidade, scores padronizados e perguntas detalhadas (Becker et al., 2012; Marques e Bosa, 2015; Wiggins et al., 2015). Por serem protocolos amplos, necessitam de capacitação para a sua aplicação, restringindo assim seu uso no Brasil (Marques e Bosa, 2015).

Gillon et al. (2017) trazem uma lista de 22 diferentes testes mais utilizados para a avaliação nos DEA em diferentes países. Dentre essas 22 avaliações, a mais utilizada foi a Preschool Language Scales (PLS-V/ Zimmerman et al., 2011) seguida por Clinical Evaluation of Language Fundamentals (CELF- Wiig et al., 2013) ou outra versão deste teste.

Com relação à avaliação fonoaudiológica, no site da Asha, além da avaliação audiométrica, fica descrito no Quadro 3, como avaliações tipicamente realizadas por fonoaudiólogos:

\begin{tabular}{|c|c|}
\hline Quadro 3 - Avaliações realizadas por fonoaudiólogos: \\
\hline Linguagem receptiva & $\begin{array}{c}\text { Linguagem expressiva, incluindo produção de sons } \\
\text { e palavras e a frequência e função das } \\
\text { comunicações verbais e não verbais }\end{array}$ \\
\hline Habilidades de leitura & Comunicação \\
\hline Uso do olhar & Atenção compartilhada \\
\hline Iniciação de comunicação & Reciprocidade social e funções comunicativas \\
\hline Interação & Funcionalidade da brincadeira \\
\hline Uso de gestos & Habilidades de conversação \\
\hline Troca de turno & Prosódia da fala \\
\hline
\end{tabular}

Fonte: American Speech-Language-Hearing Association [homepage na internet]. 
Segundo as definições do DSM-5 (APA, 2013) os prejuízos nos aspectos sociais/pragmáticos da linguagem, assim como o início ou a manutenção de conversas recíprocas com as pessoas, são uma das características definidoras do DEA. Sendo este um fator de grande importância, a avaliação da Pragmática ou Perfil Funcional da Comunicação (PFC) (Fernandes, 2004) e a terapia baseada na Comunicação Funcional Criativa (CFC) são a base do serviço de referência (LIF-DEA) ${ }^{4}$ às pessoas com DEA na cidade de São Paulo (Fernandes e Pastorello, 1995; Fernandes, 1996; Fernandes et al., 2015).

Assim como concluiu Santos (2017), diferentes instrumentos que avaliam as habilidades pragmáticas de crianças com DEA se relacionam e apresentam resultados compatíveis.

A avaliação do PFC, quando olhamos a pragmática por uma perspectiva funcionalista, oferece ferramentas para a investigação do desenvolvimento da linguagem desde o seu início, considerando também os aspectos não verbais e interacionais da comunicação (Hage et al., 2007; Sandri et al., 2009; Amato e Fernandes, 2011). Esta é uma ferramenta que pode ser utilizada para avaliar a linguagem na prática dos fonoaudiólogos em diferentes contextos, como por exemplo, instituições e clínicas (Cardoso e Fernandes, 2006; Fernandes et al., 2006; Defense e Fernandes, 2010; Santos, 2017).

Para a análise do PFC são utilizados os critérios propostos por Fernandes (2004), com as alterações comprovadas no estudo de Porto et al. (2007). Sendo assim, as filmagens com duração de 15 minutos são feitas em situações de interação espontânea entre o fonoaudiólogo e a criança/adolescente. Após a filmagem, esta é analisada e os 5 minutos mais

\footnotetext{
${ }^{4}$ Este serviço será descrito detalhadamente no Estudo 1
} 
simétricos, segundo a percepção do próprio terapeuta, são selecionados e a avaliação ocorre com base neste recorte.

Como relatam Cardoso e Fernandes (2006), o fonoaudiólogo deve avaliar a relação entre as habilidades de linguagem e a competência comunicativa.

Com esta análise é possível caracterizar a comunicação com base nas funções comunicativas predeterminadas, assim como a interação e o meio comunicativo mais utilizado. Independente do meio comunicativo utilizado pelo paciente (Amato e Fernandes, 2010), esta avaliação pode trazer dados relevantes para a complementação do diagnóstico e acompanhamento terapêutico.

Molini e Fernandes (2001) mostraram em seu estudo que o os aspectos funcionais da linguagem e o desempenho sócio cognitivo estão relacionados. Sendo assim, em 2001, Molini, com base no modelo sugerido por Wetherby e Prutting (1984), propôs uma avaliação do Desempenho Sócio Cognitivo (DSC) que envolve duas situações: espontânea (com base em filmagem realizada em um contexto de interação terapeuta-criança) e teste.

Usando estes mesmo critérios, Cardoso e Fernandes (2004) correlacionaram os dados coletados com o DSC e o PFC de crianças com DEA em situações comunicativas diversificadas e reafirmaram a importância destes instrumentos para a atividade clínica junto a esta população. Da mesma forma como mostram outros estudos (Wetherby e Prutting, 1984; Whitehouse et al., 2006; Miilher e Fernandes, 2009) que discutem as relações entre os déficits cognitivos e de linguagem nos quadros de autismo infantil.

Fernandes et al. (2008), usaram o DSC e o PFC para avaliar a 
existência de diferenças observáveis em três propostas de atendimento (individual, dupla e com o cuidador) usando a mesma metodologia de terapia e concluíram que esta metodologia pode ser utilizada em diferentes propostas. Ainda assim, ressaltaram que é necessário a adequação da estratégia levando em consideração o perfil individual de habilidades e inabilidades de cada sujeito.

\section{5 - Estudos longitudinais envolvendo autismo}

As pesquisas longitudinais podem ser consideradas, segundo Bordalo (2006), como prospectivas ou retrospectivas. A pesquisa a qual esta tese se refere é o tipo longitudinal retrospectiva.

Em um estudo longitudinal retrospectivo temos que lidar com mudanças que não estão mais ao nosso alcance, como por exemplo, as mudanças na caracterização, rotatividade de profissionais, método de organização do sistema, aplicação de questionários com diferenças na coleta, perda de dados, entre outros.

Já os estudos longitudinais prospectivos são realizados a partir da escolha de características a serem averiguadas e seleção de sujeitos, e a partir deste ponto, realizam o acompanhamento em longo prazo.

$\mathrm{Na}$ busca por estudos longitudinais envolvendo o autismo, publicados nos últimos anos, foram encontrados artigos com diferentes metodologias que serão descritos a seguir.

Misquiatti e Brito (2010) realizaram um estudo de caso com dois irmãos ao longo de quatro anos, utilizando metodologia similar de avaliação e terapia 
utilizadas no LIF-DEA. Além de concluírem que a terapia fonoaudiológica com abordagem pragmática é de grande valia, também ressaltaram a importância de documentação escrita e registro audiovisual de dados para contribuição nos estudos longitudinais e na prática baseada em evidencia.

É válido relatar que durante esta pesquisa surgiu a oportunidade de conhecer o Marcus Autism Center, um centro nacional de excelência em autismo (EMORY, 2017) na cidade de Atlanta (Georgia - EUA). Nele são realizados diversos estudos longitudinais buscando sinais para o diagnóstico precoce, analisando o contato ocular, comportamento social, comunicação entre bebês e cuidadores, novos modelos de tratamentos, estudos envolvendo neuroimagens, entre outros.

Este centro, que é parte do departamento de pediatria da Emory University, assim como o local de pesquisa na qual Saboia et al. (2017) realizaram seu estudo longitudinal (Hospital Necker Enfants Malades em Paris/ França - afiliada à Universitée de Paris Descartes) e possuem uma grande infraestrutura para coleta de dados, bem como um grande volume de pacientes.

Utilizando parte dos dados de um estudo longitudinal com 98 participantes ao longo de 2 anos que avaliou associações entre o ambiente da língua materna, habilidade de linguagem e habilidades sociais em resposta à intervenção precoce no DEA, Zhou et al. (2017), realizaram uma análise transversal exploratória com base nos dados de 13 participantes bilíngues. A metodologia descreveu que os autores selecionaram dados de três etapas: avaliação, após um ano de intervenção e após 2 anos de intervenção e utilizaram protocolos pré determinados para a avaliação dos dados. 
Na pesquisa de Toscano et al. (2018), foram examinados o crescimento e o desenvolvimento físico de 120 crianças brasileiras com DEA com idade entre 4 e 15 anos ao longo de 4 anos com 3 reavaliações durante esse período.

Já Weiss et al. (2018) selecionaram 30 sujeitos de uma pesquisa inicial anterior, que estavam disponíveis para a realização de testes adicionais e de continuidade no acompanhamento por 2 anos e meio. Constataram que os dados coletados nesse estudo longitudinal ilustram de melhor forma os dados encontrados na comparação de crianças com DEA e com desenvolvimento típico.

O National Institute for Health Research (NIHR) possui uma concessão de programas para pesquisa aplicada e por meio disso publicaram um estudo longitudinal (Murphy et al., 2018) envolvendo a transição para a vida adulta de sujeitos autistas e de Transtorno de Déficit de Atenção com Hiperatividade (TDAH). Os métodos desta pesquisa incluíram entrevistar, juntamente com suas famílias, uma amostra de mais de 180 indivíduos com diagnóstico confirmado de DEA e TDAH. Estes indivíduos estavam entre os 5.651 indivíduos com DEA em todo o Reino Unido identificados no rastreio geral e entre aproximadamente 1.600 pacientes com TEA e TDAH.

Após duas décadas de uso de um questionário criado por uma das autoras na forma impressa, foi realizada a versão online do questionário ATEC (Autism Treatment Evaluation Checklist) e analisados os dados de 4 anos de aplicabilidade do teste em sua nova versão (Mahapatra et al., 2018). Com a seleção dos dados baseados nos critérios de inclusão e exclusão, foram selecionados 2.272 participantes que completaram ao menos 3 questionários 
em 2 anos e a diferença entre o primeiro e o último questionário respondido deveria ser de 1 ano.

Analisando esses estudos é possível observar uma infinidade de opções de delineamento de pesquisas, cada uma delas trazendo a sua singularidade. Entretanto, nota-se a dificuldade de encontrar estudos detalhadamente descritos, com uma análise ao longo de vários anos.

Com essa amostra de pesquisas longitudinais encontradas na literatura é possível perceber que o termo longitudinal varia bastante, sendo aplicado tanto em pesquisas com duração de meses, como em outras com alguns anos de duração e com coleta de dados esporádicos e outras ainda realizadas ao longo de vários anos, como no caso desta pesquisa em questão. Algumas delas partem de outros grandes estudos contendo uma ampla coleta de dados.

Seguindo esta ideia, os estudos descritos a seguir foram concebidos em duas etapas diferentes, o Estudo 1, envolvendo a ideia principal do trabalho e o Estudo 2 que surgiu a partir das dificuldades encontradas na coleta de dados da ideia inicial. 


\section{$\mathcal{E S T \mathcal { T } O} 1$}

$\mathcal{A} \mathcal{T} \mathcal{E} \mathcal{N D I M E} \mathcal{N} \mathcal{T} O$ FONOAUDIOLÓGICO $\mathcal{D E}$

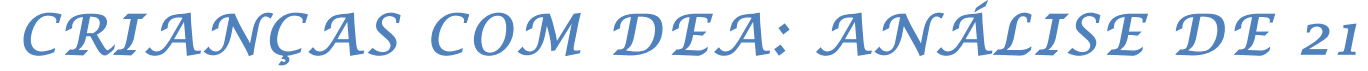

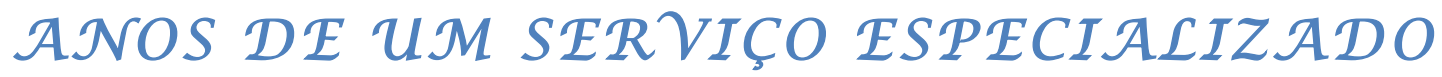




\section{1 - Introdução}

Em 1986 foi implantado junto ao Serviço de Psiquiatria da Infância e Adolescência (SEPIA) do Instituto de Psiquiatria do Hospital das Clínicas da Faculdade de Medicina da Universidade de São Paulo (HC-FMUSP) o Ambulatório Didático de Fonoaudiologia em Psiquiatria Infantil, o qual, durante muitos anos, foi o único serviço de fonoaudiologia em hospital psiquiátrico no Brasil (Fernandes e Pastorello, 1995; Fernandes, 2011).

Fernandes (2011) relata que, em 1997, após uma reestruturação curricular, surgiu a oportunidade da implementação dos Laboratórios de Investigação Fonoaudiológica (LIFs) que possibilitava a integração das atividades de ensino e pesquisa, não só no nível da graduação, mas também em programas de pós-graduação lato e stricto sensu. Assim surgiu o LIF em Distúrbios Psiquiátricos da Infância (atualmente denominado Laboratório de Investigação Fonoaudiológica dos Distúrbios do Espectro do Autismo LIFDEA) do Curso de Fonoaudiologia da Faculdade de Medicina da Universidade de São Paulo (FMUSP).

Este LIF utiliza a abordagem pragmática e além de priorizar a pesquisa e o ensino, representa também uma importante atividade assistencial especializada. Com base nos dados do LIF-DEA, em 2017, cerca de 90 pacientes eram atendidos semanalmente por cinco alunos da graduação, dois estudantes do aprimoramento, cinco estudantes do mestrado, três estudantes do doutorado e dois estudantes do pós-doutorado.

Considerando o volume de pessoas atendidas e de pessoas responsáveis pelos atendimentos, ter o registro sistemático de dados 
terapêuticos é essencial. Como é relatado por Amato et al. (2011), é fundamental o registro dos processos terapêuticos, tanto para que experiências individuais possam ser analisadas de forma significativa, como também para contribuir para a prática clínica.

Amato et al. (2011) reforçam ainda que, quando relacionados ao DEA, é de suma importância que as experiências sejam sistematizadas e descritas para que possam auxiliar outros pacientes que apresentem as mesmas necessidades, mas que não foram diagnosticados ou não encontraram atendimento especializado.

Desta mesma forma, estudos longitudinais (Mahapatra et al., 2018) e revisões de literatura (Will et al., 2018) reforçam a importância da sistematização de dados e de registros terapêuticos, para que seja possível essa análise a longo prazo.

Defense-Netrval (2014) traz outro aspecto importante, que por meio do gerenciamento de dados pode ser possível comprovar a eficácia da terapia, independentemente de sua linha teórica, seja ela, comportamental, pragmática ou outra, contribuindo assim para a prática clínica baseada em evidência.

Os resultados da revisão de literatura realizado por Parker et al. (2007) mostram a importância da Ciência da Informação ${ }^{5}$ em tudo o que ela engloba, mais aparente na pesquisa científica em saúde dos países desenvolvidos, como por exemplo, nos EUA. Porém observaram um crescimento significativo da produção científica da China e Coréia do Sul e, em menor escala, do Brasil.

Ao analisar as últimas décadas é possível observar mudanças também no funcionamento dos serviços que oferecem atendimento a crianças com

\footnotetext{
${ }^{5}$ Como foi denominado pelos autores, sendo que Ciência da informação é caracterizado pelas áreas de informação, comunicação e informática em saúde
} 
DEA. Na atuação fonoaudiológica as alterações envolvem tanto os critérios diagnósticos e de intervenção como também a metodologia das pesquisas e a sistematização de dados de processos diagnósticos (Amato et al., 2013).

Estudos com dados armazenados em um sistema comprovam as possibilidades de pesquisas com grandes populações, o que não é comum na literatura da área (Amato et al., 2013).

Além disso, a sistematização de dados facilita a visualização em longo prazo, evidenciando que um padrão nacional mínimo para o diagnóstico de DEA é necessário. Assim como foi constatado na Austrália, em que a sistematização de dados auxiliou na garantia de melhores práticas, independentemente do tipo de ambiente em que o serviço era prestado, além de se tornarem consistentes com as diretrizes internacionais de melhores práticas para diagnóstico de DEA (Taylor et al., 2016).

Alves et al. (2016) descrevem que a utilização de computadores no acompanhamento e documentação clínica representa uma mudança inovadora e ao mesmo tempo um desafio para profissionais, docentes e estagiários da área de saúde.

Defense-Netrval e Fernandes (2016) concluíram que o gerenciamento de qualidade no tratamento oferecido aos indivíduos com DEA é de suma importância, principalmente quando relacionados aos atendimentos fonoaudiológicos. As autoras constataram que diversos locais ainda negligenciam a importância da atuação do fonoaudiólogo no tratamento de pessoas autistas.

Na pesquisa realizada por Gillon et al. (2017) que buscou dados sobre a relação de fonoaudiólogos que trabalham com indivíduos com DEA ao longo do 
mundo concluiu que há tendências globais positivas e práticas eficazes na avaliação e intervenção em crianças com DEA.

Desta forma, este estudo buscou analisar o atendimento realizado no LIF-DEA nos últimos 21 anos (de 1997 a 2017). Identificando fatores intervenientes nos processos de terapia fonoaudiológica e contribuindo para o gerenciamento clínico mais produtivo. 


\section{2 - Objetivo}

Este estudo teve como objetivo caracterizar o atendimento realizado em um serviço de Fonoaudiologia especializado nos Distúrbios do Espectro do Autismo no Brasil nos últimos 21 anos.

\section{1 - Objetivos específicos:}

- Caracterizar o número de pacientes atendidos

- Verificar a existência de relação entre a idade de início do tratamento e o tempo médio de permanência no serviço;

- Verificar a possibilidade de identificação do impacto da mudança nos critérios diagnósticos dos DEA na idade do início do atendimento e volume de encaminhamentos;

- Caracterizar o campo de pesquisa a partir do levantamento dos registros de dados disponíveis. 


\section{3 - Método}

Trata-se de uma pesquisa baseada na metodologia empírica exploratória longitudinal, com a utilização de prontuários para a coleta de dados e um software criado para armazenamento de dados.

A pesquisa exploratória segundo as definições de Gil (2008), tem o objetivo de obter uma visão geral acerca de determinado fato, com a finalidade de esclarecer e modificar conceitos e ideias. Pode envolver uma revisão de bibliografia e ou de documentos, sendo realizada especialmente com assuntos que envolvem temas pouco explorados, tornando difícil a criação de hipóteses precisas e operacionalizáveis.

Método empírico é um método feito através de tentativas e erros, é caracterizado pelo senso comum, e cada um compreende à sua maneira (Gil, 2008).

Contudo, observa-se que este estudo caracteriza-se melhor como uma pesquisa ex-post-facto, ou seja, uma pesquisa na qual é estudado um fato já ocorrido e tenta-se entender ou encontrar uma explicação. Como relatam Prodanov e Freitas (2013), nela mostra-se a falta de controle do investigador sobre a variável independe, sendo esta, a principal característica que a diferencia de um estudo experimental. 


\section{1 - Corpus}

Foram selecionados todos os prontuários de pacientes que realizam ou realizaram terapia fonoaudiológica no LIF-DEA nos últimos 21 anos, ou seja, de janeiro de 1997 a dezembro de 2017.

Os critérios de inclusão envolveram todos os indivíduos que compareceram para avaliação, diagnóstico e terapia fonoaudiológica no período determinado. As informações incompletas foram estatisticamente ajustadas e sua verificação foi utilizada para o aperfeiçoamento do sistema de registros do LIF-DEA.

Os critérios de exclusão envolveram indivíduos que interromperam o atendimento no LIF-DEA antes de janeiro de 1997 e/ou os que iniciaram esse atendimento após janeiro de 2018, além de pacientes que vieram ao primeiro atendimento, realizaram avaliação e não pertenciam ao DEA.

\section{2 - Material}

Como material de coleta e armazenamento de dados foram utilizadas planilhas do Excel e o software IDEA foi utilizado para a informatização dos dados, para posterior análise dos mesmos.

O IDEA é um software que foi desenvolvido no LIF-DEA para sistematização, digitalização e armazenamento dos dados de todos os pacientes (Figura 1).

Para melhor compreensão dos dados colhidos e da dimensão das informações, o programa será explicado a seguir passo a passo: 


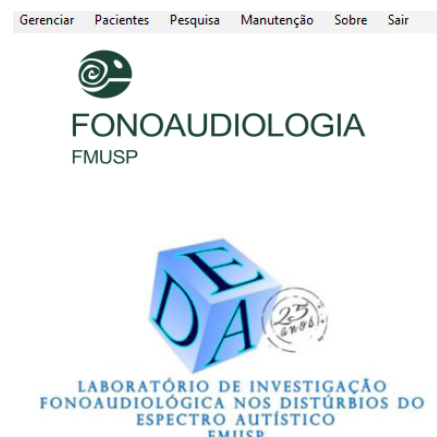

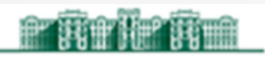 \\ MEDICINA \\ TSP}
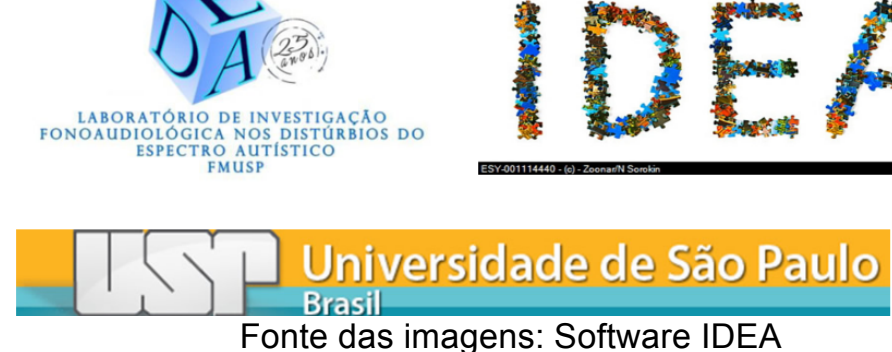

\section{Figura 1 - Tela inicial do programa IDEA}

Primeiramente é realizado o cadastro, selecionando a opção Pacientes, incluir novo paciente e cadastrar com os dados pessoais de cada paciente, contendo: nome, endereço telefone, data de nascimento, número LIF (número de registro que o paciente recebe ao entrar no atendimento), nome dos pais ou responsável legal, diagnóstico, profissionais e é possível anexar o laudo do diagnóstico médico (Figura 2).

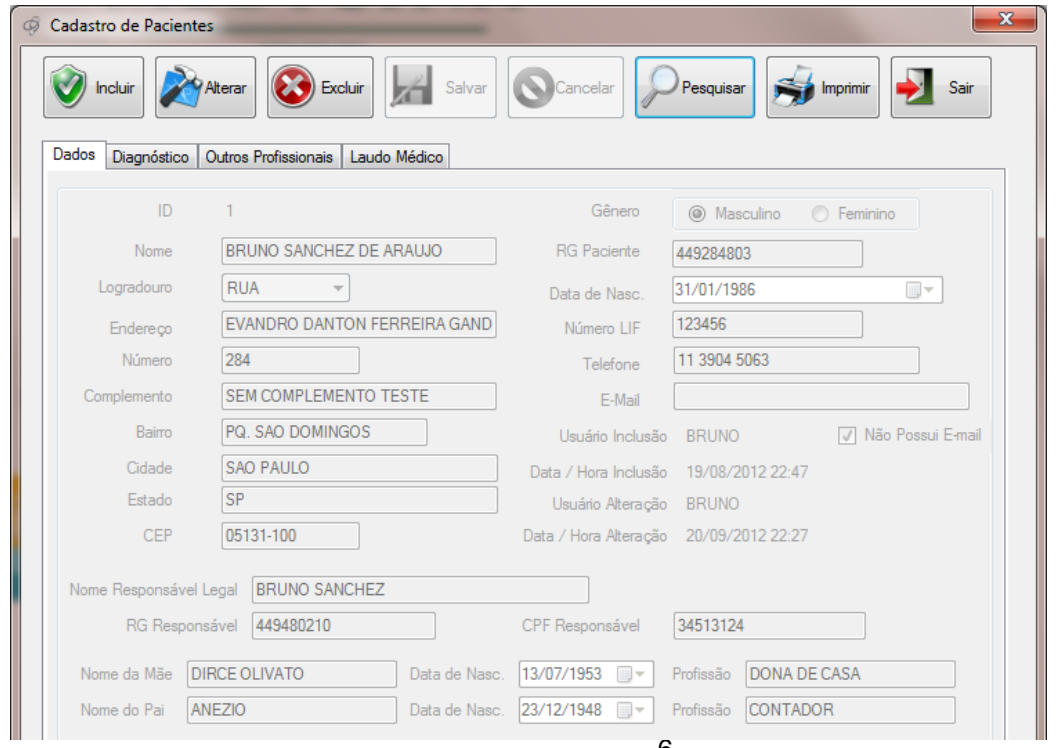

Figura 2 - Tela de cadastro de pacientes ${ }^{6}$

\footnotetext{
${ }^{6}$ O nome do paciente utilizado como exemplo é fictício, assim como seus dados.
} 
Após os pacientes serem cadastrados é possível colocar os dados das avaliações realizadas, podendo ser do tipo inicial (com a opção de aba para anamnese) ou semestral. Ou seja, se for a primeira avaliação do paciente, será cadastrado como inicial, caso contrário, será uma avaliação semestral, que é uma reavaliação do paciente que ocorre a cada seis meses.

Os itens em vermelho são de preenchimento obrigatório e os itens em azul referem-se a informações que podem ser preenchidas ou não (Figura 3).

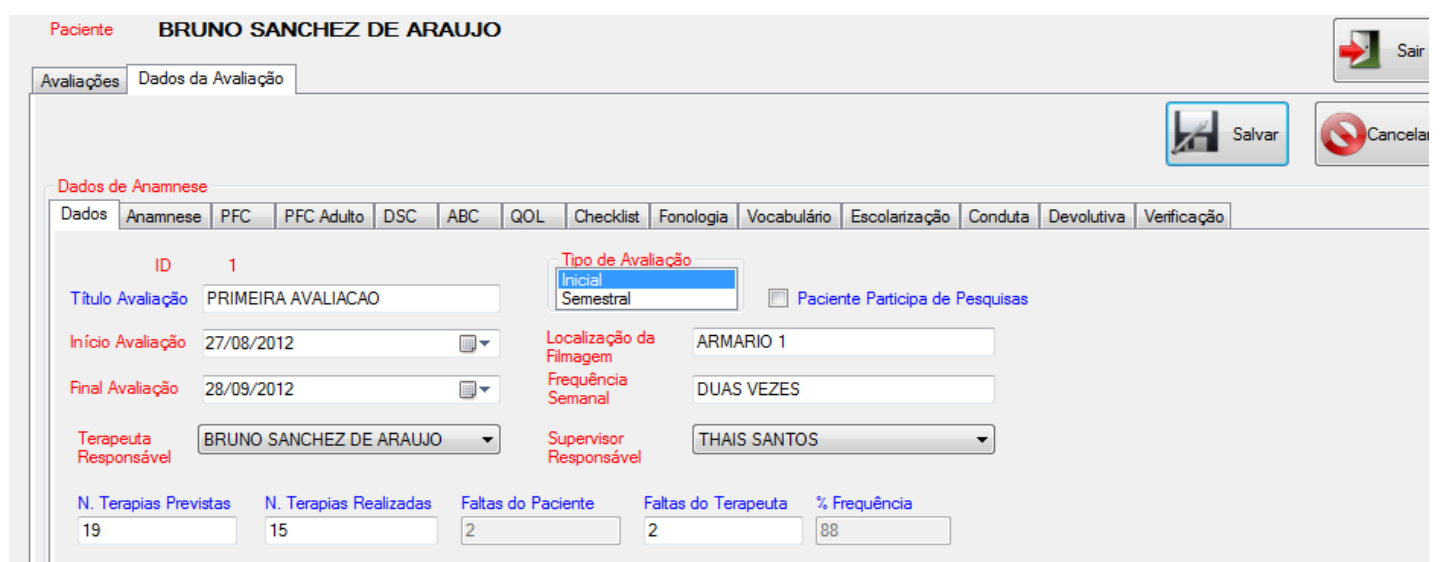

Figura 3 - Aba de preenchimento dos dados da avaliação

Esta aba contém o titulo da avaliação no qual deve ser especificado o semestre e o ano em que foi realizado, a data de início e fim da avaliação, nome do terapeuta e supervisor responsável, localização dos dados de filmagem, frequência que é relacionada ao número de terapias previstas, realizadas e o número de faltas. 


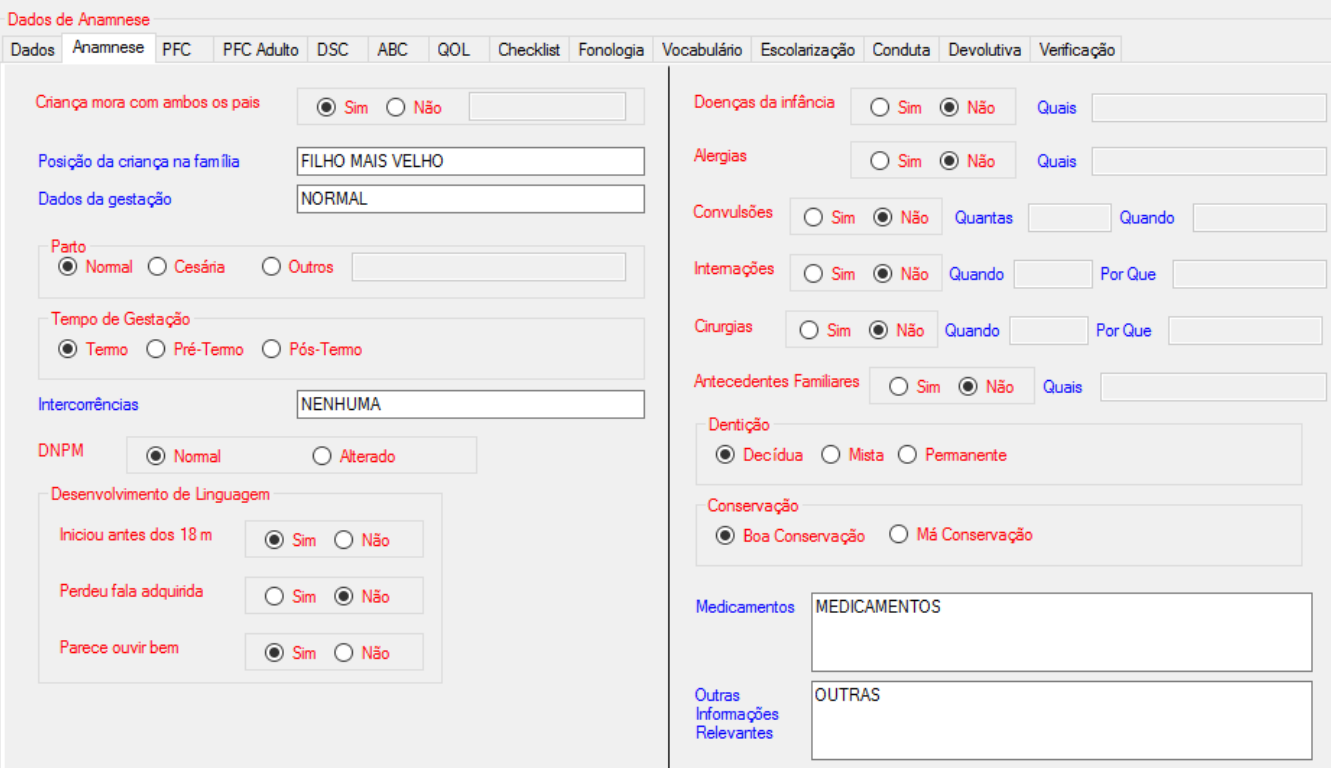

Figura 4 - Aba de preenchimento dos dados da anamnese

$\mathrm{Na}$ aba referente à Figura 4 é possível preencher os dados referentes à anamnese (se for uma avaliação inicial) ou de atualização de anamnese (se for uma avaliação semestral).

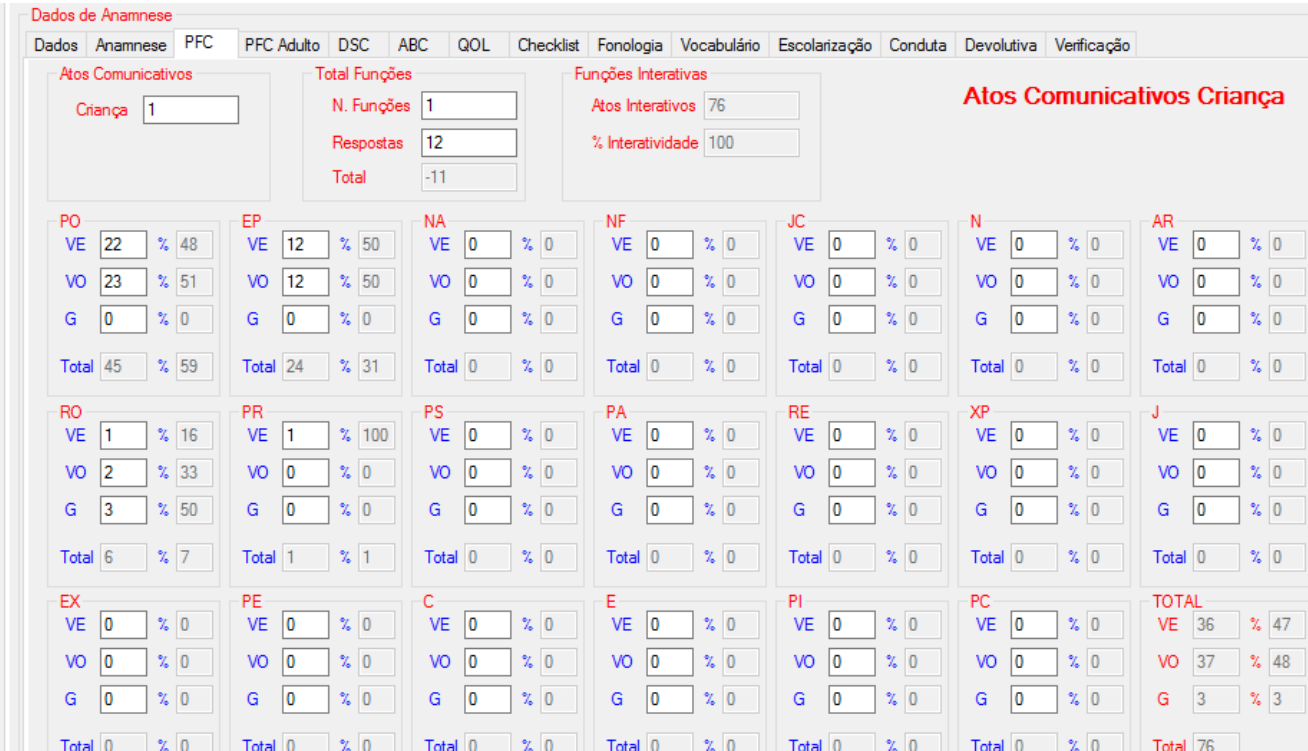

Figura 5 - Aba de preenchimento dos dados da avaliação da pragmática 
Nas abas PFC e PFC adulto, como ilustrado na Figura 5, são cadastrados os dados da avaliação da pragmática segundo os critérios propostos no ABFW (Fernandes, 2004).

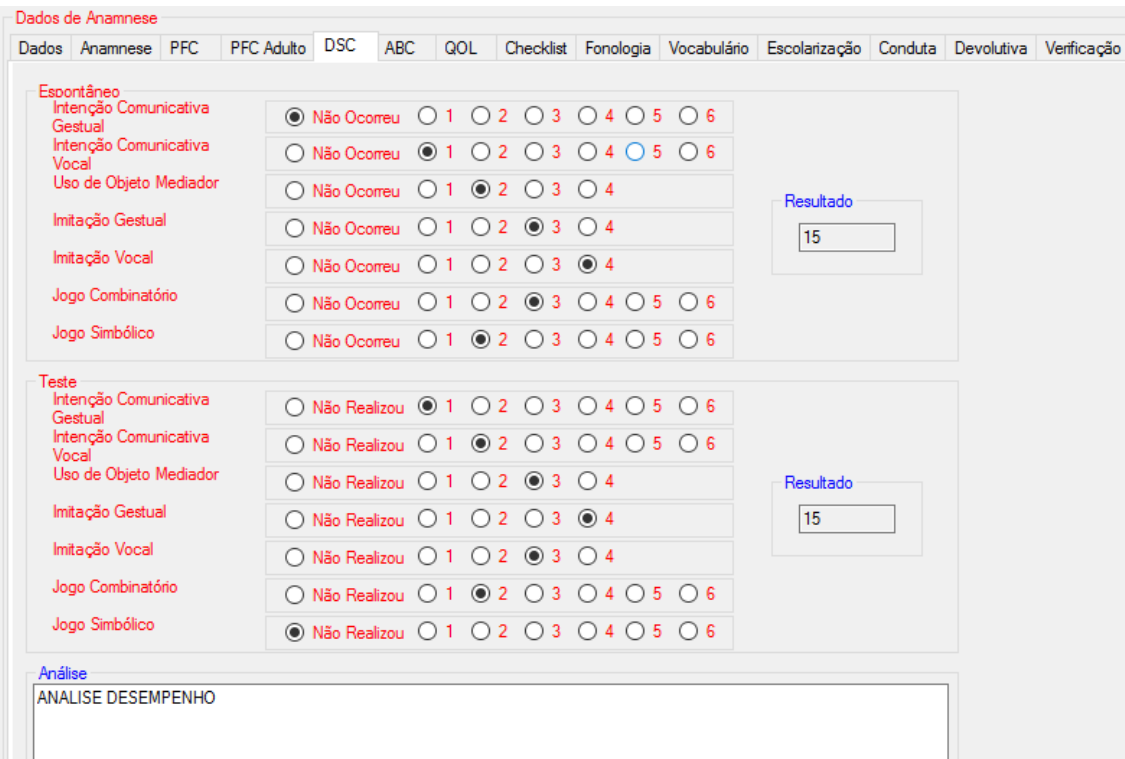
cognitivo

Figura 6 - Aba de preenchimento dos dados do desempenho sócio

Na aba DSC (Figura 6) é cadastrado o teste elaborado por MoliniAvejonas e Fernandes (2003) que verifica os seguintes aspectos: intenção comunicativa gestual, intenção comunicativa vocal, uso do objeto mediador, imitação gestual, imitação vocal, jogo combinatório e jogo simbólico. Tanto na situação espontânea (avaliado por meio da filmagem de 15 minutos da avaliação da pragmática), como na situação teste. 


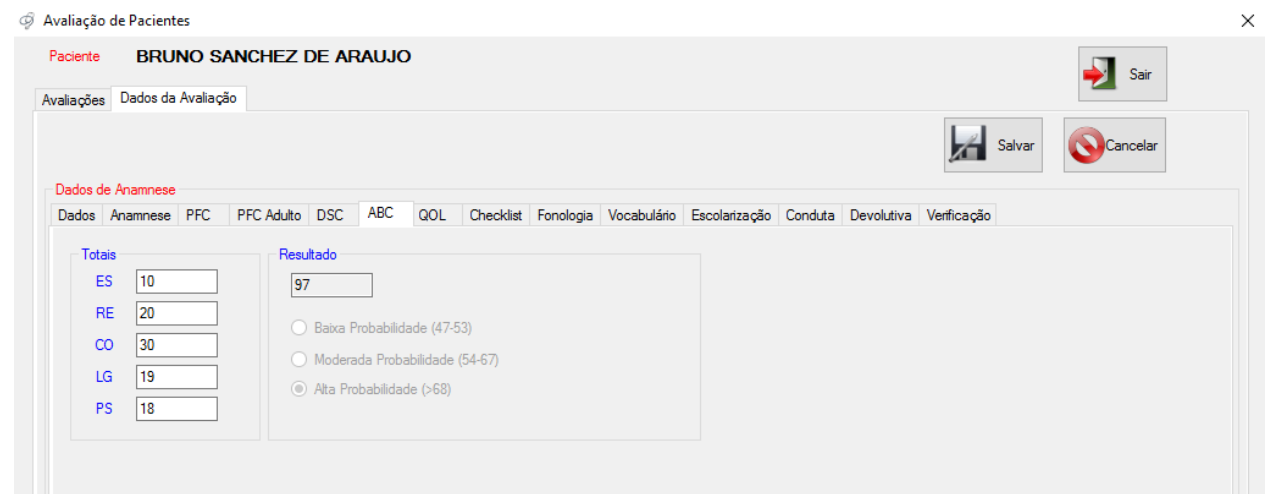

Figura 7 - Aba de preenchimento dos dados Inventário de Comportamento da Criança Autista

Esta aba, referente à Figura 7 , é preenchida com o resultado da aplicação do Inventário de Comportamento da Criança Autista (ABC) (Marteleto \& Pedromônico, 2005).

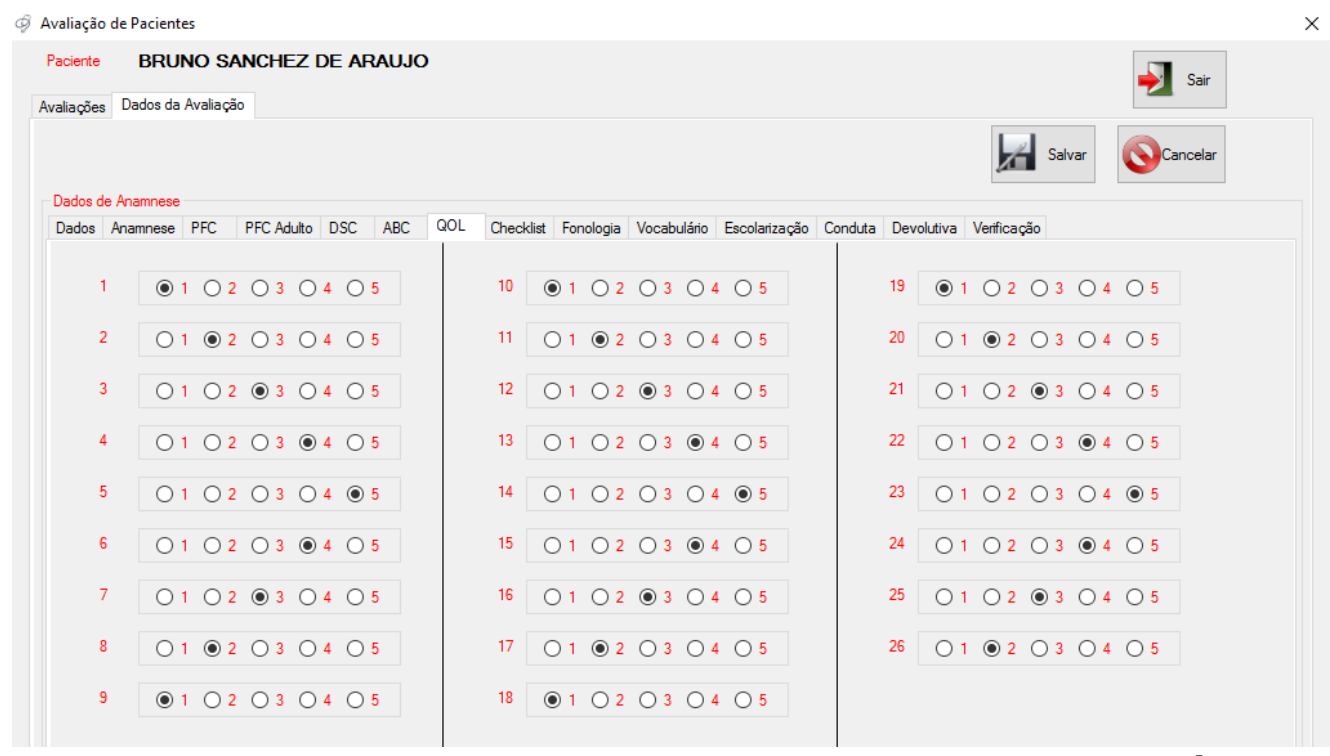

Figura 8 - Aba de preenchimento dos dados do questionário de Qualidade de Vida: QOL

Na Figura 8 está a aba QOL, na qual é colocado o resultado da aplicação do questionário de Qualidade de Vida WHOQOL - BREF (OMS, 1998). 


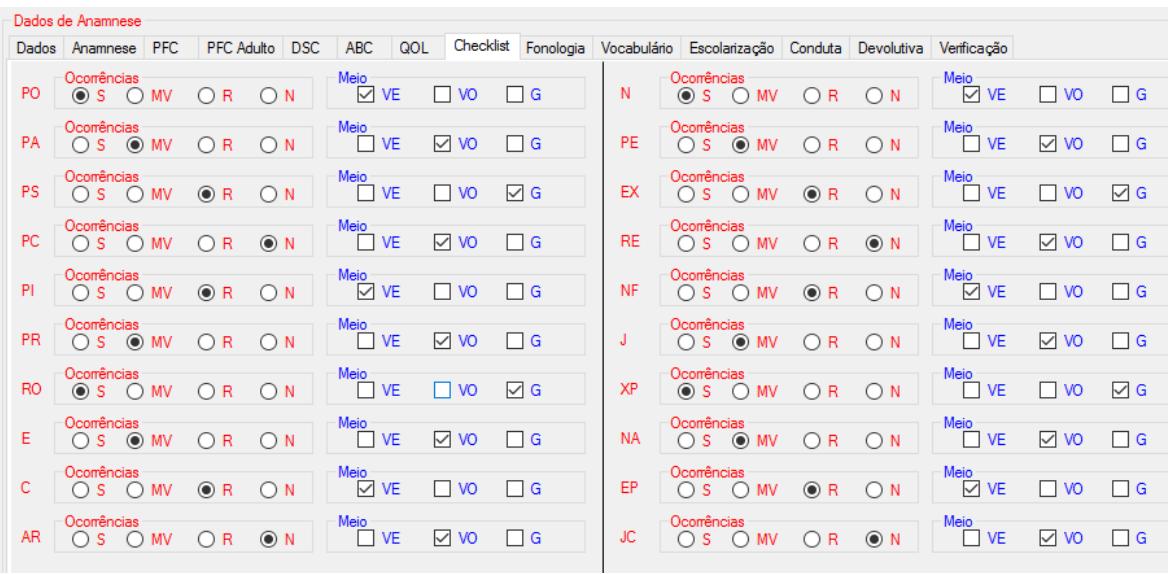

Figura 9 - Aba de preenchimento dos dados do Perfil Funcional da Comunicação - Checklist

Na aba Checklist (Figura 9) é preenchido o resultado do questionário do Perfil Funcional da Comunicação - Checklist (PFC-C), que foi proposto por Neubauer e Fernandes em 2013. Nele consta uma listagem de funções comunicativas expressadas pelos indivíduos, analisado do ponto de vista da terapeuta ou da mãe, em relação às funções comunicativas usadas pela criança, levando-se em consideração também os meios comunicativos utilizados.

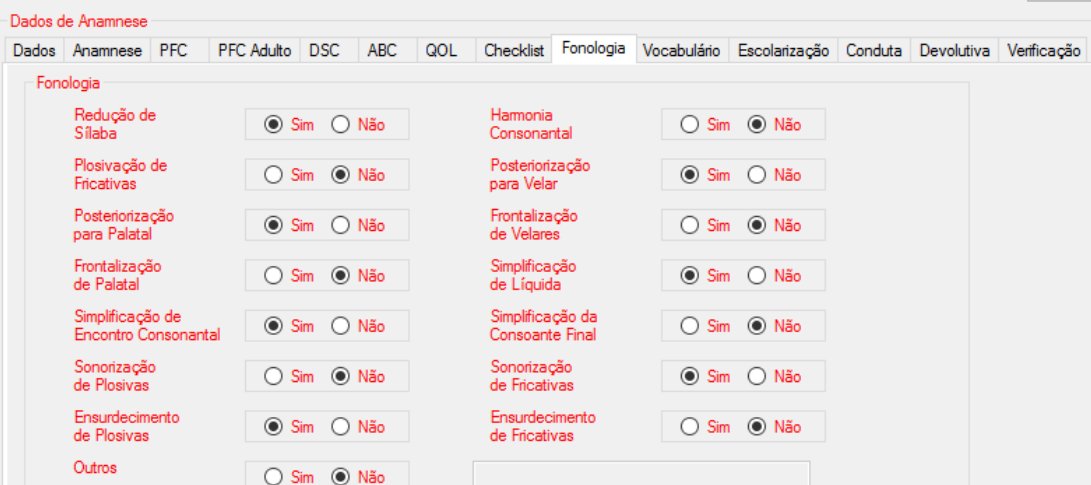

Figura 10 - Aba de preenchimento dos dados da avaliação de Fonologia

Se aplicado, o teste de fonologia do ABFW (Wertzner, 2004) pode ser preenchido na aba referente a este protocolo, como mostra a Figura 10. 


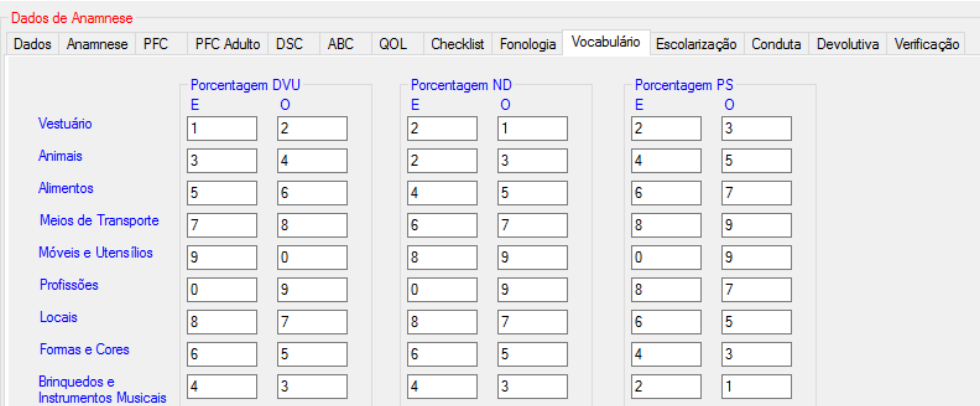

Figura 11 - Aba de preenchimento dos dados da avaliação de vocabulário

Deste mesmo modo, se aplicado, as respostas do teste de vocabulário do ABFW (Befi-Lopes, 2004) podem ser preenchidas nesta aba referente à Figura 11.

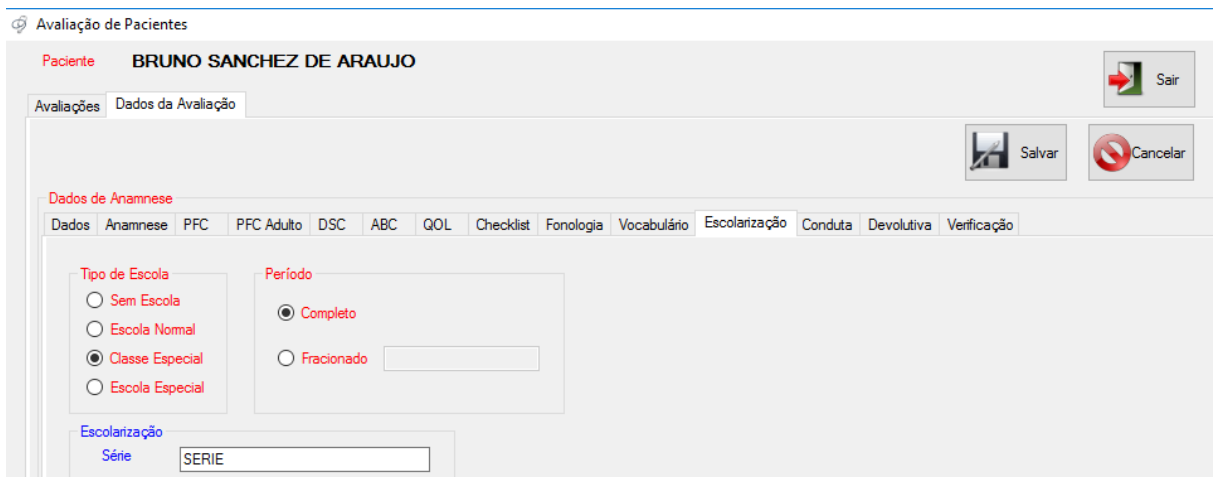

Figura 12 - Aba de preenchimento dos dados de escolarização

Os dados relacionados à escolarização do paciente podem ser preenchidos nesta aba (Figura 12), especificando se a criança frequenta a escola no período completo, ou fracionado, ou seja, apenas algumas horas do período. 


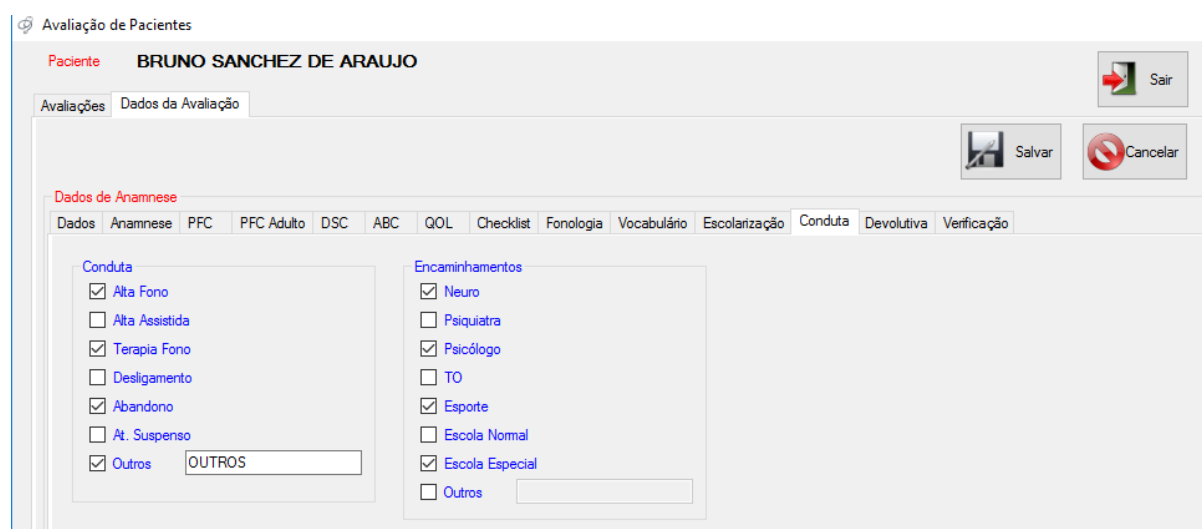

Figura 13 - Aba de preenchimento dos dados de conduta

Na Figura 13 está ilustrada a aba na qual é preenchida com a conduta adotada com o paciente e os encaminhamentos realizados.

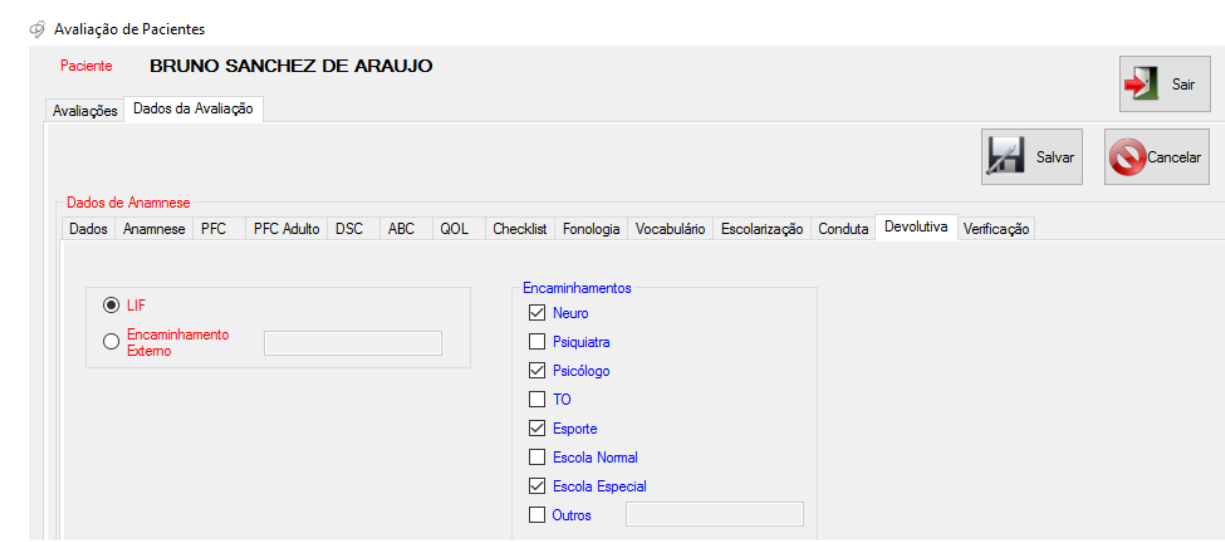

Figura 14 - Aba de preenchimento dos dados de devolutiva

Após a devolutiva, os dados em relação ao que ficou combinado são passados para esta aba (Figura 14), colocando se o paciente continuará em atendimento ou se foi encaminhado para outro atendimento e os encaminhamentos solicitados aos pais. 


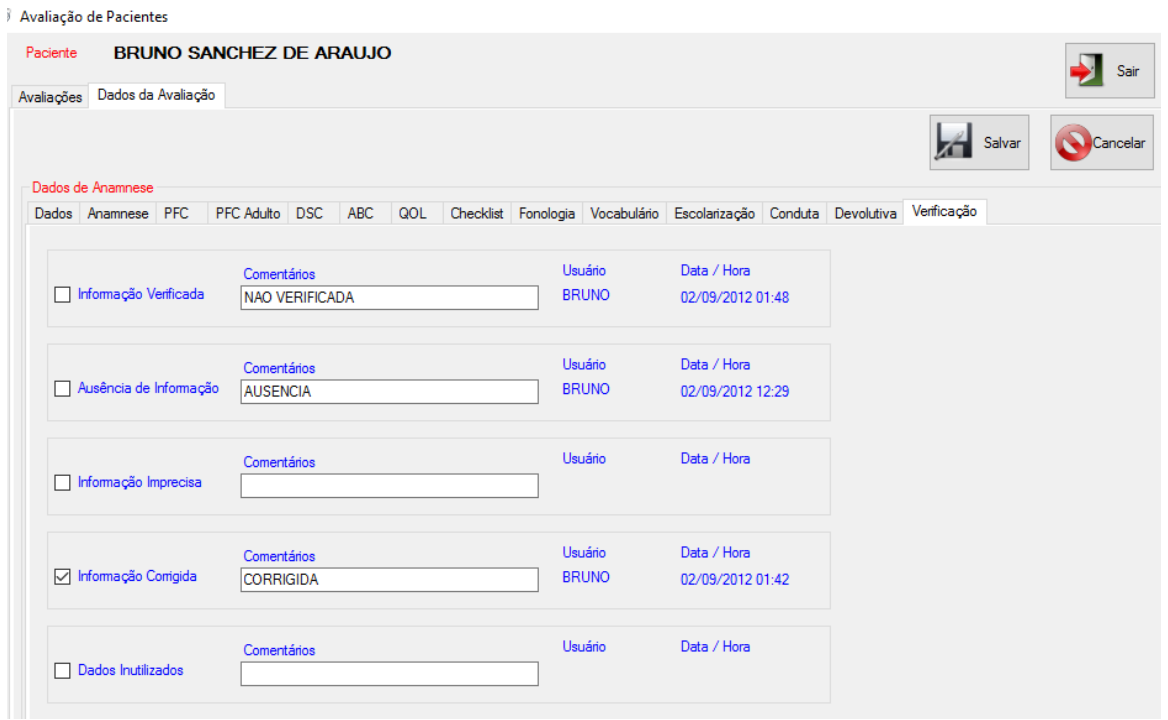

Figura 15 - Aba de preenchimento de Verificação

Como a ideia é que este Software seja acessado e alimentado por várias pessoas, como é possível observar na Figura 15, há um local especifico para realizar anotações de ausência de alguma informação ou de alterações realizadas na avaliação do paciente.

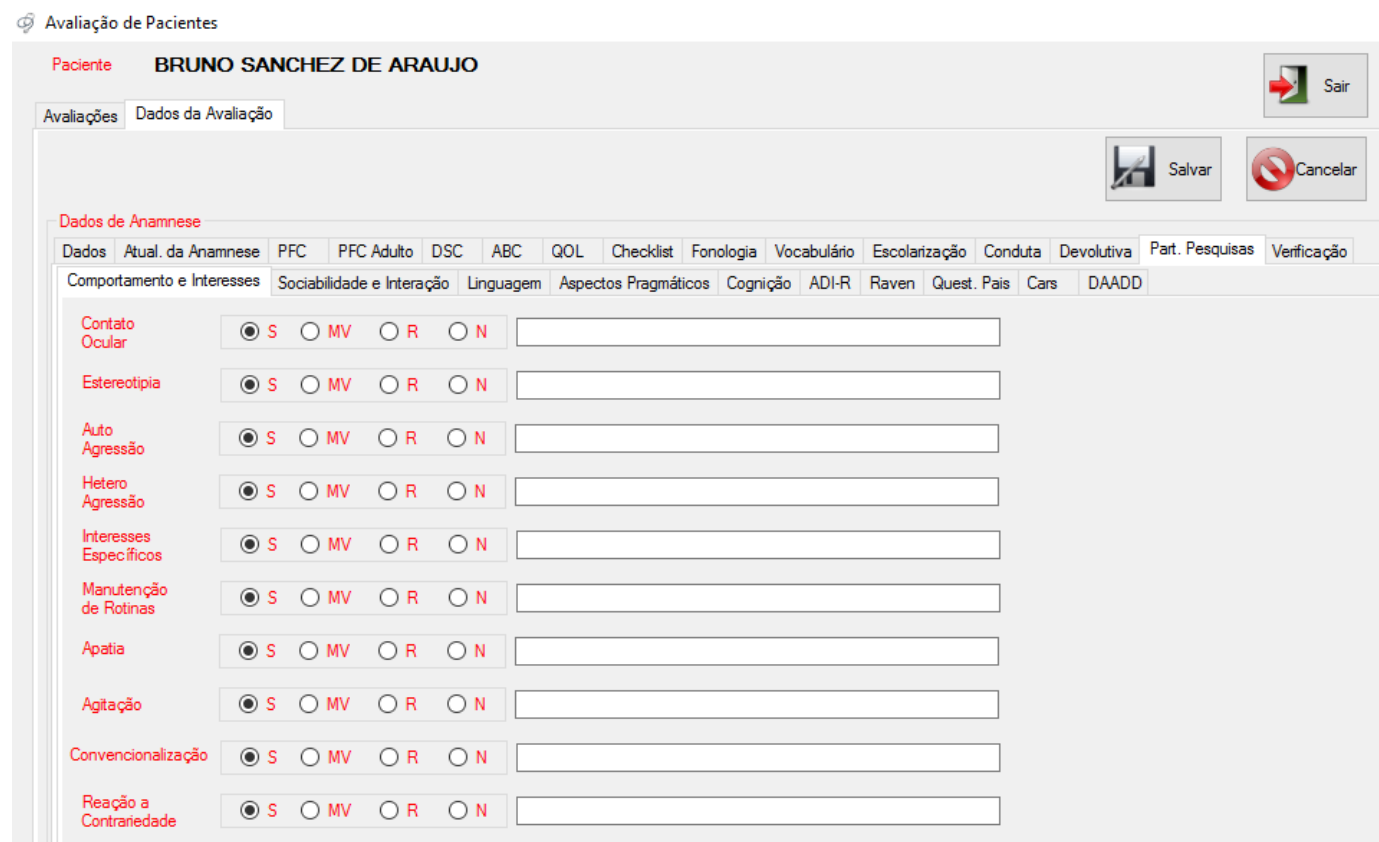

Figura 16 - Aba extra de participação em pesquisas: Comportamentos e interesses 
Se o paciente participa de outras pesquisas, no momento do castrado dos dados da avaliação no qual se refere, é possível selecionar a opção "participa de outras pesquisas" e assim outras abas poderão ser acessadas e cadastradas na aba de "Part. pesquisas".

Na aba extra, como mostra a Figura 16, denominada comportamentos e interesses, são colocados os dados equivalentes a ela, se ocorre e a frequência com que ocorre cada item ( $S=$ sempre, $M V=$ =muitas vezes, $\mathrm{R}=$ raramente e $\mathrm{N}=$ nunca), sendo possível também preencher com algum comentário, se necessário.

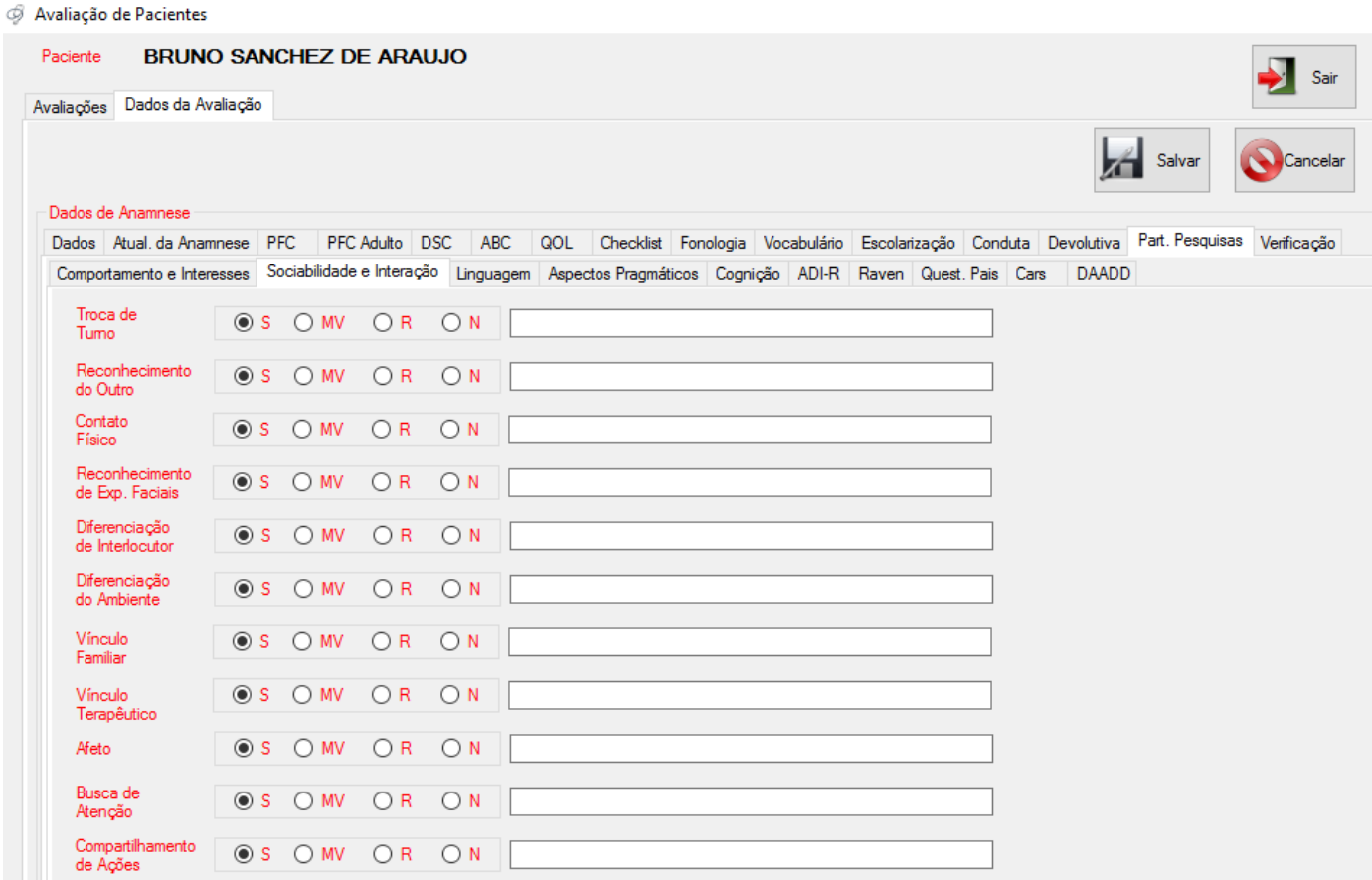

Figura 17 - Aba extra de participação em pesquisas: Sociabilidade e interação

Seguindo a ideia da aba anterior, nesta aba (Figura 17) são colocados os dados equivalentes à sociabilidade e interação do paciente, preenchendo se ocorrem e a frequência com que ocorre cada item. 


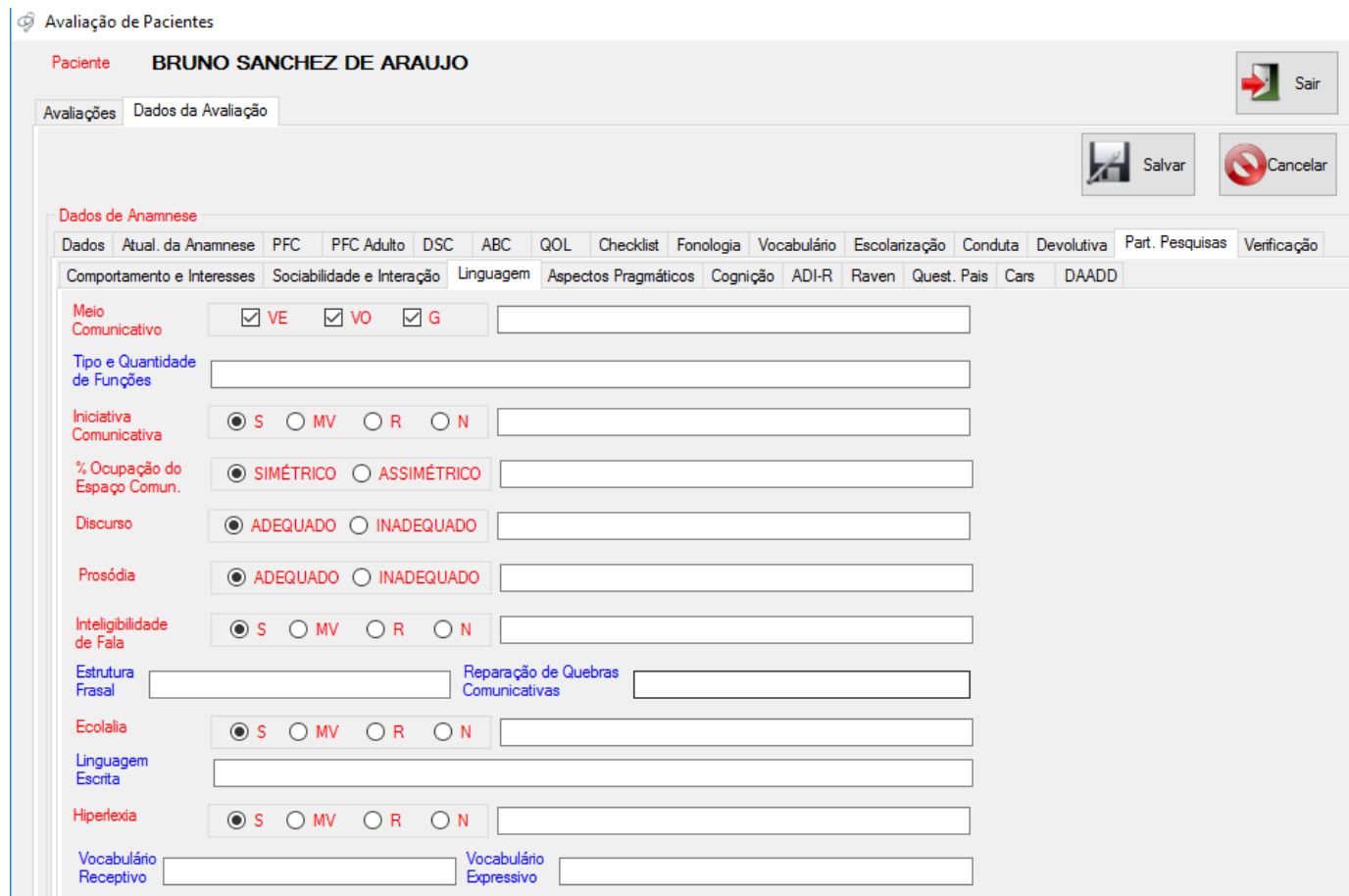

Figura 18 - Aba extra de participação em pesquisas: Linguagem

A Figura 18 ilustra onde são colocados os dados em relação à linguagem do paciente, especificando o meio comunicativo que ele utiliza, quantas funções (em relação à avaliação do PFC) mais interativas e menos interativas ele apresenta, a frequência da iniciativa comunicativa, inteligibilidade de fala, ecolalia e hiperlexia; se a ocupação de espaço comunicativo é simétrica ou não, dados com relação ao discurso e prosódia; sendo possível preencher com algumas informações adicionais que o paciente apresentar.

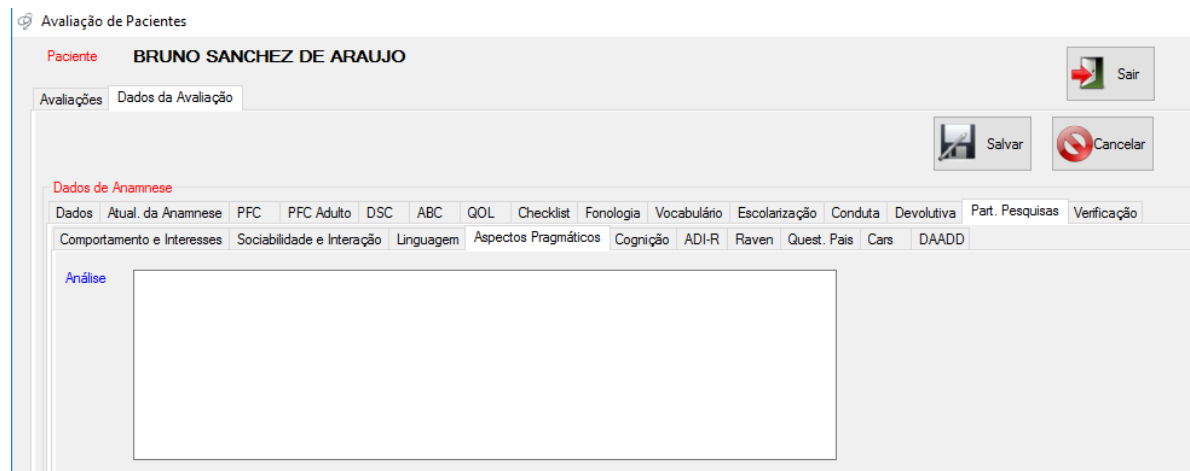

Figura 19 - Aba extra de participação em pesquisas: Aspectos Pragmáticos 
Nem sempre, quando realizada a avaliação do PFC, ela representará a real situação do paciente. Em alguns casos, por exemplo, o paciente pode estar mais agitado no dia da avaliação e não ser possível observar na análise do teste seu real desempenho.

Sendo assim, na aba referente à Figura 19 é possível preencher dados sobre os aspectos pragmáticos observados ao longo das terapias.

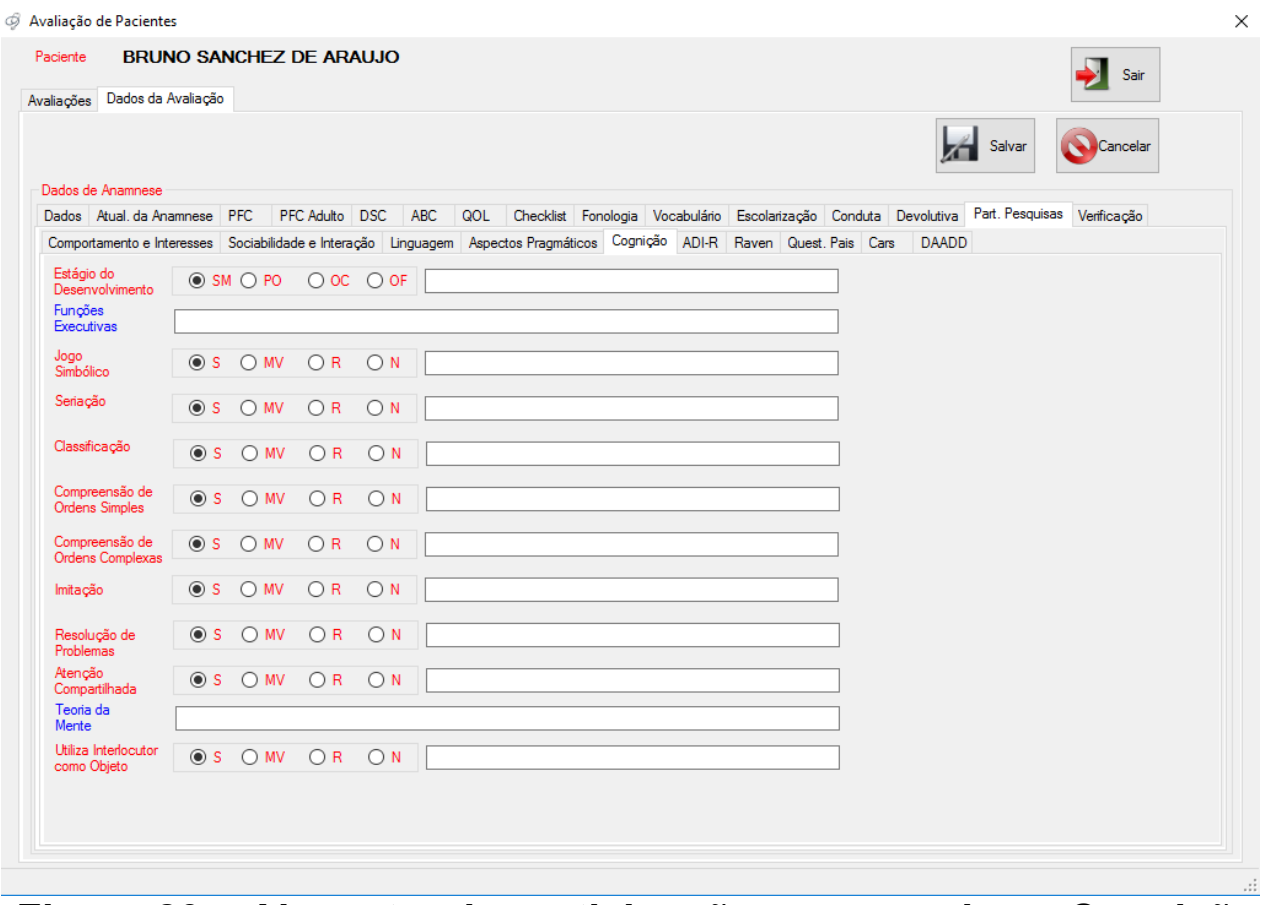

Figura 20 - Aba extra de participação em pesquisas: Cognição

Nesta aba, representada pela Figura 20, são colocados os dados equivalentes à cognição do paciente, preenchendo se ocorrem e a frequência com que ocorre cada item. No item de estágio de desenvolvimento, deve ser preenchido com $\mathrm{SM}=$ Sensório motor, $\mathrm{PO}=$ Pré operatório, $\mathrm{OC}=$ Operatório concreto e OF = Operatório formal, segundo Piaget (1972). 


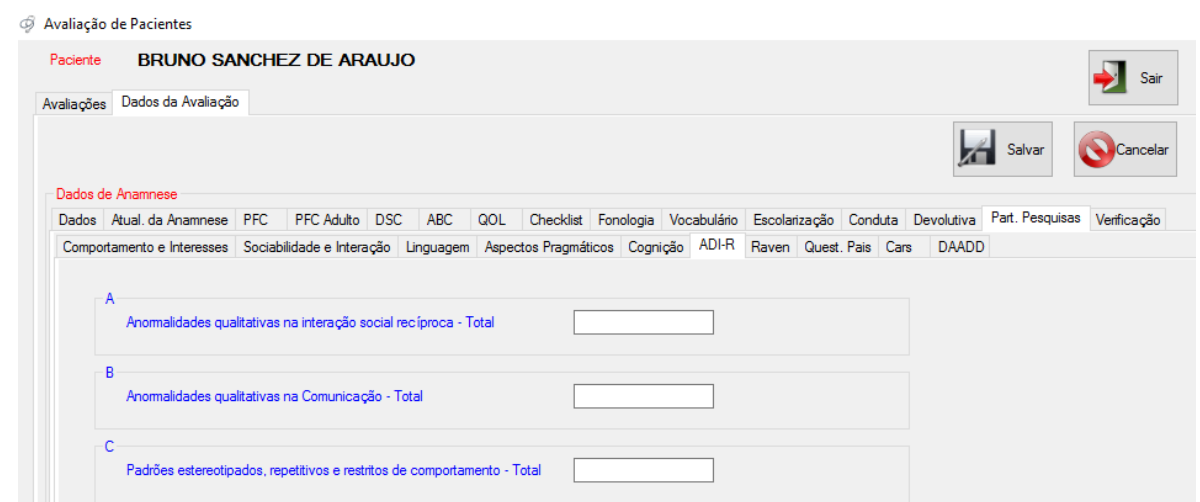

Figura 21 - Aba extra de participação em pesquisas: ADI-R

Em ADI-R, como mostra a aba da Figura 21, é colocado o resultado do questionário Autism Diagnostic Interview - Revised (Lord et al. 1994), considerado como padrão ouro no diagnóstico do autismo.

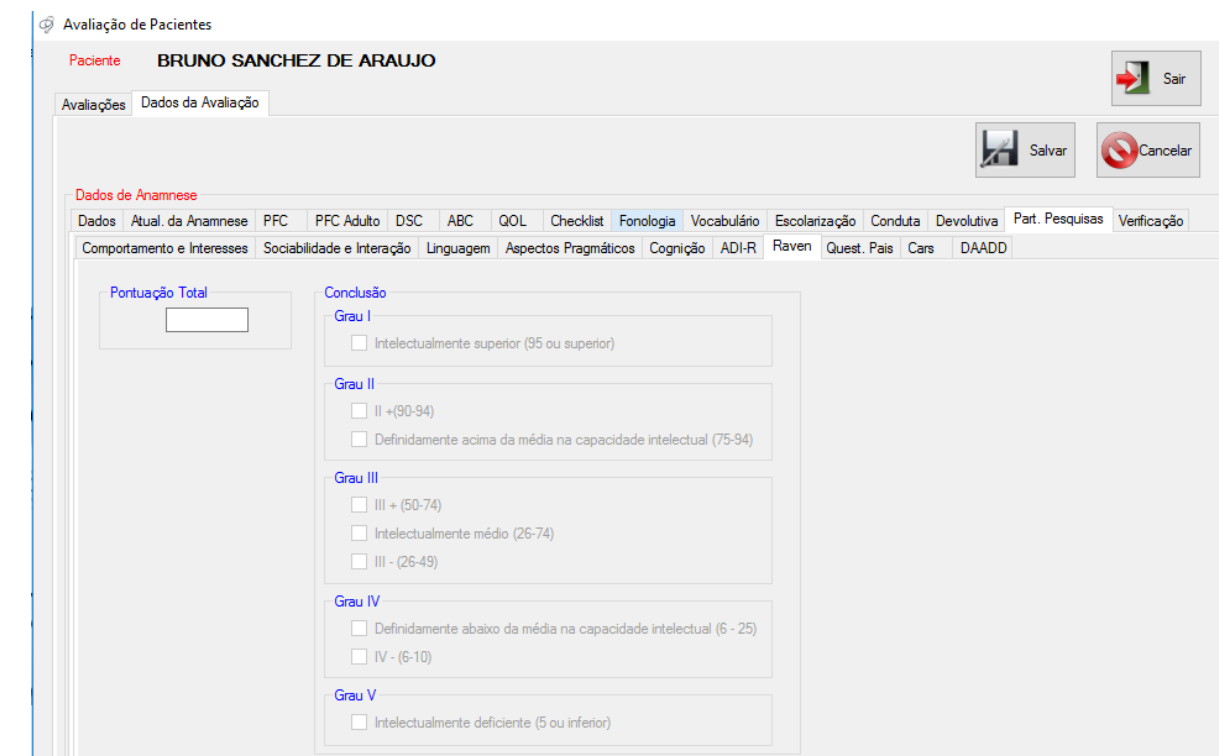

Figura 22 - Aba extra de participação em pesquisas: Raven

Se aplicado, nesta aba (Figura 22) devem ser preenchidos os resultados do teste Teste das Matrizes Progressivas Coloridas de Raven (Raven et al, 1988), que se destina à avaliação do desenvolvimento intelectual de crianças de 5 a 11 anos de idade. 


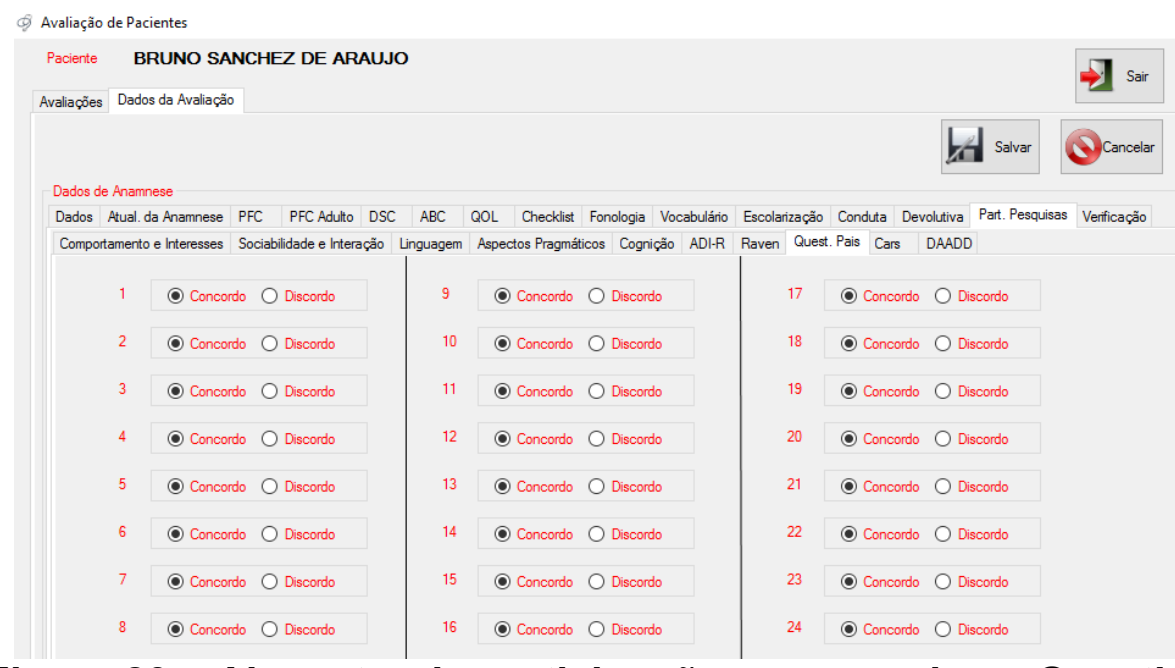
de pais

Figura 23 - Aba extra de participação em pesquisas: Questionário

A Figura 23 mostra a aba Quest. Pais, que se refere ao Questionário sobre dificuldades comunicativas percebidas por pais de crianças do espectro do autismo desenvolvido por Balestro e Fernandes (2012).

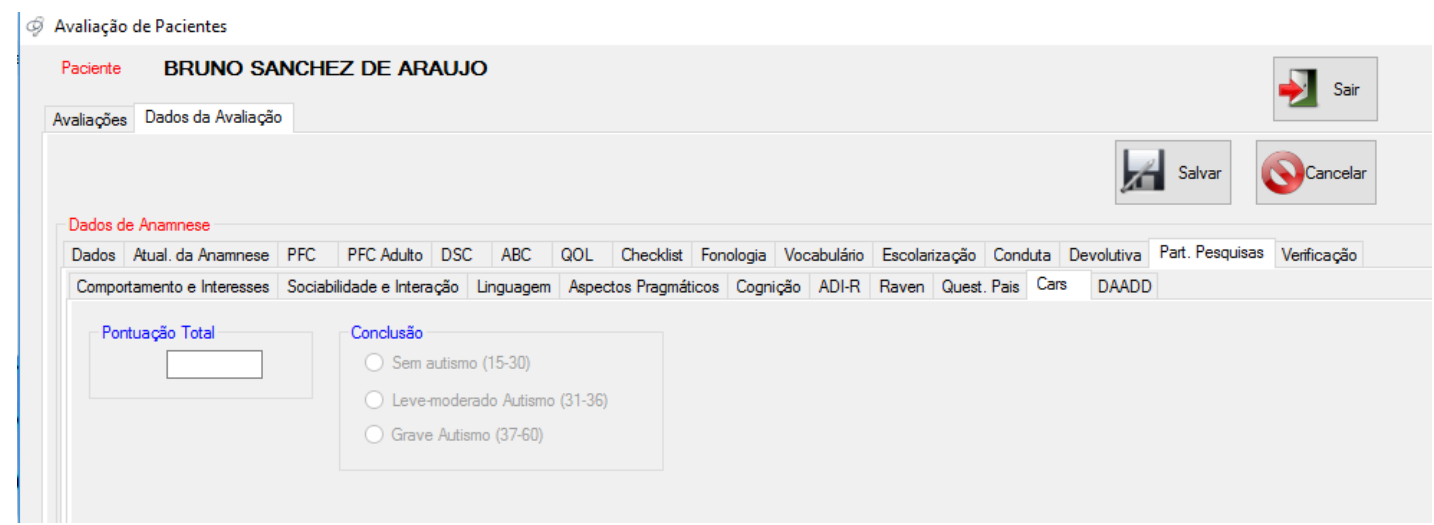

Figura 24 - Aba extra de participação em pesquisas: Cars

Nesta aba (Figura 24) deve ser preenchido o resultado da pontuação total da aplicação do questionário CARS - Childrood Autism Rating Scale (Schopler et al., 1980; Pereira et al., 2008).

A CARS é uma escala de identificação de crianças com autismo que possibilita diferenciar o autismo leve-moderado, do grave. Segundo Machado et 
al. (2014), é considerada atualmente como a escala de avaliação padrão ouro no Brasil, uma vez que a ADI-R e a ADOS ainda não passaram por todo o processo de validação e, portanto, não estão disponíveis para serem utilizadas.

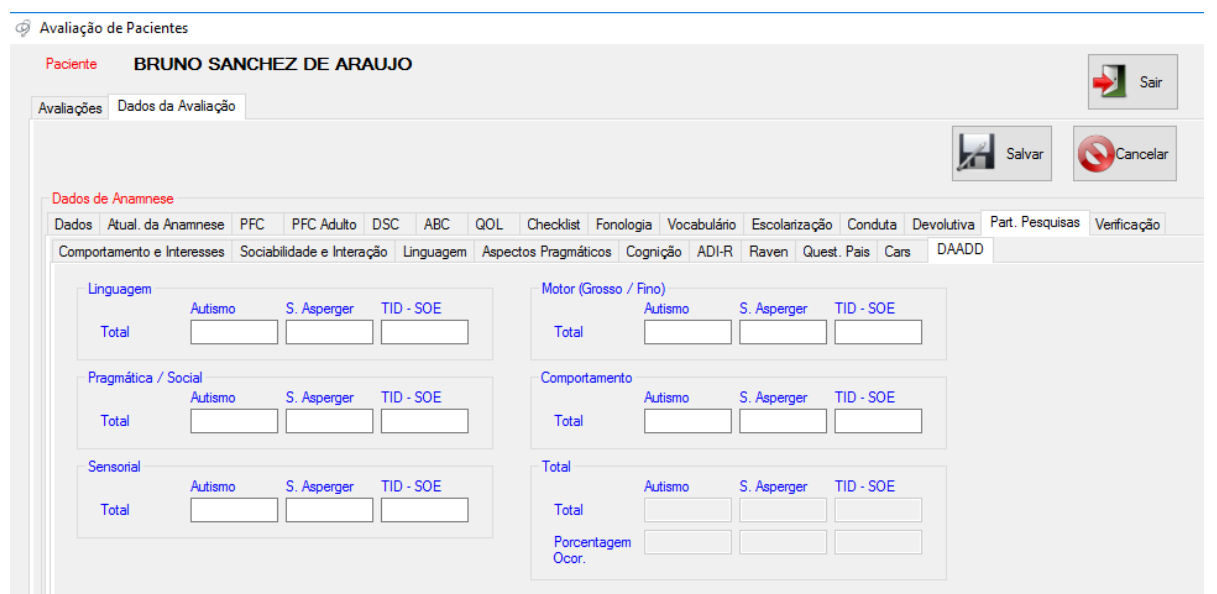

Figura 25 - Aba extra de participação em pesquisas: DAADD

Nesta aba denominada DAADD, ilustrada pela Figura 25 , é colocado o resultado do Differential Assessment of Autism and Other Developmental Disorders (Gail, 2003), um questionário que foi criado para discriminar, por meio da identificação dos comportamentos das crianças, os distúrbios específicos do desenvolvimento. Dentre eles: autismo, Síndrome de Rett, Síndrome de Asperger, Transtornos Invasivos do Desenvolvimento Não Especificados (TID-SOE), apraxia, retardo mental e outras síndromes. 


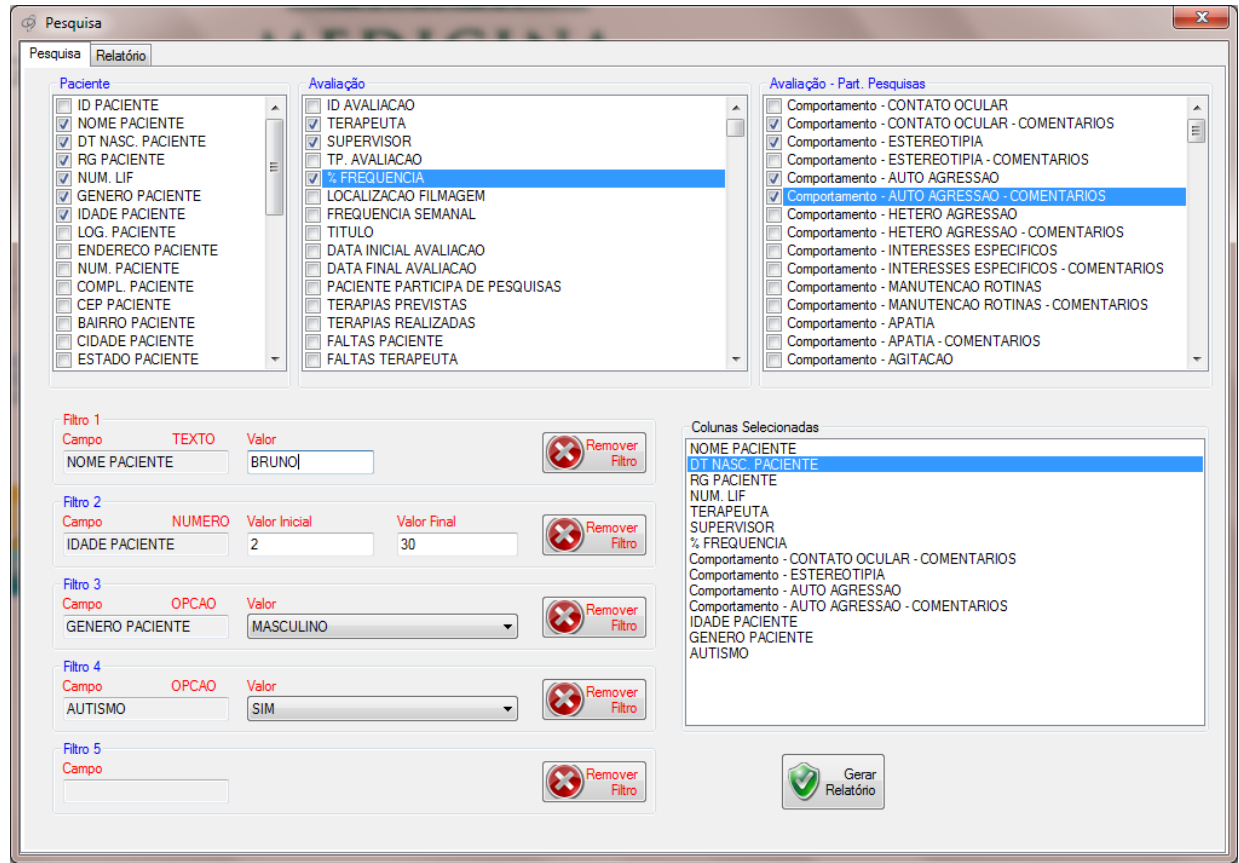

Figura 26 - Menu de pesquisas

Como mostra a Figura 26, ao selecionar o menu de Pesquisas é possível cruzar os dados de pacientes com outros cadastros diversos de avaliações e pesquisas que o paciente participa ou até mesmo com dados de outros sujeitos cadastrados.

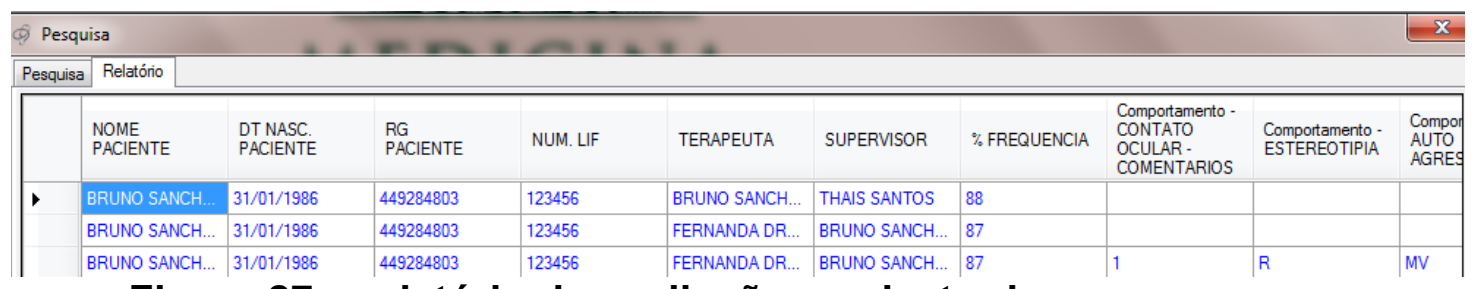

Figura 27 - relatório de avaliações cadastradas

Os dados são apresentados (Figura 27) como forma de um relatório em uma planilha, com a possibilidade de exportar para esses dados para o Excel. 


\section{3 - Procedimentos}

O campo da pesquisa foi o arquivo morto do LIF-DEA, esse material é composto por 21 caixas, totalizando dados de mais de 500 pacientes destes últimos 30 anos de atendimento, desde o início de seu funcionamento. Estes dados foram inicialmente tabulados em uma planilha do Excel na qual constam todas as informações relativas a cada paciente, como por exemplo: sexo, ano de início e fim do atendimento, razão do desligamento, data de nascimento, protocolos aplicados, tempo de atendimento, idade em que iniciou o tratamento, observações em relação aos dados incompletos.

Destes arquivos, foram selecionados todos os prontuários de pacientes que realizaram atendimento no LIF-DEA nos últimos vinte e um anos seguindo os critérios de inclusão e exclusão.

Os dados relativos à pesquisa, que atenderam aos critérios de inclusão e exclusão, foram tabulados, separados ano a ano, com informações estatísticas adicionais (moda, média, mediana e desvio padrão) em relação ao tempo de atendimento e idade de início do tratamento fonoaudiológico no LIFDEA.

Inicialmente, um dos objetivos era cadastrar no software IDEA todos os dados dos pacientes dos últimos 21 anos e daqueles em atendimento. No entanto, durante a visita a outras instituições no exterior percebeu-se que a utilização de dados de anos anteriores não auxiliaria nos objetivos e nem em comparações para análises futuras, devido às mudanças ocorridas ao longo destes anos (modo de análise, aplicação dos protocolos, características do diagnóstico). Com isso, optou-se por manter a caracterização dos pacientes 
dos últimos 21 anos nas planilhas do Excel e o cadastramento somente dos pacientes em atendimento.

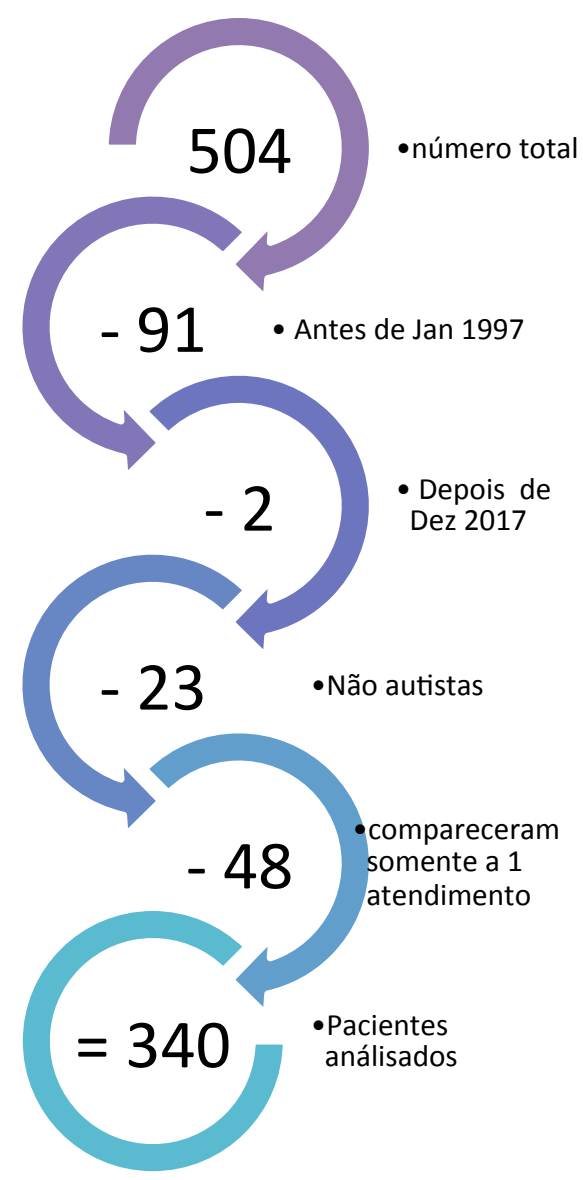

Figura 28 - Totalização dos Pacientes analisados conforme os critérios de inclusão e exclusão no Estudo 1

É importante ressaltar que a inserção dos dados no software IDEA se iniciou pelo cadastro de cada paciente (tanto do arquivo morto, como de pacientes em atendimento) para que depois os dados relativos às avaliações e dados complementares dos pacientes fossem inseridos no software. Nesta segunda etapa de inserção de dados foram identificados alguns erros de configuração do programa, sendo necessária a realização de ajustes. 
Após a reconfiguração do software, os dados voltaram a ser inseridos no programa, porém as análises estatísticas foram realizadas com base nas planilhas do Excel.

\section{4 - Local onde o estudo foi desenvolvido}

A pesquisa foi desenvolvida no Laboratório de Investigação Fonoaudiológica dos Distúrbios do Espectro do Autismo (LIF-DEA) do Departamento de Fisioterapia, Fonoaudiologia e Terapia Ocupacional da Faculdade de Medicina da Universidade de São Paulo. Este é um serviço de referência, credenciado pelo Sistema Único de Saúde (SUS).

\section{5 - Estatística}

O valor de significância estatística adotado foi igual a $5 \%(p \leq 0,05)$. Utilizou-se o software SPSS Statistics, versão 25.0 (IBM Corp., Armonk, NY, EUA). A base teórica utilizada para a análise estatística apresentada neste relatório está descrita de forma pormenorizada por Field (2017).

Para o cálculo dos intervalos de confiança de $95 \%$ foi utilizada o método de viés corrigido e acelerado com base em 2.000 amostras bootstrap. Os valores entre colchetes nas tabelas indicam os limites superior e inferior dos intervalos de confiança de $95 \%$.

Para interpretação dos tamanhos dos efeitos, sugere-se utilizar a classificação proposta por Cohen (1992).

Para o coeficiente d, adotam-se os seguintes critérios: 
- Pequeno: entre $|0,200|$ e $|0,499|$;

- Médio: entre $|0,500|$ e $|0,799|$;

- Grande: acima de $|0,800|$.

Para o coeficiente $r$, adotam-se os seguintes critérios:

- Pequeno: entre $|0,100|$ e $|0,299|$;

- Médio: entre $|0,300|$ e $|0,500|$;

- Grande: acima de $|0,500|$. 


\section{4 - Resultados}

A análise estatística dos dados do estudo foi realizada usando como base a amostra de 340 indivíduos retirados do arquivo morto do serviço, destes 73 eram do sexo feminino e 267 do sexo masculino.

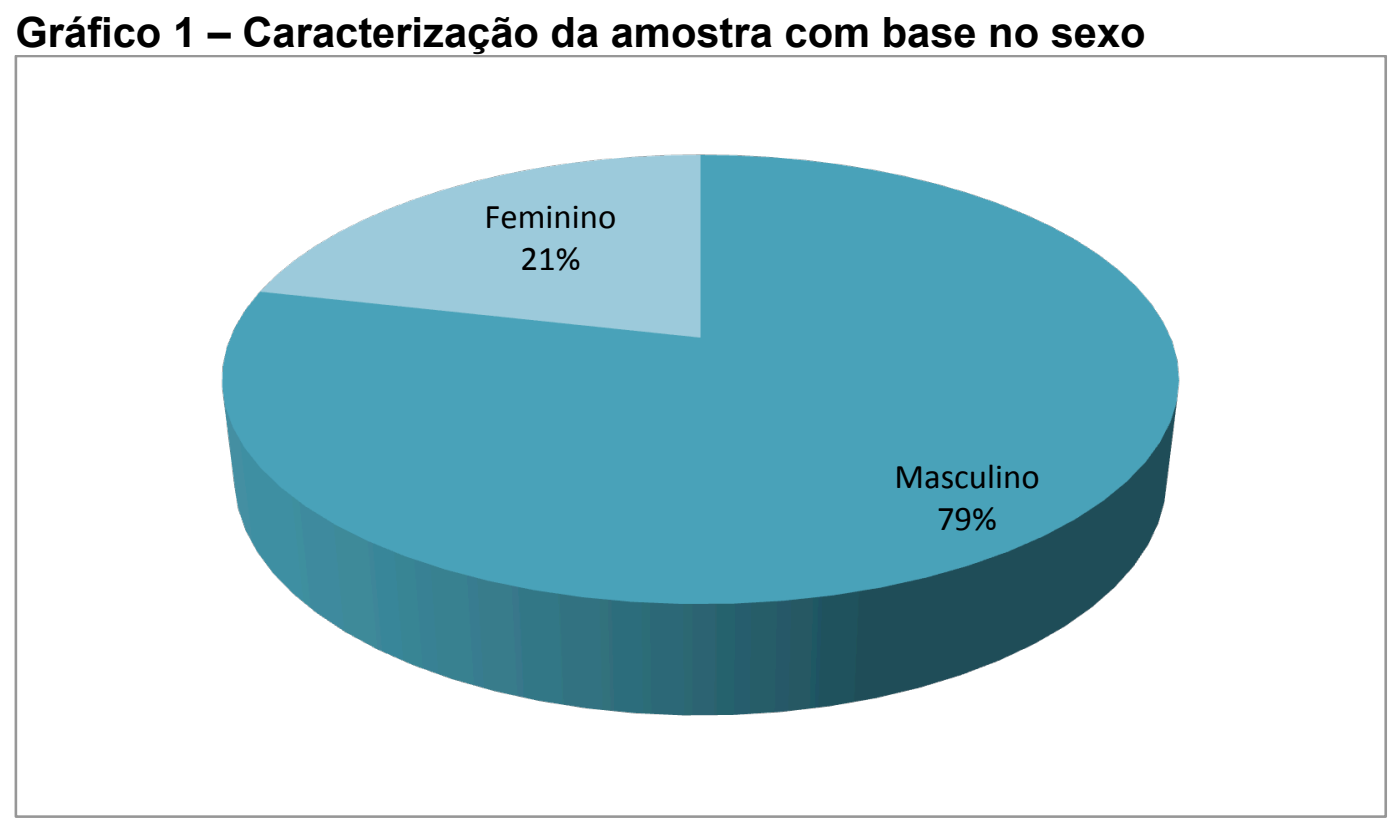

Essa proporção de 4:1 vai de acordo com os novos dados relatados nos últimos estudos envolvendo a prevalência do DEA.

Considerando a proporção com relação ao sexo encontrado a cada ano analisado neste estudo, foi possível observar uma grande variação ao longo dos anos, como é ilustrado no gráfico 2 . 


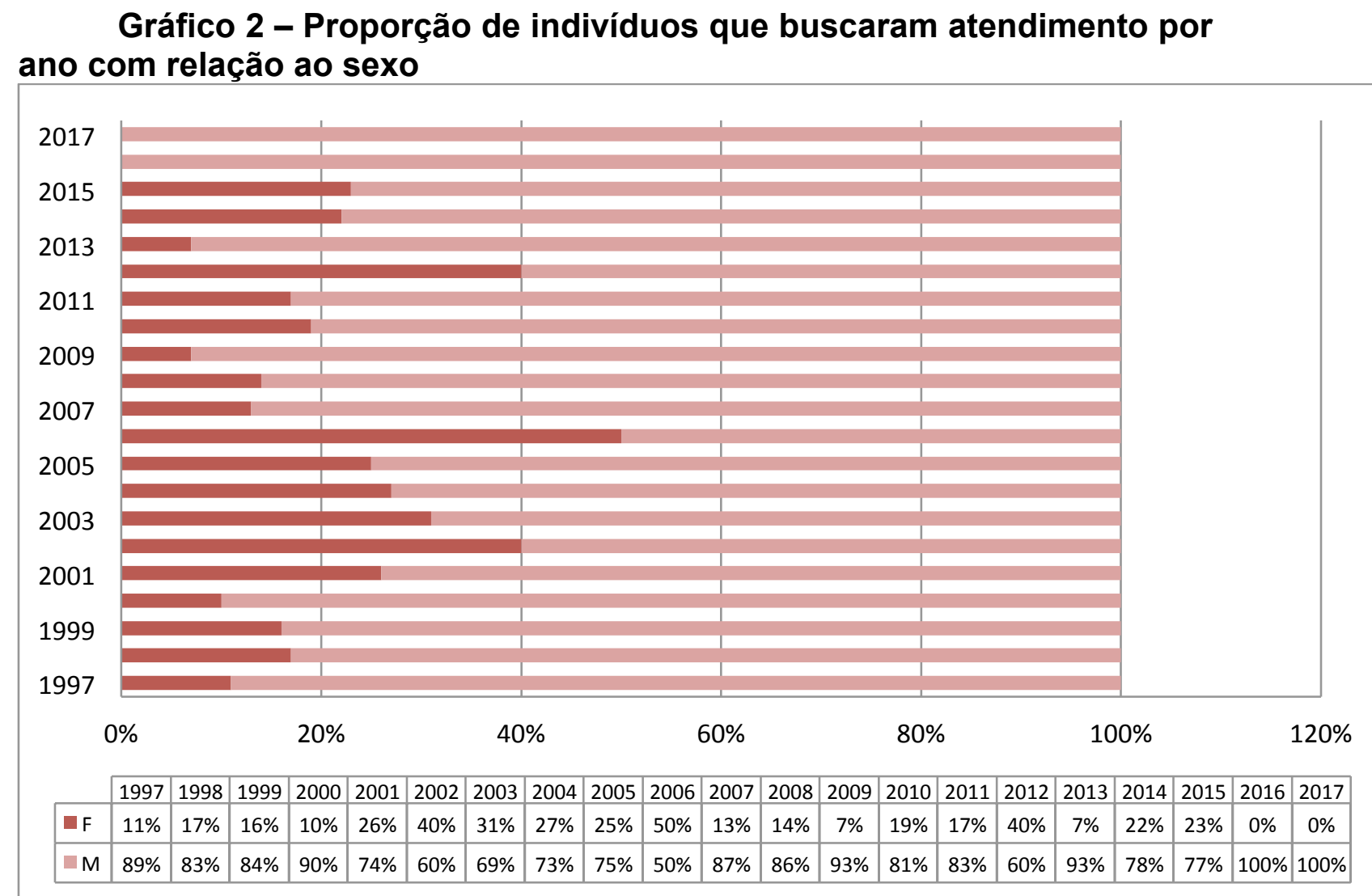

Observa-se que em 2006 foram trazidos para a avaliação/atendimento 9 indivíduos do sexo feminino e 9 do sexo masculino. Porém nos anos de 2016 e 2017 somente indivíduos do sexo masculino buscaram por avaliação/atendimento.

A faixa etária do início do atendimento variou de 0 a 20 anos. Destes 340 indivíduos, somente $12 \%$ iniciaram o atendimento com, ou antes, dos 4 anos de idade, os que iniciaram o atendimento com idade de 4 a 9 anos representaram 74\%, e 14\% iniciaram a terapia fonoaudiológica com mais de 10 anos de idade.

A Tabela 1 apresenta as medidas de tendência central e de dispersão do tempo de atendimento e da idade de chegada. 
Tabela 1 - Valores descritivos do tempo de atendimento com a idade de chegada.

\begin{tabular}{|c|c|c|c|c|c|}
\hline Variável & Média & DP & Mediana & Mín. & Máx. \\
\hline Tempo de atendimento (anos) & $\begin{array}{c}3,49 \\
{[3,22,3,78]}\end{array}$ & 2,53 & $\begin{array}{c}3,00 \\
{[3,00,3,00]}\end{array}$ & 1,00 & 14,00 \\
\hline Idade de chegada (anos) & $\begin{array}{c}6,36 \\
{[6,03,6,69]}\end{array}$ & 3,07 & $\begin{array}{c}6,00 \\
{[6,00,6,00]}\end{array}$ & 0,00 & 20,00 \\
\hline
\end{tabular}

Legenda: DP: Desvio padrão; Mín: Mínimo; Máx: Máximo

É possível observar que a média da idade de início da terapia foi de 6 anos e os indivíduos permaneceram no atendimento em média por três anos e meio.

\section{Gráfico 3 - Caracterização da amostra com base na faixa etária de} início do atendimento

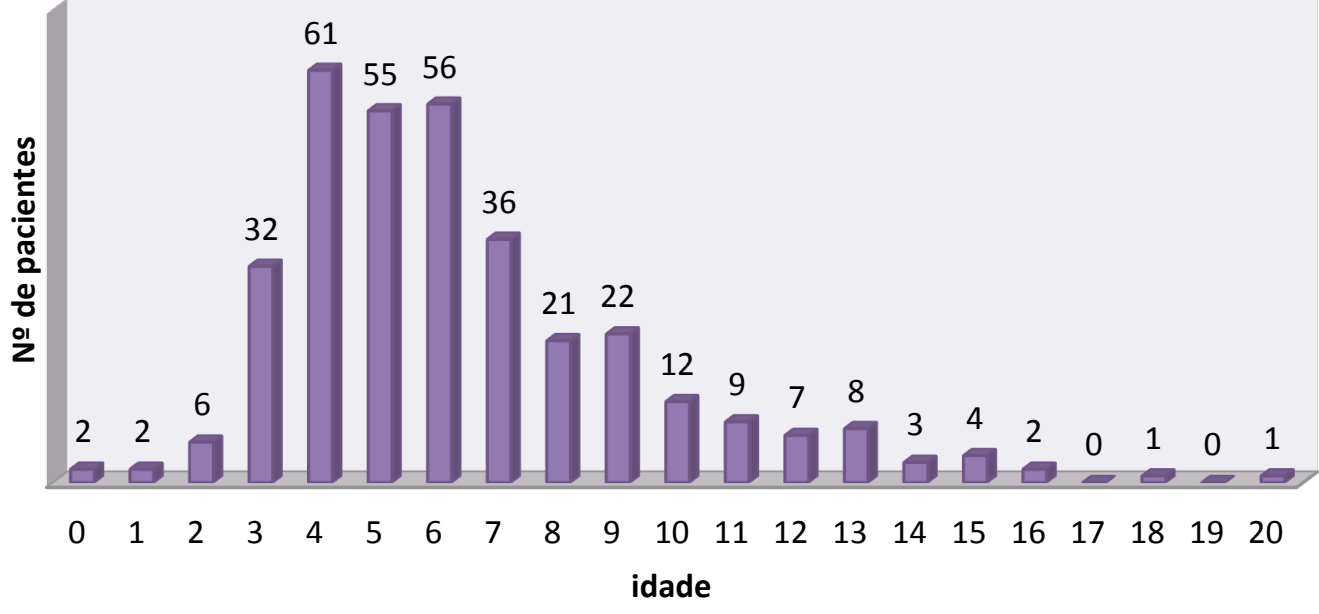

A idade de início da terapia não apresentou uma diminuição na faixa etária ao longo dos anos, ou seja, não foi observada uma diminuição da idade no momento de busca pelo serviço nos últimos anos analisados. 


\section{Gráfico 4 - Média da idade de início da avaliação e atendimento fonoaudiológico}

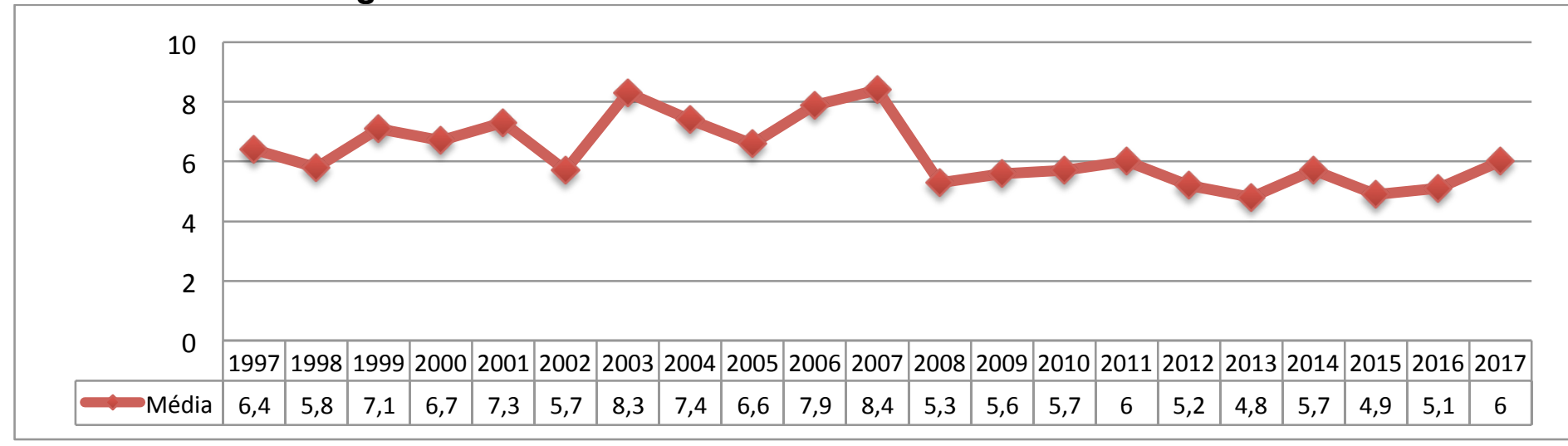

Foi realizada também a análise da mediana para a comparação com os dados da média devido a algumas variações de idade em determinados anos, como, por exemplo, no ano de 2007 , no qual houve um paciente que realizou avaliação inicial aos 20 anos. Porém este dado não foi apresentado por não haver diferença significativa entre as duas análises.

Gráfico 5 - Diferença da idade e sexo com relação à idade na qual buscou pela avaliação/terapia

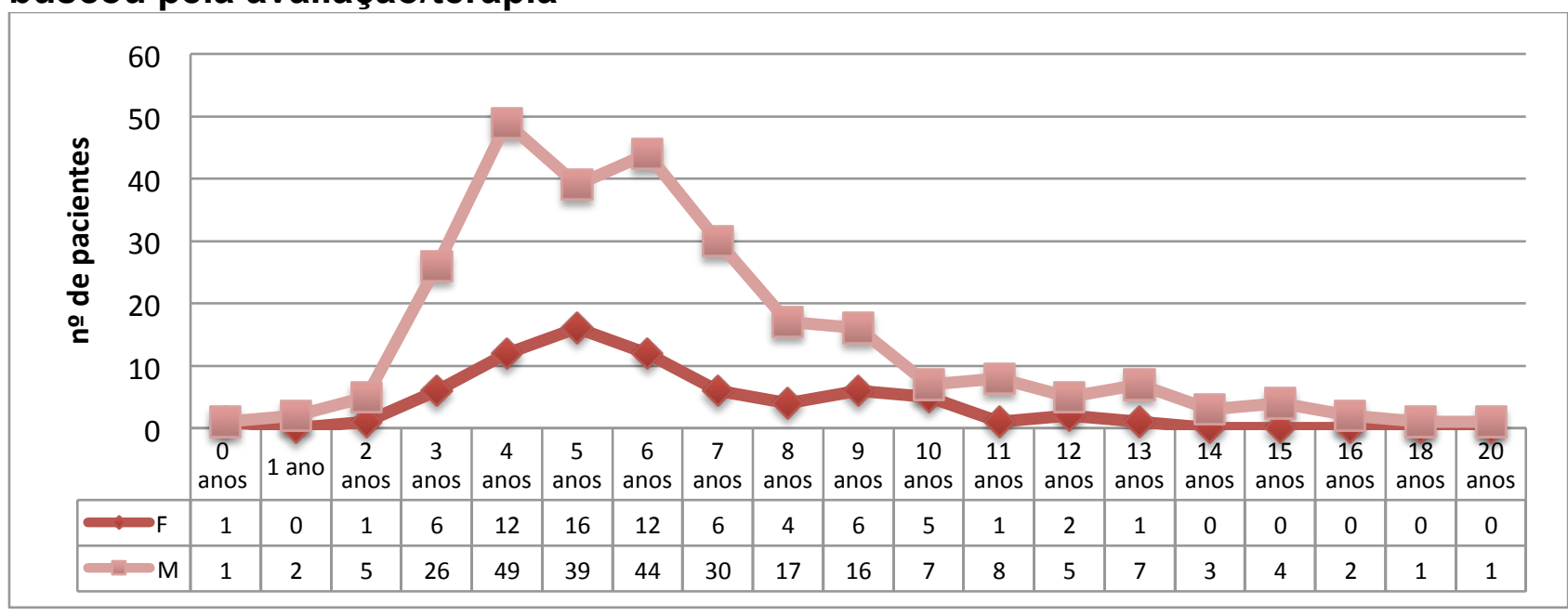

Quando pensamos na idade que o paciente foi trazido para avaliação/tratamento e relacionamos isso ao sexo é possível observar que a idade a qual dos pacientes do sexo masculino foi menor (pico aos 4 anos) do que em relação ao sexo feminino (pico aos 5 anos), além do fato de que após 
os 13 anos não houve nenhuma avaliação do sexo feminino e do sexo masculino houve a procura até os 20 anos de idade.

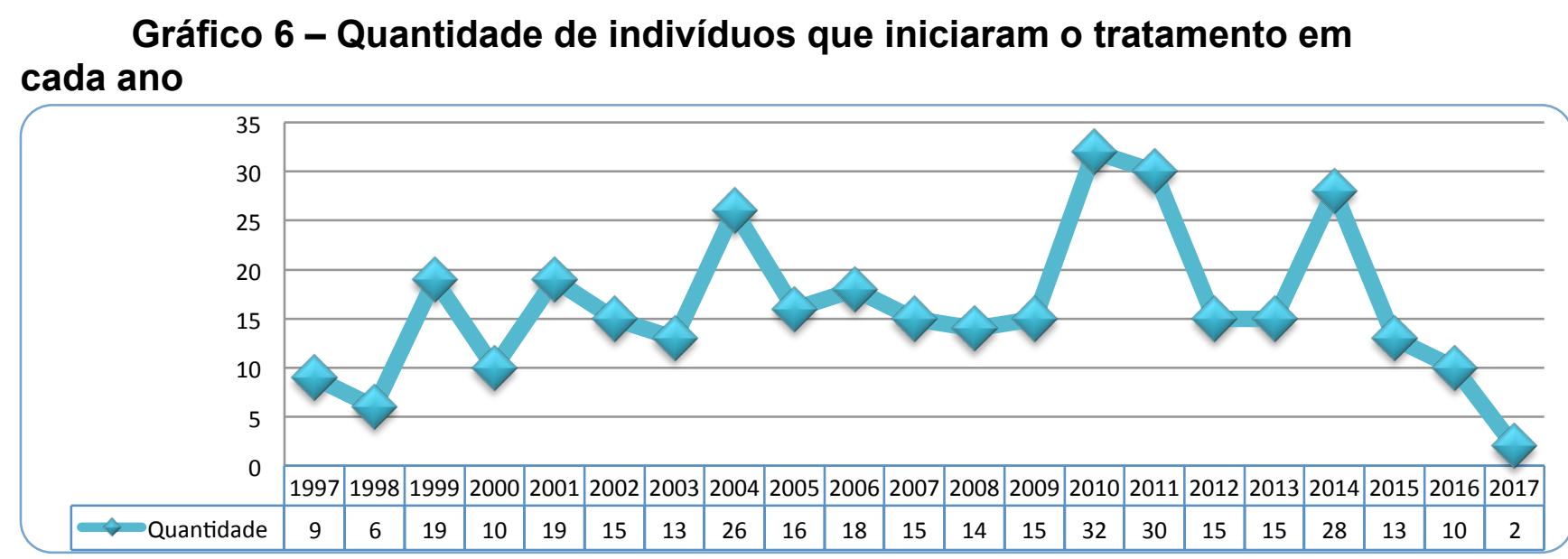

O volume de indivíduos que buscaram o atendimento apresentou oscilações com o passar de anos, entretanto esse dado varia conforme a disponibilidade de vagas para atendimento e não conforme a busca. Sendo assim, fica difícil correlacionar a atualização do DSM à quantidade de indivíduos que iniciou a avaliação/terapia, uma vez que essa quantidade é diretamente proporcional ao número de terapeutas, vagas disponíveis e salas para atendimento.

A Tabela 2 apresenta a análise de correlação entre o tempo de atendimento e a idade de chegada para a amostra total do estudo. Para esta análise, realizou-se o cálculo do coeficiente de correlação $(r)$ e do valor de $p$ por meio do teste de correlação de Pearson, uma vez que o tamanho da amostra $(n=340)$ permite a utilização de testes paramétricos em virtude do Teorema Central do Limite. 
Tabela 2 - Análise de correlação entre o tempo de atendimento e a idade de chegada para a amostra total do estudo.

\begin{tabular}{ccc}
\hline Variáveis & & Idade de chegada \\
\hline Tempo de atendimento & $r$ & $-0,072$ \\
& & {$[-0,160,0,025]$} \\
& $p$ & 0,184 \\
\hline
\end{tabular}

Teste de correlação de Pearson $\left({ }^{\mathrm{a}}\right)$.

Os resultados da Tabela 2 demonstram que não houve correlação estatisticamente significativa entre o tempo de atendimento e a idade de chegada. Sendo assim, o tempo de permanência no serviço não se correlacionou à idade de chegada.

Assim como observamos nos dados abaixo (Figura 29) relativos ao gráfico de dispersão, é possível observar que não há relação entre a idade em que a criança inicia o tratamento e o tempo no qual ela fica no serviço. Ou seja, a hipótese empírica de que quanto mais nova a criança iniciar o tratamento, maior será a adesão e a terapia será mantida por mais tempo, não foi observada nas crianças analisadas.

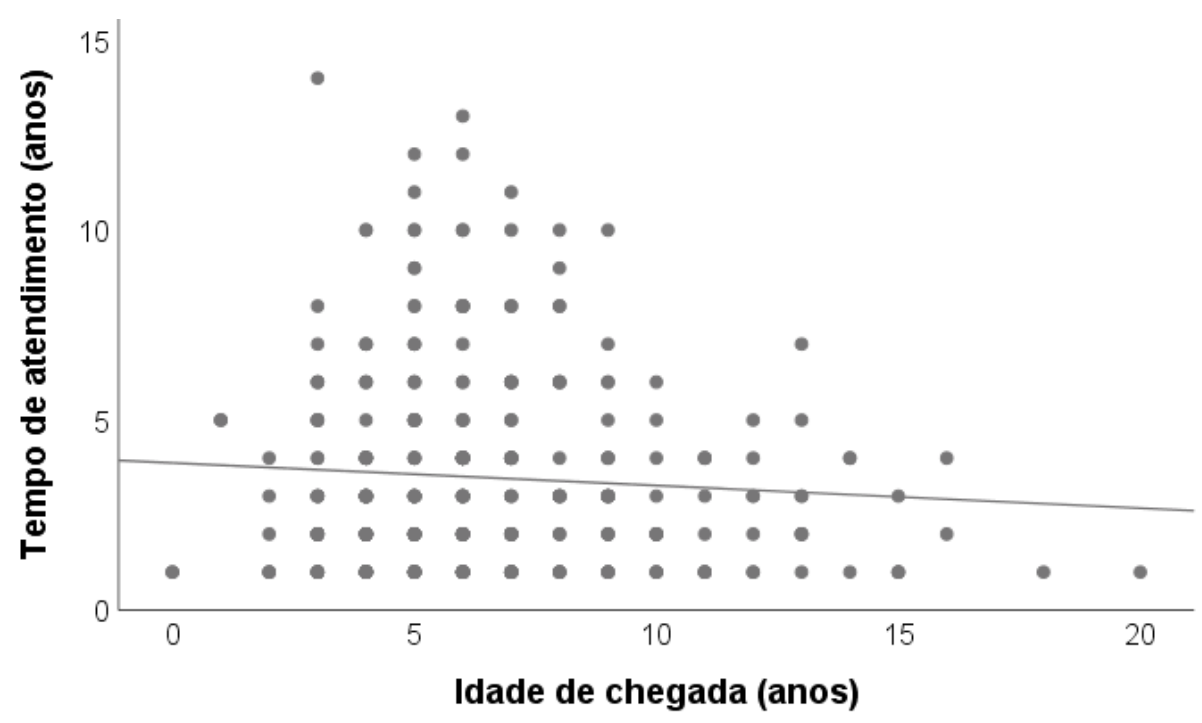

Figura 29 - Gráfico de dispersão do tempo de atendimento em função da idade de chegada. 
$\mathrm{Na}$ tabulação de dados foi observado que $\mathrm{o}$ índice de abandono/desistência do tratamento é muito alto. Dentre os 340 pacientes analisados, $81(24 \%)$ realizaram um ano ou menos de terapia, sem contar com os 48 sujeitos que foram excluídos da análise, pois, compareceram somente à primeira sessão de avaliação.

O principal motivo da interrupção do tratamento foi o abandono/desistência da vaga.

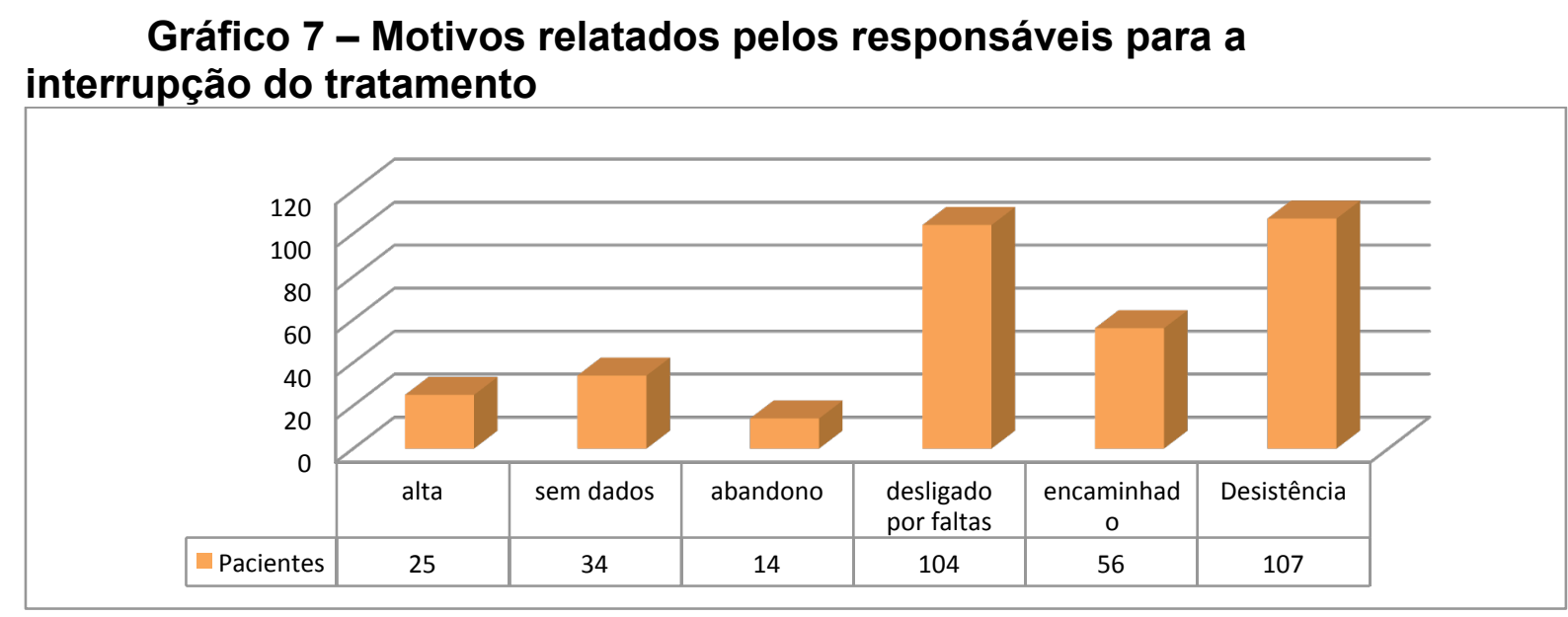

É importante ressaltar que, dos pacientes analisados, somente 25 destes receberam alta após ficarem em média 6,5 anos em atendimento especializado.

Na tabulação dos dados pode ser observado que parte dos prontuários estão incompletos, principalmente os mais antigos, não incluindo todos os dados de avaliação ou de terapia, com isso os motivos relacionados ao desligamento não estão descritos em todos os prontuários. 


\section{5 - Discussão}

Antes de começar a discussão dos dados, é fundamental lembrar que o serviço no qual os dados foram coletados possui o objetivo principal de ensino e pesquisa. Ao longo destes 21 anos analisados foram formados aproximadamente 120 alunos de graduação, 30 alunos de especialização, 60 alunos de aprimoramento, 31 mestres, 14 doutores e 4 pós-doutores, além de mais de 150 publicações e mais de 300 trabalhos apresentados em eventos científicos.

Com este cenário, levando em consideração também o grande número de pacientes, uma das dificuldades observadas durante a coleta de dados foi relacionada à grande rotatividade de estudantes e à dificuldade no controle de todos os dados. As supervisões são focadas mais no atendimento do paciente e conduta do aluno do que no armazenamento das informações/dados em si.

As tentativas de padronização e sistematização do armazenamento dos dados e de treinamento (ou conscientização) das terapeutas responsáveis, ao longo destes anos, não foram completamente bem sucedidas, resultando em uma grande variação nos dados coletados e armazenados, sendo que, em muitos casos, foi observada perda significativa dos dados, principalmente dos anos iniciais da coleta desta pesquisa.

Com o passar dos anos foi possível observar uma mudança com relação a esses aspectos mencionados e essa dificuldade foi diminuindo. Associo isso aos avanços da tecnologia, que permitem outros meios de armazenamento e também a coleta de dados desta pesquisa que detectou algumas falhas no modo de armazenamento e auxiliou no melhor monitoramento deste aspecto. 
Além da dificuldade do armazenamento de dados e da obtenção de dados incompletos, é importante ressaltar que alguns dados existem apenas em determinados períodos, pois estão relacionadas a pesquisas específicas. As mudanças ocorridas ao longo do tempo em relação aos protocolos aplicados também geraram algumas inconsistências nos registros identificados.

Após a exclusão dos registros dos sujeitos seguindo os critérios definidos, chegou-se a uma amostra de 340 indivíduos analisados. Com relação aos resultados encontrados, é possível observar dados parecidos com relação à proporção entre a prevalência no sexo masculino e feminino em outros estudos (Zablotsky et al., 2017; Baio et al., 2018).

No estudo feito pela CDC, publicado em 2018 e com dados coletados em 2014 (Baio et al., 2018), foi observado uma diminuição da proporção entre os sexos masculinos e femininos, no qual, durante 2002-2012 era de 4,5:1 e em 2014 passou para 4:1. Este dado relata a mesma proporção encontrada neste estudo, porém não foi possível observar um aumento da proporção do sexo feminino em relação ao masculino nos últimos anos e sim o inverso disto.

Quando comparamos os mesmos períodos, ou seja, se observarmos somente os dados de 2014 coletados no LIF-DEA, a proporção também era de 4:1, porém no período de 2002-2012 a proporção foi de 3:1.

Uma limitação a ser considerado neste estudo é que a idade dos indivíduos analisados corresponde ao momento no qual foram trazidos para a avaliação/terapia fonoaudiológica no LIF-DEA (entre 1997 e 2017), contudo, não foram encontrados/coletados/descritos dados com relação àqueles que já haviam realizado terapias anteriormente, se estavam em processo diagnóstico 
ou se já possuíam o diagnóstico fechado no momento em que procuraram por esse serviço.

Como relatam Sheldrick, et al. (2017), é importante ressaltar esses aspectos, principalmente quando falamos sobre a idade do diagnóstico, pois há muitas variações de idade descritas na literatura, o modo da coleta, momento no qual o processo diagnóstico foi considerado, local da pesquisa ou população analisada, ou seja, dados que podem trazer realmente variações.

Ao considerar os dados deste estudo precisa ficar claro que se trata do momento no qual os responsáveis buscaram pelo atendimento e não da idade na qual essas crianças foram diagnosticadas.

No estudo com dados globais apresentado por Gillon et al. (2017), a idade típica do diagnóstico foi aos 3 anos, um ano a menos do que observamos quanto à caracterização da amostra com base na faixa etária do início do atendimento. A grande maioria iniciou após os 4 anos e somente $12 \%$ iniciaram antes disto.

As pesquisas com dados coletados no Brasil demonstram uma realidade diferente dos dados globais, como mostra o estudo de Zanon et al. (2017), que relatam que as crianças brasileiras tendem a ser diagnosticadas quando têm cerca de cinco anos, e o de Segeren e Françoso (2014), no qual a média de idade do diagnóstico ocorreu aos 6 anos.

Nos dados relacionados aos 10 anos iniciais deste mesmo serviço (1986-1995), 28\% da população que recorreu ao serviço apresentou faixa etária entre 9 e 10 anos. Sendo que somente $8 \%$ buscaram o atendimento com até 4 anos de idade e $43 \%$ deles buscaram a terapia fonoaudiológica com mais de 10 anos de idade (Fernandes e Pastorello, 1995). 
A informação a respeito da idade no início da terapia é também de suma importância, pois, como relata Barnard-Brak et al. (2017), a intervenção precoce é baseada na identificação precoce do DEA. Sendo assim, o diagnóstico precoce é fundamental.

Outro aspecto que não foi possível determinar no estudo diz respeito à raça/etnia dos indivíduos. Pesquisas mostram que há diferenças na idade na qual o diagnóstico é realizado entre as diferentes etnias, como no caso de Travers et al. (2014) e Jo et al. (2015), que realizaram suas pesquisas no EUA. Estes estudos mencionaram disparidades encontradas no momento no qual o diagnóstico foi realizado quando relacionados a diferentes etnias ou grupos com diferenças sócio econômicas, desta mesma forma, Zablotsky et al. (2017) relatam que hispânicos e negros/afro descendentes são menos diagnosticados do que brancos.

Contudo, é importante ressaltar que não é parte da cultura brasileira em Fonoaudiologia, a inclusão de dados relacionados à raça/etnia e ao poder aquisitivo das famílias durante a anamnese e a coleta de dados, não sendo encontrados dados relacionados a estes aspectos na nossa realidade.

Um dos objetivos do presente estudo era analisar o possível impacto da atualização do DSM, no entanto, no Gráfico 6 (Quantidade de indivíduos que iniciaram o tratamento em cada ano) não é possível observar nenhuma alteração significativa. Além dos aspectos já mencionados, ao analisar os dados dos últimos anos, estes não ilustram a realidade, pois estão relacionados a dados coletados somente no arquivo morto e como os dados dos pacientes que iniciaram o atendimento após 2015 e ainda encontram-se 
em atendimento não foram considerados, dificultou a possível visualização deste suposto impacto.

Apesar disto, o site do CDC traz um dado com relação à falta de mudanças observadas na porcentagem de crianças diagnósticas após a atualização do DSM - 5 (APA, 2015) em 2013 (CDC, 2018).

Pensando na ideia da intervenção precoce, buscou-se correlacionar a idade na qual o indivíduo foi trazido ao tratamento com o tempo que ele permaneceu no serviço. Tinha-se a hipótese de que quanto antes iniciasse o tratamento melhor seria a adesão, devido à obtenção de melhores resultados com a intervenção precoce. Porém essa hipótese não foi confirmada como foi ilustrado na Tabela 2 e na Figura 29.

Uma pesquisa na qual foi analisada a relação entre a continuidade, adesão ao tratamento e o resultado de uma intervenção mediada por um cuidador para famílias de crianças de baixa renda com DEA (Carr et al., 2016) demonstrou que famílias com nível sócio econômico mais baixos abandonam mais o tratamento.

Como pode ser visto no Gráfico 7, o número de pacientes que frequentam menos de um ano de terapia é muito alto, assim como os números de desligamentos, abandonos e desistências. De acordo com Kazdin (1996), que relata sobre a continuidade da terapia psicológica com crianças, o abandono é maior dentre as famílias com baixa renda.

A maioria dos sujeitos desta pesquisa se enquadra em um nível sócio econômico baixo, necessitando de serviços públicos para garantir o tratamento dos indivíduos com DEA. 
Hock et al. (2015) apresentaram resultados mostrando que a adesão aos tratamentos medicamentosos é maior do que à terapia (independente do modelo), sendo importante analisar o "peso" da terapia na dinâmica/rotina familiar.

No momento do desligamento ou da desistência, os responsáveis relacionam a perda da vaga à questão da distância entre o local da residência e o local em que este atendimento é oferecido. Isto torna-se um empecilho ao longo dos anos, necessitando assim buscar um atendimento não especializado mais próximo à sua residência ou até perdendo a vaga devido ao número de faltas causadas pela dificuldade de locomoção.

Fermandes e Pastorello, já em 1995, informaram que 40\% das crianças encaminhadas não iniciaram ou completaram avaliação fonoaudiológica. Este número atualmente diminuiu, representando $12 \%$ quando consideramos aqueles sujeitos que foram excluídos das análises.

Esta pesquisa teve o intuito de ilustrar um dos serviços fonoaudiológicos especializados no atendimento a indivíduos com DEA, mostrando assim a importância da atuação com esta população, assim como a necessidade de serviços como este.

Sabe-se que há outros locais de atendimento a indivíduos com DEA na cidade de São Paulo, e ainda assim, a dificuldade das famílias encontrarem um serviço especializado perto de sua residência ou que simplesmente tenha vaga para atender é bem grande.

Juntamente aos abandonos ocorre o desabafo daqueles que necessitam do serviço para um familiar e precisam conciliar todas as dificuldades com a rotina diária. 
Como pode ser visto no site do Conselho Federal de Fonoaudiologia, esta é a região com maior oferta de profissionais de fonoaudiologia do país. Quando consideramos o número de fonoaudiólogos disponíveis em outras regiões, assim como mostra Santos et al. (2017), constata-se que há grande diferença entre as regiões e que o número de fonoaudiólogos é insuficiente para atender às necessidades da população.

Reafirmando então, assim como já concluído por Fernandes em 1995 e como demonstram os dados, que dentro da psiquiatria infantil há um campo importante para o fonoaudiólogo atuar e se dedicar.

É preciso levar em consideração a população estudada quando pensamos na relação entre a idade de início e o tempo de permanência no serviço. Os dados coletados reforçam a necessidade da adesão dos responsáveis ao tratamento e ilustram a necessidade de mudanças para que a permanência no tratamento aumente. 


\section{6 - Conclusão}

A partir dos dados analisados é possível observar que o número de indivíduos que foram trazidos para a avaliação e atendimento neste serviço é considerável, assim como o número de desistências e abandonos com menos de um ano de atendimento.

Segundo a análise estatística, a idade na qual o indivíduo iniciou o tratamento não está relacionado ao tempo em que ele permaneceu no serviço, ou seja, o fato da criança iniciar o tratamento mais cedo não está relacionado à maior adesão e manutenção do tratamento fonoaudiológico.

Não foi possível observar mudanças em relação ao número de pacientes que buscaram por atendimento e a mudança nos critérios diagnósticos. Dentre os diagnósticos recebidos, poucos são aqueles que, até 2017 , foram baseados nos novos critérios.

O objetivo de caracterizar o campo de pesquisa após o levantamento dos registros de dados disponíveis ocorreu devido ao grande número de dados e falta de domínio sobre esses dados relacionados aos últimos 21 anos de pesquisas armazenados em papel. Sendo assim, o delineamento total do trabalho ocorreu após o levantamento e análise inicial de todos os dados relacionados.

Este estudo permitiu também reforçar a necessidade da informatização dos dados, facilitando o acesso e a realização de pesquisas baseadas em evidência, melhorando o armazenamento e diminuindo a perda de dados com o passar os anos. 


\section{$\mathcal{E S T} \mathcal{T} O_{2}$}

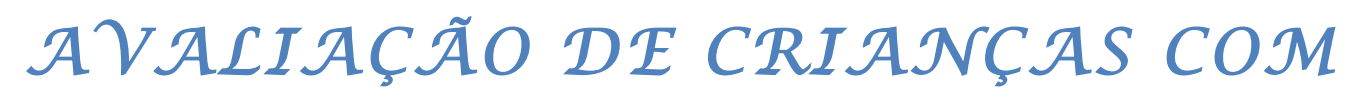
DEA: $\mathcal{E S T} U \mathcal{D O}$ LONGIT UDIJNAL DE

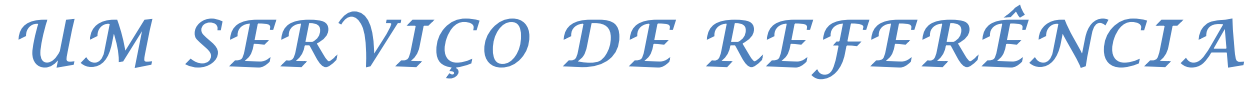




\section{1 - Introdução}

"Num contexto funcional, qualquer som ou gesto que possa ser interpretável, de forma consistente e regular; de acordo com uma função de linguagem reconhecida na linguagem do adulto é considerado linguagem." (Fernandes, 1996: p49).

As alterações na linguagem e na comunicação estão relacionadas aos DEA e são incluídas como parte da avaliação diagnóstica, sendo esta, uma alteração significativa para o fechamento do diagnóstico (Gillon et al., 2017; Parsons et al., 2017; Will et al., 2018).

Amato (2006) refere que a comunicação das crianças incluídas nos DEA tem várias particularidades e segue um percurso de desenvolvimento diferente em relação ao das crianças de desenvolvimento típico.

De acordo com Wetherby e Prutting (1984), uma das diferenças mais significativas do desenvolvimento de linguagem entre as crianças com DEA e as crianças com desenvolvimento típico está relacionado ao uso da comunicação como meio de interação.

Em relação a essas alterações de linguagem, em uma revisão bibliográfica os pesquisadores conseguiram concluir, apesar dos obstáculos encontrados ao realizaras comparações, que as crianças com DEA tendem a ter dificuldades em manter uma conversa extensa. Além disso, são mais propensas a resistir a mudanças de tópicos perseverando e fazendo comentários bizarros, quando comparadas às crianças com desenvolvimento típico (Sng et al., 2018). 
As teorias pragmáticas, segundo Fernandes (1996), permitem a abordagem das funções comunicativas, considerando as relações entre a linguagem e o contexto, incluindo seus aspectos não verbais, sociais, ambientais. A autora conclui que as teorias de desenvolvimento de linguagem relacionadas às perspectivas de abordagem pragmática permitem que a atuação fonoaudiológica seja efetiva.

Seguindo esta mesma ideia, Parsons et al. (2017) realizaram uma revisão bibliográfica com base no entendimento de que a linguagem pragmática, as habilidades sociais e a compreensão emocional estão interconectadas. Nesta revisão os autores concluem que as dificuldades na comunicação social em crianças com DEA são de longo alcance e as intervenções em linguagem pragmática, adaptadas ao longo da vida, têm o potencial de reduzir esses impactos (Parsons et al., 2017).

Buscando atualizar estas definições com relação à abordagem pragmática, Cordier et al. (2014) descreveram 27 comportamentos comunicativos observáveis que são classificados em domínios, separando os aspectos comunicativos, sociais e emocionais da linguagem. Os cinco domínios classificados foram: Introdução e capacidade de resposta; Comunicação não verbal; Sintonia sócio emocional; Função executiva e Negociação.

Além da abordagem com foco nos aspectos pragmáticos da linguagem, Wetherby e Prutting (1984), Whitehouse et. al (2006), assim como Miilher e Fernandes (2009), discutem as relações entre os déficits cognitivos e de linguagem nos quadros de autismo infantil.

Visando observar os aspectos sócio cognitivos na terapia 
fonoaudiológica de crianças com DEA, Molini (2001), utilizou uma adaptação dos critérios propostos por Wetherby e Prutting (1984) e concluiu que este instrumento é válido na estratégia de avaliação do melhor desempenho possível para cada criança.

Em 2004, Cardoso utilizou os mesmos critérios que Molini (2001) e correlacionou-os com o PFC de crianças autistas em diversas situações comunicativas e reafirmou a importância destes instrumentos para a atividade clínica junto a esta população.

Em sua pesquisa, Amato (2006) concluiu que o PFC e o DSC estão interligados e que o desenvolvimento de um desses aspectos passa necessariamente pelo desenvolvimento do outro.

Sendo assim, dentro do grande volume de informações coletadas no Estudo 1, foi observado que os protocolos PFC e DSC são aplicados com regularidade e com isso constatou-se a oportunidade de análise aprofundada a respeito destes protocolos com base em um volume significativo de dados.

$\mathrm{Na}$ análise dos dados tabulado no Estudo 1, como grande parte encontram-se impressos e arquivados em caixas no arquivo morto, foi observado que muitos deles estavam incompletos ou com dados inconsistentes, principalmente os dados relativos aos primeiros anos analisados, dificultando a inclusão nas comparações.

A partir de 2011 , os dados passaram a ser arquivados na forma digital, armazenados em um disco rígido (HD externo), no qual os dados eram facilmente localizados e organizados, diminuindo a perda de dados referente às avaliações de cada paciente. 
Com isso, surgiu a ideia de analisar somente os dados digitalizados, garantindo assim melhor consistência. Mesmo após a tabulação de todos os dados encontrados no HD, foram utilizados somente os dados daqueles que iniciaram o atendimento a partir de 2011 para fins de análises comparativas.

Diante disto, as seguintes questões de pesquisa foram propostas: Há influência da evolução do paciente na interrupção do atendimento? É possível identificar funções menos usuais analisando o PFC de pacientes que realizaram no mínimo três anos de terapia fonoaudiológica? Em certos períodos do desenvolvimento (idades), há funções comunicativas que não aparecem no PFC e outras que aparecem sistematicamente? Analisar o PFC e DSC nos últimos três anos de terapia do paciente é valido como referência de sua evolução? 


\section{2 - Objetivo}

Este estudo teve como objetivo analisar de modo aprofundado as avaliações do Perfil Funcional da Comunicação (PFC) e do Desempenho Sócio Cognitivo (DSC) dos pacientes que realizaram atendimento fonoaudiológico no LIF-DEA entre 2011 a 2017, buscado sinais de evolução e identificação de platôs do desenvolvimento terapêutico fonoaudiológico.

\section{1 - Objetivos específicos}

- Caracterizar a amostra do estudo quanto à idade e ao desempenho nas provas PFC e DSC;

- Comparar os seis momentos de avaliação em relação aos parâmetros das provas PFC e DSC;

- Verificar se a análise da evolução dos últimos três anos (seis avaliações) de atendimento, com base no PFC e DSC, é suficiente para averiguar uma evolução;

- Investigar a capacidade preditiva das ações da prova PFC em relação ao escore do DSC;

- Verificar a existência de associações relevantes entre as informações a respeito de idade e desempenho no início do atendimento com a evolução clínica;

- Comparar as faixas etárias em relação aos parâmetros nas provas PFC e DSC; 
- Investigar a presença de correlação entre o número de respostas nas provas PFC, DSC e porcentagem de atos interativos. 


\section{3 - Hipótese}

Este estudo surgiu com a hipótese de que em três anos de terapia fonoaudiológica especializada no DEA é possível observar uma evolução clínica significativa. 


\section{4 - Método}

Foi realizado um estudo de cunho retrospectivo, exploratório e descritivo com a utilização de prontuários para a coleta de dados.

Este estudo está vinculado ao estudo 1. No entanto foram considerados os dados relativos aos pacientes do arquivo morto e daqueles pacientes que ainda permanecem em atendimento, seguindo os critérios de inclusão e exclusão.

Foi utilizado o banco de dados composto por 155 sujeitos atendidos no Laboratório de Investigação Fonoaudiológica dos Distúrbios do Espectro do Autismo (LIF-DEA) da Universidade de São Paulo (USP) entre os anos de 2011 a 2017.

\section{1 - Corpus}

Dentre os prontuários dos 218 pacientes do LIF-DEA, foram selecionados 155 prontuários de pacientes com base nos critérios de inclusão e exclusão.

Os critérios de inclusão envolveram:

- Possuir diagnóstico nos DEA;

- Ter iniciado terapia fonoaudiológica a partir de 2011;

- Possuir dados completos referentes à coleta semestral do protocolo PFC; 
Os critérios de exclusão dependeram de cada análise em específico, ou seja, nas análises que envolviam os dados do DSC, aqueles sujeitos que não possuíam a avaliação em algum momento foram desconsiderados. Na análise envolvendo seis avaliações seguidas, aqueles que não possuíam ou por algum motivo não realizaram alguma reavaliação entre essas 6 avaliações, foram desconsiderados.

Para ilustrar e facilitar o entendimento dos diferentes números de sujeitos utilizados nas análises, na figura 30 , pode ser observado o número de avalições, a quantidade de dados tabulados e dos que não entraram na análise. 


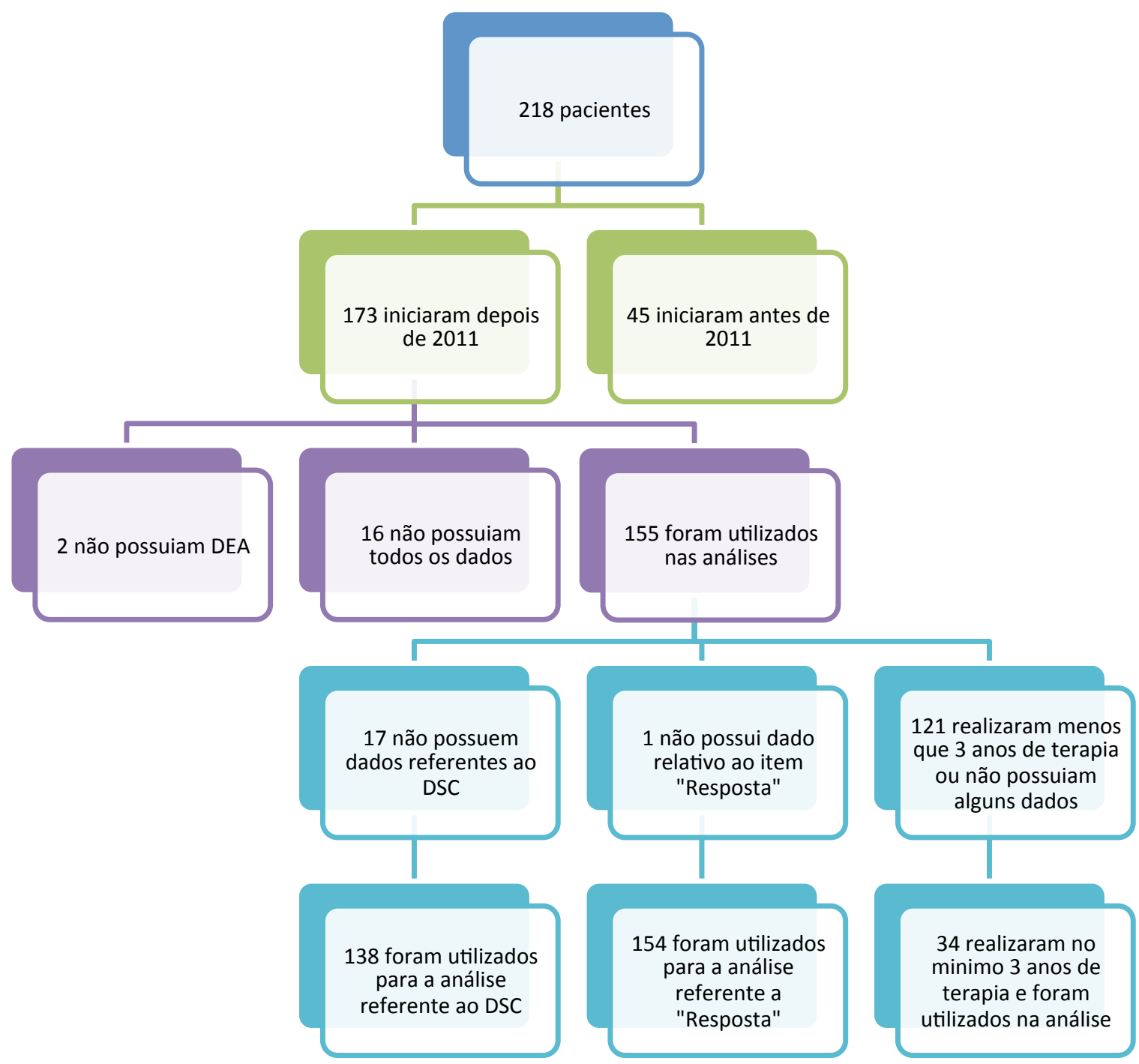

Figura 30 - Totalização dos Pacientes analisados conforme os critérios de inclusão e exclusão no Estudo 2.

Os pacientes cujos prontuários foram selecionados, realizaram atendimento em esquema ambulatorial, uma vez por semana, em terapia individual especializada nos DEA com duração de 45 minutos. Ficam em período de férias duas vezes ao ano, com duração de duas semanas em julho e três semanas entre o final de dezembro e o início de janeiro.

A cada ano são realizados dois períodos de avaliação, um no primeiro semestre, ocorrendo normalmente no mês de junho e outro no segundo semestre, ocorrendo normalmente no mês de novembro. 
Embora haja a troca anual de terapeutas no início de cada ano os processos mantêm continuidade, garantida pelas reavaliações semestrais, manutenção dos supervisores e acompanhamento sistemático de cada caso pela mesma equipe.

\section{2 - Material}

Como fonte de coleta de dados, foram utilizados: prontuário digitalizado dos pacientes, planilhas de dados, relatórios evolutivos, avaliações e reavaliações do PFC e do DSC do acervo de LIF-DEA.

O Perfil Funcional da Comunicação - Checklist (Neubauer e Fernandes, 2013) também foi analisado como possível avaliação a ser correlacionada neste estudo; porém no arquivo morto referente aos últimos cinco anos foram encontrados somente 24 prontuários contendo este protocolo. A aplicação deste checklist ocorre de forma anual, no início de cada ano, diferente dos outros dois protocolos citados acima. Com isso, neste estudo optou-se por não considerar os dados relativos a este protocolo de avaliação.

\section{3 - Procedimentos}

Foram selecionados os prontuários dos sujeitos que se enquadraram dentro dos critérios de inclusão e exclusão. Dentre esses prontuários foram separadas as avaliações do PFC e DSC. 
Os dados dessas avaliações foram transcritos para outra planilha do Excel com os dados de todos os pacientes, separados por ano e semestre no qual cada dado era relativo.

Após a transcrição de todos os dados, ou seja, 950 avalições e reavaliações tabuladas. Esses dados foram encaminhados para a estatística, que selecionou os dados aptos a serem analisados.

\subsection{1 - Para a avaliação e reavaliação do PFC:}

Foram utilizados os critérios propostos por Fernandes (2004), com as alterações comprovadas no estudo de Porto et al. (2007). Sendo assim, foram baseadas em gravações de amostras de 15 minutos de interação terapeutapaciente, no qual são transcritos e analisados os cinco minutos de interação mais simétrica de cada gravação, segundo a percepção do próprio terapeuta que realizou a avaliação (Anexo B).

Após a análise, foram transcritos para a ficha síntese (Anexo C) os dados referentes à incidência de cada função comunicativa utilizada pelo paciente, interatividade do paciente com base nas funções consideradas mais interativas, número de atos comunicativos expressos por minuto, porcentagem de ocupação do espaço comunicativo (\%OEC), número de atos comunicativos por minuto (NA/M) e proporção de interatividade (\%INT).

Para a avaliação das funções obtidas, estas foram divididas em mais e menos interpessoais, de acordo com o proposto por Cardoso e Fernandes (2003). As funções consideradas como mais interpessoais são: Pedido de objeto (PO), Pedido de ação (PA), Pedido de rotina social (PS), Pedido de consentimento $(\mathrm{PC})$, Pedido de informação (PI), Protesto (PR), 
Reconhecimento do outro (RO), Exibição $(E)$, Comentário (C), Exclamativo (EX), Narrativa (NA), Expressão de protesto (EP), Jogo compartilhado (JC). As funções consideradas como menos interpessoais são: Reativo (RE), Não focalizada (NF), Jogo (J), Exploratória (XP), Auto regulatório (AR), Nomeação (N), Performativo (PE).

A ocupação do espaço comunicativo foi definida a partir dos atos comunicativos do paciente e da terapeuta em função do tempo transcrito. 0 número de atos comunicativos por minuto foi obtido a partir dos atos comunicativos expressos pelo paciente e pelo tempo transcrito. A proporção de interatividade foi definida considerando todos os atos expressos pela criança das 13 funções consideradas mais interpessoais em relação ao número de atos total.

Os meios comunicativos considerados são verbal (MVE), vocal (MVO) e gestual (MG), sendo que é possível assinalar mais de um meio comunicativo (já que é possível realizar um ato comunicativo por mais de um meio).

Para a gravação da avaliação, foram selecionados brinquedos de acordo com a vontade e/ou solicitação das crianças para estimular a comunicação espontânea, visando melhores situações comunicativas para registro em vídeo.

\subsection{2 - Para a avaliação e reavaliação do DSC:}

Foram utilizados os critérios de análise dos aspectos sócio-cognitivos sugeridos por Wetherby e Prutting (1984) e adaptados por Molini (2001).

Sendo assim, foram registrados os números da pontuação referente ao melhor desempenho de cada criança em cada uma das áreas a seguir: 
Intenção comunicativa gestual e vocal, Imitação gestual e vocal, Uso do objeto mediador, Jogo combinatório e Jogo simbólico.

A verificação do DSC foi realizada em duas situações: a espontânea e a de teste. O modo teste desta avaliação ocorre em uma situação semidirigida, na qual algumas situações são propositalmente direcionadas e a partir disto a resposta que o indivíduo apresentar é avaliada e pontuada. A avaliação na situação espontânea ocorria no mesmo dia em que o sujeito participava da investigação do PFC, com base na mesma filmagem. A situação de teste, no geral, foi realizada na sessão seguinte após a avaliação do PFC.

Os dados obtidos foram registrados em protocolos individuais específicos (Anexo D).

A fim de considerar o desempenho global no teste e para diminuir o número de variáveis a serem correlacionadas, foi considerado como escore do teste um valor total baseado na soma de todas as áreas avaliadas, no qual a menor pontuação possível é 0 e a maior é 36. Este valor foi obtido com base na situação teste ou na situação espontânea, dependendo da melhor pontuação obtida pelo indivíduo, isso foi realizado levando em consideração que o objetivo é ter uma noção do melhor desempenho possível para cada criança.

\section{4 - Local onde o estudo foi desenvolvido}

A pesquisa foi desenvolvida no Laboratório de Investigação Fonoaudiológica dos Distúrbios do Espectro do Autismo (LIF-DEA) do Departamento de Fisioterapia, Fonoaudiologia e Terapia Ocupacional da 
Faculdade de Medicina da Universidade de São Paulo. Um serviço de referência, credenciado pelo Sistema Único de Saúde (SUS).

\section{5 - Estatística}

O valor de significância estatística adotado foi igual a $5 \%(p \leq 0,05)$. Utilizou-se o software SPSS Statistics, versão 25.0 (IBM Corp., Armonk, NY, EUA). A base teórica utilizada para a análise estatística apresentada neste relatório está descrita de forma pormenorizada por Field (2017).

Para o cálculo dos intervalos de confiança de 95\% foi utilizado o método de viés corrigido e acelerado com base em 2000 amostras bootstrap. Os valores entre colchetes nas tabelas indicam os limites superior e inferior dos intervalos de confiança de $95 \%$.

Para interpretação dos tamanhos dos efeitos, sugere-se utilizar a classificação proposta por Cohen (1992).

Para o coeficiente d, adotam-se os seguintes critérios:

- Pequeno: entre $|0,200|$ e $|0,499|$;

- Médio: entre $|0,500|$ e $|0,799|$;

- Grande: acima de |0,800|.

Para o coeficiente r, adotam-se os seguintes critérios:

- Pequeno: entre $|0,100|$ e $|0,299|$;

- Médio: entre $|0,300|$ e $|0,500|$;

- Grande: acima de $|0,500|$. 


\section{5 - Resultados}

5.1 - Caracterização da amostra do estudo quanto à idade, ao desempenho na prova do Perfil Funcional da Comunicação e ao escore do Desempenho Sócio Cognitivo

A Tabela 3 apresenta as medidas de tendência central e de dispersão da idade, dos parâmetros do PFC e DSC, considerando a primeira avaliação dos pacientes que realizaram atendimento entre 2011 e 2017.

A análise estatística destes dados foi realizada usando como base a amostra de 155 indivíduos (N=155). As variáveis: resposta (RESP) e o escore do Desempenho Sócio Cognitivo (DSC) possuem um número (n) de amostra menor devido à falta de dados.

Tabela 3 - Caracterização do grupo do estudo em relação à idade, ao desempenho no PFC e DSC.

\begin{tabular}{|c|c|c|c|c|c|c|}
\hline Variável & $\mathbf{n}$ & Média & DP & Mediana & Mín. & Máx. \\
\hline Idade & 155 & $\begin{array}{c}5,48 \\
{[5,12,5,89]}\end{array}$ & 2,37 & $\begin{array}{c}4,92 \\
{[4,50,5,50]}\end{array}$ & 0,00 & 15,58 \\
\hline PO & 155 & $\begin{array}{c}1,73 \\
{[1,21,2,32]}\end{array}$ & 3,56 & $\begin{array}{c}0,00 \\
{[0,00,0,00]}\end{array}$ & 0,00 & 19,00 \\
\hline RO & 155 & $\begin{array}{c}7,68 \\
{[6,50,8,89]}\end{array}$ & 7,96 & $\begin{array}{c}6,00 \\
{[5,00,6,00]}\end{array}$ & 0,00 & 37,00 \\
\hline EX & 155 & $\begin{array}{c}1,77 \\
{[1,25,2,38]}\end{array}$ & 3,91 & $\begin{array}{c}0,00 \\
{[0,00,0,00]}\end{array}$ & 0,00 & 22,00 \\
\hline EP & 155 & $\begin{array}{c}3,72 \\
{[2,90,4,61]}\end{array}$ & 5,91 & $\begin{array}{c}0,00 \\
{[0,00,2,00]}\end{array}$ & 0,00 & 29,00 \\
\hline PR & 155 & $\begin{array}{c}5,08 \\
{[4,10,6,17]}\end{array}$ & 6,86 & $\begin{array}{c}3,00 \\
{[3,00,3,00]}\end{array}$ & 0,00 & 35,00 \\
\hline PE & 155 & $\begin{array}{c}13,79 \\
{[11,52,15,96]}\end{array}$ & 13,38 & $\begin{array}{c}11,00 \\
{[8,00,13,00]}\end{array}$ & 0,00 & 59,00 \\
\hline NA & 155 & $\begin{array}{c}0,35 \\
{[0,06,0,94]}\end{array}$ & 3,56 & $\begin{array}{c}0,00 \\
{[0,00,0,00]}\end{array}$ & 0,00 & 44,00 \\
\hline PS & 155 & $\begin{array}{c}0,47 \\
{[0,25,0,73]}\end{array}$ & 1,68 & $\begin{array}{c}0,00 \\
{[0,00,0,00]}\end{array}$ & 0,00 & 12,00 \\
\hline
\end{tabular}




\begin{tabular}{|c|c|c|c|c|c|c|}
\hline C & 155 & $\begin{array}{c}5,79 \\
{[4,37,6,63]}\end{array}$ & 9,61 & $\begin{array}{c}0,00 \\
{[0,00,0,00]}\end{array}$ & 0,00 & 48,00 \\
\hline$N F$ & 155 & $\begin{array}{c}7,79 \\
{[6,36,9,32]}\end{array}$ & 9,96 & $\begin{array}{c}4,00 \\
{[3,00,4,00]}\end{array}$ & 0,00 & 40,00 \\
\hline PA & 155 & $\begin{array}{c}5,50 \\
{[4,37,6,63]}\end{array}$ & 7,30 & $\begin{array}{c}3,00 \\
{[2,00,3,00]}\end{array}$ & 0,00 & 33,00 \\
\hline$E$ & 155 & $\begin{array}{c}1,66 \\
{[1,09,2,31]}\end{array}$ & 3,97 & $\begin{array}{c}0,00 \\
{[0,00,0,00]}\end{array}$ & 0,00 & 23,00 \\
\hline $\mathrm{JC}$ & 155 & $\begin{array}{c}16,45 \\
{[13,82,19,02]}\end{array}$ & 15,87 & $\begin{array}{c}12,00 \\
{[9,00,15,00]}\end{array}$ & 0,00 & 65,00 \\
\hline RE & 155 & $\begin{array}{c}2,90 \\
{[2,04,3,89]}\end{array}$ & 5,87 & $\begin{array}{c}0,00 \\
{[0,00,1,00]}\end{array}$ & 0,00 & 48,00 \\
\hline $\mathrm{PI}$ & 155 & $\begin{array}{c}1,77 \\
{[1,21,2,35]}\end{array}$ & 4,07 & $\begin{array}{c}0,00 \\
{[0,00,0,00]}\end{array}$ & 0,00 & 24,00 \\
\hline$N$ & 155 & $\begin{array}{c}1,26 \\
{[0,74,1,81]}\end{array}$ & 4,04 & $\begin{array}{c}0,00 \\
{[0,00,0,00]}\end{array}$ & 0,00 & 30,00 \\
\hline$X P$ & 155 & $\begin{array}{c}12,97 \\
{[11,14,14,98]}\end{array}$ & 12,85 & $\begin{array}{c}9,00 \\
{[9,00,9,00]}\end{array}$ & 0,00 & 73,00 \\
\hline PC & 155 & $\begin{array}{c}0,20 \\
{[0,10,0,30]}\end{array}$ & 0,78 & $\begin{array}{c}0,00 \\
{[0,00,0,00]}\end{array}$ & 0,00 & 5,00 \\
\hline AR & 155 & $\begin{array}{c}0,25 \\
{[0,10,0,42]}\end{array}$ & 1,22 & $\begin{array}{c}0,00 \\
{[0,00,0,00]}\end{array}$ & 0,00 & 13,00 \\
\hline $\mathrm{J}$ & 155 & $\begin{array}{c}8,63 \\
{[6,91,10,55]}\end{array}$ & 12,01 & $\begin{array}{c}3,00 \\
{[2,00,5,00]}\end{array}$ & 0,00 & 61,00 \\
\hline EC & 155 & $\begin{array}{c}44,97 \\
{[43,89,46,05]}\end{array}$ & 6,71 & $\begin{array}{c}45,00 \\
{[44,00,47,00]}\end{array}$ & 22,00 & 70,00 \\
\hline $\mathrm{Al}$ & 155 & $\begin{array}{c}51,85 \\
{[48,37,55,35]}\end{array}$ & 21,57 & $\begin{array}{c}52,00 \\
{[50,00,54,00]}\end{array}$ & 6,00 & 100,00 \\
\hline NA/M & 155 & $\begin{array}{c}8,65 \\
{[822,9,09]}\end{array}$ & 2,92 & $\begin{array}{c}8,20 \\
{[7,40,8,60]}\end{array}$ & 2,60 & 18,80 \\
\hline NFU & 155 & $\begin{array}{c}8,67 \\
{[8,31,9,02]}\end{array}$ & 2,31 & $\begin{array}{c}9,00 \\
{[9,00,9,00]}\end{array}$ & 3,00 & 15,00 \\
\hline$N F I$ & 155 & $\begin{array}{c}5,03 \\
{[4,74,5,34]}\end{array}$ & 1,98 & $\begin{array}{c}5,00 \\
{[5,00,5,00]}\end{array}$ & 1,00 & 10,00 \\
\hline RESP & 154 & $\begin{array}{c}7,14 \\
{[6,18,8,12]}\end{array}$ & 6,10 & $\begin{array}{c}6,00 \\
{[5,00,6,00]}\end{array}$ & 0,00 & 30,00 \\
\hline DSC & 138 & $\begin{array}{c}22,08 \\
{[20,69,23,36]}\end{array}$ & 8,17 & $\begin{array}{c}22,00 \\
{[21,50,23,00]}\end{array}$ & 3,00 & 36,00 \\
\hline
\end{tabular}

Legenda: PO: Pedido de Objeto; RO: Reconhecimento do outro; EX: Exclamativo; EP: Expressão de protesto; PR: Protesto; PE: Performativo; NA: Narrativo; PS: Pedido de rotina social; C: Comentário; NF: Não focalizado; PA: Pedido de ação; E: Exibição; JC: Jogo compartilhado; RE: Reativo; PI: Pedido de informação; N: Nomeação; XP: Exploratório; PC: Pedido de consentimento; AR: Auto regulatório; J: Jogo; EC: Espaço comunicativo; Al: Atos Interativos; NA/M: Número de atos por minuto; NFU: Número de funções; NFI: Número de funções consideradas como mais interativas; RESP: Número de respostas; DSC: Desempenho Sócio Cognitivo; DP: Desvio padrão; Mín.: Mínimo; Máx.: Máximo.

Com a caracterização da amostra, considerando os dados da primeira avaliação, é possível observar que a idade média dos 155 sujeitos analisados é 
de 5 anos e meio, as funções comunicativas mais realizadas foram: JC, PE, $\mathrm{XP}$, com uma média de 9 funções por PFC analisado. A pontuação média do escore do DSC com base nos 138 sujeitos que possuíam este dado é de 22 pontos.

Na amostra deste estudo, somente 23 são do sexo feminino, ou seja, $14 \%$ dos indivíduos.

5.2 - Comparação entre as seis primeiras avaliações do PFC e o DSC

A análise estatística destes dados foi realizada usando como base a amostra de 34 indivíduos que frequentaram terapia fonoaudiológica no LIFDEA por 3 anos ou mais e possuíam os dados das seis primeiras avaliações.

A Tabela 4 apresenta as medidas de tendência central e de dispersão dos parâmetros do PFC e DSC de acordo com o momento da avaliação. Para análise de comparação entre os momentos em relação aos parâmetros do PFC e DSC foi realizado um conjunto de análises de covariância univariada (ANCOVA) de medidas repetidas. A idade à primeira avaliação foi inserida como covariável no modelo linear geral construído para esta análise para controlar o seu efeito.

Tabela 4 - Valores descritivos e análise comparativa dos momentos de avaliação em relação aos parâmetros do PFC e DSC.

\begin{tabular}{|c|c|c|c|c|c|c|c|c|}
\hline Variável & Avaliação & Média & DP & Mediana & Mín. & Máx. & $p^{\text {na }}$ & $p^{a}$ \\
\hline \multirow{2}{*}{ PO } & 1 & $\begin{array}{c}0,88 \\
{[0,24,1,71]}\end{array}$ & 2,66 & $\begin{array}{c}0,00 \\
{[0,00,0,00]}\end{array}$ & 0,00 & 12,00 & \multirow{2}{*}{$0,119^{\mathrm{HF}}$} & \multirow{2}{*}{$0,509^{\mathrm{HF}}$} \\
\hline & 2 & $\begin{array}{c}1,59 \\
{[0,54,2,85]}\end{array}$ & 3,63 & $\begin{array}{c}0,00 \\
{[0,00,0,00]}\end{array}$ & 0,00 & 14,00 & & \\
\hline
\end{tabular}




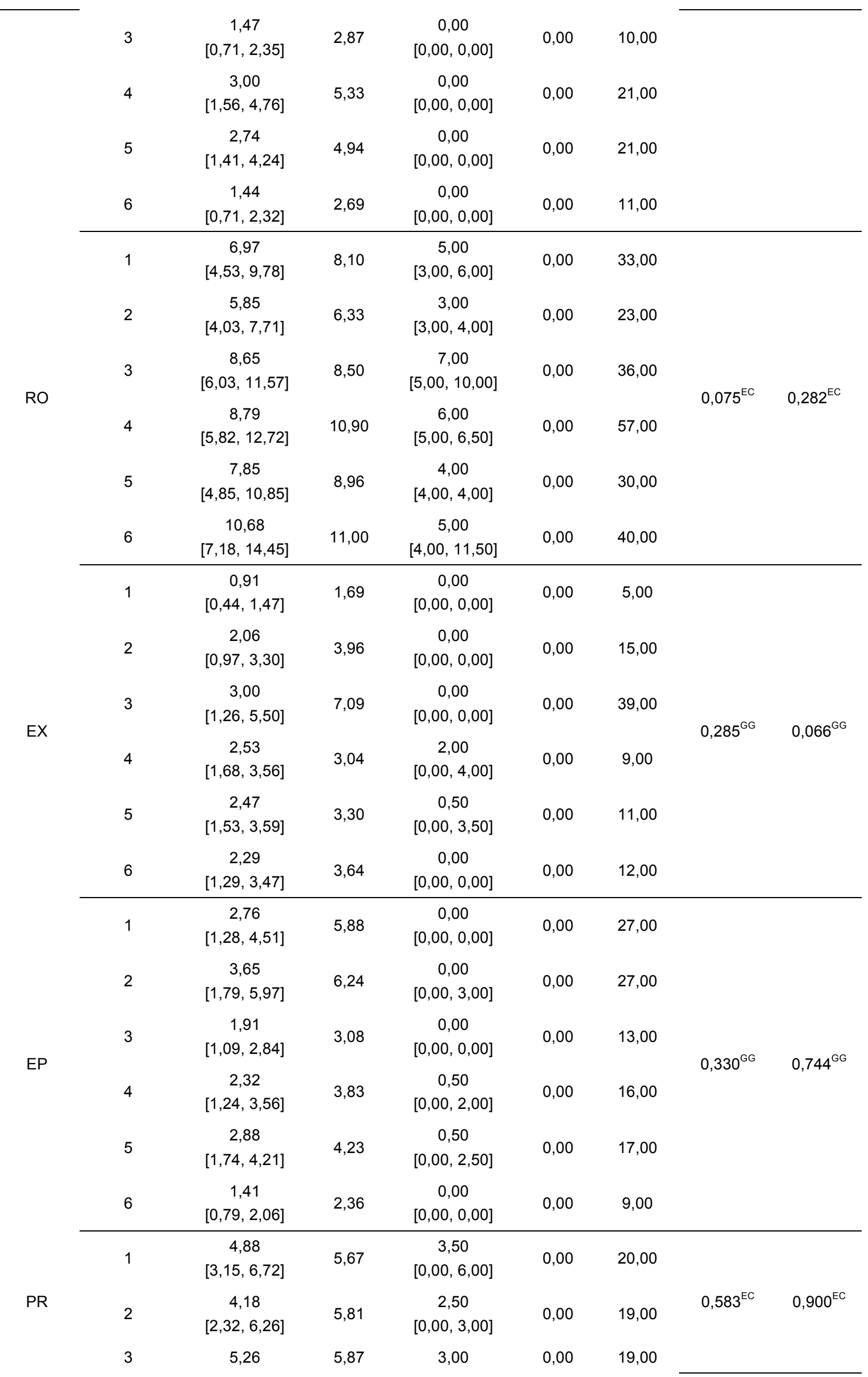




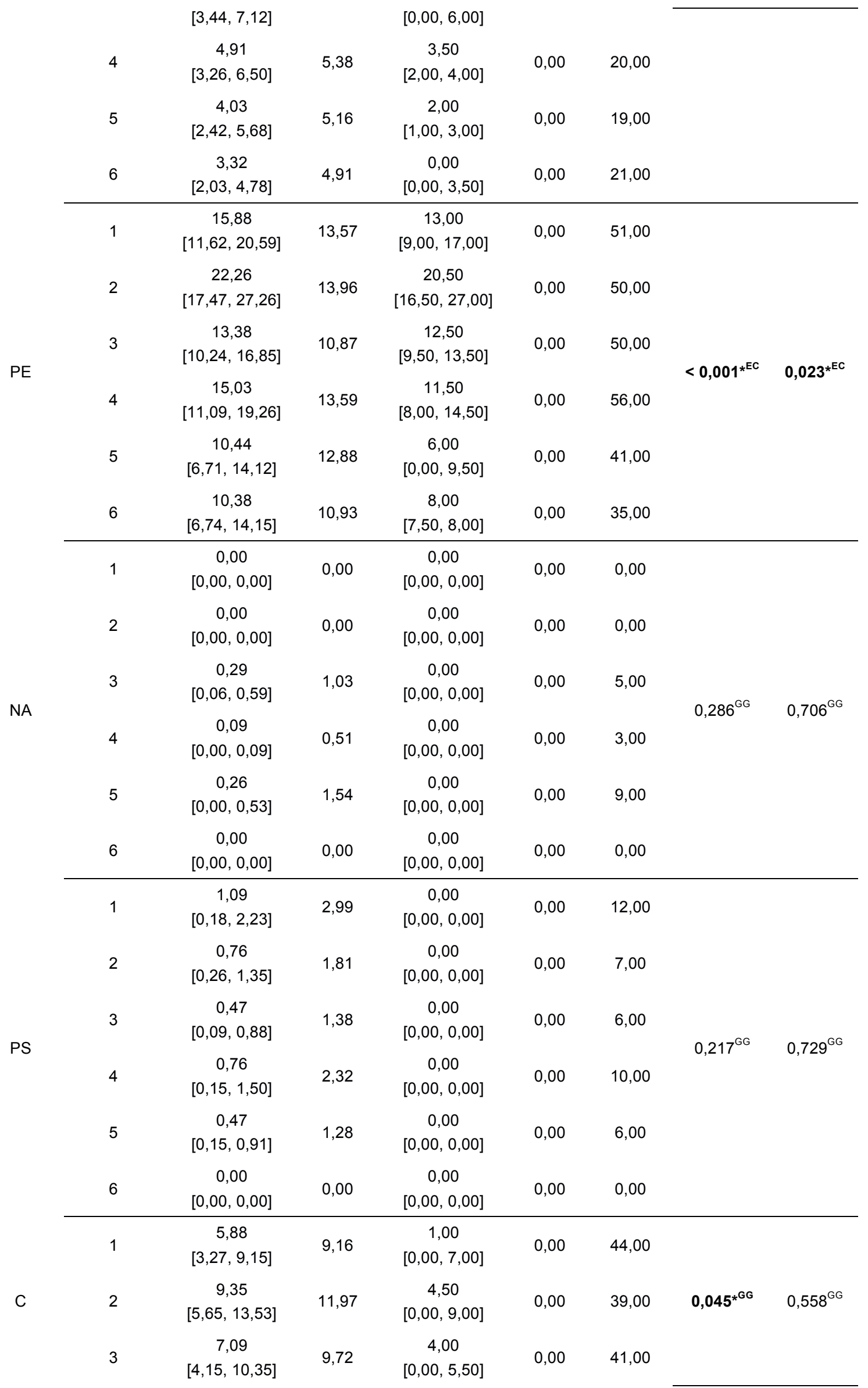




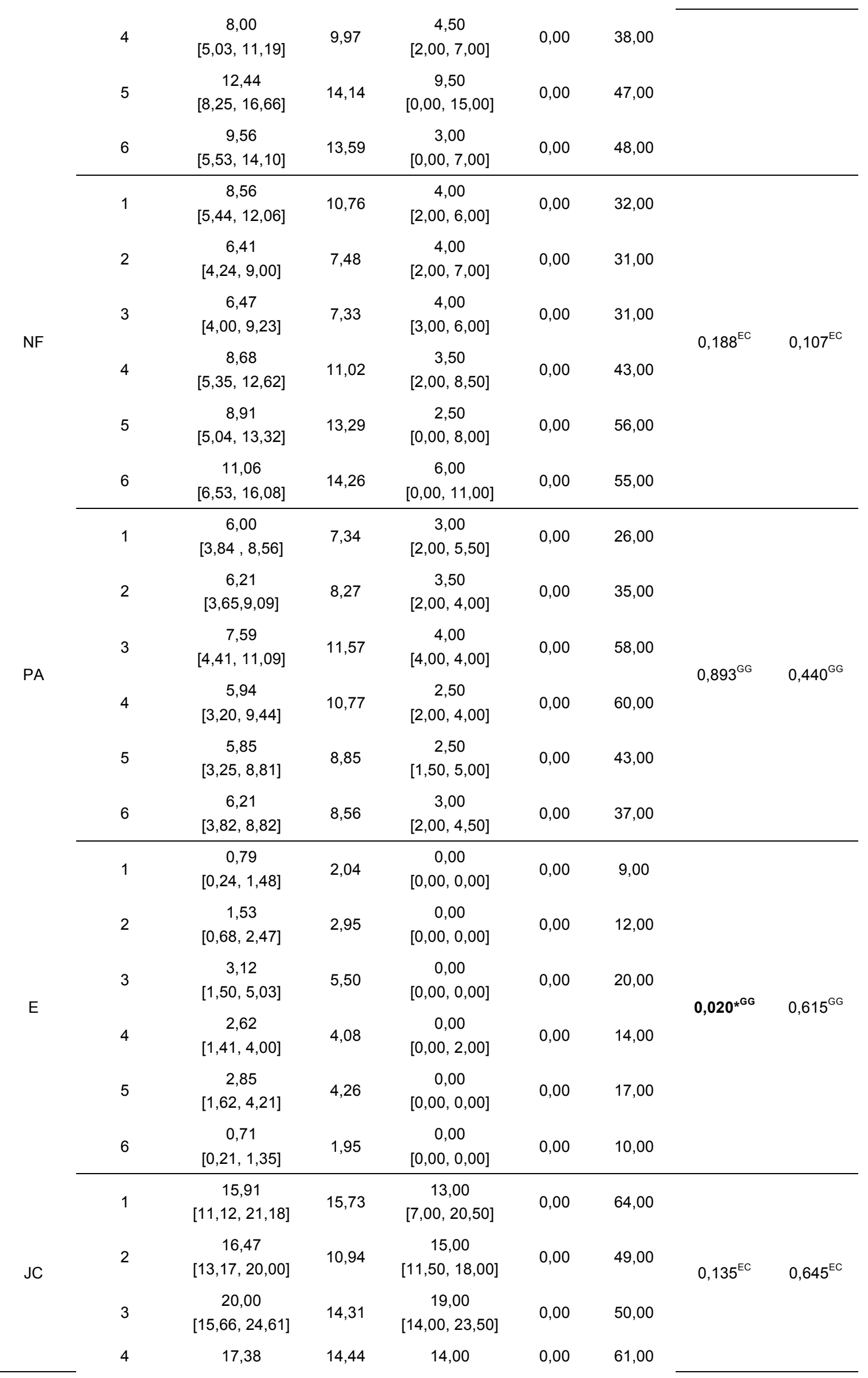




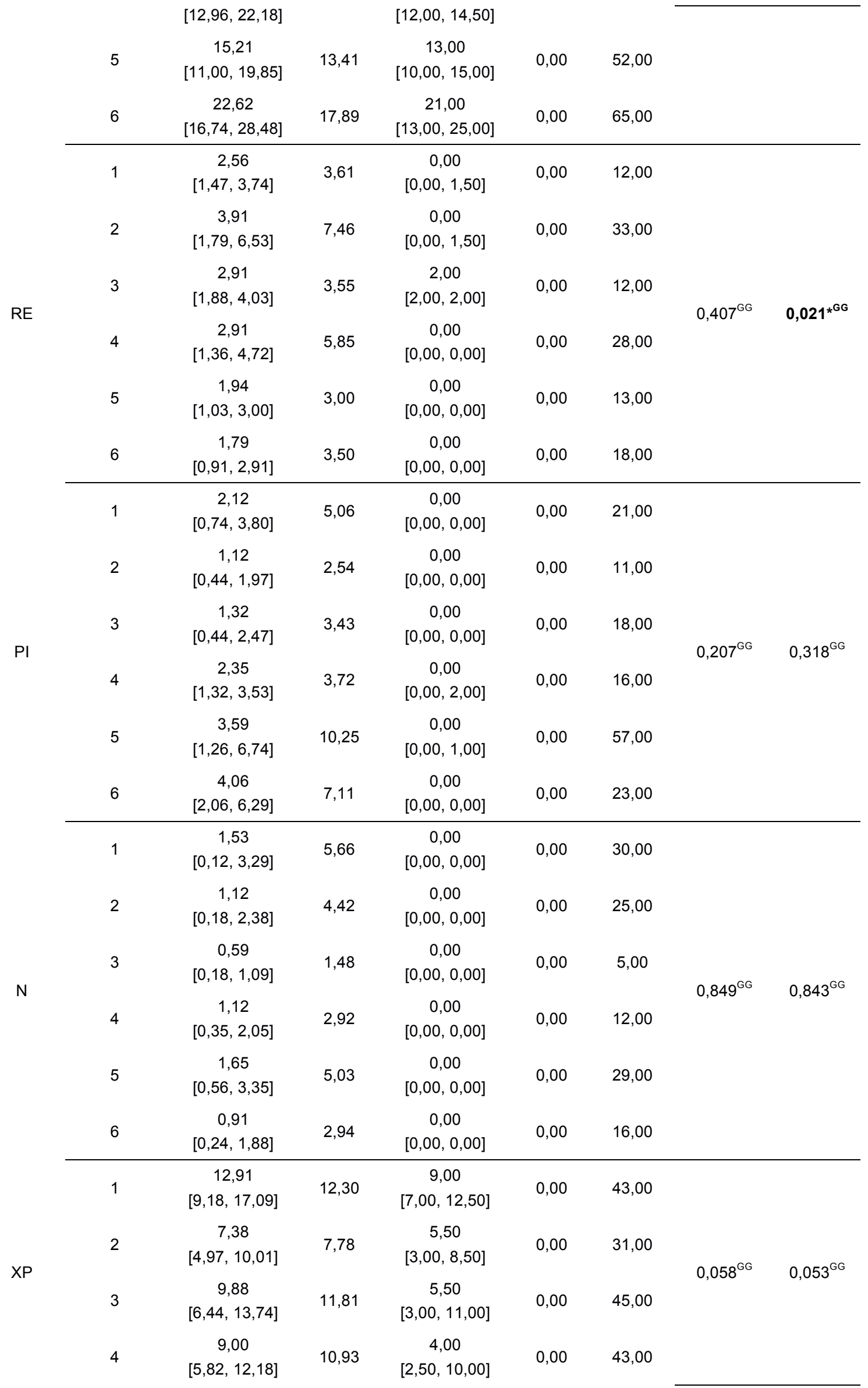




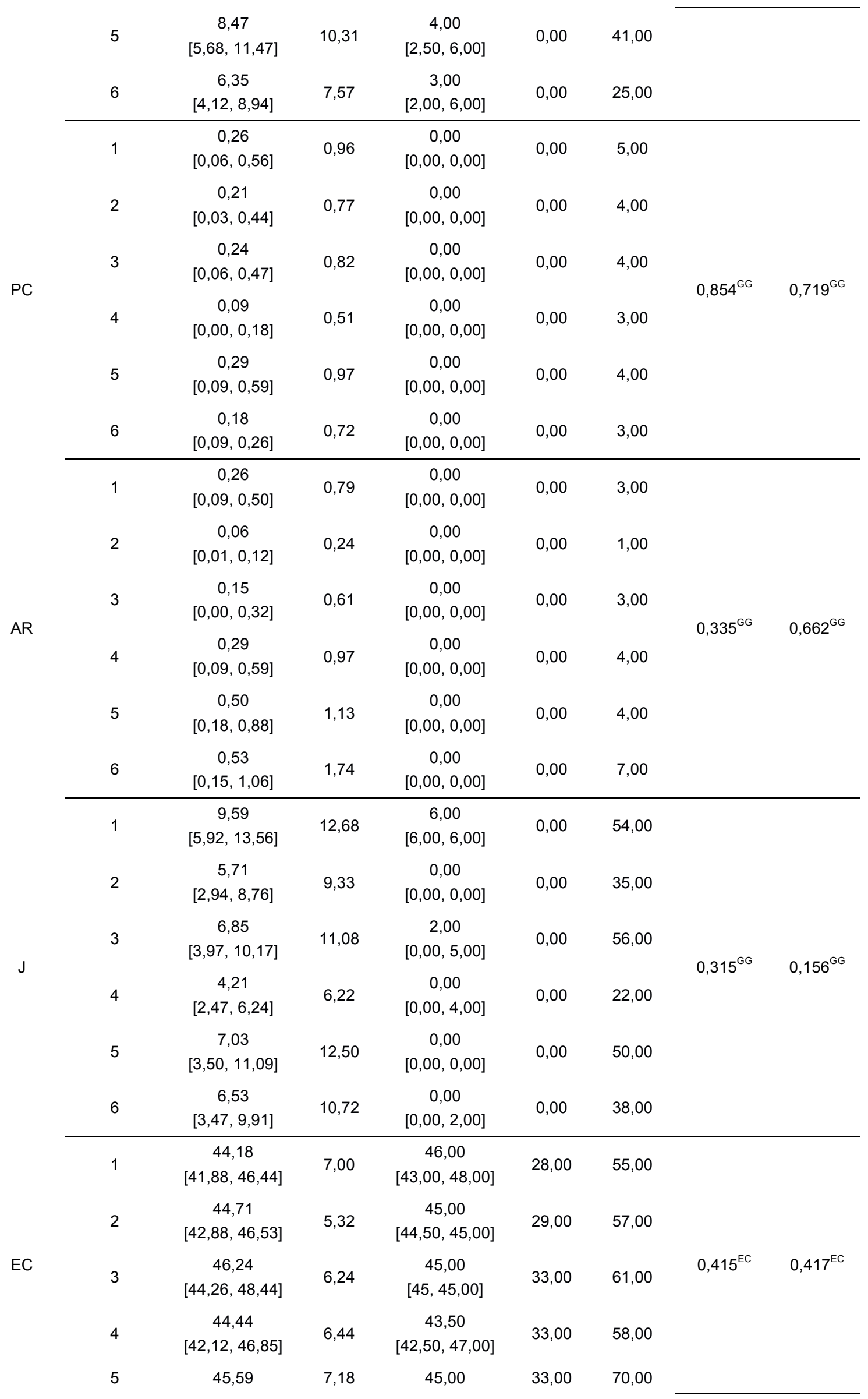




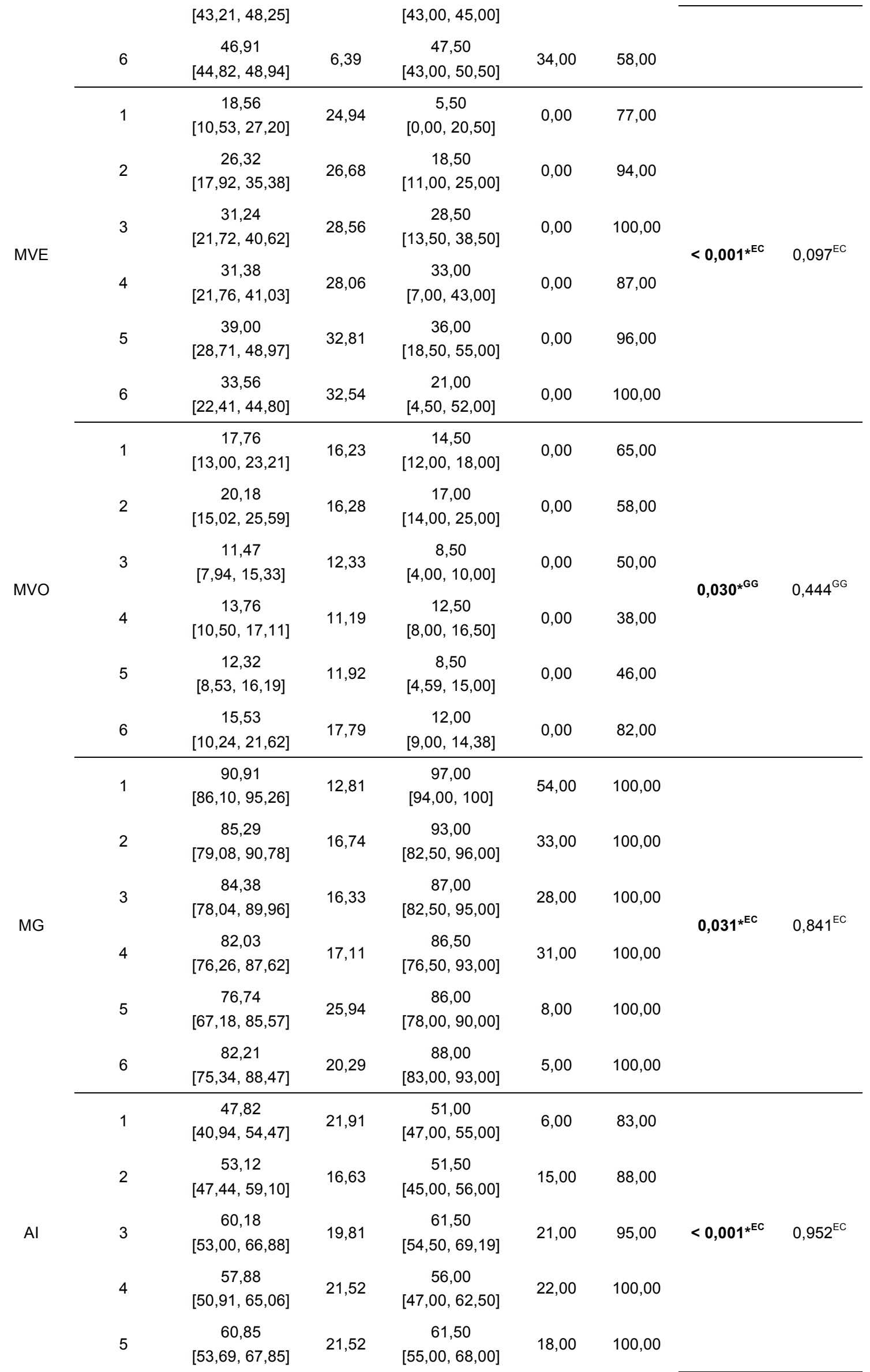




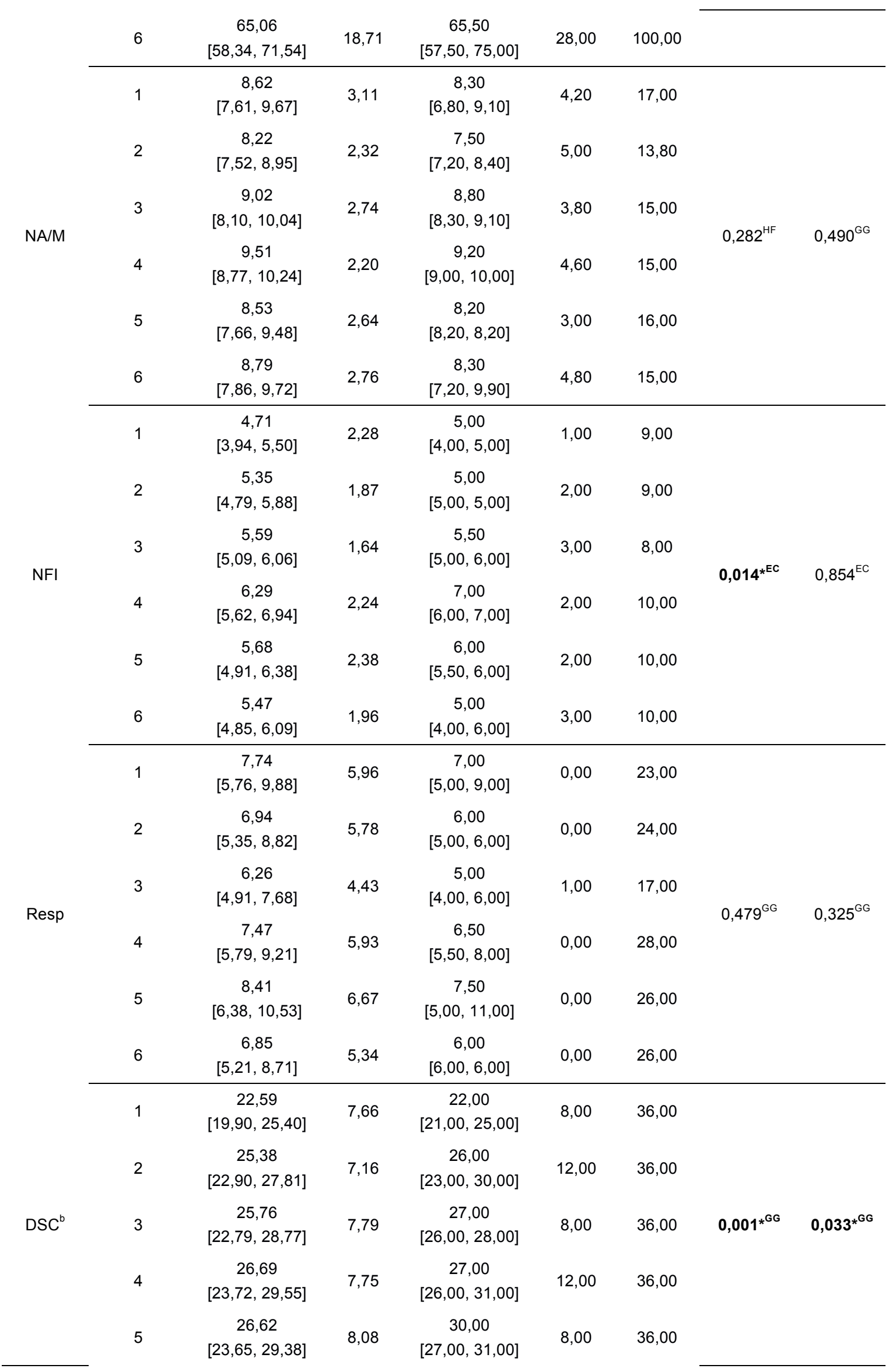


Análise de covariância (ANCOVA) de medidas repetidas.

Legenda: ${ }^{\mathrm{EC}}$ : valor calculado considerando a não-violação do pressuposto de esfericidade $(p>$ 0,05 , teste de esfericidade de Mauchly); ${ }^{\mathrm{HF}}$ : valor calculado a partir da correção de Huynh-Feldt devido à violação do pressuposto de esfericidade ( $p \leq 0,05$, teste de esfericidade de Mauchly); GG: valor calculado a partir da correção de Greenhouse-Geisser devido à violação do pressuposto de esfericidade ( $p \leq 0,05$, teste de esfericidade de Mauchly); ${ }^{\text {na: }}$ : valor de $p$ sem o controle do efeito do fator "idade à primeira avaliação"; ": valor de $p$ controlando o efeito do fator "idade à primeira avaliação"; *: Valor estatisticamente significativo no nível de 5\% ( $p \leq$ $0,05)$; ": calculado com base em apenas 29 indivíduos devido à ausência da variável em cinco indivíduos; DP: Desvio padrão; Mín.: Mínimo; Máx.: Máximo; PO: Pedido de Objeto; RO: Reconhecimento do outro; EX: Exclamativo; EP: Expressão de protesto; PR: Protesto; PE: Performativo; NA: Narrativo; PS: Pedido de rotina social; C: Comentário; NF: Não focalizado; PA: Pedido de ação; E: Exibição; JC: Jogo compartilhado; RE: Reativo; PI: Pedido de informação; N: Nomeação; XP: Exploratório; PC: Pedido de consentimento; AR: Auto regulatório; J: Jogo; EC: Espaço comunicativo; MVE: Meio comunicativo verbal; MVO: Meio comunicativo vocal; MG: Meio comunicativo gestual; Al: Atos Interativos; NA/M: Número de atos por minuto; NFI: Número de funções consideradas como mais interativas; RESP: Número de respostas; DSC: Desempenho Sócio Cognitivo.

Os resultados da Tabela 4 demonstram que, sem o controle do efeito da idade de início, os seguintes parâmetros apresentaram diferença estatisticamente significativa:

- $\operatorname{PE}\left(p^{\mathrm{na}}=0,001\right)$

- $C\left(p^{\text {na }}=0,045\right)$

- $E\left(p^{n a}=0,020\right)$

- $\operatorname{MVE}\left(p^{\text {na }}=0,001\right)$

- $\operatorname{MVO}\left(p^{\text {na }}=0,030\right)$

- $M G\left(p^{n a}=0,031\right)$

- $\mathrm{Al}\left(\mathrm{p}^{\mathrm{na}}=0,001\right)$

- $\operatorname{NFI}\left(p^{n a}=0,014\right)$

- $\operatorname{DSC}\left(p^{\mathrm{na}}=0,001\right)$

Após o efeito do controle desta covariável, apenas três parâmetros apresentaram significância estatística: PE, RE e DSC. Utilizou-se a análise de contrastes planejados para identificar entre quais duplas de momentos de 
avaliação seria possível observar diferença estatisticamente significativa nestas três variáveis. O tamanho do efeito da diferença entre os momentos foi medido por meio do cálculo do coeficiente $r$ (Rosenthal, 1991), calculado a partir da conversão da estatística F proposta por Field (2017).

Tabela 5 - Análise post hoc para os parâmetros que apresentaram diferença estatisticamente significativa entre os momentos.

\begin{tabular}{ccccccc}
\hline Grupo & & $\mathbf{1 \times 2}$ & $\mathbf{2 \times 3}$ & $\mathbf{3 \times 4}$ & $\mathbf{4 \times 5}$ & $\mathbf{5 \times 6}$ \\
\hline \multirow{2}{*}{$\mathbf{P E}$} & $\mathbf{p}$ & $\mathbf{0 , 0 0 6 ^ { * }}$ & 0,240 & 0,121 & 0,668 & 0,427 \\
& $\mathbf{r}$ & 0,465 & 0,207 & 0,271 & 0,076 & 0,141 \\
\cline { 2 - 7 } & $\mathbf{p}$ & $\mathbf{0 , 0 5 0 ^ { * }}$ & 0,076 & 0,347 & 0,076 & 0,129 \\
& $\mathbf{r}$ & 0,338 & 0,309 & 0,166 & 0,289 & 0,266 \\
\cline { 2 - 7 } & $\mathbf{p}$ & 0,281 & 0,147 & $\mathbf{0 , 0 0 6}$ & 0,791 & 0,875 \\
& $\mathbf{r}$ & 0,207 & 0,276 & 0,499 & 0,052 & 0,207 \\
\hline
\end{tabular}

Análise de contrastes planejados

Os valores acima da diagonal principal da tabela indicam os valores de $p$, enquanto os valores abaixo da diagonal principal indicam os tamanhos dos efeitos.

Legenda: * - valor estatisticamente significativo no nível de 5\% $(p \leq 0,05)$. PE: Performativo; RE: Reativo e DSC: escore do Desempenho Sócio Cognitivo.

Quanto à variável PE, houve diferença estatisticamente significativa entre os momentos 1 e 2 , sendo que o momento 2 apresentou valor maior em comparação ao momento 1. Entre os demais momentos, não foram observadas diferenças estatisticamente significativas. Sendo assim, houve aumento da variável PE na segunda avaliação em comparação a primeira e, em seguida, esta variável se manteve constante.

Quanto à variável $\mathrm{RE}$, houve diferença estatisticamente significativa entre os momentos 1 e 2 , sendo que o momento 2 apresentou valor maior em comparação ao momento 1. Entre os demais momentos, não foram observadas diferenças estatisticamente significativos. Sendo assim, houve aumento da variável RE na segunda avaliação em comparação à primeira e, em seguida, esta variável se manteve constante. 
Quanto à variável DSC, houve diferença estatisticamente significativa entre os momentos 3 e 4 , sendo que o momento 4 apresentou valor maior em comparação ao momento 3. Entre os demais momentos, não foram observadas diferenças estatisticamente significativos. Sendo assim, houve aumento da variável DSC na quarta avaliação em comparação à terceira.

5.3 - Investigação da capacidade preditiva das ações do PFC em relação ao escore do DSC

A análise estatística dos dados a seguir foi realizada usando como base a amostra de 138 indivíduos que apresentavam os dados do escore do DSC.

Inicialmente, elaborou-se um modelo de regressão linear múltipla controlando o efeito da idade de início da intervenção com o escore do DSC como variável dependente e a porcentagem de ocorrência de cada função comunicativa no PFC como variáveis independentes. No entanto, este modelo apresentou violação do pressuposto de independência devido à presença de multicolinearidade entre as variáveis independentes, indicada pelos valores de fator de inflação de variância (FIV) $>10$ e valores de tolerância $<0,2$ na Tabela 6. 
Tabela 6 - Análise de multicolinearidade entre as variáveis independentes do modelo de regressão linear múltipla envolvendo cada função comunicativa no PFC.

\begin{tabular}{|c|c|c|c|}
\hline \multirow[t]{2}{*}{ Passo } & \multirow[t]{2}{*}{ Variável } & \multicolumn{2}{|c|}{ Estatísticas de colinearidade } \\
\hline & & Tolerância & FIV \\
\hline 1 & Idade & 1,000 & 1,000 \\
\hline \multirow[t]{21}{*}{2} & Idade & 0,800 & 1,250 \\
\hline & $\mathrm{PO}$ & 0,588 & 1,699 \\
\hline & RO & 0,303 & 3,306 \\
\hline & EX & 0,569 & 1,759 \\
\hline & EP & 0,398 & 2,514 \\
\hline & PR & 0,307 & 3,254 \\
\hline & PE & 0,114 & 8,763 \\
\hline & NA & 0,703 & 1,423 \\
\hline & PS & 0,782 & 1,279 \\
\hline & C & 0,184 & 5,432 \\
\hline & NF & 0,188 & 5,333 \\
\hline & PA & 0,400 & 2,500 \\
\hline & E & 0,587 & 1,704 \\
\hline & $\mathrm{JC}$ & 0,075 & 13,278 \\
\hline & RE & 0,321 & 3,114 \\
\hline & $\mathrm{PI}$ & 0,467 & 2,142 \\
\hline & $\mathrm{N}$ & 0,619 & 1,616 \\
\hline & $\mathrm{XP}$ & 0,122 & 8,181 \\
\hline & PC & 0,834 & 1,199 \\
\hline & AR & 0,816 & 1,226 \\
\hline & $\mathrm{J}$ & 0,127 & 7,857 \\
\hline
\end{tabular}

Legenda: FIV: fator de inflação de variância; PO: Pedido de Objeto; RO: Reconhecimento do outro; EX: Exclamativo; EP: Expressão de protesto; PR: Protesto; PE: Performativo; NA: Narrativo; PS: Pedido de rotina social; C: Comentário; NF: Não focalizado; PA: Pedido de ação; E: Exibição; JC: Jogo compartilhado; RE: Reativo; PI: Pedido de informação; N: Nomeação; XP: Exploratório; PC: Pedido de consentimento; AR: Auto regulatório; J: Jogo.

Os resultados da Tabela 6 demonstram que a variável JC apresentou FIV acima do tolerável $(F I V=13,278)$ e as variáveis $P E, C, N F, J C, X P$ e J apresentaram índice de tolerância abaixo do tolerável $(<0,2)$, indicando, portanto, multicolinearidade entre estas variáveis e violação do pressuposto de independência. 
Na Tabela 7 é apresentada uma análise fatorial com a distribuição das proporções de variância de cada variável independente de acordo com as dimensões nas quais estas proporções se acumularam. Num modelo sem violação do pressuposto de independência de variáveis e, portanto, sem multicolinearidade, as maiores proporções de variância de cada variável se concentrariam em diferentes dimensões. Entretanto, observa-se o contrário na Tabela 7, uma vez que algumas proporções de variância se concentram na mesma dimensão, por exemplo: RO, PR, PE, C, NF, JC, RE, XP e J se concentram na dimensão 22, sugerindo que estas variáveis apresentam 0 mesmo fator latente.

Tabela 7 - Análise fatorial para investigação de multicolinearidade entre as variáveis independentes do modelo.

\begin{tabular}{|c|c|c|c|c|c|c|c|c|c|c|c|}
\hline \multirow[t]{2}{*}{ Dimensão } & \multicolumn{11}{|c|}{ Proporções de variância } \\
\hline & Cte. & Idade & $\mathrm{PO}$ & $\mathrm{RO}$ & EX & EP & PR & PE & NA & PS & C \\
\hline 1 & 0,00 & 0,00 & 0,00 & 0,00 & 0,00 & 0,00 & 0,00 & 0,00 & 0,00 & 0,00 & 0,00 \\
\hline 2 & 0,00 & 0,00 & 0,00 & 0,00 & 0,01 & 0,00 & 0,01 & 0,00 & 0,00 & 0,01 & 0,01 \\
\hline 3 & 0,00 & 0,00 & 0,04 & 0,00 & 0,01 & 0,02 & 0,00 & 0,00 & 0,00 & 0,16 & 0,00 \\
\hline 4 & 0,00 & 0,00 & 0,01 & 0,00 & 0,01 & 0,00 & 0,00 & 0,00 & 0,01 & 0,03 & 0,00 \\
\hline 5 & 0,00 & 0,00 & 0,00 & 0,00 & 0,01 & 0,00 & 0,00 & 0,00 & 0,39 & 0,02 & 0,00 \\
\hline 6 & 0,00 & 0,00 & 0,01 & 0,01 & 0,01 & 0,01 & 0,00 & 0,00 & 0,16 & 0,12 & 0,00 \\
\hline 7 & 0,00 & 0,00 & 0,00 & 0,00 & 0,03 & 0,03 & 0,00 & 0,00 & 0,03 & 0,00 & 0,00 \\
\hline 8 & 0,00 & 0,00 & 0,11 & 0,00 & 0,13 & 0,02 & 0,01 & 0,00 & 0,03 & 0,06 & 0,00 \\
\hline 9 & 0,00 & 0,00 & 0,05 & 0,01 & 0,01 & 0,01 & 0,00 & 0,01 & 0,00 & 0,06 & 0,00 \\
\hline 10 & 0,00 & 0,00 & 0,07 & 0,00 & 0,17 & 0,02 & 0,02 & 0,01 & 0,01 & 0,02 & 0,00 \\
\hline 11 & 0,00 & 0,00 & 0,01 & 0,01 & 0,00 & 0,03 & 0,02 & 0,00 & 0,00 & 0,00 & 0,00 \\
\hline 12 & 0,00 & 0,00 & 0,00 & 0,00 & 0,03 & 0,01 & 0,01 & 0,01 & 0,00 & 0,03 & 0,01 \\
\hline 13 & 0,00 & 0,00 & 0,03 & 0,00 & 0,04 & 0,00 & 0,05 & 0,00 & 0,00 & 0,01 & 0,00 \\
\hline 14 & 0,00 & 0,00 & 0,07 & 0,00 & 0,00 & 0,00 & 0,05 & 0,01 & 0,00 & 0,21 & 0,00 \\
\hline 15 & 0,00 & 0,00 & 0,10 & 0,01 & 0,04 & 0,00 & 0,07 & 0,01 & 0,03 & 0,02 & 0,00 \\
\hline 16 & 0,00 & 0,00 & 0,02 & 0,01 & 0,00 & 0,10 & 0,01 & 0,00 & 0,01 & 0,05 & 0,00 \\
\hline 17 & 0,00 & 0,00 & 0,02 & 0,00 & 0,03 & 0,10 & 0,02 & 0,00 & 0,02 & 0,01 & 0,02 \\
\hline 18 & 0,00 & 0,00 & 0,05 & 0,23 & 0,01 & 0,01 & 0,02 & 0,00 & 0,00 & 0,06 & 0,00 \\
\hline 19 & 0,00 & 0,00 & 0,03 & 0,00 & 0,00 & 0,00 & 0,00 & 0,00 & 0,02 & 0,01 & 0,18 \\
\hline 20 & 0,00 & 0,01 & 0,01 & 0,02 & 0,08 & 0,07 & 0,04 & 0,04 & 0,00 & 0,01 & 0,01 \\
\hline 21 & 0,00 & 0,98 & 0,00 & 0,01 & 0,01 & 0,00 & 0,00 & 0,04 & 0,01 & 0,00 & 0,01 \\
\hline 22 & 1,00 & 0,00 & 0,36 & 0,68 & 0,36 & 0,55 & 0,67 & 0,87 & 0,27 & 0,12 & 0,74 \\
\hline
\end{tabular}


Tabela 7. (Continuação)

\begin{tabular}{|c|c|c|c|c|c|c|c|c|c|c|}
\hline $\mathrm{NF}$ & PA & $E$ & $\mathrm{JC}$ & $\mathrm{RE}$ & $\mathrm{PI}$ & $\mathrm{N}$ & $X P$ & PC & AR & $\mathrm{J}$ \\
\hline 0,00 & 0,00 & 0,00 & 0,00 & 0,00 & 0,00 & 0,00 & 0,00 & 0,00 & 0,00 & 0,00 \\
\hline 0,00 & 0,00 & 0,01 & 0,00 & 0,01 & 0,04 & 0,01 & 0,00 & 0,00 & 0,04 & 0,00 \\
\hline 0,00 & 0,01 & 0,00 & 0,00 & 0,00 & 0,01 & 0,01 & 0,00 & 0,20 & 0,00 & 0,00 \\
\hline 0,01 & 0,01 & 0,08 & 0,00 & 0,01 & 0,00 & 0,18 & 0,00 & 0,01 & 0,07 & 0,00 \\
\hline 0,00 & 0,00 & 0,02 & 0,00 & 0,00 & 0,00 & 0,03 & 0,00 & 0,01 & 0,12 & 0,00 \\
\hline 0,00 & 0,00 & 0,00 & 0,00 & 0,00 & 0,02 & 0,04 & 0,00 & 0,14 & 0,09 & 0,00 \\
\hline 0,00 & 0,04 & 0,05 & 0,00 & 0,06 & 0,01 & 0,00 & 0,00 & 0,02 & 0,00 & 0,01 \\
\hline 0,00 & 0,01 & 0,04 & 0,00 & 0,01 & 0,01 & 0,00 & 0,00 & 0,05 & 0,05 & 0,00 \\
\hline 0,00 & 0,00 & 0,08 & 0,00 & 0,00 & 0,01 & 0,01 & 0,00 & 0,07 & 0,21 & 0,00 \\
\hline 0,01 & 0,00 & 0,01 & 0,00 & 0,00 & 0,02 & 0,02 & 0,01 & 0,04 & 0,00 & 0,00 \\
\hline 0,01 & 0,03 & 0,00 & 0,00 & 0,13 & 0,03 & 0,06 & 0,00 & 0,05 & 0,03 & 0,00 \\
\hline 0,05 & 0,01 & 0,00 & 0,00 & 0,00 & 0,02 & 0,06 & 0,00 & 0,00 & 0,13 & 0,02 \\
\hline 0,00 & 0,00 & 0,22 & 0,00 & 0,00 & 0,01 & 0,15 & 0,01 & 0,02 & 0,00 & 0,01 \\
\hline 0,00 & 0,05 & 0,00 & 0,00 & 0,01 & 0,05 & 0,07 & 0,01 & 0,01 & 0,00 & 0,01 \\
\hline 0,04 & 0,05 & 0,04 & 0,00 & 0,04 & 0,00 & 0,01 & 0,00 & 0,03 & 0,01 & 0,00 \\
\hline 0,00 & 0,00 & 0,01 & 0,02 & 0,04 & 0,15 & 0,01 & 0,01 & 0,21 & 0,01 & 0,01 \\
\hline 0,01 & 0,19 & 0,02 & 0,00 & 0,00 & 0,05 & 0,00 & 0,01 & 0,02 & 0,06 & 0,00 \\
\hline 0,04 & 0,00 & 0,03 & 0,00 & 0,01 & 0,02 & 0,00 & 0,00 & 0,03 & 0,00 & 0,01 \\
\hline 0,00 & 0,02 & 0,02 & 0,01 & 0,00 & 0,14 & 0,00 & 0,00 & 0,04 & 0,08 & 0,01 \\
\hline 0,01 & 0,00 & 0,00 & 0,01 & 0,02 & 0,01 & 0,00 & 0,06 & 0,00 & 0,00 & 0,03 \\
\hline 0,02 & 0,00 & 0,02 & 0,01 & 0,01 & 0,01 & 0,00 & 0,00 & 0,00 & 0,01 & 0,02 \\
\hline 0,80 & 0,58 & 0,35 & 0,93 & 0,64 & 0,37 & 0,34 & 0,88 & 0,04 & 0,08 & 0,85 \\
\hline
\end{tabular}

Legenda: Cte: constante; PO: Pedido de Objeto; RO: Reconhecimento do outro; EX: Exclamativo; EP: Expressão de protesto; PR: Protesto; PE: Performativo; NA: Narrativo; PS: Pedido de rotina social; C: Comentário; NF: Não focalizado; PA: Pedido de ação; E: Exibição; JC: Jogo compartilhado; RE: Reativo; PI: Pedido de informação; N: Nomeação; XP: Exploratório; PC: Pedido de consentimento; AR: Auto regulatório; J: Jogo.

Uma vez que a violação do pressuposto de independência e a presença de multicolinearidade comprometem a confiabilidade e a generalização do modelo de regressão e tendo em vista o pressuposto teórico de que as funções comunicativas consideradas como mais interpessoais $(\mathrm{FI})$ exercem maior relevância no DSC, optou-se pela elaboração de um novo modelo de regressão linear múltipla controlando o efeito da idade de início da intervenção com o escore do DSC como variável dependente e a porcentagem de ocorrência das FI no PFC como variáveis independentes. 
O novo modelo, apresentado na Tabela 8, cumpriu todos os pressupostos para a sua validação e generalização, incluindo o pressuposto de independência de variáveis preditoras.

Tabela 8 - Modelo linear de regressão múltipla das porcentagens de ocorrência das funções comunicativas consideradas como mais interativas do PFC como preditoras do escore do DSC controlando os efeitos de idade.

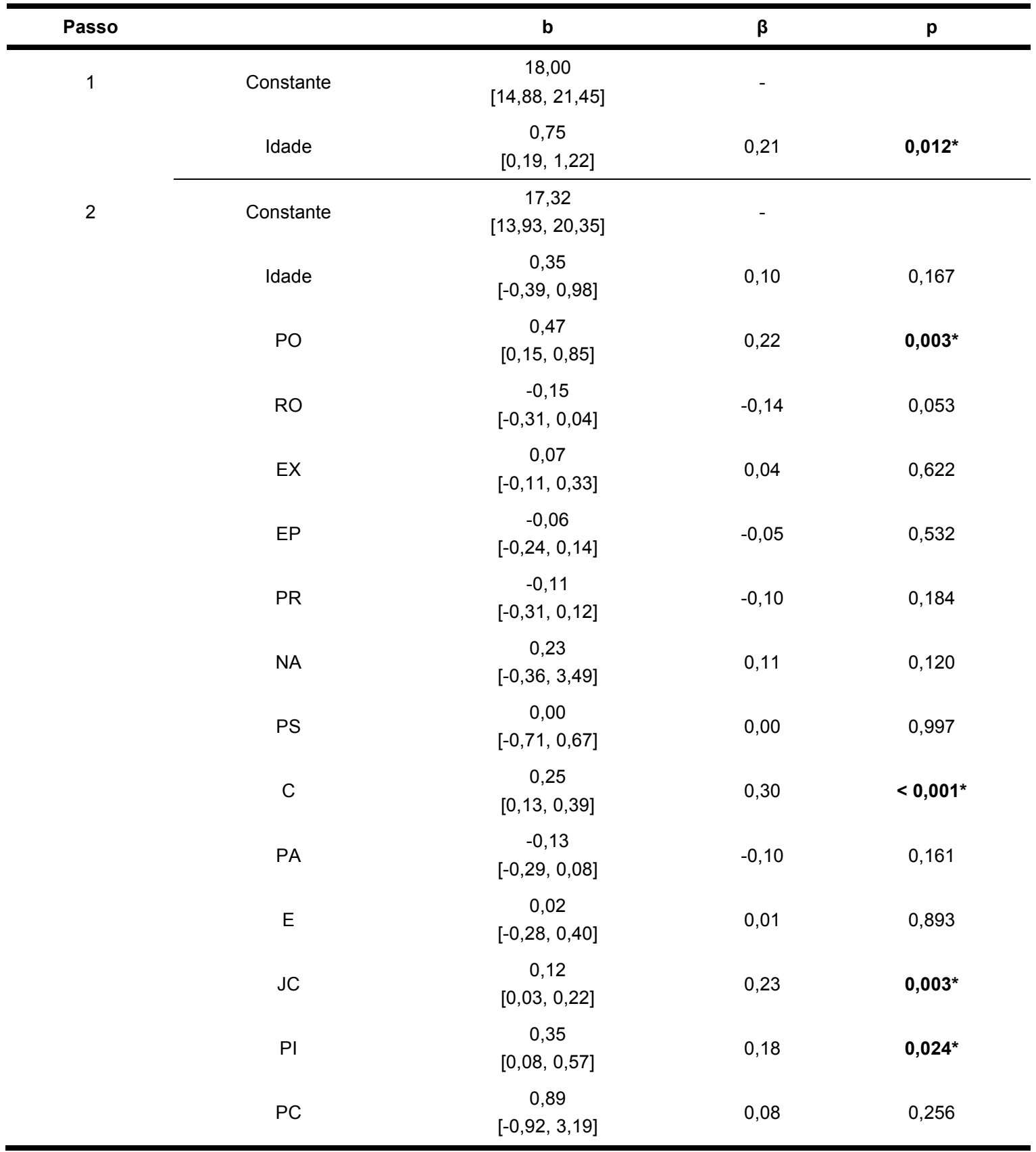

$r^{2}=0,05(p=0,012)$ para Passo $1 ; r^{2}=0,39(p<0,001)$ para Passo 2

Legenda: PO: Pedido de Objeto; RO: Reconhecimento do outro; EX: Exclamativo; EP: Expressão de protesto; PR: Protesto; NA: Narrativo; PS: Pedido de rotina social; C: Comentário; PA: Pedido de ação; E: Exibição; JC: Jogo compartilhado; PI: Pedido de informação; PC: Pedido de consentimento. 
Os resultados da Tabela 8 demonstram que o modelo linear de regressão foi significativamente melhor que a média da variável dependente na tarefa de prever o desempenho da amostra no escore do DSC, sendo que, controlando o efeito da idade, as FI foram capazes de explicar $39 \%\left(r^{2}=0,39\right)$ da variância observada no escore do DSC.

Dentre as FI, observou-se que as funções $\mathrm{PO}, \mathrm{C}$, JC e PI foram preditoras estatisticamente significativas do escore do DSC. O coeficiente não padronizado b indica que, estatisticamente, mantendo-se os demais valores constantes:

- O aumento de $1 \%$ de PO induz a esperar um aumento de 0,47 no escore do DSC;

- $\mathrm{O}$ aumento de $1 \%$ de $\mathrm{C}$ induz a esperar um aumento de 0,25 no escore do DSC;

- O aumento de $1 \%$ de JC induz a esperar um aumento de 0,12 no escore do DSC;

- O aumento de $1 \%$ de PI induz a esperar um aumento de 0,35 no escore do DSC.

As demais FI do PFC não foram preditoras estatisticamente significativas do escore do DSC.

É importante considerar que, apesar da significância estatística das relações entre o DSC e o PFC (coeficiente b), não é correto considerar qualquer relação causal entre as variáveis. Esses coeficientes indicam, apenas, que há coocorrência de resultados. Ou seja, não podemos afirmar que o aumento de $1 \%$ na ocorrência da função comunicativa "Pedido de Objeto" cause o aumento do escore do DSC em 0,47 , ou vice versa. 
5.4 - Comparação das faixas etárias em relação ao PFC e o escore do DSC

A análise estatística destes dados foi realizada usando como base a amostra de 155 indivíduos.

A Tabela 9 apresenta as medidas de tendência central e de dispersão dos parâmetros do PFC e do escore DSC de acordo com a faixa etária. Para comparação entre indivíduos de diferentes faixas etárias, utilizou-se teste de Kruskal-Wallis (não-paramétrico), uma vez que alguns grupos apresentaram baixo número amostral.

Tabela 9 - Valores descritivos e análise comparativa das idades em relação aos parâmetros do PFC e o escore do DSC.

\begin{tabular}{|c|c|c|c|c|c|c|c|}
\hline Variável & Faixa etária (anos) & Média & DP & Mediana & Mín. & Máx. & p \\
\hline \multirow{9}{*}{ PO } & 1 a 2 & $\begin{array}{c}2,00 \\
{[0,50,3,92]}\end{array}$ & 3,38 & $\begin{array}{c}0,00 \\
{[0,00,2,00]}\end{array}$ & 0,00 & 11,00 & \multirow{9}{*}{0,142} \\
\hline & 3 & $\begin{array}{c}1,37 \\
{[0,37,2,85]}\end{array}$ & 3,25 & $\begin{array}{c}0,00 \\
{[0,00,0,00]}\end{array}$ & 0,00 & 14,00 & \\
\hline & 4 & $\begin{array}{c}1,69 \\
{[1,05,2,38]}\end{array}$ & 2,61 & $\begin{array}{c}0,00 \\
{[0,00,0,00]}\end{array}$ & 0,00 & 10,00 & \\
\hline & 5 & $\begin{array}{c}0,86 \\
{[0,27,1,50]}\end{array}$ & 1,86 & $\begin{array}{c}0,00 \\
{[0,00,0,00]}\end{array}$ & 0,00 & 7,00 & \\
\hline & 6 & $\begin{array}{c}3,00 \\
{[1,37,4,85]}\end{array}$ & 4,62 & $\begin{array}{c}0,00 \\
{[0,00,0,00]}\end{array}$ & 0,00 & 15,00 & \\
\hline & 7 & $\begin{array}{c}3,14 \\
{[0,86,5,43]}\end{array}$ & 6,09 & $\begin{array}{c}0,00 \\
{[0,00,0,00]}\end{array}$ & 0,00 & 16,00 & \\
\hline & 8 & $\begin{array}{c}3,17 \\
{[0,00,6,33]}\end{array}$ & 7,76 & $\begin{array}{c}0,00 \\
{[0,00,0,00]}\end{array}$ & 0,00 & 19,00 & \\
\hline & 9 & $\begin{array}{c}0,00 \\
{[0,00,0,00]}\end{array}$ & 0,00 & $\begin{array}{c}0,00 \\
{[0,00,0,00]}\end{array}$ & 0,00 & 0,00 & \\
\hline & $\geq 10$ & $\begin{array}{c}0,00 \\
{[0,00,0,00]}\end{array}$ & 0,00 & $\begin{array}{c}0,00 \\
{[0,00,0,00]}\end{array}$ & 0,00 & 0,00 & \\
\hline \multirow{2}{*}{ RO } & 1 a 2 & $\begin{array}{c}6,92 \\
{[3,50,10,83]}\end{array}$ & 6,61 & $\begin{array}{c}4,50 \\
{[2,00,14,00]}\end{array}$ & 0,00 & 21,00 & \multirow{2}{*}{0,692} \\
\hline & 3 & $\begin{array}{c}6,48 \\
{[4,37,8,93]}\end{array}$ & 6,05 & $\begin{array}{c}6,00 \\
{[6,00,6,00]}\end{array}$ & 0,00 & 27,00 & \\
\hline
\end{tabular}




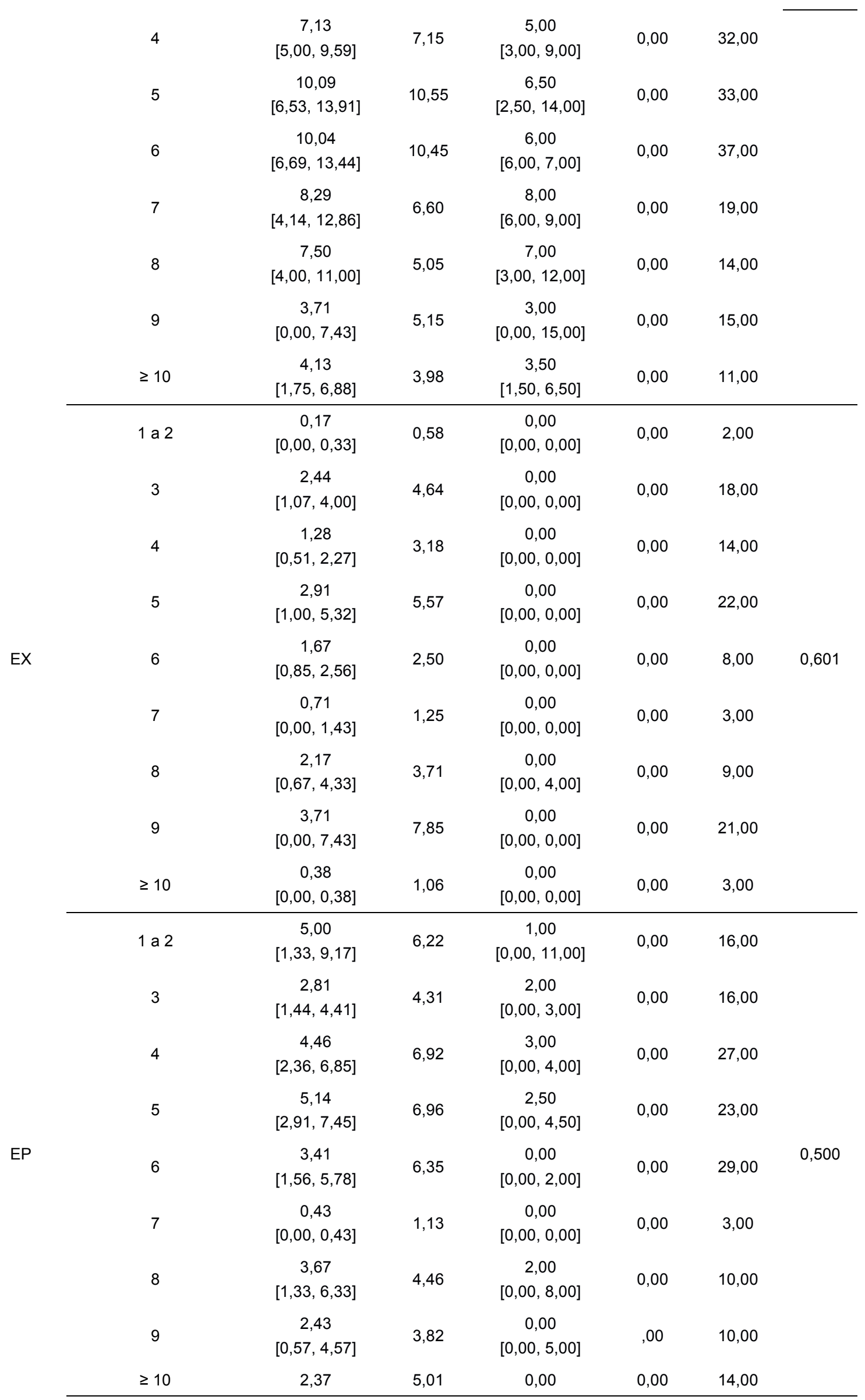




\begin{tabular}{|c|c|c|c|c|c|c|c|}
\hline & & {$[0,00,4,75]$} & & {$[0,00,0,00]$} & & & \\
\hline & 1 a 2 & $\begin{array}{c}4,25 \\
{[2,08,6,67]}\end{array}$ & 4,58 & $\begin{array}{c}3,50 \\
{[0,00,6,50]}\end{array}$ & 0,00 & 12,00 & \multirow{9}{*}{0,582} \\
\hline & 3 & $\begin{array}{c}5,19 \\
{[2,93,7,96]}\end{array}$ & 6,84 & $\begin{array}{c}4,00 \\
{[3,00,4,00]}\end{array}$ & 0,00 & 30,00 & \\
\hline & 4 & $\begin{array}{c}5,05 \\
{[3,46,6,72]}\end{array}$ & 6,63 & $\begin{array}{c}2,00 \\
{[0,00,6,00]}\end{array}$ & 0,00 & 29,00 & \\
\hline & 5 & $\begin{array}{c}4,59 \\
{[2,55,7,09]}\end{array}$ & 6,44 & $\begin{array}{c}3,00 \\
{[0,00,4,00]}\end{array}$ & 0,00 & 27,00 & \\
\hline \multirow[t]{9}{*}{ PR } & 6 & $\begin{array}{c}7,22 \\
{[4,41,10,37]}\end{array}$ & 8,82 & $\begin{array}{c}3,00 \\
{[2,00,8,00]}\end{array}$ & 0,00 & 35,00 & \\
\hline & 7 & $\begin{array}{c}6,14 \\
{[1,00,14,86]}\end{array}$ & 10,71 & $\begin{array}{c}2,00 \\
{[0,00,6,00]}\end{array}$ & 0,00 & 30,00 & \\
\hline & 8 & $\begin{array}{c}5,83 \\
{[2,67,10,00]}\end{array}$ & 5,46 & $\begin{array}{c}4,00 \\
{[4,00,7,00]}\end{array}$ & 0,00 & 16,00 & \\
\hline & 9 & $\begin{array}{c}1,71 \\
{[0,57,3,00]}\end{array}$ & 2,63 & $\begin{array}{c}0,00 \\
{[0,00,3,00]}\end{array}$ & 0,00 & 7,00 & \\
\hline & $\geq 10$ & $\begin{array}{c}1,75 \\
{[0,63,3,00]}\end{array}$ & 2,43 & $\begin{array}{c}0,00 \\
{[0,00,4,00]}\end{array}$ & 0,00 & 5,00 & \\
\hline & 1 a 2 & $\begin{array}{c}9,50 \\
{[5,67,13,25]}\end{array}$ & 7,88 & $\begin{array}{c}5,50 \\
{[3,00,17,50]}\end{array}$ & 0,00 & 22,00 & \multirow{9}{*}{0,263} \\
\hline & 3 & $\begin{array}{c}10,26 \\
{[7,37,13,30]}\end{array}$ & 9,04 & $\begin{array}{c}8,00 \\
{[5,00,13,00]}\end{array}$ & 0,00 & 33,00 & \\
\hline & 4 & $\begin{array}{c}15,38 \\
{[11,15,19,74]}\end{array}$ & 12,89 & $\begin{array}{c}13,00 \\
{[11,00,17,00]}\end{array}$ & 0,00 & 47,00 & \\
\hline & 5 & $\begin{array}{c}11,68 \\
{[7,45,16,00]}\end{array}$ & 13,44 & $\begin{array}{c}9,00 \\
{[2,50,12,50]}\end{array}$ & 0,00 & 44,00 & \\
\hline \multirow[t]{8}{*}{ PE } & 6 & $\begin{array}{c}13,78 \\
{[9,70,18,30]}\end{array}$ & 13,95 & $\begin{array}{c}10,00 \\
{[5,00,17,00]}\end{array}$ & 0,00 & 47,00 & \\
\hline & 7 & $\begin{array}{c}18,71 \\
{[6,34,35,00]}\end{array}$ & 21,40 & $\begin{array}{c}14,00 \\
{[3,00,28,00]}\end{array}$ & 0,00 & 59,00 & \\
\hline & 8 & $\begin{array}{c}9,00 \\
{[1,67,20,08]}\end{array}$ & 14,17 & $\begin{array}{c}4,00 \\
{[0,00,21,50]}\end{array}$ & 0,00 & 37,00 & \\
\hline & 9 & $\begin{array}{c}21,29 \\
{[10,96,33,14]}\end{array}$ & 17,83 & $\begin{array}{c}17,00 \\
{[8,00,28,00]}\end{array}$ & 3,00 & 51,00 & \\
\hline & $\geq 10$ & $\begin{array}{c}22,88 \\
{[14,00,32,38]}\end{array}$ & 16,22 & $\begin{array}{c}20,00 \\
{[11,50,31,50]}\end{array}$ & 3,00 & 54,00 & \\
\hline & 1 a 2 & $\begin{array}{c}0,00 \\
{[0,00,0,00]}\end{array}$ & 0,00 & $\begin{array}{c}0,00 \\
{[0,00,0,00]}\end{array}$ & 0,00 & 0,00 & \multirow{6}{*}{$0,016^{*}$} \\
\hline & 3 & $\begin{array}{c}0,00 \\
{[0,00,0,00]}\end{array}$ & 0,00 & $\begin{array}{c}0,00 \\
{[0,00,0,00]}\end{array}$ & 0,00 & 0,00 & \\
\hline & 4 & $\begin{array}{c}0,10 \\
{[0,00,0,21]}\end{array}$ & 0,64 & $\begin{array}{c}0,00 \\
{[0,00,0,00]}\end{array}$ & 0,00 & 4,00 & \\
\hline \multirow{3}{*}{ NA } & 5 & $\begin{array}{c}0,14 \\
{[0,00,0,27]}\end{array}$ & 0,64 & $\begin{array}{c}0,00 \\
{[0,00,0,00]}\end{array}$ & 0,00 & 3,00 & \\
\hline & 6 & $\begin{array}{c}1,63 \\
{[0,00,3,26]}\end{array}$ & 8,47 & $\begin{array}{c}0,00 \\
{[0,00,0,00]}\end{array}$ & 0,00 & 44,00 & \\
\hline & 7 & $\begin{array}{c}0,00 \\
{[0,00,0,00]}\end{array}$ & 0,00 & $\begin{array}{c}0,00 \\
{[0,00,0,00]}\end{array}$ & 0,00 & 0,00 & \\
\hline
\end{tabular}




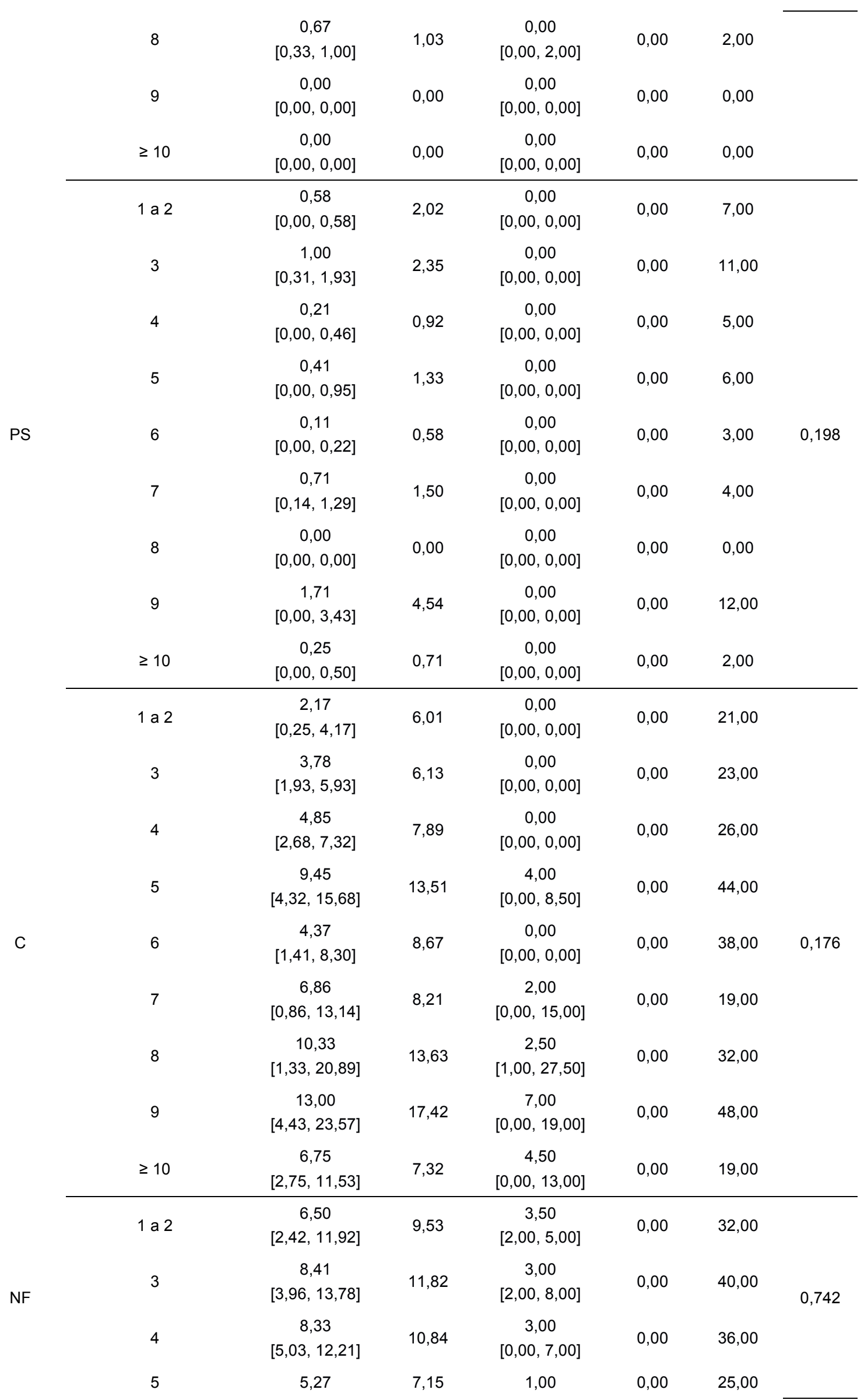




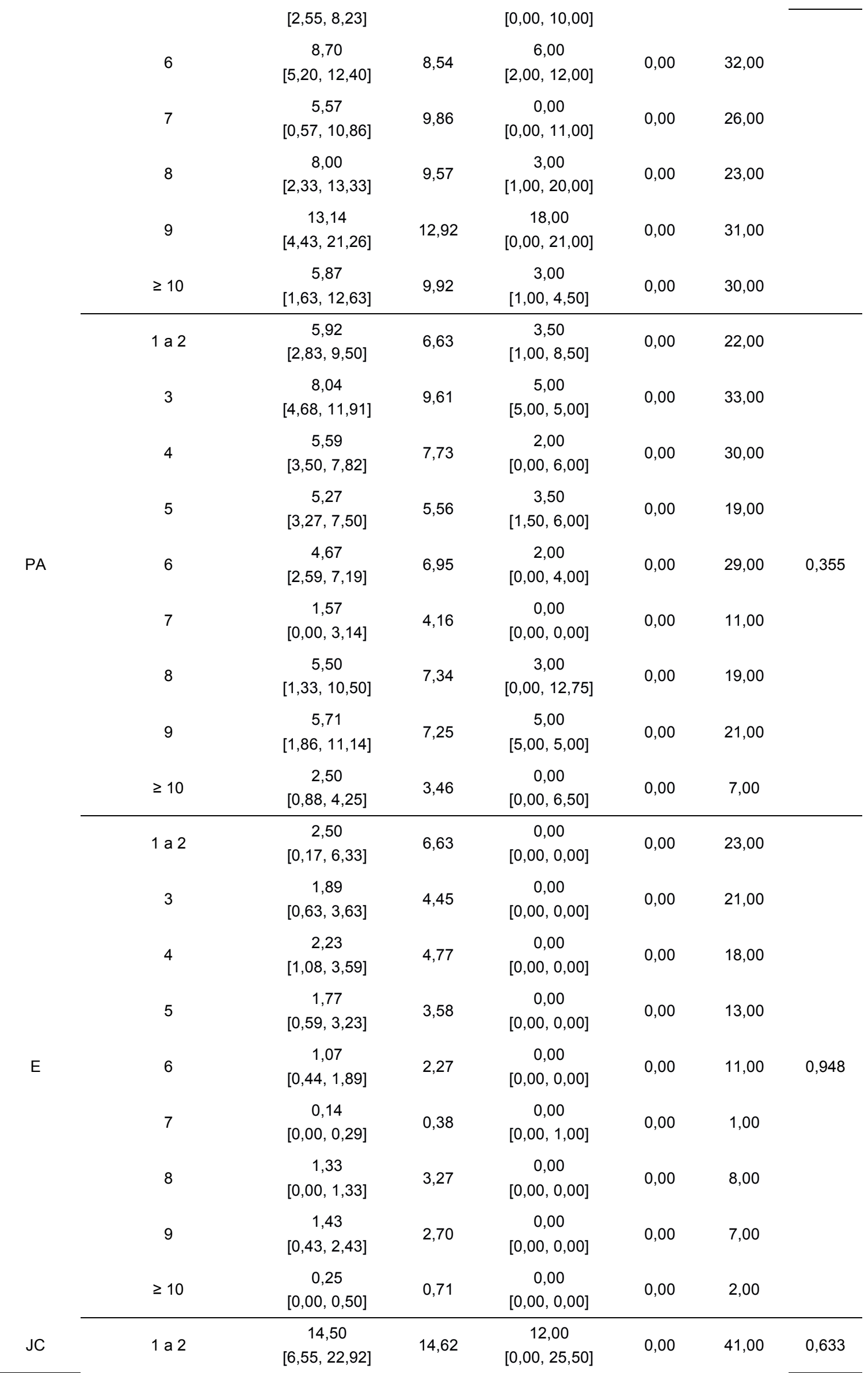




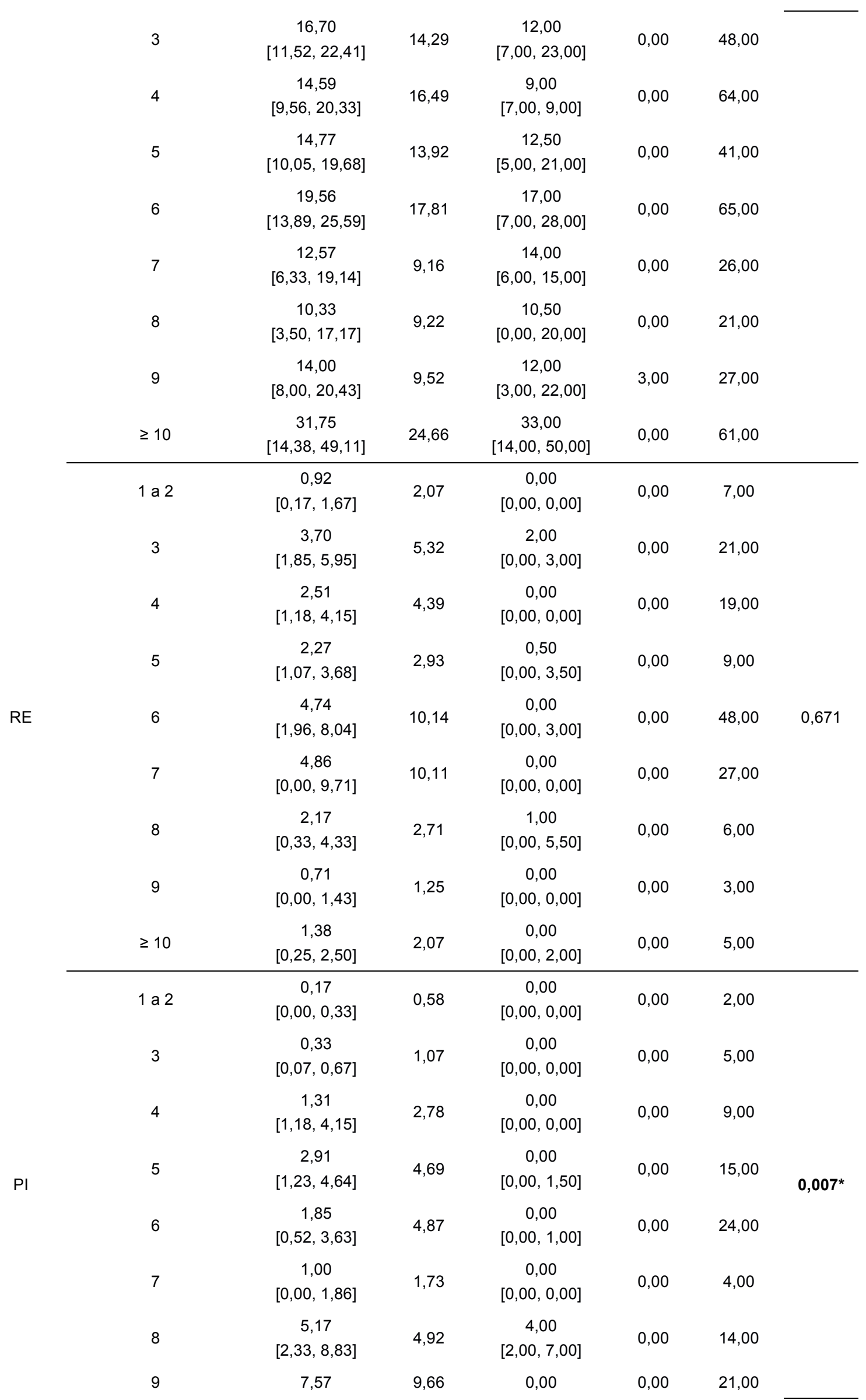




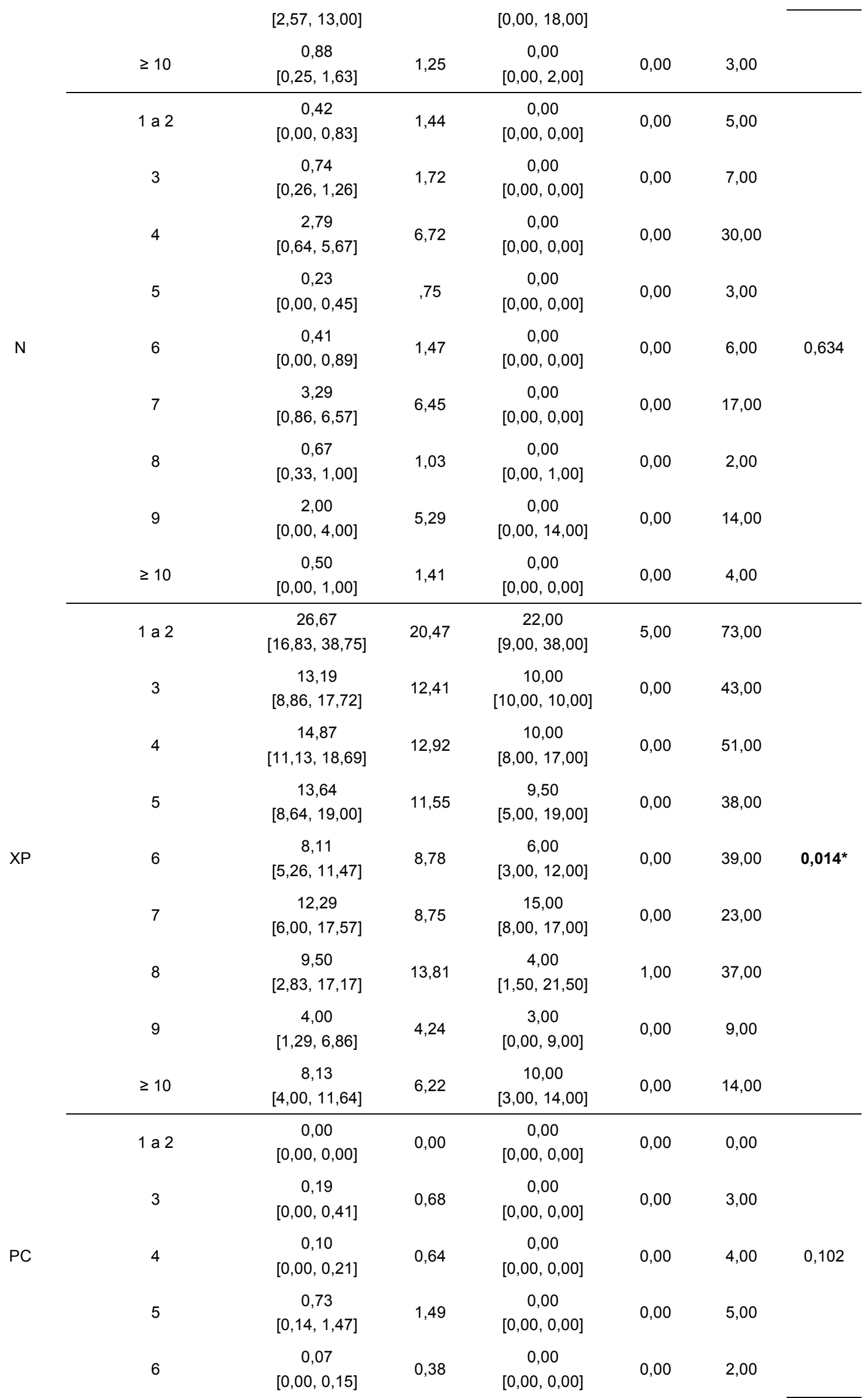




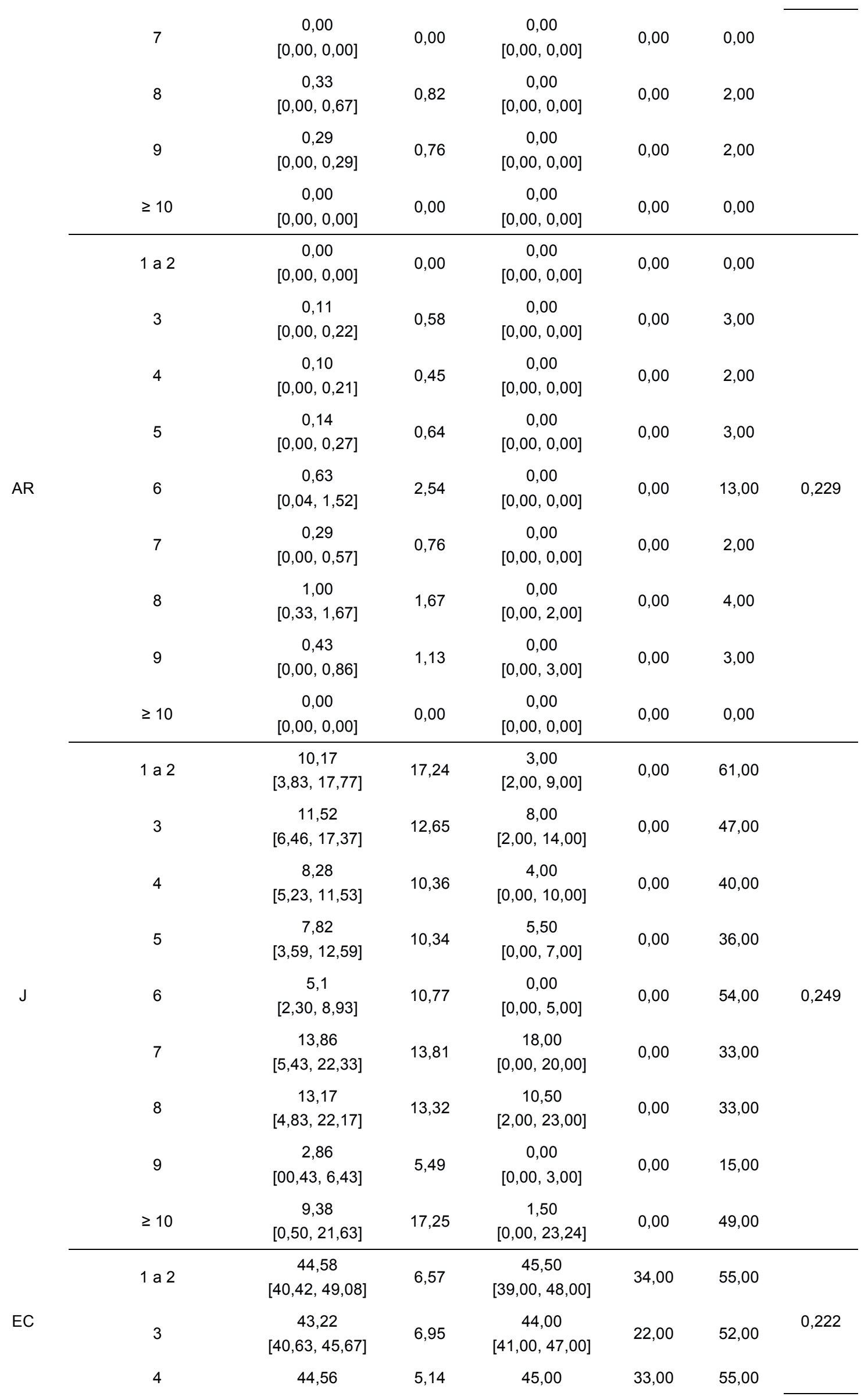




\begin{tabular}{|c|c|c|c|c|c|c|c|}
\hline & \multicolumn{2}{|r|}{$[42,87,46,23]$} & \multicolumn{2}{|r|}{$[44,00,47,00]$} & & & \\
\hline & 5 & $\begin{array}{c}48,23 \\
{[45,14,51,37]}\end{array}$ & 7,70 & $\begin{array}{c}48,00 \\
{[46,00,48,00]}\end{array}$ & 35,00 & 70,00 & \\
\hline & 6 & $\begin{array}{c}46,15 \\
{[44,07,48,19]}\end{array}$ & 6,67 & $\begin{array}{c}45,00 \\
{[44,00,47,00]}\end{array}$ & 34,00 & 61,00 & \\
\hline & 7 & $\begin{array}{c}44,86 \\
{[40,29,48,57]}\end{array}$ & 6,31 & $\begin{array}{c}47,00 \\
{[47,00,48,00]}\end{array}$ & 34,00 & 51,00 & \\
\hline & 8 & $\begin{array}{c}47,67 \\
{[41,83,53,37]}\end{array}$ & 7,31 & $\begin{array}{c}47,50 \\
{[42,00,53,50]}\end{array}$ & 37,00 & 59,00 & \\
\hline & 9 & $\begin{array}{c}40,57 \\
{[35,00,46,35]}\end{array}$ & 9,55 & $\begin{array}{c}38,00 \\
{[34,00,46,00]}\end{array}$ & 28,00 & 57,00 & \\
\hline & $\geq 10$ & $\begin{array}{c}42,38 \\
{[39,75,44,88]}\end{array}$ & 4,63 & $\begin{array}{c}43,00 \\
{[41,50,43,50]}\end{array}$ & 34,00 & 50,00 & \\
\hline & 1 a 2 & $\begin{array}{c}9,33 \\
{[0,42,21,92]}\end{array}$ & 20,80 & $\begin{array}{c}0,00 \\
{[0,00,0,00]}\end{array}$ & 0,00 & 64,00 & \\
\hline & 3 & $\begin{array}{c}15,63 \\
{[5,76,28,41]}\end{array}$ & 26,41 & $\begin{array}{c}0,00 \\
{[0,00,6,00]}\end{array}$ & 0,00 & 100,00 & \\
\hline & 4 & $\begin{array}{c}17,82 \\
{[11,08,25,41]}\end{array}$ & 23,38 & $\begin{array}{c}4,00 \\
{[0,00,19,00]}\end{array}$ & 0,00 & 86,00 & \\
\hline & 5 & $\begin{array}{c}24,82 \\
{[13,36,37,37]}\end{array}$ & 28,02 & $\begin{array}{c}10,00 \\
{[0,00,41,50]}\end{array}$ & 0,00 & 87,00 & \\
\hline \multirow[t]{9}{*}{ MVE } & 6 & $\begin{array}{c}19,15 \\
{[11,37,27,55]}\end{array}$ & 25,59 & $\begin{array}{c}6,00 \\
{[4,00,8,00]}\end{array}$ & 0,00 & 85,00 & $0,007^{*}$ \\
\hline & 7 & $\begin{array}{c}19,00 \\
{[6,43,37,00]}\end{array}$ & 26,68 & $\begin{array}{c}9,00 \\
{[1,00,19,00]}\end{array}$ & 0,00 & 77,00 & \\
\hline & 8 & $\begin{array}{c}40,50 \\
{[28,50,53,67]}\end{array}$ & 19,61 & $\begin{array}{c}39,50 \\
{[28,00,51,00]}\end{array}$ & 16,00 & 74,00 & \\
\hline & 9 & $\begin{array}{c}51,29 \\
{[27,07,76,00]}\end{array}$ & 30,93 & $\begin{array}{c}62,00 \\
{[32,00,68,00]}\end{array}$ & 14,00 & 95,00 & \\
\hline & $\geq 10$ & $\begin{array}{c}21,25 \\
{[7,13,38,95]}\end{array}$ & 26,07 & $\begin{array}{c}16,50 \\
{[0,00,30,00]}\end{array}$ & 0,00 & 77,00 & \\
\hline & 1 a 2 & $\begin{array}{c}28,75 \\
{[18,42,40,25]}\end{array}$ & 18,76 & $\begin{array}{c}24,00 \\
{[16,00,44,50]}\end{array}$ & 4,00 & 58,00 & \multirow{9}{*}{0,208} \\
\hline & 3 & $\begin{array}{c}22,85 \\
{[16,37,29,99]}\end{array}$ & 17,36 & $\begin{array}{c}19,00 \\
{[14,00,28,00]}\end{array}$ & 0,00 & 67,00 & \\
\hline & 4 & $\begin{array}{c}19,79 \\
{[15,21,24,55]}\end{array}$ & 15,87 & $\begin{array}{c}15,00 \\
{[10,00,26,00]}\end{array}$ & 0,00 & 50,00 & \\
\hline & 5 & $\begin{array}{c}20,64 \\
{[14,41,27,55]}\end{array}$ & 18,30 & $\begin{array}{c}18,00 \\
{[14,00,20,50]}\end{array}$ & 0,00 & 65,00 & \\
\hline \multirow[t]{5}{*}{ MVO } & 6 & $\begin{array}{c}20,37 \\
{[15,22,25,96]}\end{array}$ & 13,25 & $\begin{array}{c}19,00 \\
{[19,00,19,00]}\end{array}$ & 0,00 & 59,00 & \\
\hline & 7 & $\begin{array}{c}15,86 \\
{[8,29,23,29]}\end{array}$ & 11,87 & $\begin{array}{c}15,00 \\
{[3,00,29,00]}\end{array}$ & 0,00 & 31,00 & \\
\hline & 8 & $\begin{array}{c}11,67 \\
{[4,17,20,00]}\end{array}$ & 11,57 & $\begin{array}{c}10,50 \\
{[1,00,22,50]}\end{array}$ & 0,00 & 26,00 & \\
\hline & 9 & $\begin{array}{c}13,14 \\
{[7,43,19,57]}\end{array}$ & 10,42 & $\begin{array}{c}12,00 \\
{[11,00,15,00]}\end{array}$ & 0,00 & 31,00 & \\
\hline & $\geq 10$ & $\begin{array}{c}9,25 \\
{[5,50,13,75]}\end{array}$ & 7,07 & $\begin{array}{c}9,00 \\
{[6,00,11,00]}\end{array}$ & 0,00 & 23,00 & \\
\hline
\end{tabular}




\begin{tabular}{|c|c|c|c|c|c|c|c|}
\hline & 1 a 2 & $\begin{array}{c}87,08 \\
{[73,12,95,40]}\end{array}$ & 17,70 & $\begin{array}{c}93,50 \\
{[87,50,95,50]}\end{array}$ & 36,00 & 100,00 & \\
\hline & 3 & $\begin{array}{c}88,63 \\
{[80,68,94,89]}\end{array}$ & 19,48 & $\begin{array}{c}97,00 \\
{[95,00,100]}\end{array}$ & 25,00 & 100,00 & \\
\hline & 4 & $\begin{array}{c}90,44 \\
{[85,92,94,28]}\end{array}$ & 12,44 & $\begin{array}{c}97,00 \\
{[96,00,97,00]}\end{array}$ & 57,00 & 100,00 & \\
\hline & 5 & $\begin{array}{c}82,45 \\
{[74,89,89,47]}\end{array}$ & 18,64 & $\begin{array}{c}88,50 \\
{[78,50,95,00]}\end{array}$ & 34,00 & 100,00 & \\
\hline \multirow[t]{9}{*}{ MG } & 6 & $\begin{array}{c}92,00 \\
{[87,56,95,67]}\end{array}$ & 9,96 & $\begin{array}{c}96,00 \\
{[95,00,96,00]}\end{array}$ & 59,00 & 100,00 & 0,120 \\
\hline & 7 & $\begin{array}{c}91,43 \\
{[85,71,97,00]}\end{array}$ & 9,03 & $\begin{array}{c}91,00 \\
{[89,00,100]}\end{array}$ & 79,00 & 100,00 & \\
\hline & 8 & $\begin{array}{c}82,50 \\
{[69,03,92,17]}\end{array}$ & 14,49 & $\begin{array}{c}86,50 \\
{[78,00,91,00]}\end{array}$ & 56,00 & 97,00 & \\
\hline & 9 & $\begin{array}{c}76,57 \\
{[65,57,87,43]}\end{array}$ & 16,77 & $\begin{array}{c}82,00 \\
{[67,00,86,00]}\end{array}$ & 50,00 & 100,00 & \\
\hline & $\geq 10$ & $\begin{array}{c}94,38 \\
{[92,75,96,25]}\end{array}$ & 3,34 & $\begin{array}{c}94,50 \\
{[92,00,96,00]}\end{array}$ & 90,00 & 100,00 & \\
\hline & 1 a 2 & $\begin{array}{c}45,83 \\
{[35,64,56,08]}\end{array}$ & 20,85 & $\begin{array}{c}50,50 \\
{[38,50,53,00]}\end{array}$ & 11,00 & 86,00 & \\
\hline & 3 & $\begin{array}{c}50,63 \\
{[42,87,58,76]}\end{array}$ & 21,81 & $\begin{array}{c}49,00 \\
{[40,00,56,00]}\end{array}$ & 15,00 & 98,00 & \\
\hline & 4 & $\begin{array}{c}46,21 \\
{[39,04,53,46]}\end{array}$ & 22,34 & $\begin{array}{c}48,00 \\
{[45,00,49,00]}\end{array}$ & 8,00 & 89,00 & \\
\hline & 5 & $\begin{array}{c}59,09 \\
{[49,57,70,09]}\end{array}$ & 20,46 & $\begin{array}{c}58,00 \\
{[51,00,65,00]}\end{array}$ & 20,00 & 100,00 & \\
\hline \multirow[t]{8}{*}{$\mathrm{Al}$} & 6 & $\begin{array}{c}57,33 \\
{[50,73,63,90]}\end{array}$ & 20,32 & $\begin{array}{c}57,00 \\
{[48,00,69,00]}\end{array}$ & 16,00 & 95,00 & 0,226 \\
\hline & 7 & $\begin{array}{c}41,43 \\
{[34,71,49,43]}\end{array}$ & 12,75 & $\begin{array}{c}38,00 \\
{[33,00,43,00]}\end{array}$ & 28,00 & 64,00 & \\
\hline & 8 & $\begin{array}{c}60,00 \\
{[48,67,72,33]}\end{array}$ & 15,79 & $\begin{array}{c}58,50 \\
{[46,50,75,00]}\end{array}$ & 37,00 & 86,00 & \\
\hline & 9 & $\begin{array}{c}56,86 \\
{[34,52,76,82]}\end{array}$ & 28,47 & $\begin{array}{c}64,00 \\
{[50,00,69,00]}\end{array}$ & 6,00 & 95,00 & \\
\hline & $\geq 10$ & $\begin{array}{c}52,63 \\
{[37,46,68,25]}\end{array}$ & 23,65 & $\begin{array}{c}51,00 \\
{[31,50,70,50]}\end{array}$ & 25,00 & 90,00 & \\
\hline & 1 a 2 & $\begin{array}{c}7,48 \\
{[6,62,8,43]}\end{array}$ & 1,89 & $\begin{array}{c}7,00 \\
{[6,50,7,80]}\end{array}$ & 5,40 & 12,20 & \\
\hline & 3 & $\begin{array}{c}8,73 \\
{[8,04,9,47]}\end{array}$ & 1,82 & $\begin{array}{c}8,60 \\
{[8,40,8,80]}\end{array}$ & 6,00 & 12,80 & \\
\hline & 4 & $\begin{array}{c}8,56 \\
{[7,68,9,54]}\end{array}$ & 3,40 & $\begin{array}{c}7,20 \\
{[7,00,9,20]}\end{array}$ & 2,60 & 18,80 & \\
\hline \multirow[t]{4}{*}{ NA/M } & 5 & $\begin{array}{c}8,67 \\
{[7,39,9,95]}\end{array}$ & 3,48 & $\begin{array}{c}8,10 \\
{[6,60,10,10]}\end{array}$ & 3,60 & 17,00 & 0,263 \\
\hline & 6 & $\begin{array}{c}8,82 \\
{[7,65,10,04]}\end{array}$ & 2,83 & $\begin{array}{c}8,60 \\
{[8,00,9,80]}\end{array}$ & 3,40 & 13,80 & \\
\hline & 7 & $\begin{array}{c}10,00 \\
{[7,57,13,15]}\end{array}$ & 4,24 & $\begin{array}{c}9,20 \\
{[6,80,13,20]}\end{array}$ & 6,20 & 18,00 & \\
\hline & 8 & 10,73 & 2,90 & 9,70 & 8,60 & 16,20 & \\
\hline
\end{tabular}




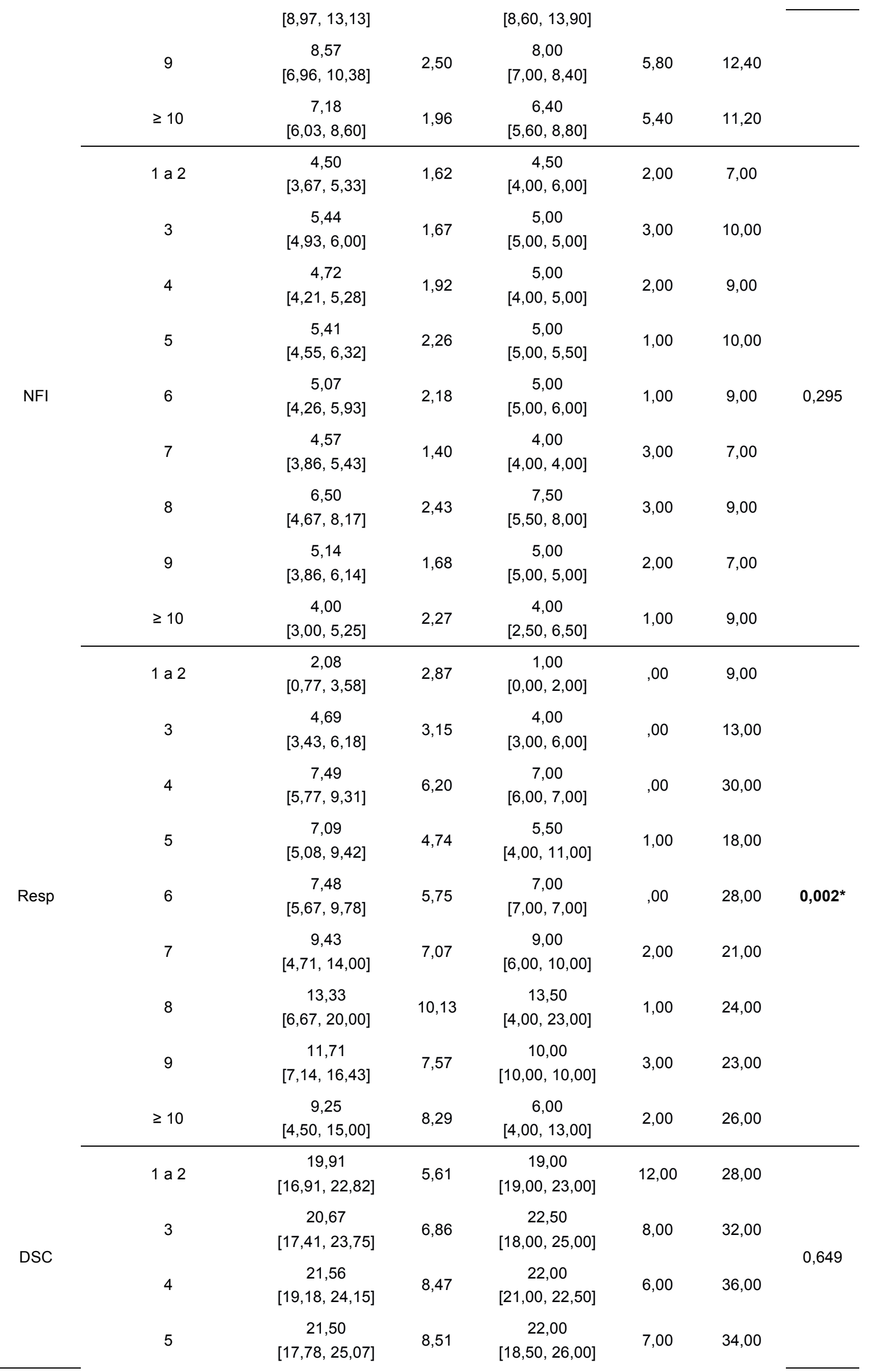




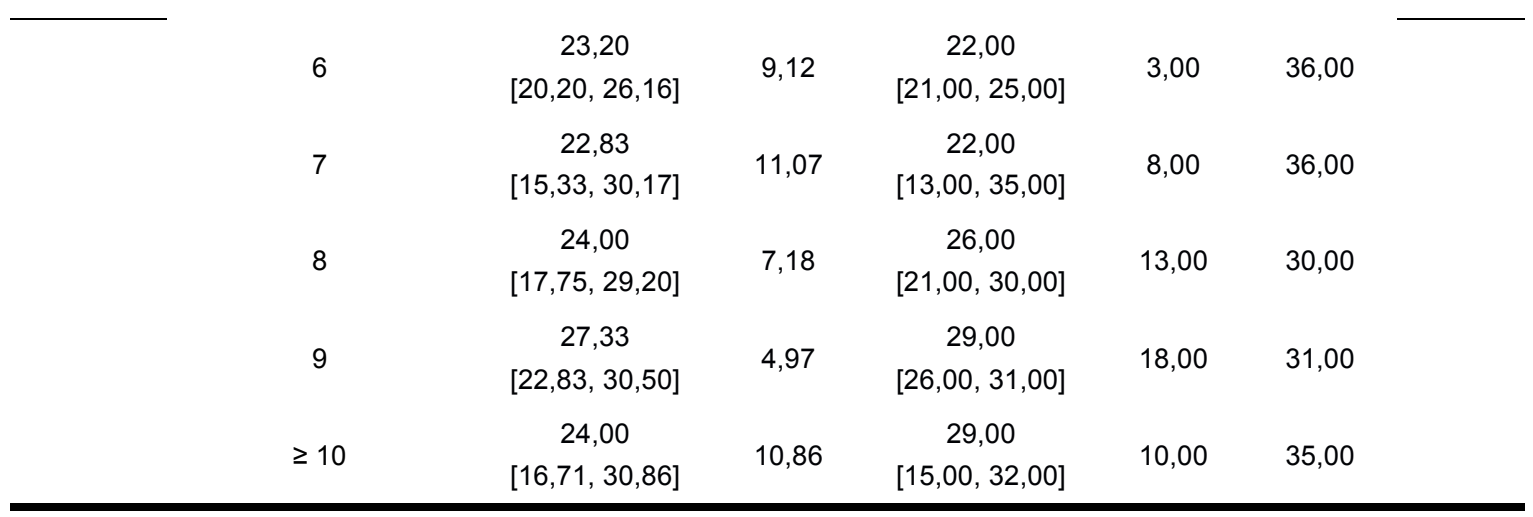

Teste de Kruskal-Wallis.

Legenda: * - valor estatisticamente significativo no nível de 5\% ( $p \leq 0,05)$ DP: Desvio padrão; Mín.: Mínimo; Máx:: Máximo; PO: Pedido de Objeto; RO: Reconhecimento do outro; EX: Exclamativo; EP: Expressão de protesto; PR: Protesto; PE: Performativo; NA: Narrativo; PS: Pedido de rotina social; C: Comentário; NF: Não focalizado; PA: Pedido de ação; E: Exibição; JC: Jogo compartilhado; RE: Reativo; PI: Pedido de informação; N: Nomeação; XP: Exploratório; PC: Pedido de consentimento; AR: Auto regulatório; J: Jogo; EC: Espaço comunicativo; MVE: Meio comunicativo verbal; MVO: Meio comunicativo vocal; MG: Meio comunicativo gestual; Al: Atos Interativos; NA/M: Número de atos por minuto; NFI: Número de funções consideradas como mais interativas; RESP: Número de respostas; DSC: Desempenho Sócio Cognitivo.

Os resultados da Tabela 9 demonstram que, os seguintes parâmetros apresentaram diferença estatisticamente significativas entre as faixas etárias:

NA, PI, XP, MVE e Resp.

Utilizou-se a análise post hoc com teste de Dunn com correção de Bonferroni para múltiplas comparações para identificar entre quais duplas de faixas etárias seriam observadas diferenças estatisticamente significativas nestas variáveis. O tamanho do efeito da diferença entre as faixas etárias foi medido por meio do cálculo do coeficiente $r$ (Rosenthal, 1991). 
Tabela 10 - Análise post hoc para os parâmetros que apresentaram diferenças estatisticamente significativas entre as faixas etárias.

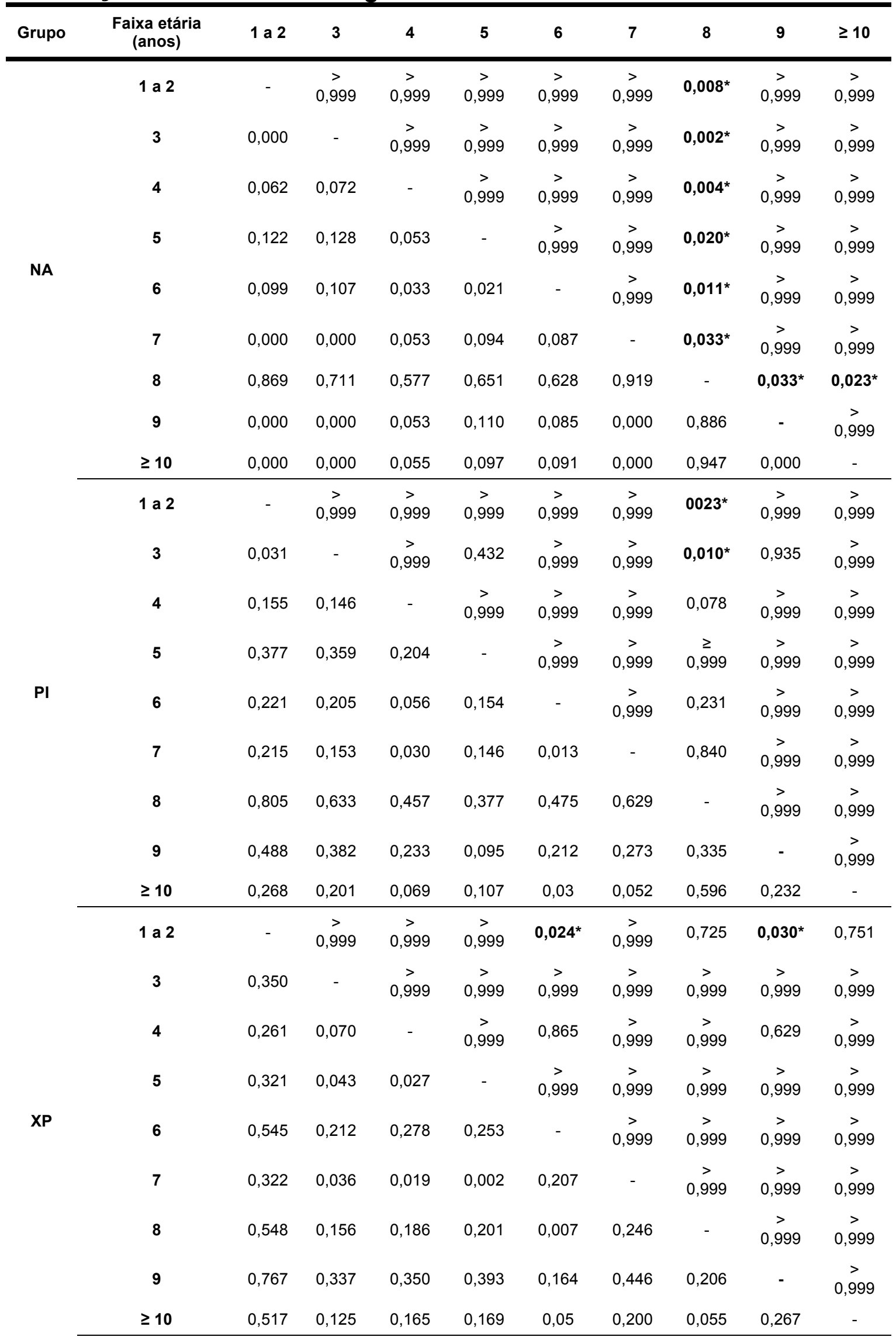




\begin{tabular}{|c|c|c|c|c|c|c|c|c|c|c|}
\hline & 1 a 2 & - & $\begin{array}{c}> \\
0,999\end{array}$ & $\begin{array}{c}> \\
0,999\end{array}$ & $\begin{array}{c}> \\
0,999\end{array}$ & $\overrightarrow{>}>\overrightarrow{9} 99$ & $\begin{array}{c}> \\
0,999\end{array}$ & 0,084 & $0,019^{*}$ & $\begin{array}{c}> \\
0,999\end{array}$ \\
\hline & 3 & 0,129 & - & $\overrightarrow{0,999}$ & $\begin{array}{c}> \\
0,999\end{array}$ & $\overrightarrow{>}$ & $\overrightarrow{0,999}$ & 0,212 & $0,045^{*}$ & $\begin{array}{c}> \\
0,999\end{array}$ \\
\hline & 4 & 0,201 & 0,095 & - & $\begin{array}{c}> \\
0,999\end{array}$ & $\begin{array}{c}> \\
0,999\end{array}$ & $\begin{array}{c}> \\
0,999\end{array}$ & 0,601 & 0,150 & $\begin{array}{c}> \\
0,999\end{array}$ \\
\hline & 5 & 0,353 & 0,229 & 0,128 & - & $\begin{array}{c}> \\
0,999\end{array}$ & $\begin{array}{c}> \\
0,999\end{array}$ & $\begin{array}{c}> \\
0,999\end{array}$ & $\begin{array}{c}> \\
0,999\end{array}$ & $\stackrel{>}{0,999}$ \\
\hline \multirow[t]{9}{*}{ MVE } & 6 & 0,272 & 0,155 & 0,057 & 0,075 & - & $\begin{array}{c}> \\
0,999\end{array}$ & $\begin{array}{c}> \\
0,999\end{array}$ & 0,448 & $\begin{array}{c}> \\
0,999\end{array}$ \\
\hline & 7 & 0,359 & 0,188 & 0,098 & 0,003 & 0,063 & - & $\overrightarrow{0,999}$ & $\begin{array}{c}> \\
0,999\end{array}$ & $\begin{array}{c}> \\
0,999\end{array}$ \\
\hline & 8 & 0,718 & 0,479 & 0,357 & 0,321 & 0,360 & 0,387 & - & $\begin{array}{l}\overrightarrow{>} \\
0,999\end{array}$ & $\begin{array}{c}> \\
0,999\end{array}$ \\
\hline & 9 & 0,795 & 0,554 & 0,422 & 0,389 & 0,422 & 0,437 & 0,061 & - & 0,999 \\
\hline & $\geq 10$ & 0,312 & 0,150 & 0,062 & 0,045 & 0,020 & 0,056 & 0,455 & 0,505 & - \\
\hline & 1 a 2 & - & $\begin{array}{l}> \\
0,999\end{array}$ & $0,022^{*}$ & $0,048^{*}$ & $0,022^{*}$ & 0,103 & $0,035^{*}$ & $0,009^{*}$ & 0,163 \\
\hline & 3 & 0,320 & - & $\overrightarrow{0,999}$ & $\begin{array}{c}> \\
0,999\end{array}$ & $\begin{array}{c}> \\
0,999\end{array}$ & $\begin{array}{c}> \\
0,999\end{array}$ & $\begin{array}{c}> \\
0,999\end{array}$ & 0,529 & $\begin{array}{c}> \\
0,999\end{array}$ \\
\hline & 4 & 0,480 & 0,211 & - & $\begin{array}{l}> \\
0,999\end{array}$ & $\begin{array}{c}> \\
0,999\end{array}$ & $\begin{array}{c}> \\
0,999\end{array}$ & $\begin{array}{c}\overrightarrow{>} \\
0,999\end{array}$ & $\begin{array}{l}> \\
0,999\end{array}$ & 0,999 \\
\hline & 5 & 0,551 & 0,224 & 0,010 & - & $\overrightarrow{0,999}$ & $\overrightarrow{0,999}$ & $\begin{array}{l}\overrightarrow{>} \\
0,999\end{array}$ & $\overrightarrow{0,999}$ & $\begin{array}{l}> \\
0,999\end{array}$ \\
\hline \multirow[t]{5}{*}{ Resp } & 6 & 0,549 & 0,244 & 0,029 & 0,019 & - & $\begin{array}{c}> \\
0,999\end{array}$ & $\begin{array}{c}> \\
0,999\end{array}$ & $\begin{array}{c}> \\
0,999\end{array}$ & $\begin{array}{c}> \\
0,999\end{array}$ \\
\hline & 7 & 0,684 & 0,290 & 0,103 & 0,114 & 0,092 & - & $\begin{array}{c}\overrightarrow{>} \\
0,999\end{array}$ & $\begin{array}{l}\overrightarrow{>} \\
0,999\end{array}$ & $\begin{array}{c}> \\
0,999\end{array}$ \\
\hline & 8 & 0,778 & 0,366 & 0,176 & 0,204 & 0,177 & 0,115 & - & $\overrightarrow{0,999}$ & 0,999 \\
\hline & 9 & 0,838 & 0,418 & 0,217 & 0,250 & 0,218 & 0,154 & 0,041 & - & 0,999 \\
\hline & $\geq 10$ & 0,635 & 0,250 & 0,062 & 0,063 & 0,045 & 0,064 & 0,182 & 0,220 & - \\
\hline
\end{tabular}

Teste de Dunn com correção de Bonferroni para múltiplas comparações.

Os valores acima da diagonal principal da tabela indicam os valores de $p$, enquanto os valores abaixo da diagonal principal indicam os tamanhos dos efeitos.

Legenda: * - valor estatisticamente significativo no nível de $5 \%(p \leq 0,05)$; NA: Narrativa; PI: Pedido de Informação; XP: Exploratório; MVE: Meio comunicativo verbal; Resp: Respostas.

Quanto à variável NA, houve diferença estatisticamente significativa entre a faixa etária de 8 anos e as demais faixas etárias, sendo que a faixa etária de 8 anos apresentou maior porcentagem para esta variável em comparação às demais faixas etárias. Entre as demais faixas etárias, não foram observadas diferenças estatisticamente significativas. Sendo assim, a faixa etária de 8 anos apresentou maior porcentagem de NA em comparação às demais faixas etárias e estas foram semelhantes entre si. 
Quanto à variável $\mathrm{PI}$, houve diferença estatisticamente significativa entre a faixa etária de 8 anos e as faixas etárias de 1 a 2 anos e 3 anos, sendo que a faixa etária de 8 anos apresentou maior porcentagem para esta variável em comparação às faixas etárias de 1 a 2 e 3 anos. Entre os demais pares de faixas etárias, não foram observadas diferenças estatisticamente significativas. Sendo assim, a faixa etária de 8 anos apresentou maior porcentagem de $\mathrm{PI}$ em comparação às faixas etárias de 1 a 2 e 3 anos e foi semelhante em comparação às demais faixas etárias. As demais faixas etárias foram semelhantes entre si quanto à porcentagem de $\mathrm{PI}$.

Quanto à variável $\mathrm{XP}$, houve diferença estatisticamente significativa entre a faixa etária de 1 a 2 anos e as faixas etárias de 6 e 9 anos, sendo que a faixa etária de 1 a 2 anos apresentou maior porcentagem para esta variável em comparação às faixas etárias de 6 e 9 anos. Entre os demais pares de faixas etárias, não foram observadas diferenças estatisticamente significativas. Sendo assim, a faixa etária de 1 a 2 anos apresentou maior porcentagem de XP em comparação às faixas etárias de 6 e 9 anos e foi semelhante em comparação às demais faixas etárias. As demais faixas etárias foram semelhantes entre si quanto à porcentagem de XP.

Quanto à variável MVE, houve diferença estatisticamente significativa entre a faixa etária de 9 anos e as faixas etárias de 1 a 2 anos e 3 anos, sendo que a faixa etária de 9 anos apresentou maior porcentagem para esta variável em comparação às faixas etárias de 1 a 2 e 3 anos. Entre os demais pares de faixas etárias, não foram observadas diferenças estatisticamente significativas. Sendo assim, a faixa etária de 9 anos apresentou maior porcentagem de MVE em comparação às faixas etárias de 1 a 2 e 3 anos e foi semelhante em 
comparação às demais faixas etárias. As demais faixas etárias foram semelhantes entre si quanto à porcentagem de MVE.

Na variável Resp houve diferença estatisticamente significativa entre as faixas etárias de 1 a 2 anos com 4, 5, 6, 8 e 9 anos. Entre os demais pares de faixas etárias, não foram observadas diferenças estatisticamente significativas. Sendo assim, pode-se dize que apenas as crianças menores (entre 1 e 2 anos) apresentaram menos respostas do que as crianças mais velhas, sem que tenha havido diferenças entre estas, a partir dos 4 anos o aumento apresentouse constante.

5.5 - Investigação da presença de correlação entre a evolução nos parâmetros do PFC e a idade de início da intervenção

A análise estatística dos dados referentes aos parâmetros do PFC e a idade de início da intervenção foi realizada usando como base a amostra de 34 indivíduos que possuíam dados relativos aos três primeiros anos de intervenção, ou seja, as seis primeiras avaliações e reavaliações.

A Tabela 11 apresenta a análise de correlação entre a evolução nos parâmetros do PFC e a idade de início da intervenção. Para esta análise, realizou-se o cálculo do coeficiente de correlação $(r)$ e do valor de p por meio do teste de correlação de Pearson, uma vez que o tamanho da amostra $(\mathrm{n}=$ 34) permite a utilização de testes paramétricos em virtude do Teorema Central do Limite. 
Tabela 11 - Análise de correlação entre a evolução nos parâmetros da prova de pragmática e a idade de início da intervenção.

\begin{tabular}{cccccc}
\hline Variáveis & & Al & NA/M & NFU & NFI \\
\hline \multirow{2}{*}{ Idade } & $\mathrm{r}$ & 0,315 & $\mathbf{- 0 , 3 4 9}$ & $-0,085$ & $-0,070$ \\
& & {$[0,019,0,556]$} & {$[-\mathbf{0 , 6 1 3 , 0 , 0 9 1}]$} & {$[-0,394,0,286]$} & {$[-0,385,0,274]$} \\
& $\mathrm{p}$ & 0,069 & $\mathbf{0 , 0 4 3}$ & 0,633 & 0,695 \\
\hline
\end{tabular}

Teste de correlação de Pearson $\left({ }^{\mathrm{a}}\right)$.

Legenda: *: Valor estatisticamente significativo no nível de $5 \%(p \leq 0,05)$; Al: Atos interativos; NA/M: Número de atos por minuto; NFU: Número de funções; NFI: Número de funções consideradas como mais interpessoais.

Os resultados da Tabela 11 demonstram que houve correlação estatisticamente significativa negativa entre o aumento do número de atos por minuto no PFC da $1^{\text {a }}$ para a $6^{\mathrm{a}}$ avaliação e a idade de início da intervenção. Sendo assim, observou-se correlação negativa entre as duas variáveis, isto é, o aumento do valor de uma variável se associou à diminuição do valor da outra variável.

5.6 - Investigação da presença de correlação entre o número de respostas no PFC e escore do DSC e porcentagem de atos interativos

A análise estatística destes dados foi realizada usando como base a amostra de 155 indivíduos.

A Tabela 12 apresenta a análise de correlação entre o número de respostas no PFC e escore do DSC e porcentagem de atos interativos. Para esta análise, realizou-se o cálculo do coeficiente de correlação ( $r$ ) e do valor de p por meio do teste de correlação de Pearson, uma vez que o tamanho da amostra $(n=138$ e $n=154$, sendo a exclusão de alguns indivíduos da amostra nas duas análises decorrente da ausência de dados em pelo menos uma das variáveis) permite a utilização de testes paramétricos em virtude do Teorema Central do Limite. 
Tabela 12 - Análise de correlação entre o número de respostas no PFC e o escore do DSC e porcentagem de atos interativos.

\begin{tabular}{|c|c|c|c|}
\hline Variáveis & & n & Pragmática - Número de respostas \\
\hline \multirow[t]{2}{*}{ Sócio-Cognitivo } & $r$ & 138 & $\begin{array}{c}0,364 \\
{[0,232,0,496]}\end{array}$ \\
\hline & $\mathrm{p}$ & & $<0,001^{*}$ \\
\hline \multirow[t]{2}{*}{$\begin{array}{l}\text { Pragmática - Atos } \\
\text { interativos }\end{array}$} & $r$ & 154 & $\begin{array}{c}0,285 \\
{[0,151,0,410]}\end{array}$ \\
\hline & $\mathrm{p}$ & & $<0,001^{*}$ \\
\hline
\end{tabular}

Teste de correlação de Pearson $\left({ }^{a}\right)$.

Legenda: *: Valor estatisticamente significativo no nível de $5 \%(p \leq 0,05)$.

Os resultados da Tabela 12 demonstram que houve correlação estatisticamente significativa positiva entre o número de respostas no PFC e o escore do DSC e a porcentagem de atos interativos. Sendo assim, observou-se correlação positiva entre as duas duplas de variáveis, isto é, o aumento do valor de uma variável se associou ao aumento do valor da outra variável, conforme demonstrado nas Figuras 31 e 32.

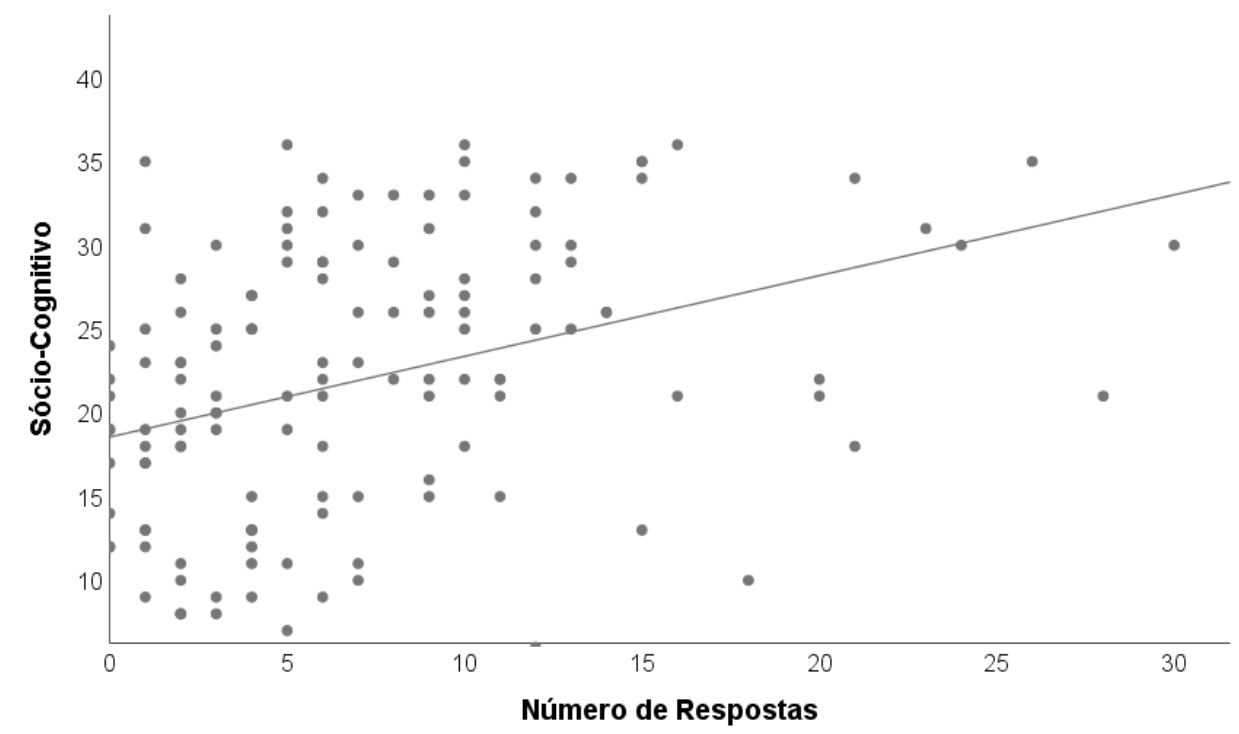

Figura 31 - Gráfico de dispersão do escore do DSC em função do número de respostas no PFC. 


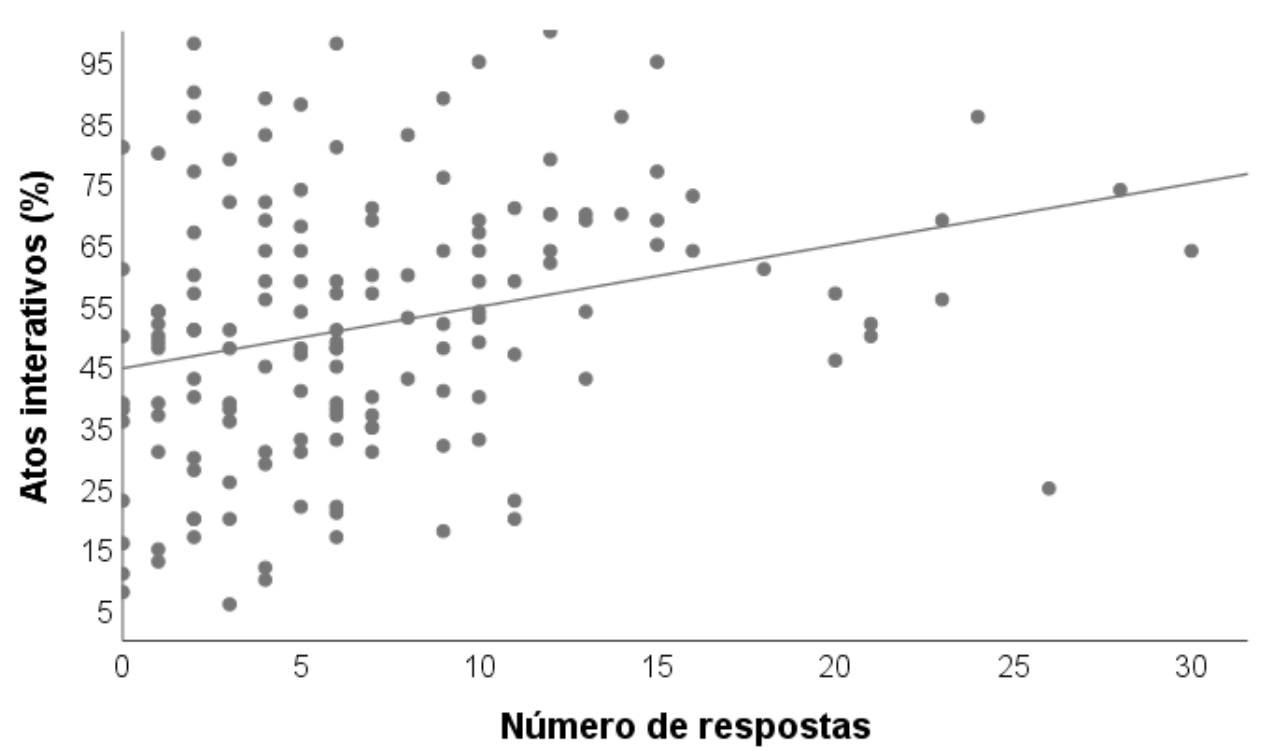

Figura 32 - Gráfico de dispersão da porcentagem de atos interativos em função do número de respostas no PFC. 


\section{6 - Discussão}

Quando comparamos a caracterização destes sujeitos com os dados daqueles analisados e publicados por Fernandes em 1996, é possível verificar uma diminuição na idade média de 8,3 para 5,5 , mostrando assim uma diminuição significativa da idade em que crianças com DEA são incluídas em processos de intervenção fonoaudiológica.

A ideia de que a intervenção precoce auxilia no melhor desenvolvimento é válida, porém, mais estudos são necessários para que essa hipótese seja realmente confirmada (Pasco, 2018). No entanto, assim como afirma Pasco (2018), com o diagnóstico precoce é possível diminuir a ansiedade e estresse apresentado pelos pais, assim como garantir àqueles que dependem do sistema público de saúde a conseguir um tratamento especializado antes do que vem ocorrendo atualmente.

Em uma revisão de literatura envolvendo intervenções relacionadas aos aspectos pragmáticos, os autores sugerem que a idade dos indivíduos, assim como o modelo da intervenção, não são tão significativas quanto ao envolvimento das crianças e de seus pais/responsáveis no processo de intervenção (Parsons et al. 2017). A inclusão total na intervenção da criança com DEA e seus pais podem maximizar os benefícios.

Analisando os dados relativos ao sexo destes sujeitos, entre 2011 e 2017, somente $14 \%$ eram do sexo feminino, representando uma diminuição considerável quando comparados aos dados do Estudo 1, no qual $21 \%$ eram do sexo feminino. Em 1996, Fernandes descreveu que $28 \%$ eram do sexo feminino. Esse dado novamente vai contra os dados encontrados na literatura 
(Baio et al., 2018) que ilustram um aumento na proporção do sexo feminino nos casos diagnosticados com DEA.

Estudos indicam que algumas meninas com DEA podem passar despercebidas pelos procedimentos diagnósticos atuais considerados como padrão-ouro e receberem menos diagnósticos, quando comparadas ao sexo masculino (Ratto et al., 2018; Young et al., 2018).

Isso pode estar relacionado às Influências socioculturais e familiares, como também ao modo em que as dificuldades relacionadas ao DEA são percebidas pelos responsáveis, sendo assim, necessária a realização de uma diferenciação nos procedimentos diagnósticos, levando em consideração às caraterísticas relacionadas ao sexo (Ratto et al., 2018; Young et al., 2018).

Uma dificuldade na realização dos estudos longitudinais, como pode ser observada na figura 33, é quantidade de amostras que são excluídas devido à falta de dados. Na literatura estatística há descrito metodologias para realizar comparações utilizando pressupostos para completar essas lacunas, contudo, por não haver outros estudos longitudinais como este, optou-se em manter somente os dados reais. 


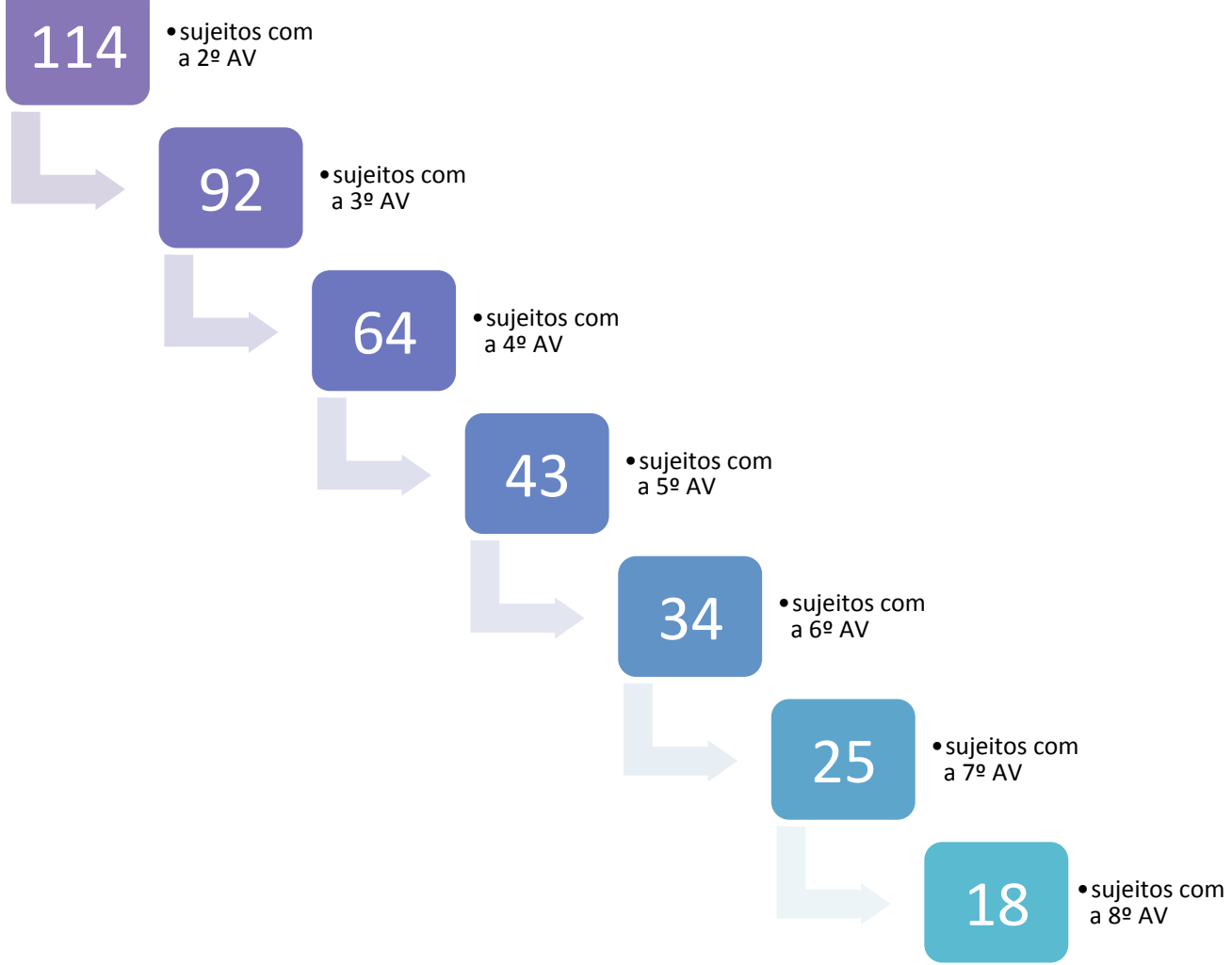

Figura 33 - Quantidade de pacientes que realizaram atendimento ao longo de quatro anos

Ao longo da coleta de dados surgiu a ideia de comparar a evolução dos sujeitos que realizaram 2 anos de terapia (4 avaliações), 3 anos de terapia (6 avaliações) e aqueles com 4 anos de terapia (8 avaliações), mas diante do baixo número de amostras, isso não foi possível.

Quando realizamos a comparação entre as 6 primeiras avaliações é possível observar que ao longo das avaliações, o meio verbal aumentou e os meios vocais e gestuais diminuíram. Os atos interativos, assim como o número de funções consideradas como mais interpessoais, aumentaram ao longo das avaliações. 
O mesmo aconteceu no estudo realizado por Cardoso e Fernandes (2006), que também mostrou um aumento da porcentagem de funções interpessoais após um ano de intervenção.

Na maioria das funções comunicativas é possível ver uma diferença entre a $4^{\mathrm{a}}$ avaliação quando comparada à $1^{\mathrm{a}}$. No geral, nas funções comunicativas mais interpessoais, a diferença representou um pequeno aumento e nas menos interpessoais, representou uma leve diminuição. llustrando o que esperamos de evolução com relação a esses aspectos.

Amato e Fernandes (2011), ao aplicar o PFC em crianças de 0 a 3 anos de idade constataram que com o avanço da idade há ampliação quantitativa e qualitativa das habilidades comunicativas.

Quando controlamos a covariável "idade de início", apenas três parâmetros representaram diferenças estatísticas significativas. A função comunicativa RE (reativo) e PE (performativo) apresentaram um aumento na segunda avaliação quando comparadas à primeira, mesmo sendo funções consideradas como menos interpessoais, o aumento na segunda avaliação pode representar uma melhora na ambientação da criança no ambiente terapêutico.

Novamente observamos uma mudança significativa na quarta avaliação, o DSC apresentou um aumento, representando assim uma melhora no desempenho sócio cognitivo no segundo ano de terapia.

Quando observamos uma violação do pressuposto de independência devido à presença de multicolinearidade, como ocorreu na Tabela 6, isso significa que, quando sempre que uma das variáveis se altera, outras também alteram seu valor, porém não é possível saber qual influência em qual. Neste 
caso as variáveis $\mathrm{PE}, \mathrm{C}, \mathrm{NF}, \mathrm{JC}, \mathrm{XP}$ e J sempre variam em conjunto, mas não é possível criar nenhuma análise em cima disto. Buscando uma explicação, realizou-se uma análise fatorial com a distribuição das proporções de variância de cada variável independente e nesta análise observou-se o contrário do que se esperava, ou seja, várias funções apresentaram o mesmo fator latente. Isso significa que determinadas funções estão representando coisas parecidas no perfil funcional da comunicação e com isso não é possível determinar a capacidade preditiva das ações do PFC em relação ao escore do DSC.

Para conseguir determinar quais as funções comunicativas que podem estar mais diretamente relacionadas ao aumento do escore do DSC, optou-se por utilizar somente as funções comunicativas consideradas como mais interpessoais e com isso foi possível observar (Tabela 8) que as funções PO, C, JC e PI são as que mais induzem a esperar um aumento no escore do DSC.

Como relatam Molini e Fernandes (2001) e Cardoso e Fernandes (2006), o desempenho sócio cognitivo e os aspectos funcionais da linguagem estão interligados, porém as mudanças nesses desempenhos podem não ser lineares. Como foi dito nos resultados, apesar da significância estatística das relações entre o DSC e o PFC (coeficiente b), é preciso levar em consideração que esses coeficientes indicam, apenas, que há coocorrência de resultados.

Um dos objetivos deste estudo foi analisar se as variáveis em análise estão relacionadas às respectivas idades. Com base na Tabela 9 constata-se que NA, PI, XP, MVE e Resp apresentaram resultados significativos.

Quando aplicamos outra análise nestas variáveis observamos que aos 8 anos foram verificadas as relações mais significativas, principalmente em relação às funções comunicativas NA e PI. Estas funções comunicativas são 
consideradas mais interpessoais, sendo a NA envolve uma complexidade linguística que exige diversos recursos da linguagem. Em uma recente revisão de literatura, Sng et al. (2018) identificaram que as inabilidades linguísticas de crianças autistas envolvem três aspectos fundamentais para a narrativa: essas crianças tendem a perseverar em um determinado tema; por outro lado, tendem também a não manter o foco, dificultando a troca de turnos e apresentam também dificuldades em fornecer informações novas relevantes, dificultando a interação dialógica. Entretanto, neste estudo não foram verificadas dificuldades relevantes de manutenção de contato ocular.

Quando observamos a função comunicativa XP, nota-se que a mesma ocorre mais entre 1 a 2 anos, o que é esperado, pois esta função representa a exploração do objeto de modo mais simples, no qual a criança coloca os objetos na boca, lambe ou fica explorando sem dar uma continuidade na brincadeira.

O MVE foi maior aos 9 anos quando comparada a faixa etária de 1 a 2 anos e 3 anos, ou seja, a verbalização foi estatisticamente significativa somente nessa comparação. Quando pensamos na verbalização realizada por crianças com desenvolvimento típico, como mostra o resultado da pesquisa de Amato e Fernandes (2011), notamos que essa diferença ocorreu tardiamente.

A variável Resp trouxe mais diferenças entre as idades comparadas, entretanto esse dado ilustra uma dificuldade dos sujeitos com DEA em realizar repostas adequadas e coerentes como uma criança de desenvolvimento típico, por mais que as respostas ocorram, esse número é menor do que o esperado para a idade. 
Assim como mostra o estudo de Sng et al. (2018), o qual traz que as crianças com DEA tendem a perseverar mais em um determinado assunto e a iniciar e a responder menos durante as conversas. Ao contrário do esperado, um número similar de turnos foi oferecido entre os parceiros, como também foi constatado nesta pesquisa ao analisar o espaço comunicativo utilizado (Tabela 4).

Seguindo a ideia das vantagens da intervenção precoce, buscou-se correlacionar a idade na qual a criança iniciou a terapia com alguns parâmetros avaliativos do PFC para constatação da evolução, como a porcentagem de atos interativos, o número de atos por minuto, número de funções comunicativas utilizadas e o número de funções consideradas como mais interpessoais. Sendo assim foi possível observar uma correlação significativa entre a idade de início e o número de atos comunicativos por minuto, ou seja, quanto menor a idade de início da terapia, maior o número de atos comunicativos apresentados pela criança.

Mesmo que não tenha apresentado um resultado significativo é possível observar também uma tendência à correlação negativa no número de funções e no número de funções interpessoais

Durante a tabulação de dados observou-se um padrão no qual o número de respostas estava relacionado a um maior escore no DSC, assim como, a um maior número de atos interativos. Pensando nisso realizou-se a investigação sobre a correlação entre esses dados, no qual a hipótese foi confirmada, ou seja, quanto maior o número de respostas, maior será o escore do DSC e a porcentagem de atos interativos. 
Esse dado chamou a atenção para o que Miilher e Fernandes (2013) também já haviam concluído sobre a importância de se considerar as respostas na análise do PFC. Atualmente quando realizamos a análise seguindo os critérios propostos por Fernandes (2004), com as alterações comprovadas no estudo de Porto et al. (2007), as respostas realizadas pelas crianças não entram na análise e mesmo assim, percebe-se a relação entre eles.

Uma vez que olhamos para a resposta da criança como uma participação da situação comunicativa (Miilher e Fernandes, 2013), nota-se como a interação pode ser considerada maior, ou seja, no PFC representado pelo aumento da porcentagem de atos comunicativos.

Considerando o fato de que, em uma análise com relação a linguagem de crianças com 3 anos, com desenvolvimento típico, foi observado que elas mais respondem do que iniciam a conversação e, raramente deixam de responder ao interlocutor (Hage et al., 2007). Considero importante a inclusão dos dados relativos às respostas apresentadas durante a avaliação do PFC em sua análise.

Como concluem Miilher e Fernandes (2013), considerar as respostas na avaliação do PFC de crianças com DEA fornece informações sobre a estrutura global das interações e as habilidades comunicativas mais amplas que possam realizam. Além disso, essa informação auxilia no planejamento terapêutico, pois, levando em consideração a assertividade e responsividade da criança é possível compreender com que tipo de comunicador está sendo realizada a interação e assim tornar a comunicação mais efetiva. 


\section{7 - Conclusão}

Analisando os dados do PFC e do DSC de forma longitudinal, comparando-os em seis momentos diferentes, foi possível observar que há evolução com relação à funcionalidade da comunicação e ao DSC ao longo do tratamento. Contudo, devido à falta de dados com relação a um período maior de tratamento fonoaudiológico de crianças com DEA fica difícil afirmar qual o maior pico de desenvolvimento e se há um platô dessa evolução.

Foi possível observar também que alguns dos parâmetros da prova do PFC são preditivos do DSC, confirmando que o desempenho sócio cognitivo e os aspectos funcionais da linguagem estão interligados.

Constatou-se que a idade de início da terapia fonoaudiológica está relacionada à melhora no desempenho e na evolução clínica, ou seja, quanto antes a criança iniciar o tratamento, melhor será a sua evolução clínica.

Nos parâmetros NA, PI, XP, MVE e Resp, foi possível observar que houve diferenças estatisticamente significativas entre as faixas etárias. Após análise detalhada destes parâmetros, as idades de 8 e 9 anos foram a faixa etária que apresentou maior porcentagem de ocorrências e de diferenças significativas; entretanto somente quando comparadas a faixa etária de 1 a 3 anos de idade.

O Parâmetro NA em específico apresentou aumento ao longo das faixas

etárias e aos 8 anos apresentou a maior porcentagem de ocorrência. O XP apresentou sua maior ocorrência entre 1 e 2 anos, o que vai de encontro ao esperado, sendo esta uma função comunicativa considerada como mais primitiva. Já o MVE, que está relacionado ao meio verbal, apresentou sua 
maior porcentagem de ocorrência aos 9 anos de idade em comparação às faixas etárias de 1 a 2 e 3 anos. No entanto, foi semelhante em comparação às demais faixas etárias. A variável Resp foi a que mais apresentou diferenças estatisticamente significativas, apresentando um aumento constante entre as faixas etárias.

Quando correlacionamos o número de respostas (Resp) apresentadas no PFC ao escore do DSC e a porcentagem de atos interativos, notamos a importância da utilização deste dado na análise do Perfil Funcional da Comunicação, no qual o aumento do número de respostas está diretamente relacionado a um maior escore do DCS e a um aumento da porcentagem de atos interativos.

Após todas essas análises é possível afirmar que a hipótese deste estudo, no sentido de que em três anos de terapia fonoaudiológica especializada nos DEA seria possível observar evolução clínica significativa, pôde ser confirmada. Quando analisamos os dados dos indivíduos que realizaram três anos seguidos de atendimento foi observado uma evolução no início do segundo ano de atendimento, o qual, na maioria dos casos, se manteve nas reavaliações seguintes. 


\section{LIMITAÇÕES}




\section{LIMITAÇÕES}

Devido ao grande número de lacunas identificadas ao longo da coleta de dados, a amostra reduziu-se consideravelmente. Sugere-se a análise longitudinal destes mesmos dados utilizando a metodologia estatisticamente recomendada para diminuir a perda de dados e o melhor aproveitamento da análise.

As dificuldades com os estudos longitudinais, muitas vezes não são descritas na literatura e em alguns casos necessitam de uma adaptação do foco principal.

No caso desta pesquisa, além de períodos de frustração essas limitações trouxeram também uma flexibilidade cognitiva à pesquisadora, trazendo além de aprendizado, um crescimento pessoal e profissional de grande valia. 


$$
\begin{aligned}
& \text { CONSIDERAÇÕES }
\end{aligned}
$$

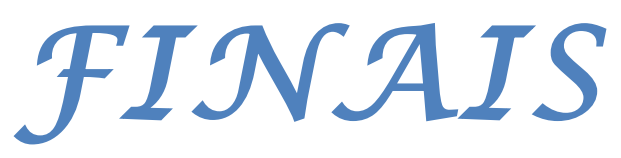




\section{CONSIDERAÇÕES FINAIS}

Analisando os dados relativos ao Estudo 2, notou-se melhor ganho no desenvolvimento aos dois anos de terapia. Entretanto, quando associamos esta análise aos dados encontrados no Estudo 1, é difícil associar essa melhora com o abandono do atendimento.

Como pode ser observado no Gráfico 8, a maior parte dos indivíduos do Estudo 1 realizaram um ano ou menos de terapia, sendo possível observar uma diminuição rápida nos primeiros anos.

\section{Gráfico 8 - Número de sujeitos e o tempo de atendimento}

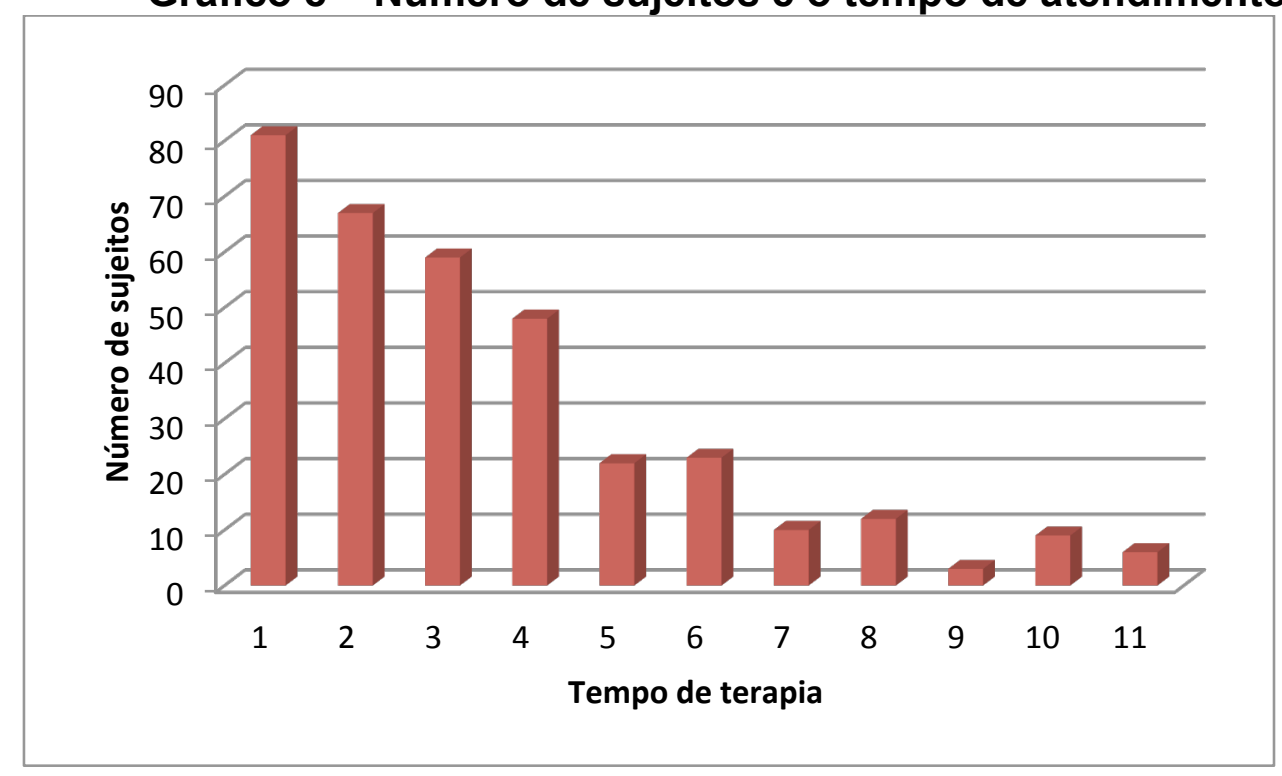

Sabe-se que a alta fonoaudiológica para crianças com DEA, independente do grau de severidade, quando considerados todos os aspectos a serem trabalhados, pode demorar anos.

Contudo, com estes estudos, foi possível observar a necessidade do acompanhamento evolutivo daqueles pacientes com longos anos de terapia 
para a realização da identificação de platôs do desenvolvimento, e assim a realização do encaminhamento mais adequado.

Com isso, pode ocorrer um melhor aproveitamento do serviço, de forma que um maior número de pacientes possa receber terapia de modo mais efetivo. 
$\mathcal{A} \mathcal{N} \mathcal{X} X S$ 


\title{
ANEXo A - Aprovação do Comitê de Ética em Pesquisa
}

\author{
Pativitint \\ MEDICINA \\ TSP \\ COMITÊ DE ÉTICA EM PESQUISA
}

\section{APROVAÇÃO}

o Comitê de Ética em Pesquisa da Faculdade de Medicina da Universidade de São Paulo, em sessão de 20/07/2016, APROVOU o Protocolo de Pesquisa $n^{0}$ 224/16 intitulado: "ATENDIMENTO FONOAUDIOLÓGICO A CRIANÇAS COM DISTÚRRIOS DO ESPECTRO DO AUTISMO: UM ESTUDO LONGITUDINAL" apresentado pelo Departamento de FISIOTERAPLA, FONOAUDIOLOGIA E TERAPIA OCUPACIONAL

Cabe ao pesquisador elaborar e apresentar ao CEPFMUSP, os relatórios parciais e final sobre a pesquisa (Resolução do Conselho Nacional de Saúde $n^{0} 466 / 12$, inciso $\mathrm{XX}$. , letra "c").

Pesquisador (a) Responsável: Fernanda Dreux Miranda Fernandes Pesquisador (a) Executante: Leticia Segeren

CEP-FMUSP, 22 de Julho de 2016 .

Profa. Dra. Maria Aparecida Azevedo Koilke Folgueira Coordenador Comitê de Ética em Pesquisa 


\title{
ANEXO B - Protocolo para transcrição de 5 minutos da filmagem para avaliação do PFC
}

\author{
Capítulo 4 - Pragmática
}

Fernanda Dreux Miranda Fernandes

ANEXO 1

Pragmática. Protocolo para Transcrição de Fita

\begin{tabular}{|c|c|}
\hline $\begin{array}{l}\text { Nome } \\
\text { Idade }\end{array}$ & Data \\
\hline
\end{tabular}

\begin{tabular}{|c|c|c|c|c|}
\hline \multicolumn{5}{|c|}{ Atos Comunicativos } \\
\hline $\mathrm{N}$ & $\begin{array}{c}\text { Meio } \\
(\mathrm{VE}-\mathrm{VO}-\mathrm{G})\end{array}$ & $\begin{array}{c}\text { Iniciativa } \\
\text { Criança (C.) } \\
\text { Adulto (A.) }\end{array}$ & Função & $\begin{array}{l}\text { Observações/ } \\
\text { Comentários }\end{array}$ \\
\hline & & & & \\
\hline & & & & \\
\hline & & & & \\
\hline & & & & \\
\hline & & & & \\
\hline & & & & \\
\hline & & & & \\
\hline & & & & \\
\hline & & & & \\
\hline & & & & \\
\hline & & & & \\
\hline & & & & \\
\hline & & & & \\
\hline & & & & \\
\hline & & & & \\
\hline & & & & \\
\hline & & & & \\
\hline & & & & \\
\hline & & & & \\
\hline & & & & \\
\hline & & & & \\
\hline & & & & \\
\hline & & & & \\
\hline & & & & \\
\hline
\end{tabular}




\section{ANEXO C - Ficha síntese para análise após a transcrição do PFC}

Fernanda Dreux Miranda Fernandes

Pragmática. Ficha-Sintese

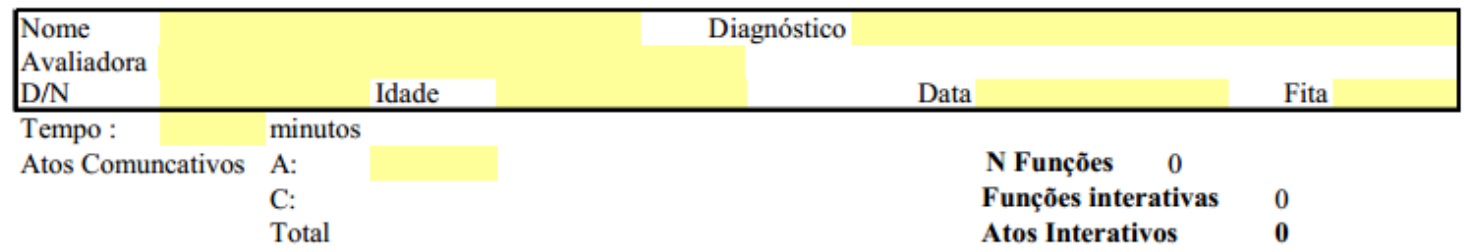

Atos Comunicativos por minuto

\begin{tabular}{|c|c|c|c|c|c|c|c|c|c|c|c|}
\hline Função & Meio & $\mathrm{N}$ & $\%$ & Função & Meio & $\mathrm{N}$ & $\%$ & Função & Meio & $\mathrm{N}$ & $\%$ \\
\hline \multirow{3}{*}{$\begin{array}{l}\text { PO } \\
0 \%\end{array}$} & VE & & $0 \%$ & \multirow{3}{*}{$\begin{array}{l}\text { P S } \\
0 \%\end{array}$} & VE & & $0 \%$ & \multirow{3}{*}{$\begin{array}{c}\text { PI } \\
0 \%\end{array}$} & VE & & $0 \%$ \\
\hline & $\mathrm{VO}$ & & $0 \%$ & & $\mathrm{VO}$ & & $0 \%$ & & \begin{tabular}{|l|}
$\mathrm{VO}$ \\
\end{tabular} & & $0 \%$ \\
\hline & G & & $0 \%$ & & $\overline{\mathrm{G}}$ & & $0 \%$ & & G & & $0 \%$ \\
\hline \multirow{3}{*}{$\begin{array}{l}\text { RO } \\
0 \%\end{array}$} & $\mathrm{VE}$ & & $0 \%$ & \multirow{3}{*}{$\begin{array}{c}\mathrm{C} \\
0 \%\end{array}$} & VE & & $0 \%$ & \multirow{3}{*}{$\begin{array}{c}\mathbf{N} \\
0 \%\end{array}$} & $\mathrm{VE}$ & & $0 \%$ \\
\hline & $\mathrm{VO}$ & & $0 \%$ & & $\overline{\mathrm{VO}}$ & & $0 \%$ & & $\mathrm{VO}$ & & $0 \%$ \\
\hline & $\mathrm{G}$ & & $0 \%$ & & $\mathrm{G}$ & & $0 \%$ & & $\mathrm{G}$ & & $0 \%$ \\
\hline \multirow{3}{*}{$\begin{array}{l}\text { EX } \\
0 \%\end{array}$} & $\overline{V E}$ & & $0 \%$ & \multirow{3}{*}{$\begin{array}{l}\text { NF } \\
0 \%\end{array}$} & $\overline{V E}$ & & $0 \%$ & \multirow{3}{*}{$\begin{array}{l}\text { XP } \\
0 \%\end{array}$} & $\overline{V E}$ & & $0 \%$ \\
\hline & $\mathrm{VO}$ & & $0 \%$ & & $\mathrm{VO}$ & & $0 \%$ & & $\mathrm{VO}$ & & $0 \%$ \\
\hline & $\mathrm{G}$ & & $0 \%$ & & $\mathrm{G}$ & & $0 \%$ & & $\mathrm{G}$ & & $0 \%$ \\
\hline \multirow{3}{*}{$\begin{array}{l}\text { EP } \\
0 \% \\
\end{array}$} & VE & & $0 \%$ & & VE & & $0 \%$ & \multirow{3}{*}{$\begin{array}{l}\text { PC } \\
0 \% \\
\end{array}$} & VE & & $0 \%$ \\
\hline & $\mathrm{VO}$ & & $0 \%$ & PA & $\mathrm{VO}$ & & $0 \%$ & & $\mathrm{VO}$ & & $0 \%$ \\
\hline & $\mathrm{G}$ & & $0 \%$ & $0 \%$ & $\overline{\mathrm{G}}$ & & $0 \%$ & & $\mathrm{G}$ & & $0 \%$ \\
\hline \multirow{3}{*}{$\begin{array}{l}\text { PR } \\
0 \% \\
\end{array}$} & VE & & $0 \%$ & & VE & & $0 \%$ & \multirow{3}{*}{$\begin{array}{l}\text { AR } \\
0 \% \\
\end{array}$} & VE & & $0 \%$ \\
\hline & $\mathrm{VO}$ & & $0 \%$ & $\mathbf{E}$ & $\mathrm{VO}$ & & $0 \%$ & & $\overline{\mathrm{VO}}$ & & $0 \%$ \\
\hline & $\mathrm{G}$ & & $0 \%$ & $0 \%$ & $\mathrm{G}$ & & $0 \%$ & & $\bar{G}$ & & $0 \%$ \\
\hline \multirow{3}{*}{$\begin{array}{l}\text { PE } \\
\mathbf{0} \% \\
\end{array}$} & VE & & $0 \%$ & & VE & & $0 \%$ & \multirow{3}{*}{$\begin{array}{c}\mathbf{J} \\
\mathbf{0} \% \\
\end{array}$} & VE & & $0 \%$ \\
\hline & $\mathrm{VO}$ & & $0 \%$ & $\mathrm{JC}$ & $\mathrm{VO}$ & & $0 \%$ & & $\mathrm{VO}$ & & $0 \%$ \\
\hline & $\mathrm{G}$ & & $0 \%$ & $0 \%$ & $\mathrm{G}$ & & $0 \%$ & & $\mathrm{G}$ & & $0 \%$ \\
\hline \multirow{3}{*}{$\begin{array}{l}\text { NA } \\
0 \%\end{array}$} & VE & & $0 \%$ & & VE & & $0 \%$ & \multirow{3}{*}{$\begin{array}{c}0 \\
\text { TOTAL }\end{array}$} & VE & 0 & $0 \%$ \\
\hline & $\mathrm{VO}$ & & $0 \%$ & RE & $\mathrm{VO}$ & & $0 \%$ & & $\mathrm{VO}$ & 0 & $0 \%$ \\
\hline & $\mathrm{G}$ & & $0 \%$ & $0 \%$ & $\mathrm{G}$ & & $0 \%$ & & $\mathrm{G}$ & 0 & $0 \%$ \\
\hline
\end{tabular}




\section{ANEXO D - Protocolo de registro individual da pontuação obtida no DSC}

Ficha-Resumo de Registro e Análise dos Aspectos Sócio-cognitivos adaptados por Molini (2001)

\begin{tabular}{|c|c|c|}
\hline Nome: & Idade: & Terapeuta: \\
\hline$N^{\circ}$ da fita & Data: & Diagnóstico: \\
\hline ASPECTOS SÓCIO COGNITIVOS & & NIVELL DE DESEMPENHO \\
\hline Intenção comunicativa gestual: & & $1-2-3-4-5-6$ \\
\hline Intenção comunicativa vocal: & & $1-2-3-4-5-6$ \\
\hline Uso do objeto mediador: & & $1-2-3-4$ \\
\hline Imitação gestual: & & $1-2-3-4$ \\
\hline Imitação vocal: & & $1-2-3-4$ \\
\hline Jogo combinatório: & & $1-2-3-4-5-6$ \\
\hline Jogo simbólico: & & $1-2-3-4-5-6$ \\
\hline
\end{tabular}




\section{REFER $\hat{E} \mathcal{N} C I \mathcal{A S}$ BIBLIOGRÁAICAS}




\section{Referências Bibliográficas:}

Achkova M, Manolova H. Diagnosis "Autism" - from Kanner and Asperger to DSM-5. J Intellect Disabil Res. 2014;2:112-8 http://dx.doi.org/10.6000/22922598.2014.02.02.4

AL Jabery MA, Arabiat DH, AL Khamra HA, Betawi IA, Abdel Jabbar SK. Parental Perceptions of Services Provided for Children with Autism in Jordan. $J$ Child Fam Stud. 2014; 23(3):475-86. https://doi.org/10.1007/s10826-012-97030

Alves DA, Kuroishi RCS, Mandrá PP. Prontuário eletrônico em cenário de prática: percepção dos graduandos e profissionais de fonoaudiologia. Revista CEFAC. 2016;18(2):385-91. https://doi.org/10.1590/1982-0216201618217915

Amato CAH. Questões funcionais e sócio-cognitivas no desenvolvimento da linguagem em crianças normais e autistas. [Tese]. São Paulo: Faculdade de Medicina, Universidade de São Paulo; 2006

Amato CAH, Fernandes FDM. O uso interativo da comunicação em crianças autistas verbais e não verbais. Pró-Fono. 2010;22(4):373-8. https://doi.org/10.1590/s0104-56872010000400002

Amato CAH, Fernandes FDM. Aspectos funcionais da comunicação: estudo longitudinal dos primeiros três anos de vida. J Soc Bras Fonoaudiol. 2011;23(3):277-80. https://doi.org/10.1590/s2179-64912011000300015

Amato CAH, Molini-Avejonas DR, Santos THF, Pimentel AGL, Valino VC, Fernandes FDM. Fatores intervenientes na terapia fonoaudiológica de crianças autistas. Revista da Sociedade Brasileira de Fonoaudiologia. 2011;16(1):1048.

Amato CAH, Santos THF, Barbosa MRP, Fernandes FDM. Estudo longitudinal da terapia de linguagem de 142 crianças e adolescentes com distúrbios do espectro do autismo. CoDAS.2013;25(4):388-90.

https://doi.org/10.1590/s2317-17822013000400015

American Psychiatric Association. DSM-III. Diagnostic and Statistical Manual of Mental Disorders. 3rd ed. Washington (DC):APA; 1980.

American Psychiatric Association. DSM-IV. Manual Diagnóstico e Estatístico de Transtornos Mentais. 4a ed. Porto Alegre: ARTMED:APA; 2002.

American Psychiatric Association. DSM 5. Manual Diagnóstico e Estatístico de Transtornos Mentais. 5a ed. Porto Alegre: ARTMED:APA; 2013. 
American Speech-Language-Hearing Association [homepage na internet]. Autism. (Acesso em 12 fev 2019) Disponível em: https://www.asha.org/PRPSpecificTopic.aspx?folderid $=8589935303 \&$ section $=T r$ eatment

Atladottir HO, Gyllenberg D, Langridge A, Sandin S, Hansen SN, Leonard H, et al. The increasing prevalence of reported diagnoses of childhood psychiatric disorders: a descriptive multinational comparison. Eur Child Adolesc Psychiatry. 2015;24(2):173-83. https://doi.org/10.1007/s00787-014-0553-8

Autism Speaks [homepage na internet]. Autism CARES Act. (Acesso em $27 \mathrm{fev}$ 2019) Disponível em: https://www.autismspeaks.org/autism-cares-act

Baio J, Hall-Lande J, White T, Kurzius-Spencer M, Warren Z, Wiggins L, et al. Prevalence of Autism Spectrum Disorder Among Children Aged 8 Years Autism and Developmental Disabilities Monitoring Network, 11 Sites, United States, 2014. Morb Mortal Wkly Rep Surveill Summ. 2018;67(6):1-23. https://doi.org/10.15585/mmwr.ss6706a1

Balestro JI, Fernandes FDM. Questionário sobre dificuldades comunicativas percebidas por pais de crianças do espectro do autismo. Revista Da Sociedade Brasileira de Fonoaudiologia. 2012;17(3):279-86.

https://doi.org/10.1590/s1516-80342012000300008

Barnard-Brak L, Richman D, Ellerbeck K, Moreno R. Health care provider responses to initial parental reports of autism spectrum disorder symptoms: results from a nationally representative sample. Child and Adolesc Ment Health. 2017;22(1):30-5. doi:10.1111/camh.12194

Baxter AJ, Brugha TS, Erskine HE, Scheurer RW, Vos T, Scott JG. The epidemiology and global burden of autism spectrum disorders. Psychol Med. 2015;45:601-13. doi:10.1017/S003329171400172X

Becker MM, Wagner MB, Bosa CA, Schmidt C, Longo D, Papaleo C, Riesgo RS. Translation and validation of Autism Diagnostic Interview-Revised (ADI-R) for autism diagnosis in Brazil. Arq Neuropsiquiatr. 2012;70(3):185-90. https://doi.org/10.1590/S0004-282X2012000300006

Befi-Lopes DM. Vocabulário. In: Andrade CRF, Befi-Lopes DM, Fernandes FDM, Wertzner HF, editors. ABFW: teste de linguagem infantil nas áreas de fonologia, vocabulário, fluência e pragmática. $2^{\circ}$ edição - revisada, ampliada e atualizada ed. Barueri: Pró-Fono; 2004.

Bethell C, Reuland C, Abrahms M, Schor E, Halfon N. Rates of ParentCentered Developmental Screening: Disparities and Links to Services Access. Pediatrics. 2011;128(1):146-55. https://doi.org/10.1542/peds.2010-0424 
Bordalo AA. Estudo transversal e/ou longitudinal. Revista Paraense de Medicina. 2006;20(4). https://doi.org/10.5123/s0101-59072006000400001

Brasil. Presidencia da Republica. Lei $n^{0} 12.764$. Institui a Política Nacional de Proteção dos Direitos da Pessoa com Transtorno do Espectro Autista. Diário Oficial da União, Brasilia (DF). 2012 Disponivel em:

https://presrepublica.jusbrasil.com.br/legislacao/1033668/lei-12764-12 acessado 06 de março de 2019

Brasil (a). Ministério da Saúde. Secretaria de Atenção à Saúde. Departamento de Atenção Especializada e Temática. Linha de cuidado para a atenção às pessoas com transtornos do espectro do autismo e suas famílias na Rede de Atenção Psicossocial do Sistema Único de Saúde / Ministério da Saúde, Secretaria de Atenção à Saúde, Departamento de Atenção Especializada e Temática. - Brasília: Ministério da Saúde, 2015.

Brasil (b). Presidência da Republica. Lei no 13.146. Institui a Lei Brasileira de Inclusão da Pessoa com Deficiência (Estatuto da Pessoa com Deficiência). Diário Oficial da União, Brasilia (DF). 2015 Disponivel em: http://www.planalto.gov.br/ccivil_03/_ato2015-2018/2015/lei//13146.htm acessado 06 de março de 2019

Brasil. Presidencia da Republica. Projeto de Lei $n^{\circ}$ 10.119. Dispõe sobre a Carteira de Identificação da Pessoa com Transtorno do Espectro Autista (CIPTEA), e dá outras providências. Diário Oficial da União, Brasilia (DF). 2018 Disponivel em: https://www.camara.leg.br/sileg/integras/1657475.pdf acessado 06 de março de 2019

Cardoso C, Fernandes FDM. A comunicação de crianças do espectro autístico em atividades em grupo. Pró Fono Revista de Atualização Científica. Barueri (SP). 2004;16(1):67-74. Jan-abr.

Cardoso C, Fernandes FDM. Relação entre os aspectos sócio cognitivos e perfil funcional da comunicação em um grupo de adolescentes do espectro autístico. Pró-Fono Revista de Atualização Científica. 2006;18(1):89-98. https://doi.org/10.1590/s0104-56872006000100011

Carr T, Shih W, Lawton K, Lord C, King B, Kasari C. The relationship between treatment attendance, adherence, and outcome in a caregiver-mediated intervention for low-resourced families of young children with autism spectrum disorder. Autism. 2016;20(6):643-52.

https://doi.org/10.1177/1362361315598634

Centers for Disease Control and Prevention [homepage na internet]. Learn the Signs. Act Early. (Acesso em 12 fev 2019). Disponível em:

https://www.cdc.gov/ncbddd/actearly/index.html 
Centers for Disease Control and Prevention [homepage na internet]. Data on Autism: Five Facts to Know (Acesso em 07 jan 2019). Disponível em:

https://www.cdc.gov/features/new-autism-data/index.html

Clark LA, Cuthbert B, Lewis-Fernández R, Narrow WE, Reed GM. Three Approaches to Understanding and Classifying Mental Disorder: ICD-11, DSM-5, and the National Institute of Mental Health's Research Domain Criteria (RDoC). Psychol Sci Public Interest. 2017;18(2):72-145. https://doi.org/10.1177/1529100617727266

Cohen J. A power primer. Psychol Bull. 1992 Jul;112(1):155-9.

Conselho Federal de Fonoaudiológia. Recomendação CFFa $\mathrm{n}^{\circ}$ 10, de 05 de dezembro de 2009. Dispõe sobre o registro de procedimentos fonoaudiológicos em prontuários. Brasília (DF) 2009. Disponivel em:

http://www.fonosp.org.br/wordpress/wp-content/uploads/2009/12/of-circ-cffanc2ba-175-09-crfas.pdf. Acesso em 02 de agosto de 2017.

Conselho Federal de Fonoaudiologia [homepage na internet]. Quantitativo de fonoaudiólogos no Brasil por conselho regional. (Acesso em 9 mar 2019). Disponível em: http://www.fonoaudiologia.org.br/cffa/index.php/numero-porregiao/

Conselho Federal de Medicina. Resolução CFM n.1638, de 10 de julho de 2002. Define prontuário médico e torna obrigatória a criação da Comissão de prontuário nas instituições de saúde. Diário Oficial da União, Brasília (DF) 2002. Sec.1:184-5.

Cordier R, Munro N, Wilkes-Gillan S, Speyer R, Pearce WM. Reliability and validity of the Pragmatics Observational Measure (POM): A new observational measure of pragmatic language for children. Res Dev Disabil. 2014;35(7):158898. doi:10.1016/j.ridd.2014.03.050

Daniels AM, Mandell DS. Explaining differences in age at autism spectrum disorder diagnosis: A critical review. Autism. 2014;18(5):583-97. https://doi.org/10.1177/1362361313480277

Defense DA, Fernandes FDM. Perfil funcional de comunicação e desempenho sócio-cognitivo de adolescentes autistas institucionalizados. Revista CEFAC. 2010;13(6):977-85. https://doi.org/10.1590/s1516-18462011005000009

Defense-Netrval DA. Proposta de modelo de indicadores de qualidade para o atendimento oferecido aos indivíduos autistas na cidade de São Paulo. [Tese]. São Paulo: Faculdade de Medicina, Universidade de São Paulo; 2014

Defense-Netrval DA, Fernandes FDM. A oferta da terapia fonoaudiológica em locais de assistência a indivíduos com Transtornos do Espectro do Autista (TEA). CoDAS. 2016;28(4):459-62. https://doi.org/10.1590/23171782/20162015094 
Diário Oficial da União- Seção 1 - 27/4/2017, Página 2 (Publicação Original). Lei $n^{\circ}$ 13.438. Disponivel em: 〈http://pesquisa.in.gov.br/imprensa/jsp/visualiza/index.jsp?data=27/04/2017\&jor nal=1\&pagina=2\&totalArquivos=184 . Acesso em 24 de julho de 2017

Elsabbagh M, Divan G, Koh YJ, Kim YS, Kauchali S, Marcín C, et al. Global Prevalence of Autism and Other Pervasive Developmental Disorders. Autism Research. 2012;5(3):160-79. https://doi.org/10.1002/aur.239

EMORY news center [homepage na internet]. Marcus Autism Center receives Autism Center of Excellence designation from NIH. (Acesso em 24 fev 2019). Disponível em:

http://news.emory.edu/stories/2017/09/autism_center_of_excellence/

EUA. Public Law 113-157. Autism Collaboration, Accountability, Reaserch, Education and Support Act of 2014. 2014. (acesso em 27 fev 2018) Disponível em: https://chrissmith.house.gov/uploadedfiles/autism_cares_act.pdf

European Commission. European Disability Strategy 2010-2020: A Renewed Commitment to a Barrier-Free Europe. Brussels, 2010. (Acesso em $27 \mathrm{fev}$ 2019) Disponível em: https://eurlex.europa.eu/LexUriServ/LexUriServ.do?uri=COM:2010:0636:FIN:en:PDF

Fernandes FDM, Pastorello LM. Fonoaudiologia em ambulatório psiquiátrico. In: Fernandes FDM, Pastorello LM, Scheuer, CL. Fonoaudiologia em Distúrbios Psiquiátricos da Infância. Editora Lovise, São Paulo, 1995. p.121-144.

Fernandes FDM. Autismo infantil, repensando o enfoque fonoaudiológico Aspectos funcionais da Comunicação. São Paulo: Editora Lovise. 1996

Fernandes FDM. Pragmática. In: Andrade CRF, Befi-Lopes DM, Fernandes FDM, Wertzner HF. ABFW: teste de linguagem infantil nas áres de fonologia, vocabulário, fluência e pragmática. 2ed. Carapicuíba: Pró-Fono. 2004.

Fernandes FDM, Molini-Avejonas DR, Sousa-Morato PF. Perfil funcional da comunicação nos distúrbios do espectro autístico. Rev CEFAC. 2006;8(1):206.

Fernandes FDM, Sassi FC, Sousa-Morato PF, Amato CAH, Cardoso C. Fonoaudiologia e autismo: resultado de três diferentes modelos de terapia de linguagem. Pró-Fono Revista de Atualização Científica. 2008;20(4):267-72. https://doi.org/10.1590/s0104-56872008000400011

Fernandes FDM, Amato CAH, Molini-Avejonas DR. Adherence of ASD Children and Adolescents to Language Therapy. Autism-Open Access. 2015;05(03):2013-6. https://doi.org/10.4172/2165-7890.1000150

Fernandes FDM. Memorial apresentado à Faculdade de Medicina da 
Universidade de São Paulo para a obtenção de progressão de carreira de docente da Universidade de São Paulo. 2011

Fernandes FDM, Amato CAH, Cardoso C, Navas, ALGP, Molini-Avejonas DR. Reading in Autism Spectrum Disorders: A Literature Review. Folia Phoniatr Logop. 2016;67(4):169-77. https://doi.org/10.1159/000442086

Field A. Discovering Statistics Using IBM SPSS Statistics. California: SAGE Publications. 1070 p. 5th ed. 2017.

Gail JR, Lynn KC. Differential Assessment of Autism and Other Developmental Disorders (DAADD). East Moline, IL: LinguiSystems; 2003.

Gil AC. Métodos e Tecnicas de Pesquisa Social. 6ª Edição. São Paulo: Atlas. 2008

Gillon G, Hyter Y, Fernandes FDM, Ferman S, Hus Y, Petinou K, et al. International Survey of Speech-Language Pathologists' Practices in Working with Children with Autism Spectrum Disorder. Folia Phoniatr Logop. 2017;69(12):8-19. https://doi.org/10.1159/000479063

Green VA, O'Reilly M, Itchon J, Pituch KA, Choi A, Sigafoos J. Internet survey of treatments used by parents of children with autism. Res Dev Disabil. 2006;27(1);70-84. https://doi.org/10.1016/j.ridd.2004.12.002

Guareschi T, Alves MD, Naujorks MI. Políticas públicas e educação especial: uma análise sobre o autismo. Atos de Pesquisa Em Educação. 2016;11(2):374-95.

Hage SRV, Resegue MM, Viveiros DCS, Pacheco EF. Análise do perfil das habilidades pragmáticas em crianças pequenas normais. Pró-Fono Revista de Atualização Científica. 2007;19(1):49-58.

Hansen SN, Schendel DE, Parner ET. Explaining the Increase in the Prevalence of Autism Spectrum Disorders. JAMA Pediatr. 2015;169(1):56-62. https://doi.org/10.1001/jamapediatrics.2014.1893

Houte Autorité de Santé, (2018). Autism spectrum disorder: Warning signs, detection, diagnosis and assessment in children and adolescents. Elaborado por Houte Autorité de Santé, 2018. Disponível em: https://www.hassante.fr/portail/jcms/c_468812/en/autism-spectrum-disorder-warning-signsdetection-diagnosis-and-assessment-in-children-andadolescents?cid=c_2051455\&portal=r_1455081

Hess KL, Morrier MJ, Heflin LJ, Ivey ML. Autism treatment survey: Services received by children with autism spectrum disorders in public school classrooms. J Autism Dev Disord. 2008;38(5):961-71. https://doi.org/10.1007/s10803-007-0470-5 
Hock R, Kinsman A, Ortaglia A. Examining treatment adherence among parents of children with autism spectrum disorder. Disabil Health J. 2015;8(3):407-13. doi:10.1016/j.dhjo.2014.10.005

Jo H, Kogan MD, Rice CE, Schieve LA, Blumberg SJ, Tian LH, et al. Age at Autism Spectrum Disorder (ASD) Diagnosis by Race, Ethnicity, and Primary Household Language Among Children with Special Health Care Needs, United States, 2009-2010. Matern Child Health J. 2015;19(8):1687-97. https://doi.org/10.1007/s10995-015-1683-4

Junior $\mathrm{P}$, Ribeiro $\mathrm{S}$. Pesquisa do $\mathrm{CDC}$ revela número alto de prevalência de autismo nos EUA em crianças de oito anos, além de grande aumento em relação a pesquisa anterior. Revista Autismo, Informação gerando ação. 2010; 0 (online). Disponível em: 〈http://www.revistaautismo.com.br/edic-o-0/numeroimpressionante-uma-em-cada-110-criancas-tem-autismo». Acesso em 02 de agosto de 2017

Kazdin AE. Dropping Out of Child Psychotherapy: Issues for Research and Implications for Practice. Clin Child Psychol Psychiatry. 1996;1(1):133156.doi:10.1177/1359104596011012

Kleinert S, Horton R. Brazil: towards sustainability and equity in health. The Lancet. 2011;377(9779):1721-2

Kulage KM, Smaldone AM, Cohn EG. How will DSM-5 affect autism diagnosis? A systematic literature review and meta-analysis. J Autism Dev Disord. 2014;44(8):1918-32. https://doi.org/10.1007/s10803-014-2065-2

Lampreia CA. Perspectiva desenvolvimentista para a intervenção precoce no autismo. Estudos de Psicologia. 2007;24(1):105-114.

Lima RC. A construção histórica do autismo (1943-1983). Ci. Huma. e Soc. em Rev. RJ, EDUR. 2014;36(1):109-23.

Lord C, Rutter M, Le Couter A. Autism Diagnostic Interview-Revised: a revised version of a diagnostic interview for caregivers of Individuals with possible pervasive developmental disorders. J Autism Dev Disord. 1994; 24(5):659- 85.

Lord C, Risi S, Lambrecht L, Cook EH, Leventhal BL, Dilavore PC, Pickles A, Rutter, M. The Autism Diagnostic Observation Schedule - Generic : A Standard Measure of Social and Communication Deficits Associated with the Spectrum of Autism. J Autism Dev Disord. 2000;30(3):205-23.

Losapio MF, Pondé MP. Tradução para o português da escala M-CHAT para rastreamento precoce de autismo. Revista de Psiquiatria Do Rio Grande Do Sul. 2008;30(3):221-9. https://doi.org/10.1590/s0101-81082008000400011 
Machado FP, Lerner R, Novaes BCAC, Palladino RRR, Cunha MC.

Questionário de Indicadores Clínicos de Risco para o Desenvolvimento Infantil : avaliação da sensibilidade para transtornos do espectro do autismo. Audiol Commun Res. 2014;19(4):345-51.

Machado JD, Caye A, Frick PJ, Rohde LA DSM-5. Principais Mudanças nos Transtornos de Crianças e Adolescentes. In Rey JM (ed), IACAPAP e-Textbook of Child and Adolescent Mental Health (edição em Português; Dias Silva F, ed). Genebra: International Association for Child and Adolescent Psychiatry and Allied Professions. 2015.

Maenner MJ, Rice CE, Arneson CL, Cunniff C, Schieve LA, Carpenter LA, et al. Potential impact of DSM-5 criteria on autism spectrum disorder prevalence estimates. JAMA Psychiatry, 2014;71(3):292-300.

https://doi.org/10.1001/jamapsychiatry.2013.3893

Mahapatra S, Khokhlovich E, Martinez S, Kannel B, Edelson SM, Vyshedskiy A. Longitudinal Epidemiological Study of Autism Subgroups Using Autism Treatment Evaluation Checklist (ATEC) Score. J Autism Dev Disord. 2018:1-12. https://doi.org/10.1007/s10803-018-3699-2

Marques DF, Bosa CA. Protocolo de Avaliação de Crianças com Autismo: Evidências de Validade de Critério. Psicologia: Teoria e Pesquisa.

2015;31(1):43-51. https://doi.org/10.1590/0102-37722015011085043051

Marteleto MRF, Pedromônico MRM. Validity of Autism Behavior Checklist (ABC): preliminary study. Revista Brasileira de Psiquiatria. 2005;27(4):295-301. https://doi.org/10.1590/s1516-44462005000400008

McConkey R, Truesdale-Kennedy M, Cassidy A. Mothers' recollections of early features of autism spectrum disorders. Child Adolesc Ment Health.

2009;14(1):31-6. https://doi.org/10.1111/j.1475-3588.2008.00495.x

Miilher LP, Fernandes FDM. Habilidades pragmáticas, vocabulares e gramaticais em crianças com transtornos do espectro autístico. Pró-Fono Revista de Atualização Científica, 2009;21(4):309-14.

https://doi.org/10.1590/s0104-56872009000400008

Miilher LP, Fernandes FDM. Considerando a responsividade: uma proposta de análise pragmática no espectro do autismo. CoDAS. 2013;25(1):70-5

Misquiatti ARN, Brito MC. Terapia de linguagem de irmãos com transtornos invasivos do desenvolvimento: estudo longitudinal. Revista Da Sociedade Brasileira de Fonoaudiologia. 2010;15(1):134-9. https://doi.org/10.1590/s151680342010000100022

Molini DR, Fernandes FDM. Teste específico para análise sociocognitiva de crianças autistas: um estudo preliminar. Temas sobre o Desenvolvimento. 2001;10(55):5-13. 
Molini DR, Fernandes FDM. Intenção Comunicativa e Uso de Instrumento em Crianças com Distúrbios Psiquiátricos. Pró-Fono Revista de Atualização Científica. Barueri (SP) 2003;15(20):149-158.

Molini DR. Verificação de diferentes modelos de coleta de dados dos aspectos sócio-cognitivos na terapia fonoaudiológica de crianças com distúrbios psiquiátricos [dissertação]. São Paulo: Faculdade de Medicina, Universidade de São Paulo; 2001.

Mulas F, Ros-Cervera G, Millá MG, Etchepareborda MC, Abad L, Téllez de Meneses M. Modelos de intervención en niños com autismo. Rev Neurol. 2010; 50(Supl 3):S77-84

Murphy D, Glaser K, Hayward H, Eklund H, Cadman T, Findon J, et al. Crossing the divide: a longitudinal study of effective treatments for people with autism and attention deficit hyperactivity disorder across the lifespan. Programme Grants For Applied Research. 2018;6(2). https://doi.org/10.3310/pgfar06020

National Research Council. Educating Children with Autism. Washington, DC: The National Academies Press. 2001:175-229. https://doi.org/10.17226/10017. Disponível em http://nap.edu/10017

National Autism Center. Findings and conclusions: National standards project, phase 2. Randolph, MA: Author. 2015 https://doi.org/10.1097/00006199197003000-00021

Neubauer MDA, Fernandes FDM. Perfil Funcional da Comunicação e diagnóstico fonoaudiológico de crianças do espectro autístico : uso de um checklist. CoDAS, 2013;25(6):605-9.

Organização Mundial de Saúde - OMS. Divisão de Saúde Mental. Grupo WHOQOL. Versão em português dos instrumentos de avaliação de qualidade de vida (WHOQOL) 1998; Disponível em:

http://www.ufrgs.br/psiquiatria/psiq/whoqol.html

Oro AB, Briseño JV, García CAC, Sepúlveda RFC, Villalobos AMH, Sanchez CE. Manifestaciones iniciales de los trastornos del espectro autista. Experiencia en 393 casos atendidos en un centro neurológico infantil. Neurologia. 2012; 27(7):414-420. https://doi.org/10.1016/j.nrl.2011.09.011

Packer AL, Tardelli AO, Castro RCF. A distribuição do conhecimento científico público em informação, comunicação e informática em saúde indexado nas bases de dados MEDLINE e LILACS.Ciência \& Saúde Coletiva. 2006;12(3): 587-599. 
Paim J, Travassos C, Almeida C, Bahia L, Macinko J. The Brazilian health system: history, advances, and challenges. The Lancet, 2011;377(9779):177897. https://doi.org/10.1016/S0140-6736(11)60054-8

Parsons L, Cordier R, Munro N, Joosten A, Speyer R. A systematic review of pragmatic language interventions for children with autism spectrum disorder. PLOS ONE. 2017;12(4):1-37 https://doi.org/10.1371/journal.pone.0172242

Pasco, G. The value of early intervention for children with autism. Paediatrics and Child Health (United Kingdom), 2018;28(8):364-7.

https://doi.org/10.1016/j.paed.2018.06.001

Paul R. Interventions to Improve Communication. Child Adolesc Psychiatr Clin N Am. 2008 October;17(4):835-x. doi:10.1016/j.chc.2008.06.011.

Paula CS, Ribeiro SH, Fombonne E, Mercadante MT. Brief Report: Prevalence of Pervasive Developmental Disorder in Brazil: A Pilot Study. J Autism Dev Disord. 2011;41(12):1738-42. doi:10.1007/s10803-011-1200-6

Pereira JCR, Paes AT, Okano V. Espaço aberto: Questões comuns sobre epidemiologia, estatística e informática. Revista do IDPC. São Paulo. 2000;7:12-17.

Pereira A, Riesgo RS, Wagner MB. Childhood autism: translation and validation of the Childhood Autism Rating Scale for use in Brazil. Jornal de Pediatria, 2008;84(6):487-94. https://doi.org/10.2223/jped.1828

Piaget J. Os estágios do desenvolvimento intelectual da criança e do adolescente. In Leite, DM. O desenvolvimento da criança. Atualidades Pedagógicas, col 109 São Paulo: EDUSP 1972.

Porto E, Limongi SCO, Santos IG, Fernandes, FDM. Amostra de filmagem e análise da pragmática na síndrome de Down. Pró-Fono Revista de Atualização Científica. 2007;19(2):159-66.

Phelps-Terasaki D, Phelps-Gunn T. Test of pragmatic language. 2nd edn. Austin, TX: ProEd. 2007

Prodanov CC, Freitas EC. Metodologia do Trabalho Científico: Métodos e Técnicas da Pesquisa e do Trabalho Acadêmico. $2^{a}$ Edição. Novo Hamburgo:Feevale, 2013

Prizant BM, Wetherby AM, Rubin E, Laurent AC. The SCERTS Model: A transactional, family-centered approach to enhancing communication and socioemotional abilities of children with autism spectrum disorder. Infants Young Children. 2003;16(4):296-316. https://doi.org/10.1097/00001163200310000-00004 
Public Health Agency of Canada [homepage na internet]. Public Health Agency of Canada Releases First-Ever National Autism Spectrum Disorder (ASD) Statistics. (Acesso em 27 fev 2019). Disponível em: https://www.canada.ca/en/public-health/news/2018/03/public-health-agency-ofcanada-releases-first-ever-national-autism-spectrum-disorder-asd-statistics.html

Radecki L, Sand-Loud N, O'Connor KG, Sharp S, Olson LM. Trends in the Use of Standardized Tools for Developmental Screening in Early Childhood: 20022009. Pediatrics. 2011;128(1):14-9. https://doi.org/10.1542/peds.2010-2180

Ratto AB, Kenworthy L, Yerys BE, Bascom J, Wieckowski AT, White SW, et al. What About the Girls? Sex-Based Differences in Autistic Traits and Adaptive Skills. J Autism Dev Disord. 2017;48(5):1698-711. doi:10.1007/s10803-0173413-9

Raven JC, Raven J, Court JH. Matrizes Progressivas Coloridas de Raven. Manual. São Paulo: Casa do Psicólogo. 1988

Rosenthal R. Meta-analytic procedures for social research. 2nd ed. Newbury Park, CA: Sage; 1991. 168 p.

Rutter M, Bartak L. Causes of infantile autism: some considerations from recent research. Journal of Autism and Childhood Schizophrenia, New York. 1971;1(1):20-32.

Rutter M, Bartak L, Newman, Steven. Autism: a central disorder of cognition and language? In: Rutter, Michael (Ed.) Infantile autism: concepts, characteristics and treatment. London: Churchill. 1971:148-171.

Rutter M. Diagnosis and definition of childhood autism. Journal of Autism and Childhood Schizophrenia. 1978;8(2):139-161.

Saboia C, Gomes C, Viodé C, Gille M, Golse B. Do Brincar do Bebê ao Brincar da Criança: Um Estudo sobre o Processo de Subjetivação da Criança Autista. Psicologia: Teoria e Pesquisa, 2017;33:1-8.

https://doi.org/10.1590/0102.3772e33426

Salomone E, Beranová Š, Bonnet-Brilhault F, Lauritsen, MB, Budisteanu, M, Buitelaar J, et al. Use of early intervention for young children with autism spectrum disorder across Europe. Autism, 2015;20(2):233-49. https://doi.org/10.1177/1362361315577218

Sandri MA, Meneghetti SL, Gomes E. Perfil comunicativo de crianças entre 1 e 3 anos com desenvolvimento normal de linguagem. Revista CEFAC. 2009;11(1):34-41.

Santos JAP, Arce VAR, Magno LD, Ferrite S. Oferta da Fonoaudiologia na rede pública municipal de saúde nas capitais do Nordeste do Brasil. Audiology - 
Communication Research, 2017;22(0):1-8. https://doi.org/10.1590/2317-64312015-1665

Santos THF. Diferentes perspectivas na verificação das habiliadades pragmaticas de crianças incluidas no espectro do autismo. [Tese]. São Paulo: Faculdade de Medicina, Universidade de São Paulo; 2017.

São Paulo. Secretaria da Saúde do Estado de São Paulo. Secretaria dos Direitos da Pessoa com Deficiência. Protocolo do Estado de São Paulo de Diagnóstico Tratamento e Encaminhamento de Pacientes com Transtorno do Espectro Autista (TEA). São Paulo, 2013. Disponivel em http://www.saude.sp.gov.br/resources/ses/perfil/profissional-dasaude/homepage//protocolo_tea_sp_2014.pdf acessado em 06 de março de 2019

Segeren L, Françozo MFC. As vivências de mães de jovens autistas. Psicologia Em Estudo, 2014;19(1):39-46. https://doi.org/10.1590/1413-7372189590004

Schopler E, Reichler RJ, DeVellis RF, Daly K. Toward objective classification of childhood autism: Childhood Autism Rating Scale (CARS). J Autism Dev Disord. 1980;10(1):91-103.

Sheldrick RC, Maye MP, Carter AS. Age at First Identification of Autism Spectrum Disorder: An Analysis of Two US Surveys. J Am Acad Child Adolesc Psychiatry. 2017;56(4):313-20. https://doi.org/10.1016/j.jaac.2017.01.012

Sng CY. Carter M. Stephenson J. A systematic review of the comparative pragmatic differences in conversational skills of individuals with autism. Autism Dev Lang Impair. 2018;3:1-24. doi:10.1177/2396941518803806

Taylor LJ, Eapen V, Maybery MT, Midford S, Paynter J, Quarmby L, et al. Diagnostic evaluation for autism spectrum disorder : a survey of health professionals in Australia. BMJ Open 2016;6:e012517. doi:10.1136/bmjopen2016-012517

Toscano CVA, Ferreira JP, Gaspar JM, Carvalho HM. Growth and weight status of Brazilian children with autism spectrum disorders: A mixed longitudinal study. Jornal de Pediatria. 2018. https://doi.org/10.1016/j.jped.2018.06.008

Travers JC, Krezmien MP, Mulcahy C, Tincani M. Racial Disparity in Administrative Autism Identification Across the United States During 2000 and 2007. J Spec Educ. 2014;48(3):155-66.

https://doi.org/10.1177/0022466912454014

Veldhuizen S, Clinton J, Rodriguez C, Wade TJ, Cairney J. Concurrent validity of the ages and stages questionnaires and bayley developmental scales in a general population sample. Acad Pediatr. 2015;15(2):231-7.

https://doi.org/10.1016/j.acap.2014.08.002 
Warren Z, Veenstra-VanderWeele J, Stone W, Bruzek JL, Nahmias AS, FossFeig JH, et al. Therapies for Children With Autism Spectrum Disorders. Comparative Effectiveness Review No. 26. (Prepared by the Vanderbilt Evidence-based Practice Center under Contract No. 290-2007-10065-I.) AHRQ Publication No. 11-EHC029-EF. Rockville, MD: Agency for Healthcare Research and Quality. April 2011. Available at: www.effectivehealthcare.ahrq.gov/reports/final.cfm.

Weiss EM, Walter C, Fink A, Schulter G, Mittenecker E, Papousek, I. Agemoderating effect in prepotent response inhibition in boys with Asperger syndrome: a 2.5 years longitudinal study. Eur Arch Psychiatry Clin Neurosci. 2018:1-4. https://doi.org/10.1007/s00406-018-0915-1

Wetherby AM, Prutting CA. Profiles of communicative and cognitive-social abilities in autistic children. J Speech Hear Res. 1984;27:364-77.

Wertzner, HF. Fonologia. In: Andrade CRF, Befi-Lopes DM, Fernandes FDM, Wertzner HF. ABFW: teste de linguagem infantil nas áres de fonologia, vocabulário, fluência e pragmática. 2ed. Carapicuíba: Pró-Fono. 2004.

Whitehouse AJO, Maybery MT, Durkin K. Inner speech impairments in autism. J Child Psychol Psychiatry. 2006;47(8):857-65. https://doi.org/10.1111/j.14697610.2006.01624.x

Wiggins LD, Reynolds A, Rice CE, Moody EJ, Bernal P, Blaskey L, et al. Using Standardized Diagnostic Instruments to Classify Children with Autism in the Study to Explore Early Development. Autism Dev Disord. 2015 May;45(5):1271-80. doi:10.1007/s10803-014-2287-3.

Will MN, Currans K, Smith J, Weber S, Duncan A, Burton J, et al. EvidencedBased Interventions for Children with Autism Spectrum Disorder. Curr Probl Pediatr Adolesc Health Care. 2018;48(10):234-49. https://doi.org/10.1016/j.cppeds.2018.08.014

Wing L, Gould J. Severe impairments of social interaction and associated abnormalities in children: Epidemiology and classification. J Autism Dev Disord. 1979;9(1):11-29. https://doi.org/10.1007/BF01531288

Wigg EH, Semel E, Secord WA. Clinical Evaluation of Language Fundamentals - Fifth Edition - CELF 5. Person: 2013.

World Health Organization. ICD-6. Manual of the international statistical classification of diseases, injuries, and causes of death : 6th revision of the International lists of diseases and causes of death, adopted 1948. Geneva:World Health Organization. Retirado de: http://www.who.int/iris/handle/10665/42893

World Health Organization. ICD-11. Manual of the international statistical classification of diseases, injuries, and causes of death : eleven revision 2018. 
Geneva : World Health Organization Retirado de: https://icd.who.int/browse11/lm/en\#/http\%3a\%2f\%2fid.who.int\%2ficd\%2fentity\%2f437815624. Acessado 20 de fevereiro de 2019

World Health Organization. "ICD-10, the ICD-10 classification of mental and behavioural disorders: Diagnostic criteria for research." Geneva: World Health Organization (1993).

Wozniak RH, Leezenbaum NB, Northrup JB, West KL, Wozniak RH, Iverson JM. The development of autism spectrum disorders: variability and causal complexity. Wiley Interdiscip Rev Cogn Sci. 2017;8(1-2):e1426.

https://doi.org/10.1002/wcs.1426

Young $\mathrm{H}$, Oreve M-J, Speranza M. Clinical characteristics and problems diagnosing autism spectrum disorder in girls. Arch Pediatr. 2018 doi:10.1016/j.arcped.2018.06.008

Zablotsky B, Black L, Maenner, M, Schieve LA, Blumberg SJ. Estimated Prevalence of Autism and Other Developmental Disabilities Following Questionnaire Changes in the 2014 National Health Interview Survey. National Health Statistics Report. 2015;87:1-21.

Zablotsky, B, Black LI, Blumberg SJ. Estimated Prevalence of Children With Diagnosed Developmental Disabilities in the United States, 2014-2016. NCHS Data Brief, 2017;291:1-8. https://doi.org/10.1002/aur.1873 Retrieved from http://www.ncbi.nlm.nih.gov/pubmed/29235982

Zanon RB, Backes B, Bosa CA. Identificação dos primeiros sintomas do autismo pelos pais. Psicologia: Teoria e Pesquisa, 2014;30(1):25-33. https://doi.org/10.1590/s0102-37722014000100004

Zanon RB, Backes B, Bosa CA. Diagnóstico do autismo: relação entre fatores contextuais, familiares e da criança. Psicologia - Teoria e Prática. 2017;19(1): 152-63. https://doi.org/10.5935/1980-6906/psicologia.

Zimmerman IL, Steiner VG, Pond RE. Preschool Language Scales, 5th Edition (PLS-5), Person:2011

Zhou V, Munson JA, Greenson J, Hou Y, Rogers S, Estes AM. An exploratory longitudinal study of social and language outcomes in children with autism in bilingual home environments. Autism. 2017:1-11.

https://doi.org/10.1177/1362361317743251 